\title{
Loyalty Schemes in Retailing
}

A Comparison of Stand-alone and Multi-partner Programs 
Loyalty Schemes in Retailing 


\section{Forschungsergebnisse der WU Wirtschaftsuniversität Wien

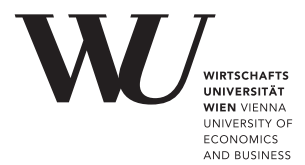

Band 61 


\section{Loyalty Schemes in Retailing}

A Comparison of Stand-alone and Multi-partner Programs 


\section{Bibliographic Information published by the Deutsche Nationalbibliothek}

The Deutsche Nationalbibliothek lists this publication in the Deutsche Nationalbibliografie; detailed bibliographic data is available in the internet at http://dnb.d-nb.de.

Sponsored by the WU Vienna University of Economics and Business.

Cover design: Atelier Platen according to a design of Werner Weißhappl.

University logo of the WU Vienna University of Economics and Business:

Printed with kind permission of the University.

\section{Library of Congress Cataloging-in-Publication Data}

Hoffmann, Nicolas, 1983-

Loyalty schemes in retailing : a comparison of stand-alone and multi-partner programs / Nicolas Hoffmann. - 1 Edition.

pages $\mathrm{cm}$. - (Forschungsergebnisse der wirtschaftsuniversität Wien :

Band 61)

ISBN 978-3-631-63880-4

1. Customer loyalty. 2. Consumer satisfaction. 3. Retail trade. I. Title. HF5415.525.H64 2013

ISSN 1613-3056

ISBN 978-3-631-63880-4 (Print)

E-ISBN 978-3-653-03515-5 (E-Book)

DOI 10.3726/ 978-3-653-03515-5

(c) Peter Lang $\mathrm{GmbH}$

Internationaler Verlag der Wissenschaften

Frankfurt am Main 2013

All rights reserved.

$\mathrm{PL}$ Academic Research is an Imprint of Peter Lang $\mathrm{GmbH}$.

Peter Lang - Frankfurt am Main - Bern · Bruxelles · New York .

Oxford · Warszawa $\cdot$ Wien

All parts of this publication are protected by copyright. Any utilisation outside the strict limits of the copyright law, without the permission of the publisher, is forbidden and liable to prosecution. This applies in particular to reproductions, translations, microfilming, and storage and processing in electronic retrieval systems.

This book is part of an editor's series of PL Academic Research and was peer reviewed prior to publication. 


\section{Table of Contents}

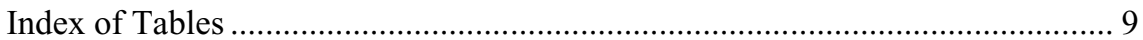

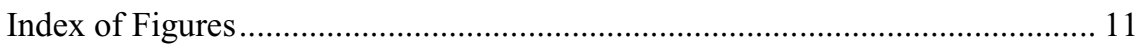

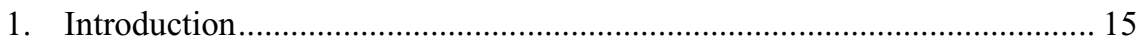

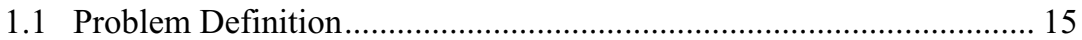

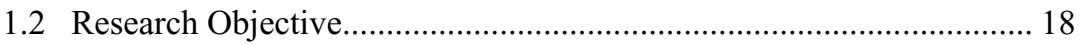

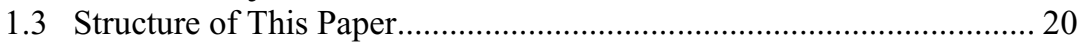

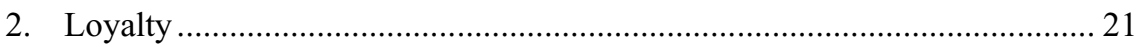

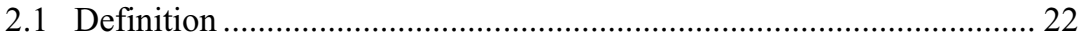

2.1.1 Historical Development of the Loyalty Definition..................... 23

2.1.2 An Attempt at Pinpointing the Terms ....................................... 23

2.2 Exploring the Emergence of Loyalty ………...................................... 25

2.2.1 Classifying the Reasons for Loyalty Formation.......................... 25

2.2.2 The S-O-R Model as a Way Out ................................................ 27

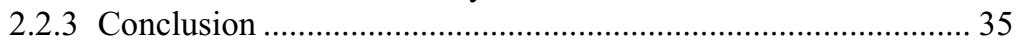

2.3 Customer Loyalty Schemes and Loyalty............................................. 35

2.3.1 Predominantly Positive Evidence .............................................. 40

2.3.2 Predominantly Negative Evidence ............................................ 44

2.3.3 Possible Explanations for the Mixed Results ............................ 46

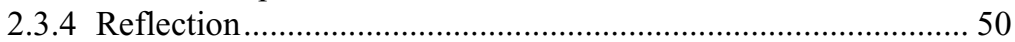

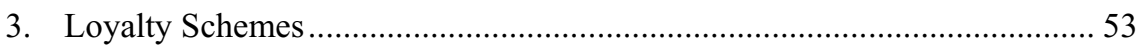

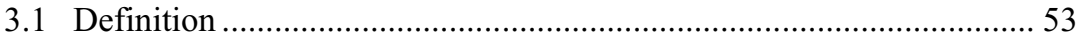

3.2 Historical Development and Current Spread...................................... 54

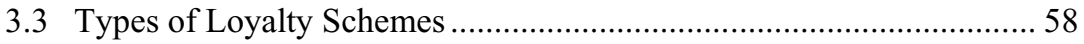

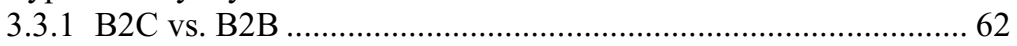

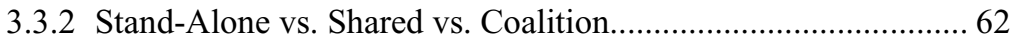

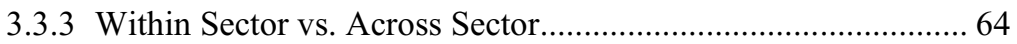

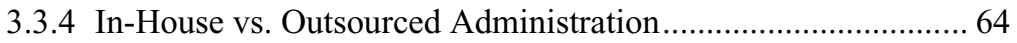

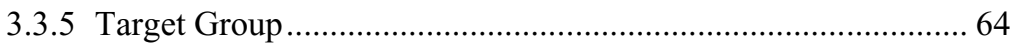

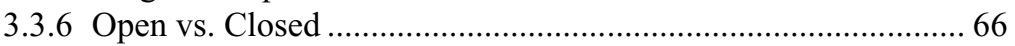

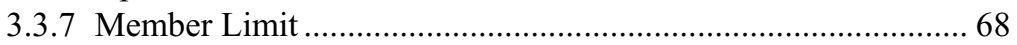




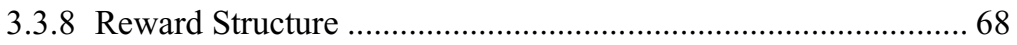

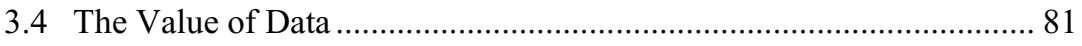

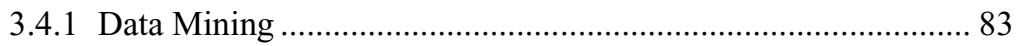

3.4.2 A Look at Retailing and Market Basket Analysis ..................... 88

3.5 Characteristics of Loyalty Schemes ………........................................ 91

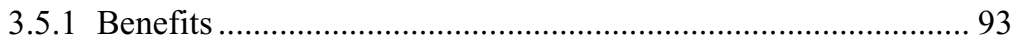

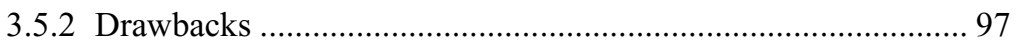

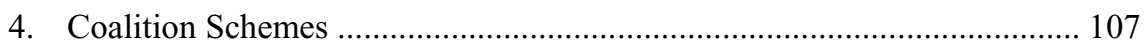

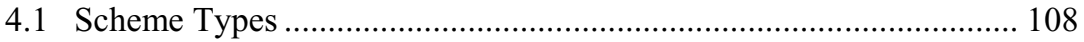

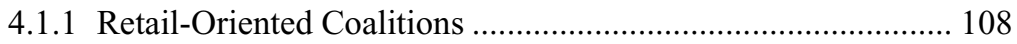

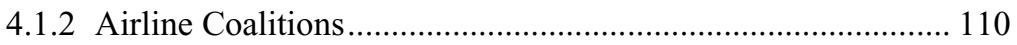

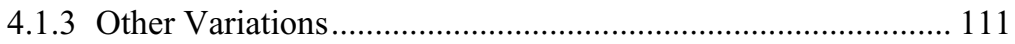

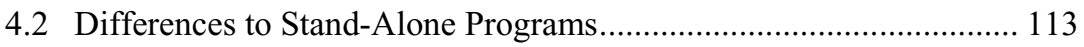

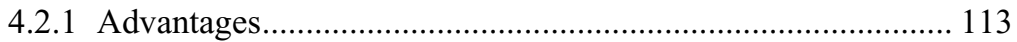

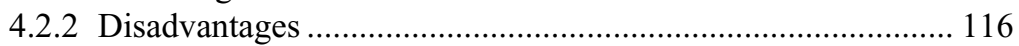

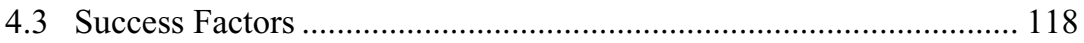

4.4 Impact, Spread, and Customer Perception ....................................... 119

4.5 The Next Evolutionary Step? .......................................................... 124

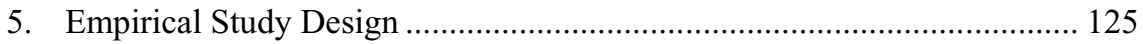

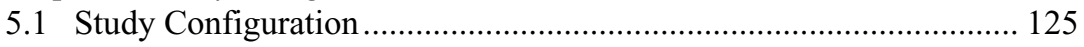

5.1.1 Qualitative Component ......................................................... 126

5.1.2 Quantitative Component ...................................................... 127

5.1.3 Overview of the Subjects of Study........................................... 132

5.2 The First Stage of Developing a Conceptual Framework:

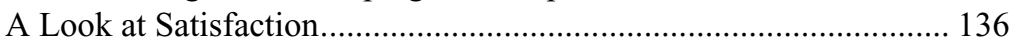

5.3 Theoretical Reference Points ............................................................. 144

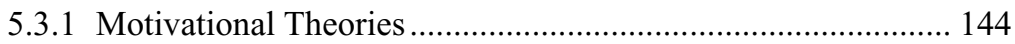

5.3.2 Transaction Cost Theory ...................................................... 147

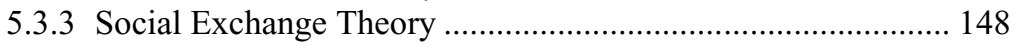

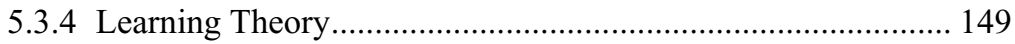

5.3.5 Theory of Perceived Risk..................................................... 151

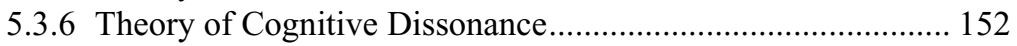

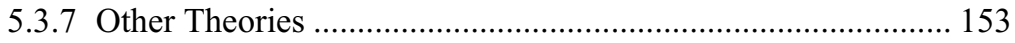

5.4 Finalizing the Conceptual Model and the Hypotheses ...................... 154

5.4.1 The Relationship between Loyalty Program Membership,

Store Satisfaction, and Loyalty................................................ 154

5.4.2 The Effect of Shopper Characteristics .................................. 156

5.4.3 The Influence of Competing Loyalty Program Memberships.. 158 


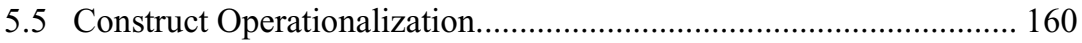

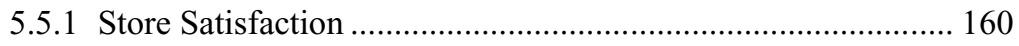

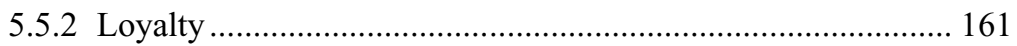

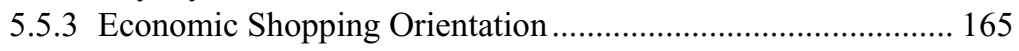

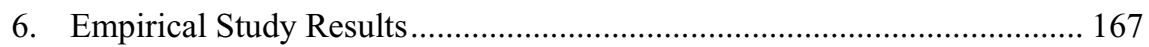

6.1 Sample Description and Data Cleansing Processes........................... 167

6.2 Extended Descriptive Statistics ...................................................... 169

6.2.1 Demographic, Socio-Economic, and Other Shopper

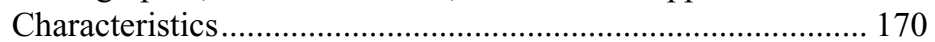

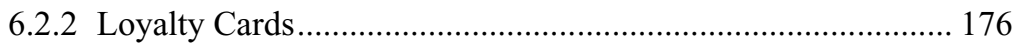

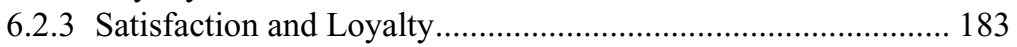

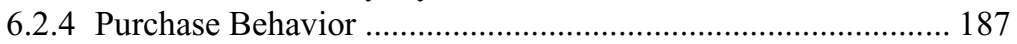

6.2.5 Common Loyalty Program Member-Specific Items ................ 190

6.2.6 Remaining Coalition Scheme-Specific Items.......................... 200

6.2.7 Remaining Stand-Alone Scheme-Specific Items ..................... 202

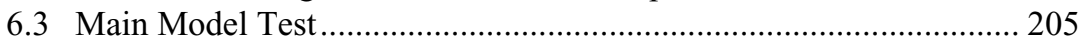

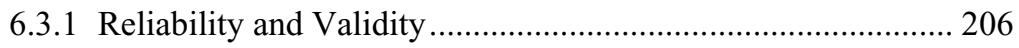

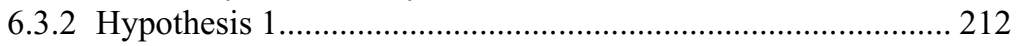

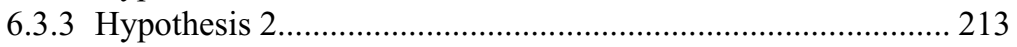

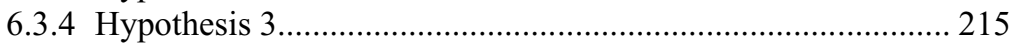

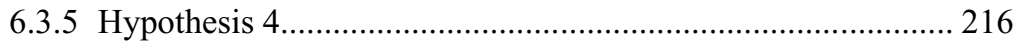

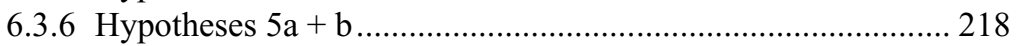

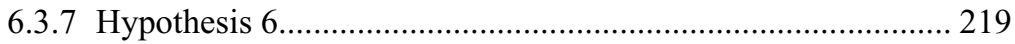

6.3.8 The Multi-Partner vs. Stand-Alone Comparison....................... 220

6.4 Qualitative Study Roundup ............................................................ 223

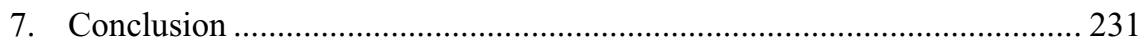

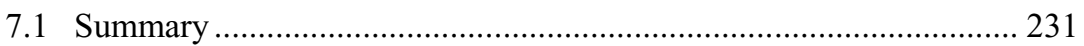

7.2 Managerial Implications.............................................................. 242

7.3 Limitations and Further Research ................................................... 245

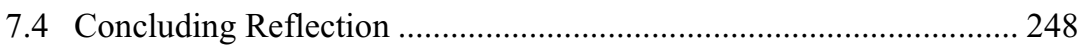

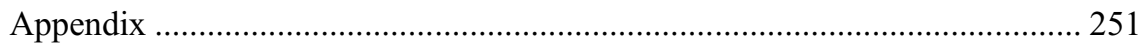

Appendix A: Survey Form Cover Page............................................... 251

Appendix B: Survey Form 1 - Aral Main Group...................................... 252

Appendix C: Survey Form 2 - Shell Main Group.................................... 256

Appendix D: Survey Form 3 - Aral Control Group................................... 260

Appendix E: Survey Form 4 - Shell Control Group ................................ 263

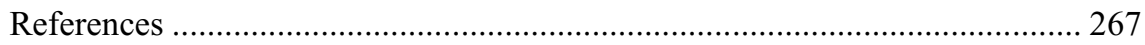





\section{Index of Tables}

Table 1: Literature Review of Loyalty Scheme Success Research .................. 39

Table 2: Classification of Reward Types ...................................................... 70

Table 3: Multi-Category Models of Consumer Purchasing ............................. 89

Table 4: Approaches to Basket Analysis ...................................................... 90

Table 5: Retail-Oriented Coalition Schemes................................................. 109

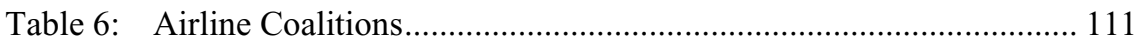

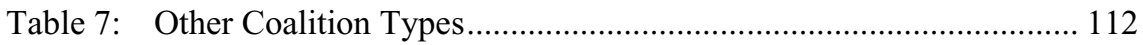

Table 8: Advantages and Disadvantages of Possible Research Methods....... 129

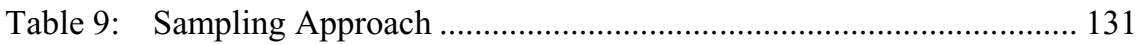

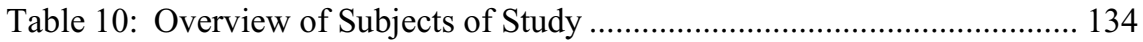

Table 11: Overview of the Multi-Partner Program Operator ........................... 136

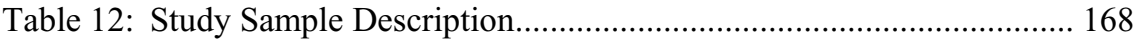

Table 13: Descriptive Statistics - Income........................................................ 175

Table 14: Descriptive Statistics - Share-of-Wallet ......................................... 188

Table 15: Program Type Comparison - Determination of Homogeneous

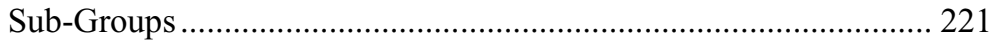

Table 16: Comparison of Statements from Expert Interviews ......................... 230

Table 17: Summary - General Findings Regarding Loyalty Cards ................. 239

Table 18: Summary - Membership-Specific Findings Regarding Loyalty

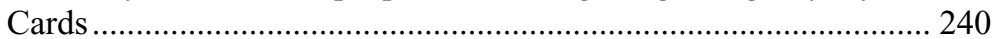

Table 19: Summary - Satisfaction, Loyalty, and Other Purchase Behavior .... 241

Table 20: General Managerial Implications................................................... 245 



\section{Index of Figures}

Figure 1: Drivers Causing a Decrease of Consumer Loyalty in Retailing ....... 15

Figure 2: Categories of Literature on Customer Loyalty Schemes .................. 16

Figure 3: Research Questions and Where They are Evaluated within This

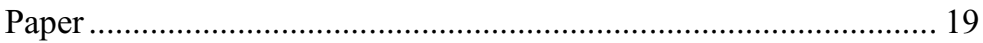

Figure 4: The S-O-R Model Applied to Customer Loyalty.............................. 28

Figure 5: A Framework of Customer Loyalty ……....................................... 32

Figure 6: Modeling Different Forms of Loyalty .......................................... 33

Figure 7: S\&H Green Stamp ...................................................................... 55

Figure 8: Number of US Loyalty Program Memberships by Industry ……...... 57

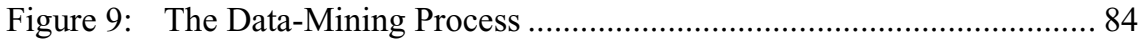

Figure 10: Loyalty Program Goals - Framework 1....................................... 92

Figure 11: Loyalty Program Goals - Framework 2 …...................................... 93

Figure 12: Proclaimed Benefits of Loyalty Schemes .......................................... 94

Figure 13: Proclaimed Drawbacks of Loyalty Schemes ..................................... 98

Figure 14: Overview of the Study's Qualitative and Quantitative

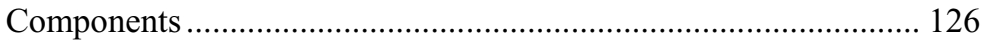

Figure 15: Research Methods Used in Loyalty Scheme Success Research ..... 128

Figure 16: Customer Loyalty from a Behavioral Standpoint ........................... 138

Figure 17: The Satisfaction-Profit Chain ...................................................... 141

Figure 18: The Asymmetric Link Between Customer Satisfaction and

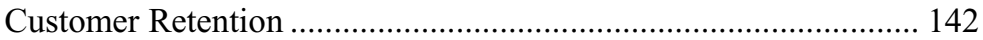

Figure 19: The Influence of the Competitive Environment on the Satisfaction-Loyalty Relationship.................................................. 143

Figure 20: Transforming the General S-O-R Model into the Conceptual Framework's Core Piece.............................................................. 144

Figure 21: Attractivity and Dependence in Business Relationships................ 149

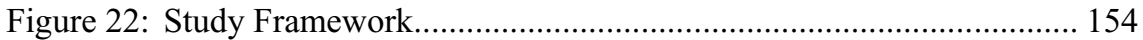

Figure 23: Schematic Illustration of Chapter Structure................................... 170

Figure 24: Descriptive Statistics - Gender................................................... 171

Figure 25: Descriptive Statistics - Age _........................................................ 172

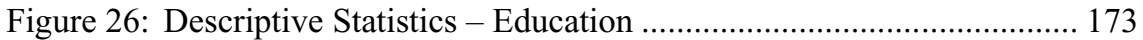

Figure 27: Descriptive Statistics - Professional Position ................................. 174 
Figure 28: Descriptive Statistics - Economic Shopping Orientation ................ 175

Figure 29: Descriptive Statistics - Convenience Orientation............................. 176

Figure 30: Descriptive Statistics - Memberships in Loyalty Schemes in the Industry

Figure 31: Descriptive Statistics - Memberships in Other Coalition Schemes 178

Figure 32: Descriptive Statistics - Number of Loyalty Cards Carried............. 179

Figure 33: Descriptive Statistics - Preferred Type of Loyalty Scheme ........... 180

Figure 34: Descriptive Statistics - Barriers of Exit.......................................... 181

Figure 35: Descriptive Statistics - General Attitude Towards Loyalty

Programs 182

Figure 36: Descriptive Statistics - Privacy Concerns ..................................... 183

Figure 37: Descriptive Statistics - Store Satisfaction ........................................ 184

Figure 38: Descriptive Statistics - Attitudinal Loyalty .................................... 185

Figure 39: Descriptive Statistics - Word-of-Mouth ......................................... 186

Figure 40: Descriptive Statistics - Loyalty Scheme-Related Loyalty .............. 187

Figure 41: Descriptive Statistics - Purchase Frequency ................................... 189

Figure 42: Descriptive Statistics - Monthly Category Spend and Cost per

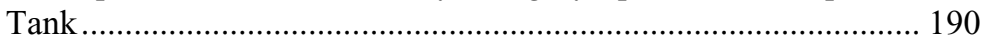

Figure 43: Descriptive Statistics - Place Where Loyalty Card is Kept ............ 191

Figure 44: Descriptive Statistics - Reward Redemption Behavior .................. 192

Figure 45: Descriptive Statistics - Reward Redemption Behavior (Details) ... 193

Figure 46: Descriptive Statistics - Patronization Prior to Program

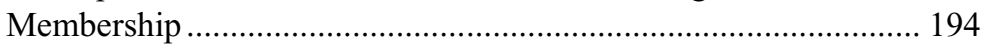

Figure 47: Descriptive Statistics - Past Purchase Frequency ........................... 194

Figure 48: Descriptive Statistics - Reaction to Up-Selling Incentives.............. 195

Figure 49: Descriptive Statistics - Reaction to Up-Selling Incentives

(Details Stand-Alone Program)................................................... 196

Figure 50: Descriptive Statistics - Permanent Change to Premium Product ... 197

Figure 51: Descriptive Statistics - Rating of Own Program ........................... 197

Figure 52: Descriptive Statistics - Assessment of Point and Reward

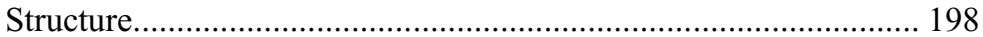

Figure 53: Descriptive Statistics - Regularity of Use ....................................... 199

Figure 54: Descriptive Statistics - Alteration of Purchase Behavior Through Membership

Figure 55: Descriptive Statistics - Coalition Partner Where Membership

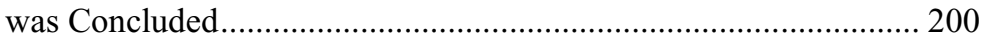

Figure 56: Descriptive Statistics - Number of Partner Companies Shopped at in the Past Year. 
Figure 57: Descriptive Statistics - Collection of Sticker Points Prior to the Coalition Start....

Figure 58: Descriptive Statistics - Reaction to Cross-Selling Incentives (Coalition Scheme) 202

Figure 59: Descriptive Statistics - Membership in Special Program Tier ....... 203

Figure 60: Descriptive Statistics - Response to Specials From Stand-Alone Program Partner. 204

Figure 61: Descriptive Statistics - Reaction to Cross-Selling Incentives (Stand-Alone Scheme) 204

Figure 62: Study Framework and Hypotheses ................................................ 205

Figure 63: Reflective vs. Formative Models .................................................. 208

Figure 64: Validity/Reliability Test - Satisfaction Construct .......................... 209

Figure 65: Validity/Reliability Test - Economic Shopping Orientation

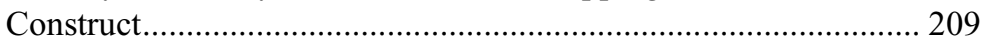

Figure 66: Validity/Reliability Test - Attitudinal Loyalty Construct .............. 210

Figure 67: Validity/Reliability Test - Word-of-Mouth Construct .................. 211

Figure 68: Main Model Test - Hypothesis 1 ............................................... 212

Figure 69: Main Model Test - Hypothesis 2 ................................................ 213

Figure 70: Main Model Test - Hypothesis 3 .................................................... 215

Figure 71: Main Model Test - Hypothesis 4 ………..................................... 217

Figure 72: Main Model Test - Hypothesis 5a + b ...................................... 218

Figure 73: Main Model Test - Hypothesis 6................................................ 219

Figure 74: The Multi-Partner vs. Stand-Alone Comparison - Concept

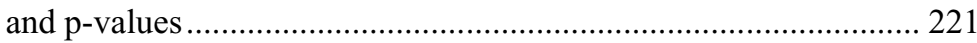

Figure 75: The Multi-Partner vs. Stand-Alone Comparison - Findings............ 222

Figure 76: Sample Expert Interview Quotes ................................................. 223

Figure 77: Research Questions and Where They are Evaluated Within This

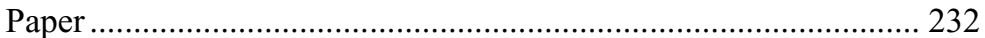

Figure 78: Topics Addressed by the Consumer Survey ………....................... 237

Figure 79: Cost/Benefit Comparison for Multi-Partner and Stand-Alone Programs 



\section{Introduction}

\subsection{Problem Definition}

Loyal customers, it is said, are worth striving for. They spread positive word-ofmouth, reduce defection rates, and amplify the purchase frequency, to name just a few examples. But what can be done to induce that loyalty? Can loyalty schemes help us to do so, and most importantly, under what circumstances, at what cost, and with what possible result?

Customer loyalty has become an increasingly important goal in retailing, as the industry in general is characterized by declining rates of consumer loyalty (Hoffmann 2008). Looking at Figure 1 listing the drivers causing these diminishing loyalty rates, it becomes clear that the proclamation of this trend is just a general assertion. Some retailers naturally do implement successful innovations (and thereby foster customer loyalty), while others fail with theirs. In any case, loyalty, at least when it goes hand in hand with profitability, is something that is always worth aiming for. For example, Reichheld \& Seidensticker (2006) discovered that a $5 \%$ increase in loyalty can lead to a $25-200 \%$ boost in profits (see Chapter 2 for a more detailed view on customer loyalty).

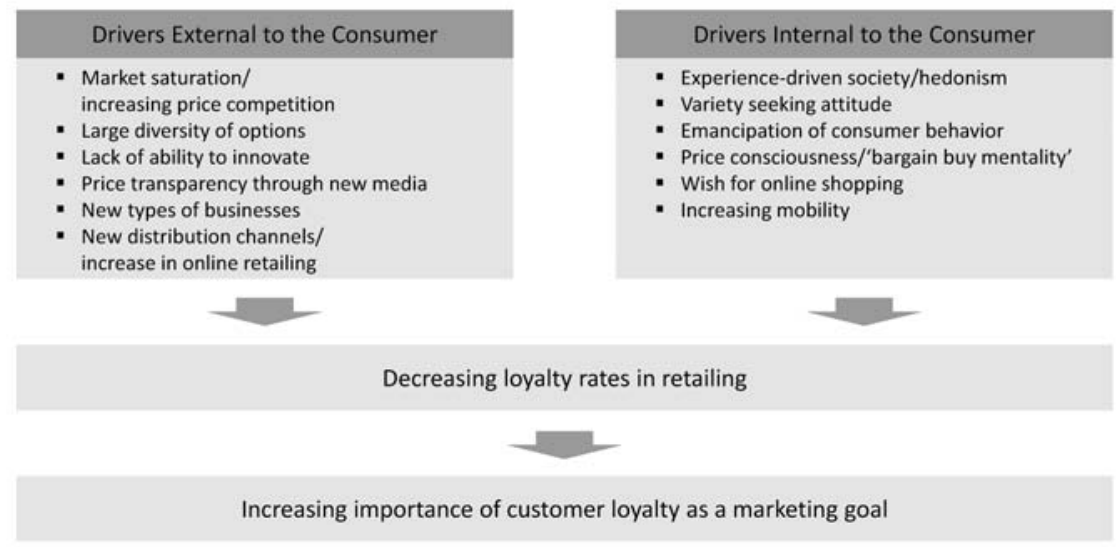

Figure 1: Drivers Causing a Decrease of Consumer Loyalty in Retailing

Source: Hoffmann (2008) 
But can customer loyalty schemes, as their name suggests, really help to engender or enhance customer loyalty? Numerous retailers, service providers, and manufacturers have - some more successfully than others - attempted to establish or at least foster loyalty among their current and prospective customers with the help of such solutions. At the same time, a vast number of researchers have found interest in this topic, in an endeavor to evaluate the effects of these schemes, their effectiveness, and their efficiency. Still, customer loyalty schemes are, at least in their modern forms that enable companies to gather detailed transaction data, a comparatively recent and also constantly advancing development. Literature regarding this topic stems primarily from the second half of the 1990s and the new millennium, and while this field of research still appears to be a 'hot topic,' many questions remain unanswered or at least inconclusively answered.

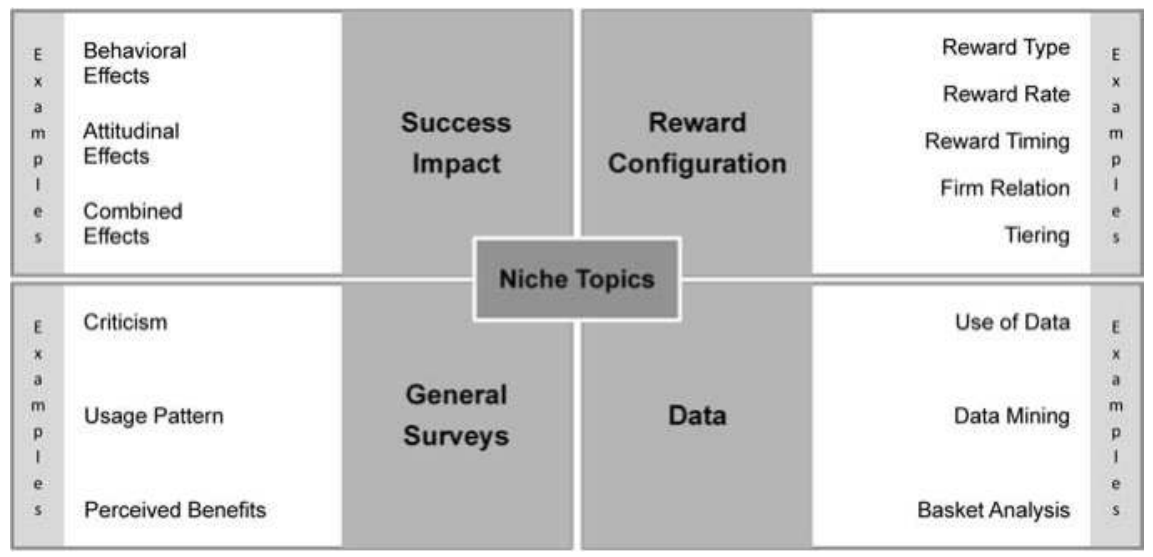

Figure 2: Categories of Literature on Customer Loyalty Schemes

Broadly speaking, literature on loyalty programs can be distinguished into four areas: success impact, reward configuration, data capture and analysis, and general studies regarding a range of surrounding issues such as customer acceptance or usage frequency (see Figure 2). Among these groups, research on success impact appears particularly interesting, as existing studies on this subject have led to differing results. A detailed literature review of 23 publications has revealed a range of causes for this situation (see Chapter 2.3), with varying definitions of success, dissimilar program configurations in various industries, and diverse research methods allowing for the explanation of a good part of these irregularities. In summary, it may be noted that loyalty programs can indeed have a positive effect on customer behavior. The German fuel station chain Aral, for instance, attributed the rise in market share from $22.5 \%$ to $23 \%$ in the three months 
following its partnership with the Payback coalition scheme in May 2006 exclusively to this decision (Payback 2007; personal communication, 21 July 2009). While it is anywhere between difficult and impossible to determine the accuracy of companies' claims regarding the success of their respective schemes from an outside perspective, it is at least noteworthy that a multitude of organizations have employed a loyalty program for an extended period of time and continue to make such favorable assertions.

Interestingly, among the 23 reviewed studies in the success research category, only one focused on the special type of program that Aral - the fuel station featured in the previous example - is also part of: loyalty coalitions. Still, no comparison with stand-alone programs was made. Up until now, academic literature has indeed neglected to deal with the question of how well these multi-partner programs really perform in comparison to stand-alone solutions. This is particularly noteworthy, as various authors have begun to praise loyalty coalitions as the next evolutionary step in customer loyalty schemes. Comments on this subject include the following:

- "According to Frequency Marketing Inc., there are 3 trends to watch for in card marketing in the new millennium: [...], and coalition programs" (Barlow 1999, p. 76)

- "Coalitions represent both the natural evolution and the future of loyalty marketing programs, both within the USA and abroad" (Capizzi \& Ferguson 2005, p. 297)

- "The 22 major factors that will shape the future of customer loyalty: [...] 3. An explosion of loyalty coalitions and networks" (Clark 2006, p. 1)

- "The efficiencies inherent in coalition loyalty models [...] make coalitions the natural end-game for loyalty evolution" (Ferguson \& Hlavinka 2006, p. 1 f.)

Without doubt, multi-partner solutions boast various advantages over stand-alone programs: administrative costs can be shared between the partner companies, a multitude of options for point collection and consequently faster redemption are hypothesized to result in higher customer interest, customers need to keep only one loyalty card in their wallet, the resulting pool of data is considerably richer, and moreover, large, nation-wide programs enable companies to quickly achieve a high penetration rate. On the other hand, for example, the partner companies' leeway for program design is limited, there is a danger that customers will develop loyalty towards the scheme and not the partner company, and it is also difficult to pilot such programs. For a majority of practitioners and academics, the advantages nevertheless seem to outweigh the disadvantages. 
As far as the few pieces of literature on this topic are concerned, some ground is covered by studies from market research organizations (usually commissioned by coalition operators, however; e.g. TNS Emnid 2006 or GfK 2007), and in fact, some of the rare academic literature was also written by practitioners from research organizations (e.g. Capizzi \& Ferguson 2005 or Ferguson \& Hlavinka 2006). Next to a few current or former practitioners (e.g. Humby et al. 2008 or Clark \& Clark 2009), the truly academic view on coalition schemes remains extremely limited, with only a handful of papers such as those by Sharp \& Sharp (1997) or Lara \& De Madariaga (2007). At best, authors with an academic background have mentioned examples of coalition schemes within studies of other aspects of loyalty schemes (e.g. Stone et al. 2004 referred to UK's Nectar coalition in a general evaluation of loyalty schemes or Rowley 2005 in a case study of Tesco's Clubcard). Scientific information on this topic is consequently scant, with unbiased, empirical evidence of the superiority of coalition schemes still outstanding.

\subsection{Research Objective}

Given these prophecies made with regard to the superiority of multi-partner schemes on the one hand, and the scarcity of work on this topic on the other hand, the decision was taken to primarily engage in (1) success research with (2) special focus given to the subject of coalition schemes. In addition, a general survey component will form part of this study in order to retrieve answers to a range of further questions that are expected to be relevant to practitioners.

Specifically, the following research questions have been singled out as the focus of this paper (see Figure 3 for a graphical illustration):

- How do coalition schemes perform in direct comparison with stand-alone solutions, or put in more concrete terms, what is the differential impact of these two loyalty program types (1) on a classical behavioral success indicator such as share-of-wallet and (2) on attitudinal loyalty measures?

- What dependencies and interrelationships exist between loyalty, program membership, and other variables often cited in connection with the subject (namely store satisfaction, membership in competing loyalty schemes, and effect of certain shopper characteristics)?

- What do loyalty executives think about these program types and what experiences have they gathered?

- What do members of these program types think about a whole range of questions revolving around different facets of this topic that might be relevant to practitioners (e.g. privacy concerns, exit barriers, program/reward attractiveness, redemption behavior, response to up- or cross-selling incentives, etc.)? 


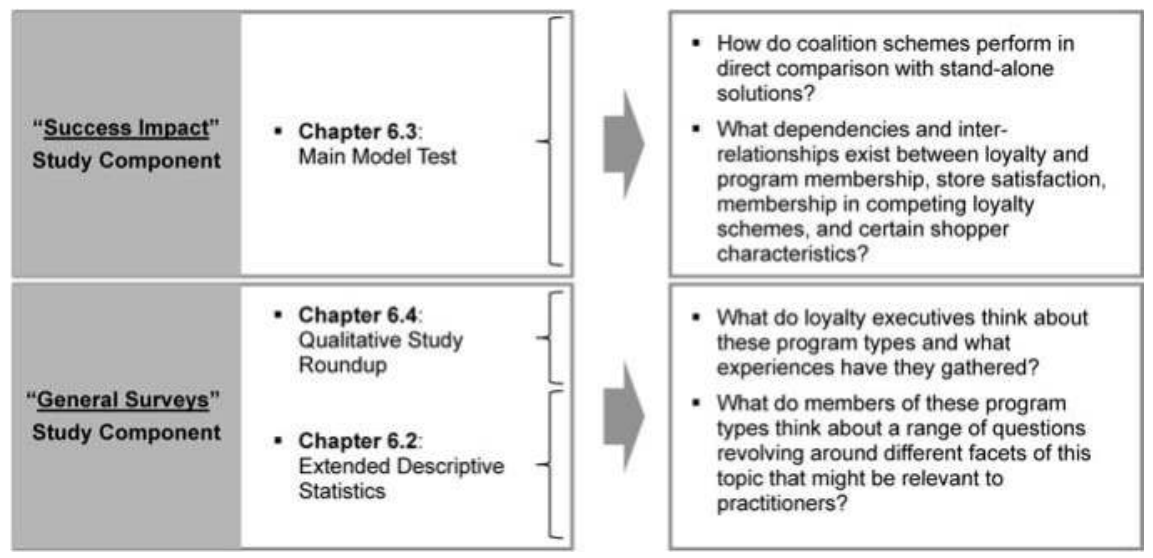

Figure 3: Research Questions and Where They are Evaluated Within This Paper

These questions shall be answered with data from a proprietary, two-pronged empirical investigation. Due to the lack of any sizable, nation-wide coalition program in Austria, Germany was selected as the place to conduct the study. To be precise, the focus will be set on the fuel retailing market, with Aral (as a partner company of Payback - Germany's biggest multi-partner program) and Shell (with the nation's major fuel station loyalty scheme Clubsmart) constituting two subjects of study which, being strong and similarly large competitors, ensure good comparability. This decision has been taken, following an analysis of all partner companies in Germany's three major coalition programs and their comparable competitors with a stand-alone solution in place.

A customer survey will form the heart of this study, with questionnaires being distributed in person to participants at the point of sale, along with a postagepaid, self-addressed return envelope. In addition, explorative interviews with the management of Aral, Shell, and Loyalty Partner (the organization administrating the Payback coalition scheme) will precede this survey, in order to gather background information and to hear about these managers' experiences with the two types of loyalty programs.

Finally, the comprehensive literature review preceding the empirical component is expected to give a good overview of the field of loyalty research, as well as both loyalty schemes in general and coalition schemes in particular. Next to summarizing, structuring, and critically evaluating the stream of previous publications on loyalty programs, it is the compilation of material on multi-partner programs that is expected to account for a noteworthy contribution to the body of literature. 


\subsection{Structure of This Paper}

Chapter 1 has marked the starting point of this paper by providing a brief overview of the decision process that led to this paper's focus on loyalty scheme success research in connection with a comparison between coalition and standalone solutions.

Chapter 2 will primarily be dedicated to a review of the whole subject of loyalty research. A section on definitions will precede a reflection on pieces of literature dealing with the formation of loyalty, which in turn will be followed by a thorough evaluation of previous studies from the field of loyalty scheme success research.

Chapter 3 will revolve around a comprehensive overview of loyalty schemes. Beginning again with a segment on definitions, this section will also include the historical development and current spread of loyalty programs. This will be followed by a detailed illustration of the known loyalty scheme types as well as the different program characteristics that are commonly used as parameters in these categorizations. Thereafter, an excursion will be made on the value of data being generated by these programs, with a comparison of advantages and disadvantages idiosyncratic to such loyalty tools concluding this chapter.

Chapter 4 will form the end of the literature-centered segment of this paper, offering a synthesis of existing publications on coalition schemes. Hereby, a classification of multi-partner solutions will be compiled, differences to standalone programs exposed, and success factors relating to such operations highlighted. In addition, the limited information available on impact, spread, and customer perception will be screened and processed.

Chapter 5 will represent the opening to the empirical segment of this paper, whereby an overview of the qualitative and quantitative study components will first be given, followed by an illustration of the process of developing the study framework, corresponding hypotheses, and underlying theoretical basis. Eventually, a sub-section will be dedicated to the operationalization of the constructs used.

Chapter 6 will be dedicated to a discussion of the findings stemming from the empirical study. First, an overview of the sample and data cleansing processes will be given, followed by a section on descriptive statistics, the main model test, and a brief roundup of the qualitative component.

Chapter 7 will provide a finale to this paper by summarizing the study's most important findings, highlighting emanating managerial implications and elaborating on limitations of the study as well as suggestions for further research. Finally, a concluding, critical reflection of the research area in general will be given. 


\title{
2. Loyalty
}

\begin{abstract}
"Napoleon Bonaparte, the most feared French commander of the early nineteenth century, achieved extraordinary results through the unrelenting loyalty of the soldiers under his command. Coming to the civilized world of the $21^{\text {st }}$ century, we see Generals in the form of marketers striving to defend or capture market share with the help of a loyal customer base" (Kumar \& Shah 2004, p. 318).
\end{abstract}

The concept of loyalty is nothing new and has received a significant amount of attention in customer research. Most examinations of loyalty tended to focus on consumer goods (brand loyalty) (Dick \& Basu 1994), although the concept is of similar significance for industrial goods (vendor loyalty), services (service loyalty) and retailers (store loyalty). Since Dick \& Basu's assertion in the 1990s, the focus has broadened conspicuously, with more and more research dedicated to the latter forms of loyalty, and some even extending the view to the loyalty cards (card loyalty) themselves (Mauri 2003).

Regardless of the form of loyalty, loyal customers are certainly a valuable asset to any company, and various notable examples exist in research literature supporting this fact. It is, for instance, common marketing knowledge that winning over new customers is many times more expensive than keeping current ones. As a rule of thumb for many industries, $20 \%$ of customers are said to be responsible for $80 \%$ of the revenue (Reichheld \& Sasser 1990, Reichheld 1996). Naturally then, it should be a priority for managers to prevent customers from defecting, particularly if they are important, profitable or even important and profitable. A more specific example discovered while exploring the connection between loyalty and growth, was that a $5 \%$ improvement of customer loyalty can lead to a $25-100 \%$ increase in profits (Reichheld \& Seidensticker 2006). The authors also proved that those companies that had the highest level of customer loyalty were typically able to increase their turnover at double the rate their competitors could. Consequently, such companies exceeded their competitors' performance at the stock market by a factor of 2.2 during the 1990s (Finnie \& Randall 2002). A possible explanation for this is presented by Tellis (1988), as outlined by Oliver (1997). Using panel scanner data over a 20-week interval, Tellis (1988) explored the relative effects of advertising, brand on display, coupons, special promotions, long-term loyalty, and price on buying behavior. "Without question, loyalty is the strongest determinant of purchase behavior" (p. 142), the author concluded. 
Loyalty, then, is something that makes good business sense. With some promoters of loyalty schemes claiming that they are even able to create or foster the growth of true attitudinal loyalty, this is a topic that needs to be addressed in the course of any paper dealing with the marketing instrument of loyalty programs. In the course of this chapter, a definition of loyalty will be given (Chapter 2.1) and the drivers of customer loyalty analyzed (Chapter 2.2). Following this introduction to loyalty research, the chapter will be concluded with a comprehensive review of loyalty scheme success research (Chapter 2.3).

\subsection{Definition}

A common theme found among most academic definition attempts is that of at least partial disaccord. Loyalty - like terms such as "emotion" or "satisfaction," as Oliver (1997) rightfully pointed out - is easy to discuss in the course of casual conversation, but difficult to analyze for meaning in a scientific context. In the case of loyalty, Jacoby \& Chestnut (1978) found 53 definitions in their analysis of the 1970s alone, with one being Jacoby \& Kyner's (1973) definition as a function of six necessary and collectively sufficient conditions. They stated that "brand loyalty is (1) the biased (i.e. nonrandom), (2) behavioral response (i.e. purchase), (3) expressed over time, (4) by some decision-making unit, (5) with respect to one or more alternative brands out of a set of such brands, and (6) is a function of psychological (decision-making, evaluative) processes" (p. 2). Despite the exclusive focus on brands, Jacoby \& Kyner's explanation contains most of the generally accepted characteristics of loyalty, but lacks the important factor of external influence. A more recent, and arguably more elegant definition is that of Oliver (1997), who suggested that "customer loyalty is a deeply held commitment to rebuy or repatronize a preferred product or service consistently in the future, despite situational influences and marketing efforts having the potential to cause switching behavior"“ (p. 392).

While minor details might be added to contribute to universal applicability, this definition comes very close to what appears up-to-date in the context of today's state of research. Based on Oliver, for the purpose of evaluating the concept of loyalty later on in this paper, the following more comprehensive definition is suggested:

Customer loyalty is a deeply held commitment to a product, service, store, or any other aspect of an organization that causes the customer to rebuy or repatronize the organization's product, service, or store consistently in the future, despite marketing efforts or other external influences having the potential to cause switching behavior. 


\subsubsection{Historical Development of the Loyalty Definition}

The roots of loyalty research date back to the 1920s, when Copeland (1923) first dealt with the question of brand repeat purchase behavior. Over time, the narrow focus on brands gradually shifted to a broader view on relationships between customers and companies, but models remained largely behavioral in nature (Homburg \& Bruhn 2008). In that regard, the early 1970s marked an important turning point in loyalty research, following the contributions of Day (1969), Jacoby \& Olsen (1970), and Jacoby \& Kyner (1973). As Dick \& Basu (1994) pointed out, brand loyalty research used to rely on behavioral measures like proportion of purchase or purchase frequency, for example. The problem with this type of measurement is that research based on pure observation of activities obviously misses out on the factors that underlie the customer's purchases. Repeat purchase of a certain brand could be influenced by a lack of choice at a store with a limited range of articles, a stock-out, or even variety seeking behavior. Behavioral measures alone, Jacoby \& Chestnut (1978) criticized, were thus inadequate to explain the concept of loyalty. Loyalty was reconsidered to be more than just the simple repeated patronization of a store.

Day (1969) emphasized that it is the internal disposition of the customer that drives loyalty and proposed a shift to the combination of behavioral and attitudinal loyalty in loyalty research. Jacoby \& Chestnut (1978) theorized that true single brand loyalty of a consumer could be present only if three conditions persisted: belief (i.e. the cognitive dimension), affection (i.e. the attitudinal aspect), and intention (i.e. the conative element). The consumer thus needed to (1) believe that the brand information he has is superior to that of competitive brands, (2) have a clearly higher degree of affective preference for the specific brand, and (3) must have the intention to purchase the brand in an upcoming buying decision (Oliver 1997).

This reorientation towards the analysis of loyalty through a more detailed description of cognitive activities manifested itself in the following decades, and loyalty was eventually accepted to be "a function of psychological (decisionmaking, evaluative) processes" (Jacoby \& Chestnut 1978, p. 2). Today, it is widely accepted that this conclusion needs to be taken into account for any type of research focused on loyalty in its true sense.

\subsubsection{An Attempt at Pinpointing the Terms}

A plethora of terms surrounds the concept of customer loyalty and its management by organizations. Customer relationship management (CRM), loyalty marketing, relationship marketing, retention marketing, database marketing, micromarketing, 
direct marketing, or 1-to-1 marketing are all but a few examples. Indeed, whatever term you start from, a situation parallel to that of defining loyalty arises. Focusing on relationship marketing literature, for example, Harker (1999) made out 28 definitions. Also dealing with the vast number of terms and definitions from the viewpoint of relationship marketing, Egan (2004) concluded that many of these are merely "relational variations [which] describe a particular or closely associated aspect of relationship marketing philosophy rather than necessarily a holistic concept $[\ldots]$. Others are associate concepts that may be seen to overlap with relationship marketing in some way" (p. 20). While direct marketing, micromarketing, 1-to-1 marketing, and database marketing thus do mean vaguely the same thing (as a database is paramount to direct/micro/1-to-1 marketing), Egan argued that they could not be used interchangeably with the term relationship marketing, as they, despite sharing several relational strategies and tactics, are more transactional than relational in nature (see e.g. Berry 1983, Dwyer et al. 1987, Grönroos 1994, Peck et al. 1999, or Ryals 2005 for background on the development of relationship marketing as a comparatively new paradigm in the marketing sciences).

CRM, then, is a term with a heavy focus on its technological aspect as a means to executing loyalty marketing (Dowling 2002; see e.g. Anderson et al. 2007 for an overview of CRM in retailing) and retention marketing as compared to loyalty marketing is a somewhat broader term with respect to its measures towards reducing customer defection, but a narrower concept in the sense that it aims at current customers only (Oggenfuss 1992). All in all, relationship marketing and loyalty marketing are probably closest to what could be called umbrella terms. As far as the difference between these two is concerned, one could argue that relationships might exist even without loyalty (e.g. in the form of simple behavior), while loyalty marketing is oriented exclusively towards creating true psychological commitment.

Several of these terms certainly seem to give the impression that they mean the same, at least to such a large extent that it seems unnecessary to coin a new term (were it not for authors in need of a novel title for their publication). The rough distinction presented in this chapter ought to suffice for this paper, bearing in mind that the intention of virtually all these concepts is the creation or development of what is commonly referred to as loyalty in the literature on the subject (Duffy 2003). What needs to be noted, however, is that some of these concepts do not necessarily distinguish between behavioral and attitudinal loyalty. 


\subsection{Exploring the Emergence of Loyalty}

\subsubsection{Classifying the Reasons for Loyalty Formation}

Numerous possible causes for repurchase behavior exist and each is characterized by a different loyalty background. To better distinguish between the two categories of behavioral and attitudinal loyalty, it is important to differentiate between the underlying factors. This chapter attempts to provide an overview of existing typologies. Few of them are explicitly founded in theory, but they are nevertheless helpful in getting accustomed to the topic of customer loyalty, as they can be considered preliminary stages of a loyalty theory (Diller 1996). Various attempts to group the numerous causes exist, with German literature providing a few notable examples.

Meyer \& Oevermann (1995) made out five fundamental causes for relationships between a customer and an organization:

- Psychological factors

- Situational factors

- Legal factors

- Economic factors

- Technological factors

Among these five elements, only psychological factors are likely to include attitudinal aspects. Situational causes like convenience, stock-outs, or special promotions are much more likely to influence pure behavioral loyalty. Likewise, legal factors such as contractual obligations, economic reasons like high costs of substitution, or technological factors such as a lock-in created by the inefficient transition period during the shift to a new software vendor can hardly be viewed as a form of attitudinal loyalty. Even though it might be argued that reasons related to technology are not very different from economic causes, this basic categorization does serve the purpose of revealing the nuances underlying a repurchase decision.

In a similar approach, Hill \& Alexander (2006) distinguished five variables that lead to some form of loyalty. In the following enumeration, they were sorted in degree of allegiance from low to high:

- Monopolies

- Habit

- Cost of change

- Incentives

- Commitment 
At a more simplified level, Homburg \& Bruhn (2008) suggested a categorization into habitual, voluntary and involuntary relationship drivers. Like other basic categorization attempts, this proposition seems theoretically sound, and one could even attempt to merge other classifications such as those distinguished by Meyer \& Oevermann (1995) into them in a mutually exclusive and collectively exhaustive manner.

Diller (1996) focused on four of the numerous possible antecedents to relationships. The following examples were selected to demonstrate how a variation in the degree of these antecedents (high vs. low; plus "bought" in the case of commitment) results in different types of relationships, despite the relationship being intense in all cases:

- Involvement relates to the customer's readiness to absorb and process information and signifies a construct fundamental to any research on customer behavior (Trommsdorff 2004). Diller (1996) argued that beyond its significant impact on purchase behavior and information handling, the extent of involvement of a customer also determines his readiness to form a relationship with a business partner. The case of an intense relationship coupled with a high level of involvement is what Diller called "hot customer relation" (i.e. a relationship characterized by enthusiasm), as opposed to "cold customer relation" (i.e. a relationship despite indifference) in the case that an intense relationship meets a low level of involvement.

- Likewise, varying degrees of commitment can lead to different kinds of relationship. If an intense relationship is coupled with a low level of commitment, an "involuntary relation" arises (e.g. in the case of a monopoly in a certain sector), while a "functional relation" would exist in a case where the supplier has "bought" commitment from the customer by offering a sufficient amount of value (i.e. whenever the customer voluntarily enters a business relationship, but no attitudinal loyalty is present). Eventually, if the relationship is intense and commitment is high, a "truly voluntary relation" sets in (i.e. loyalty in its attitudinal sense).

- Despite being a possible consequence of a relationship, trust can be viewed as a significant antecedent to relationships as well. It creates harmony and stability and helps to oppose complexity and uncertainty, to name just a few examples. When an intense relationship meets a low level of trust, Diller expected a "relation on reserve" to persist, while a "liaison" might be present in the case of a high level of trust.

- Finally, satisfaction is the key variable that has probably received the most attention in literature as a potential relationship driver (see e.g. Oliver 1997 or Kumar \& Reinartz 2006). In an intense relationship, Diller (1996) expected 
one of two outcomes: either a "hollowed-out relation" in the case of low satisfaction or an "endorsed relation" in the case of high satisfaction.

\subsubsection{The S-O-R Model as a Way Out}

Chapter 2.2.1 makes it evident that there is no even rudimentary consensus in literature on a structure by which to categorize the reasons for loyalty, and indeed, the whole process from influencing factors to the type of loyalty created lacks an acknowledged theory. Despite his criticism of the graphical presentation of existing models describing this process (which he called "a pipe-fitters nightmare" - a look into Howard \& Osterlund 1973, for example, will clarify why), Jacoby (2002) made several noteworthy, further-reaching observations: they are arbitrary to a large extent in the way that variables are categorized, relationships drawn up, and indeed in the way that the variables are chosen in the first place. Furthermore, a clear designation to a particular category is not always clear or even possible. Most importantly, however, authors have failed to build their models on prior knowledge in the way that science is commonly understood. "At the very least, the current state of affairs makes it unnecessarily difficult to compare and contrast the various models, or to identify the unique contributions and deficiencies" (p. 53), Jacoby noted.

This needs to be kept in mind when considering the stimulus-organismresponse (S-O-R) model as a way to bring some kind of structure to the multitude of models prevailing in the literature, trying to explain one aspect or another in the overall process from stimuli to output. In fact, within this paper it should be regarded as no more than a tool to structure this chapter, and not as what could be considered yet another model. Variables were chosen in a comprehensive, but nevertheless exemplary manner. The way they were assigned to the three boxes stimuli, organism, and response is not without reason, but it would be arguable that a particular variable could be placed in another, into several, or even outside these boxes. The way that relationships are drawn is based on the original S-O-R paradigm, and is thereby exposed to the prevailing criticism Jacoby highlighted. The reason it was still chosen as a model in this paper is, aside from its ability to provide a good overview (and because its purpose within this paper is limited to just that), that it is widely accepted and still firmly rooted in business curricula.

Historically, the S-O-R model emanated from a more recent form of behaviorism. In its original version, behaviorism dates back to a classic of psychological history, Watson's (1913) "Psychology as the Behaviorist Views it," and has roots that can be traced back even further to Ivan Petrovich Pavlov's salivating dog. 
Watson's model, and indeed most developments following up to the 1960s (including the notable works of authors such as Skinner 1938 or Hull 1966 [first published in 1943]), were simple input-output $(\mathrm{I} \rightarrow \mathrm{O})$ models in that they completely disregarded factors internal to the individual (Jacoby 2002). These models were then outdated by what Jacoby called $2^{\text {nd }}$ generation models. Sometimes referred to as neobehaviorism, these models began to embed the organism as part of the theory, and eventually became known as the S-O-R paradigm, or S-O-R model (Houston \& Rothschild 1977, Slama \& Tashchian 1987). Stimulus $\rightarrow$ organism $\rightarrow$ response became the new mantra, expanding the old stimulus (i.e. input) $\rightarrow$ response (i.e. output) idea.

Figure 1 provides an overview of a possible way to view the steps from influencing factors to the generation of a particular kind of loyalty as one of several possible responses emerging from the individual.

Stimulus
Organization-related
- Price
- Product
- Place
- Promotion
- Servmunication
- Legal factors
- Customer loyalty schemes
Market-related
- Transaction costs
- Substitution costs
- Information
Social
- People
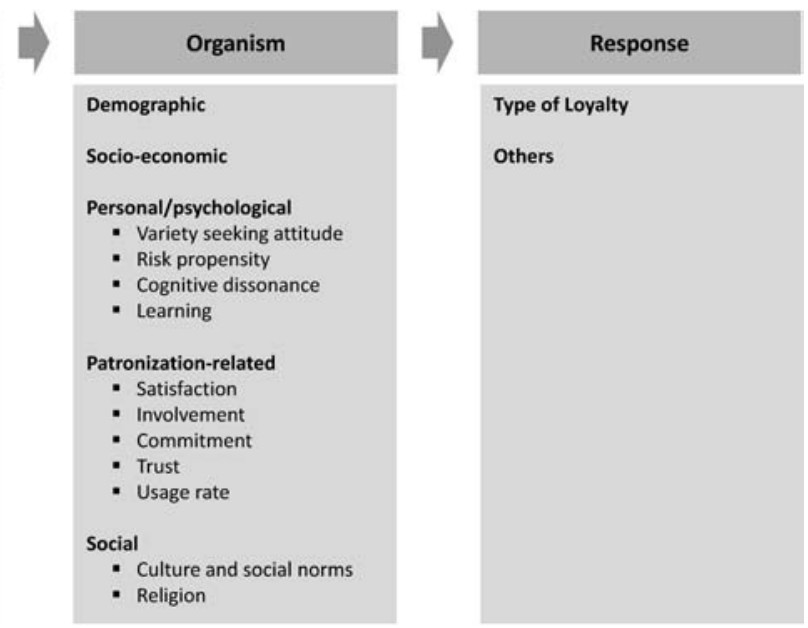

Figure 4: The S-O-R Model Applied to Customer Loyalty

Source: $\quad H o w a r d \&$ Osterlund (1973), Straßburger (1991), Engel et al. (1995), Meyer \& Oevermann (1995), Diller (1996), Sheth et al. (1999), Jacoby (2002), Pan \& Zinkhan (2006), Hill \& Alexander (2006), Hoyer \& MacInnis (2007), Kuß \& Tomczak (2007), Homburg \& Bruhn (2008)

\section{1) Stimulus}

For the purpose of this paper, stimuli were defined as influences (and consequently potential drivers of loyalty) that stem from outside the organism. A lot of classic models use a different approach by adding several factors from the organism box to the stimulus category (see e.g. Howard \& Osterlund 1973, Straßburger 1991, 
Hoyer \& MacInnis 2007). In the case of this paper, however, it is argued that they find a more harmonious fit in the organism segment, which will be discussed in the following section.

A literature review helped to determine the various elements that were taken into account as an external stimulus by one model or the other. These were then categorized into the following three groups: organization-related (i.e. containing all factors influenced by the organization), market-related (i.e. made up of influences stemming from the market), and social (i.e. referring to variables of social nature which exert influence from outside the individual).

- Organization-related:

- Price is probably one of the more obvious drivers leading to some form of loyalty.

- Product refers, for example, to the quality or specific value-add that makes customers buy it.

- Place concerns retail channels, geographical location, and convenience.

- Promotion deals with special offers to the customer, whether or not they are price-related.

- Communication relates to the quality of communication attempts of the organization with the consumer. These could include high-quality service centers, well-made direct mailings, or the opportunity for customers to be integrated into the product development process.

- Service describes the quality of a performed service (as opposed to the quality of products), or that of customer service, other than that contained in the communication category.

- Legal factors could, for instance, exist when a contract limits the customer in his alternative seeking behavior.

- Customer loyalty schemes, the focus of this paper, are associated with the use of this marketing instrument as a driver of loyalty.

- Market-related:

- Transaction costs are, according to transaction cost theory, also a driver of buying behavior.

- Substitution costs have an impact on repurchase behavior, as they reduce the probability of customers defecting.

- Information relates to intelligence coming from the market (e.g. product tests) that cannot be controlled by the organization.

- Competition is another important factor that sways buying behavior. The presence, structure, and intensity of any competitive offering or other action will naturally have influence on customers involved in their purchase decision. 
- Social:

- People are a notable example of social influence coming from the buyer's surrounding. This kind of influence comes from outside the organism (e.g. in the form of a friend's opinion or parental advice), as opposed to culture or religion, which can be seen as being anchored within the individual.

\section{2) Organism}

Factors listed in the organism box are those variables associated with the individual that determine how external stimuli are processed. As mentioned before, several authors consider these to be stimuli - internal ones, but stimuli nonetheless.

It is argued that once factors such as social class, ethnicity, culture, or religion have become part of the individual, they should be considered internal to the organism. A possible explanation for the difficulty in classifying these factors as either stimulus or organism is that association with any of these categories depends on how far these factors are internalized. If, for instance, an individual becomes religious at a late stage in life (e.g. following exposure to Buddhism during a journey to Tibet), religion might at first be more of an external stimulus to behavior. If, however, a person is born into a Buddhist family, he is exposed to religion from early life and likely to have truly internalized it sooner. What makes it so hard to draw the line, is that this transition from external stimulus to internal characteristic (i.e. "true religious belief" in this case), is likely to be one marked by a more or less continuous transition.

Ascribed to the organism category are the following five categories: demographic, socioeconomic, personal/psychological, patronization-related, and social.

- Demographic:

- Demographic variables refer to the composition and development of the population (e.g. characteristics such as age or gender).

- Socio-economic:

- Socio-economic factors describe the relationship between economic activities and social life (e.g. income, education, or profession).

- Personal/psychological:

- Variety seeking attitude is related to the consumer's desire for change.

- Risk propensity means the individual's tendency to take chances when deviating from the proven path.

- Cognitive dissonance is a state of mind that humans are theorized to be trying to avoid. Disloyalty to a product, for example, bears the risk of creating such cognitive dissonance through potential dissatisfaction. 
- Learning refers to learnt behavior. That promise of rewards leads to conditioned behavior is a prominent example of instrumental conditioning (a form of learning that will be discussed in Chapter 5.3.4).

- Patronization-related:

- Satisfaction is often considered to be the most significant driver of customer loyalty (see e.g. Oliver 1997, Homburg 2006, or Kumar \& Reinartz 2006 for further information).

- Involvement is commonly agreed to be a concept central to the organism. The readiness to absorb and process information has been proven crucial to the development of loyalty.

- Commitment to an organization, store, product or service is also considered to impact customer behavior.

- Trust is a further factor related to products, services, or stores that will sway the purchase decision process of the consumer.

- Usage rate is the final patronization-related factor, resulting from customers' different needs and preferences, leading to different usage rates. A higher usage rate of a product, for example, will most likely expose its strengths and weaknesses to a greater extent, and involvement might be increased.

- Social:

- Culture and social norm (i.e. the way of life for an entire society) exert influence on the decision process of an individual if internalized to a large enough degree. Otherwise, influence might persist as a pure external stimulus.

- Religion can be of significance similar to that of culture and social norm, once it has become part of the individual.

\section{3) Response}

Finally, having dealt with influencing factors as well as the way consumers process them, notable examinations of the response "loyalty" shall be presented. One way of categorizing loyalty is offered by Plinke (1989), who, Diller (1996) summarized, elaborated on nine different forms of relationships by contrasting three types of relational objects (things, people, and organizations) with three kinds of commitment (only at the supplier-level, only at the customer-level, and at both levels). Another example is that of Enis \& Paul (1970), who, discussing store loyalty, devised an index to capture the varying degrees of loyalty by looking at share-ofwallet allocated to the retail outlet, the amount of switching, as well as the number of opportunities to do so. With a focus on profitability, Reinartz \& Kumar (2002) contrasted the duration of patronization (short- and long-term) with profitability (high and low) and came up with four types of customers that require different 
managerial action: strangers (short-term customers/low profitability), butterflies (short-term customers/high profitability), barnacles (long-term customers/low profitability), and true friends (long-term customers/high profitability).

Referring to the type of loyalty that is engendered within the individual, Dick \& Basu (1994) distinguished between no loyalty, latent loyalty, spurious loyalty, and loyalty in its typical sense. A final example is that of Oliver (1997), who took a somewhat different approach and came to the conclusion that the phases of cognitive, affective, conative, and action loyalty follow one another. The individual approach (including the description of possible stimuli) taken by these latter two authors in the theoretical development of these loyalty types will now be briefly elaborated on. In addition to explaining these categories of loyalty in more detail, this discussion serves the purpose of gaining a complete overview of two seminal contributions to the field of loyalty research.

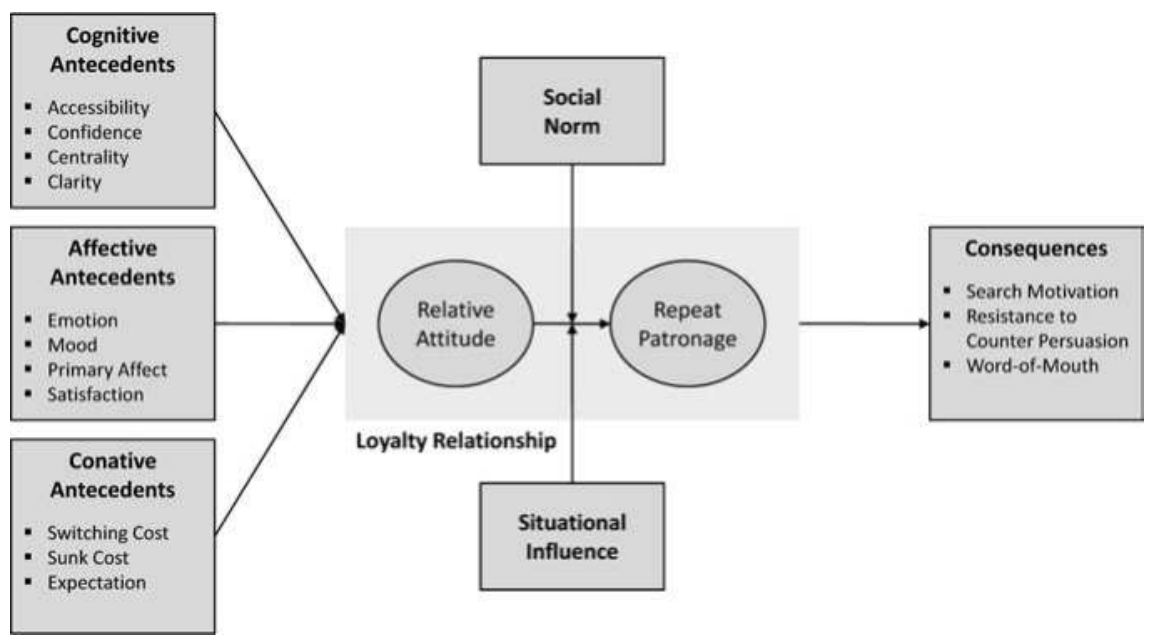

Figure 5: A Framework of Customer Loyalty

Source: Dick \& Basu (1994)

Following Jacoby \& Chestnut's (1978) work, it took until the 1990s for a notable progress of the loyalty literature to take place (Oliver 1997). Dick \& Basu (1994) expanded the loyalty literature with the view that the customer's relative assessment of the alternatives within a set of choices would also hold high potential significance. To construct what they called an "integrated framework" for customer loyalty (see Figure 5), the authors conceptualized loyalty as a relationship between the customer's relative attitude towards an entity such as a brand, store, vendor or service provider and repeat patronage behavior, and in addition to that, 
distinguished attitudinal and non-attitudinal moderators of the relationship between relative attitude and repeat patronage behavior.

In order to determine the kind of loyalty a consumer possesses, the authors used the two matrices provided in Figure 6. The left one distinguishes the level of relative attitude by cross-classifying attitude strength on the one hand and attitudinal differentiation on the other hand. Applying Ajzen \& Fishbein's (1980) notion of judging the degree of attitude by examining the position of, for instance, a particular product along a "continuum of favorability," one can determine whether it is weak or strong. This is then put in contrast to attitudinal differentiation, asking whether the customer perceives any differentiation in his choice set. The highest relative attitude could thus be perceived if the customer has a strong attitude and there is differentiation within the focal product group. The degree of relative attitude is then placed on the y-axis of the second $2 \times 2$ matrix and compared to the intensity of repeat patronage, which consequently results in four specific kinds of loyalty, each characterized by a different possible background:

- No Loyalty: a low relative attitude and low repeat patronage could, for example, be due to a market with little possible differentiation or a customer who is unaware of recent product introductions.

- Latent Loyalty: non-attitudinal influences, such as subjective norms and situational effects, are likely to exert significant influence in a scenario where repeat patronage is low despite high relative attitude.

- Spurious Loyalty: this case is, similar to that of latent loyalty, characterized by non-attitudinal influences. High repeat patronage despite low relative attitude could be caused by factors such as social influence or familiarity.

- Loyalty: naturally, the state where high relative attitude meets high repeat patronage is the most desirable for an organization, as this situation signifies true loyalty.
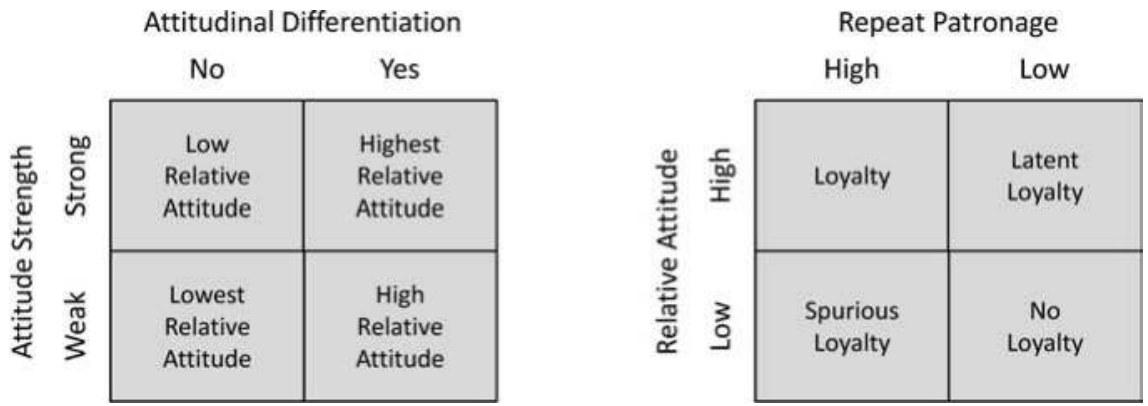

Figure 6: Modeling Different Forms of Loyalty

Source: $\quad$ Dick \& Basu (1994) 
Going back to the framework depicted in Figure 5, Dick \& Basu (1994) further elaborated on cognitive, affective, and conative attitudinal antecedences influencing the loyalty relationship by building on the ideas of Jacoby \& Chestnut (1978). Cognitive antecedents consist of the ease of accessing an attitude from memory, the level of confidence in regard to an attitude, the degree to which an attitude is central to a person's value system, and the clarity of the definition of the particular attitude. Affective antecedents are composed of emotion, mood, primary affect (i.e. physiological responses independent of cognitions), and satisfaction, while conative antecedents comprise switching costs, sunk costs, and future expectations.

Finally, the authors considered two additional non-attitudinal factors influencing repeat purchase behavior. On the one hand, social norm was seen as a moderator of loyalty in certain situations, and on the other hand, situational influences such as stock-outs or special promotions for a rival product were accounted for.

Similar to Dick \& Basu (1994) and Jacoby \& Chestnut (1978), Oliver (1997) differentiated between the formation of beliefs, likes and dislikes, and behavioral intention. He further theorized that these three phases are sequential in nature, meaning that customers become loyal along the information base first, upon which they develop a favorable attitude, which eventually leads to a commitment to buy. At the first level, consumers are simply swayed by the value that a particular service, for instance, provides to them over the offer of competitors. At the second level, attitude enters the picture, which, the author noted, is formed by expectations in the early phases of purchase on the one hand, and expectation disconfirmation, prior attitude, and satisfaction in the later phases on the other hand. Pointing to Eagly \& Chaiken (1993), Oliver (1997) highlighted that the important attribute of affect (i.e. attitude) in this context is that it is firmly connected to overall brand evaluation as well as cognition. For that reason, affect is much less vulnerable to counter-argumentation than cognition. Marking the third level, behavioral intention, or commitment as it could also be called, takes affection one step further by adding the wish to take action.

These three phases fall short of achieving true loyalty, however. To solve this problem, Oliver turned to a stream of research called "action control," the study of the mechanism by which intent is converted to action (see Kuhl \& Beckmann 1985 for further details), to describe a fourth level. In line with this theory, motivation as well as a desire to overcome obstacles is needed for intention to develop into a readiness to act (Oliver 1999). Only then, the author denoted, are all necessary requirements of loyalty accurately considered, and a state of loyalty in its true sense achieved. 


\subsubsection{Conclusion}

It can be seen that numerous elements are expected to exert some kind of influence on the creation or development of customer loyalty. Different authors consider different ones in their models, but none of them seem to have found either final consensus or an ultimate solution. Possibly, we do not have to understand what exactly goes on within the organism, as long we can prove a connection between a stimulus and a response. A lot of these factors are interconnected, which makes them extremely difficult to model. For example, satisfaction was shown to be correlated with loyalty and is commonly considered to be a very important driver of customer retention. The link between satisfaction and retention is nonlinear, however, as Anderson \& Mittal (2000) demonstrated, with the impact of satisfaction on retention being strongest on its extremes, and a flat slope (the so-called zone of indifference) spanning out in between. The shape of this curve, Kumar \& Reinartz (2006) summarized, is influenced by various factors, including the competitive environment, switching costs, and the level of perceived risks. It is, for instance, not uncommon in many business sectors that aggressive competition offering desirable products lures away satisfied customers from their current brand of choice (Jones \& Sasser 1995; see Chapter 5.2 for further elaboration on this topic).

This section tried to give an overview of the framework of loyalty and its status in research. As mentioned before (and indeed, as the name suggests), one of those elements argued to exert some kind of influence on customers are customer loyalty schemes. Numerous authors have investigated their ability to engender or foster loyalty and the following chapter aims at distilling their findings.

\subsection{Customer Loyalty Schemes and Loyalty}

"Do these programs really create extra loyalty beyond that which is derived from the relative value of the product or service? Do they encourage customers to spend more? Or do they merely bribe a customer to buy again," Dowling \& Uncles (1997, p. 71) rightfully asked themselves and their readers. In this connection it needs to be kept in mind that retailing is, as opposed to the service industry or B2B relationships, characterized by a lower level of personal contact and interdependence (O’Malley \& Tynan 2000). The question came up, whether true loyalty could even exist in this sector (Uncles et al. 2003). After all, a risky investment decision certainly has a higher potential to lead to a relationship between two companies than the purchase of pickles will have for that between an organization and a regular grocery shopper. It is not certain, Dowling \& Uncles (1997) accentuated, whether customers really want a relationship for lowinvolvement products. Somehow, one is tempted to say "probably not." 
A good part of research on loyalty programs was dedicated to answering the question of whether they are able to engender loyalty. Often focused on the behavioral aspect of loyalty, a whole range of authors has attempted to answer the question of "whether these programs actually work," and came up with mixed results. Table 1 gives an overview of the literature reviewed in this section. The focus of this compilation was put on the context of retailing, complemented by a few notable papers from other industries. The categorization into publications employing a comparison across competitors, as opposed to those comparing across time or across consumers was suggested by Liu (2007) and has, in a slightly modified form, been adapted for the overview in Table 1 to help make sense of the heterogeneous literature. In Chapters 2.3.1 and 2.3.2, findings will then be presented in more detail in chronological order, based on these papers' assignment to the two categories that ultimately matter most: that with either predominantly positive or predominantly negative evidence. In the course of this, all retail-related papers, but only the most noteworthy of the selected papers from other industries will be covered. 


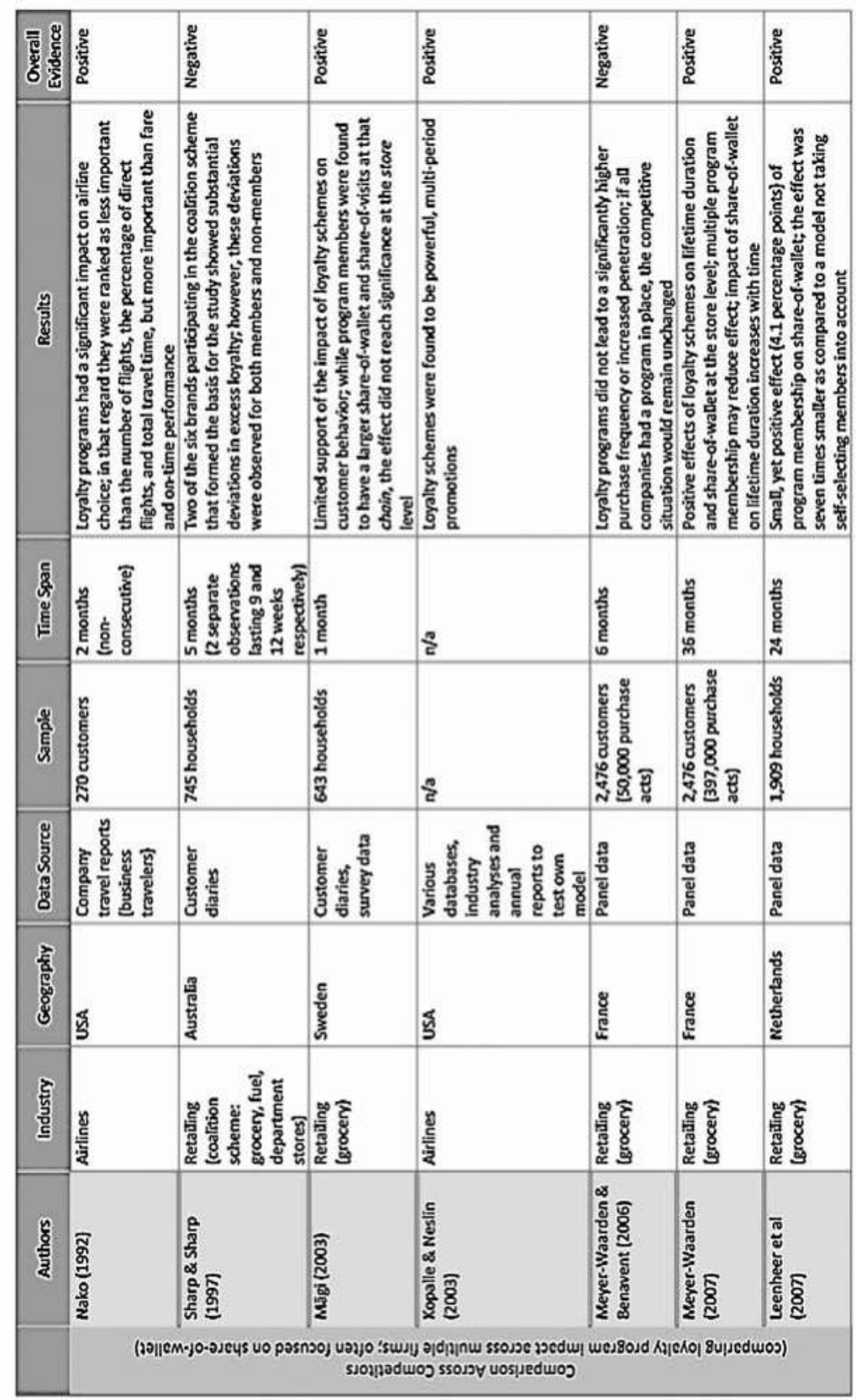




\begin{tabular}{|c|c|c|c|c|c|c|c|c|}
\hline & : : & 害 & 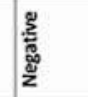 & క్్요 & 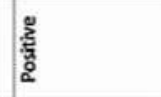 & 薮 & 悹 & : \\
\hline 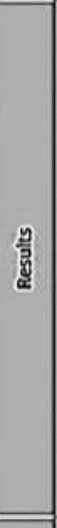 & 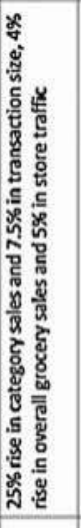 & 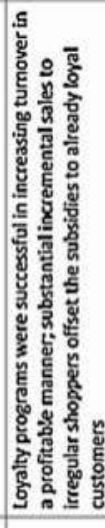 & 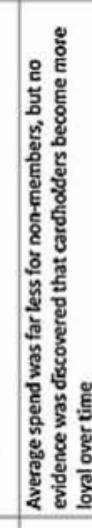 & 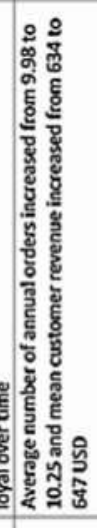 & 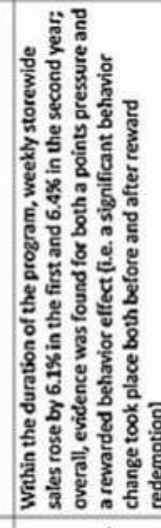 & 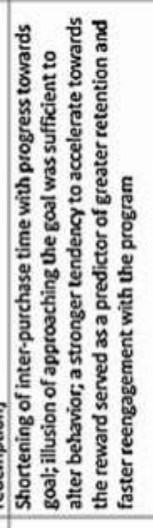 & 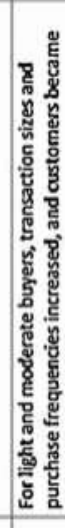 & 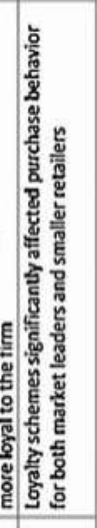 \\
\hline $\begin{array}{l}\text { है } \\
\text { है } \\
\text { है }\end{array}$ & 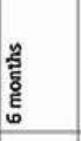 & 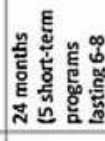 & & 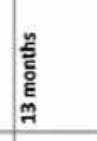 & 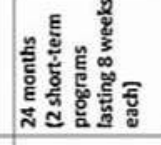 & $\Xi$ & 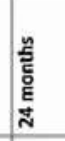 & 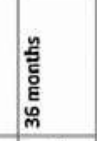 \\
\hline 育 & है & $\frac{\pi}{\varepsilon}$ & & 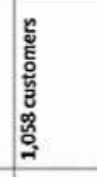 & 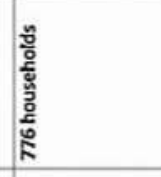 & 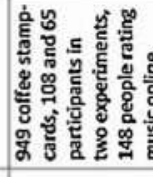 & : & 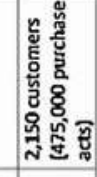 \\
\hline $\begin{array}{r}8 \\
\frac{8}{8} \\
\frac{0}{8} \\
\end{array}$ & 总 & 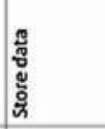 & 产产 & 药 & 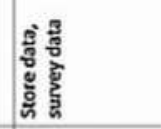 & 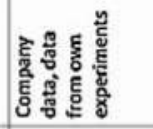 & 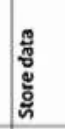 & 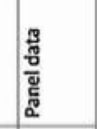 \\
\hline $\begin{array}{l}\text {. } \\
8 \\
8 \\
\end{array}$ & 5 & 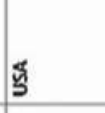 & 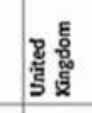 & $\$$ & \$ & 㧒 & 5 & 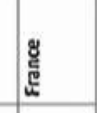 \\
\hline$\underline{\underline{g}}$ & 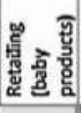 & & 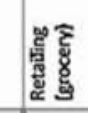 & & & 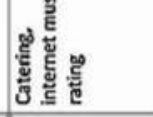 & 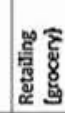 & 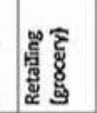 \\
\hline 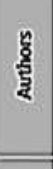 & 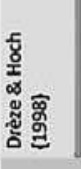 & 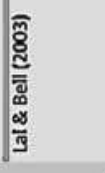 & 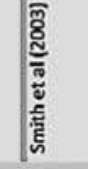 & 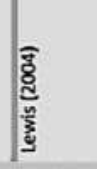 & 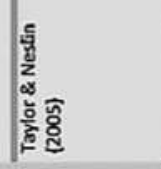 & 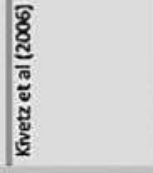 & 造 & 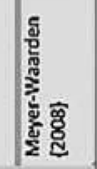 \\
\hline \multicolumn{9}{|c|}{ OAReNo3590) } \\
\hline
\end{tabular}




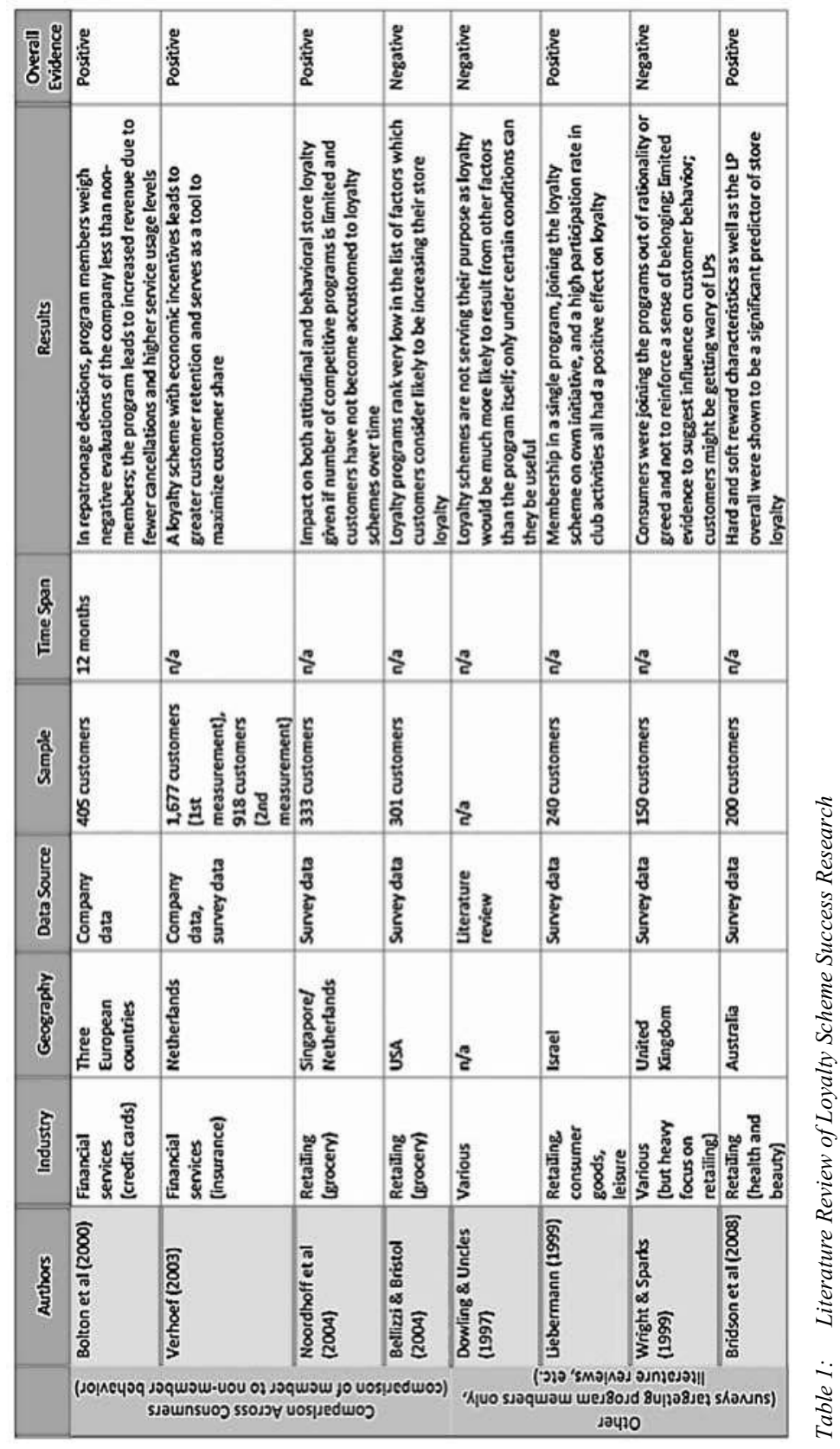




\subsubsection{Predominantly Positive Evidence}

First in a range of examples with "net positive evidence" comes the work of Drèze \& Hoch (1998). During a six month time period, the authors observed a category destination program (i.e. a program that is similar in nature to a loyalty scheme in that it aims to encourage spending, but limited in the sense that it does so only for a single category) for baby products at all 70 outlets of ABCO Markets in the American state of Arizona. Backed by advertisements both in-store and broadcasted by radio and television, the program offered one "Baby Buck" for every USD spent on baby-related products. 100 such baby bucks could then be exchanged for a store-wide voucher of 10 USD. In terms of category sales, the program led to an overall increase of $25 \%$, resulting from a $25 \%$ rise in the number of customers buying baby products and a $7.5 \%$ increase of the average transaction size. Overall, store traffic increased by $5 \%$ and total grocery sales by $4 \%$.

In a preliminary study covering six small Israeli loyalty schemes across three industries (one being retail) with an average of around 15,000 members each, Liebermann (1999) conducted telephone interviews with 40 members of each program. The author discovered a significant effect of membership on word-ofmouth, while no significant effect of membership on expenditure was found, however, even though $20 \%$ of customers reported having spent significantly more due to their membership, and $32 \%$ indicated having bought slightly more. In any case, the article nevertheless leaves a positive impression.

Using data provided to them by a supermarket chain in the mid-west of the USA, Lal \& Bell (2003) analyzed the effects of five non-institutionalized shortterm loyalty schemes such as a ham promotion (where vouchers for a certain amount of ham were handed out, depending on the amount spent) or the socalled "discount and turkey promotion" (coupling a store-wide voucher with a coupon for a turkey, whereby the size of the reward again depended on the amount spent). The authors concluded that the programs were successful in increasing turnover by their customers and added that interestingly, the spend of customers in the lower spending deciles was greater than that of the supermarket's best customers. Moreover, these programs were run in a profitable manner.

Mägi (2003) gathered data on 643 households by having them keep a four week store choice diary and complete a questionnaire at the end of this period. Her results were mixed. On the one hand, the author's hypothesis that members of a loyalty scheme of their primary store will have a larger share-of-wallet and share-of-visits at the primary store could not be supported. Although support was found to be slightly positive, it did not reach significant levels. On the other hand, the hypothesis that customers having a loyalty card of a chain will have a larger share-of-wallet and share-of-visits at this chain could be maintained. This 
was only true, however, for the $35 \%$ of customers who did not possess a competitive loyalty card. Still, all in all, limited positive support for loyalty schemes was discovered.

Next to the influence of email-coupons, pricing changes and shipping fees as three other marketing efforts, Lewis (2004) presented a model of customer response to a loyalty scheme. The model included both previous behavior by looking at cumulative purchases and forward-looking elements such as loyalty rewards. To test the model, Lewis used a sample of 1,058 customers stemming from a complete 13 month data set of 30,000 customers provided by an internet retailer focused on grocery and drug store articles. Conducting both simulation and policy experiments (e.g. to test the effect of changing or removing the loyalty scheme), the author found that the loyalty program effectively increased repeat purchase rates and was indeed successful in increasing turnover for a substantial proportion of customers. Specifically, the average number of annual orders increased from 9.98 to 10.25 and the mean customer revenue increased by 13 USD from a baseline of 634 USD. Consequentially, Lewis noted, the relative fit of the dynamic model (which considered future rewards) as compared to a static model did point towards the effectiveness of loyalty schemes.

In a study with questionnaires personally administered to 333 grocery shoppers in the Netherlands and Singapore, Noordhoff et al. (2004) analyzed, among other things, inter-cultural differences in the impact of card possession on loyalty. While doing so, the authors also differentiated between behavioral and attitudinal store loyalty and came up with surprising results. While loyalty card possession yielded a significant increase in both behavioral and attitudinal loyalty in Singapore, the analyses of the Dutch sample could only confirm a link to attitudinal loyalty. Partly due to fact that the amount of loyalty was significantly higher in Singapore, the authors hypothesized that the lack of a connection between loyalty card possession and behavioral loyalty in the Netherlands could be due to the effectiveness of loyalty programs eroding with their age and the emergence of a multitude of competitive schemes. As for the particularly strong links in Singapore, Noordhoff et al. argued that this might have been due to the Asian economic crisis of the late 1990s having increased price consciousness and consequently the sensitivity to price reductions. Despite the unexpected peculiarity as regards behavioral loyalty in the Netherlands, overall support for the ability of loyalty schemes to engender loyalty remains nevertheless positive.

Taylor \& Neslin (2005) examined the effect of a loyalty program on sales both in the short and in the long run. Short-term impact, they argued, is created by what they termed points pressure, as customers increase their purchase levels to surpass a necessary threshold for obtaining a reward. By contrast, long-term impact is hypothesized to be generated through rewarded behavior, where, possibly due 
to the learning theory of instrumental conditioning or positive affect resulting from the reward, customers exhibit a higher than baseline level of sales in the period following the receipt of a reward. Complemented by an initial mail survey, two years of grocery shopping basket item data for close to 776 households formed the basis for the study. The reward program which offered a free turkey to customers was employed for eight weeks once every year. During their analysis, Taylor \& Neslin found evidence for both the points pressure and the rewarded behavior effect. During the eight week period the program was employed, weekly storewide sales rose by $6.1 \%$ in the first year and by $6.4 \%$ in the second year. Furthermore, sales did not immediately return to pre-program levels following the redemption of the free turkey. Still, unlike one might expect, the overall impact of the rewarded behavior did not surpass that of the points pressure effect.

This points pressure effect was also proven by Kivetz et al. (2006) who (1) analyzed 949 completed ten-stamp cards at a café on a university campus promising a free coffee, (2) conducted a field experiment with 108 participants in a free coffee setting, (3) carried out a questionnaire-based experiment with 65 respondents set around free pizzas as a reward, and (4) analyzed a data set of close to 148 people participating in a program that incentivized them with Amazon vouchers for rating music on a website. The authors found that the purchase frequency accelerated while customers progressed towards receiving a free coffee. Similarly, customers visited the rating website more often, rated more songs, and persisted longer in their rating effort while approaching the reward. This was further fortified by the observation that a slowdown set in following the achievement of a reward, while eventually another phase of acceleration was noticed once a reward could be reached for the second time. Interestingly, even the illusion of approaching a goal was sufficient to alter behavior. During the coffeeexperiment, certain customers were handed out cards that required 12 stamps but had 2 fields already stamped as part of a "special promotion," while others received empty cards requiring 10 stamps. Despite the fact that the number of purchased coffees needed to receive a reward was the same in both cases, the already pre-filled cards were completed faster than the empty ones. Furthermore, the authors noted, a stronger tendency to accelerate towards the reward served as a predictor of greater retention and faster reengagement with the program.

Leenheer et al. (2007) emphasized another important aspect: loyalty programs can not automatically be considered effective if members of loyalty schemes are found to have a higher share-of-wallet than non-members. This is due to the fact that already loyal members are the ones most likely to sign up for a loyalty program, as they are benefiting most from its rewards. Taking this endogeneity into account in an analysis of seven loyalty programs of Dutch grocers, the authors found a small, yet positive effect of program membership on share-of- 
wallet (which would have been seven times that large without accounting for self-selecting members). According to the authors' calculations, the programs were able to generate more additional revenue than additional cost in terms of saving and discount reward. Still, given the limitations of this study, these findings need to be put into perspective. Next to several other issues, it featured a significant flaw in that it did not incorporate any expense factors (e.g. administrative, IT, or marketing spending) other than the rewarding costs.

Using a random sample of 1,000 customers from an American convenience store chain, Liu (2007) observed the effect of the company's loyalty program over the first two years following its inception. The author found that the effect of the loyalty scheme depended on the customer's initial usage levels. For heavy spending customers, spend levels and exclusive loyalty to the store did not increase over time, while the opposite was true for light and moderate spending buyers. Their transaction sizes and purchase frequencies increased, and furthermore, they became more loyal to the store. This increase, Liu added, was most evident in the first three months of the program's creation, upon which growth decelerated to a slower pace.

In a series of two similar articles, Meyer-Waarden $(2007,2008)$ evaluated panel data from the French town of Angers, covering customers' purchases in five hypermarkets and two supermarkets. Over a period of 156 weeks each, and covering 397,000 purchase acts by 2,476 customers and 475,000 purchases by 2,150 customers respectively, the author concluded that loyalty schemes significantly affected purchase behavior at smaller retailers as well as market leaders. For instance, Meyer-Waarden (2007) noted, program subscription not only significantly reduced the relative risk of defection, but also increased share-of-wallet at the particular store. "Specifically, cardholders have significantly higher purchase intensities in terms of total and average shopping baskets, share-of-category purchases, purchase frequencies and inter-purchase times than do non-members over the entire three-year period and throughout the trading areas," MeyerWaarden (2008, p. 102) summed up the results.

Bridson et al. (2008) gathered survey data from 200 customers of two stores of an Australian health and beauty retailer, and found an empirical verification for the relationship between the loyalty program, store satisfaction and store loyalty. Specifically, hard and soft reward characteristics as well as the loyalty scheme overall were shown to be significant predictors of store satisfaction. As for store satisfaction, the authors confirmed its mediating role on store loyalty, and concluded that loyalty schemes were indeed a significant predictor of store loyalty.

Positive evidence of loyalty schemes is not limited to studies set in the retailing context, however. Apart from the work of Kivetz et al. (2006) that has already been described in greater detail due to its notable findings, examples include 
Nako (1992) and Kopalle \& Neslin (2003) who found proof for loyalty programs' effectiveness in the airline industry, or Bolton et al. (2000) and Verhoef (2003) who ascribed a positive influence to customer loyalty schemes in the financial industry.

\subsubsection{Predominantly Negative Evidence}

An important part of loyalty research in the retailing context has historically been that of store loyalty. Various authors have analyzed the factors influencing store patronage (e.g. Bellenger et al. 1977, Arnold et al. 1983, Louviere \& Gaeth 1987, Bellizzi \& Bristol 2004), but be it product assortment, convenient location or fast check-out lines that fetch the top place as the factor with the highest impact, results in these studies tend to be similar (see East at al 1995, Bloemer \& de Ruyter 1998, or De Wulf \& Odekerken-Schröder 2003 for examples with a narrower focus). Pan \& Zinkhan's (2006) thorough meta-analysis of the determinants of retail patronage confirms this impression. Interestingly, none of these studies mention the role of loyalty schemes. When asked about the reason for not including loyalty programs as a driver of store choice, Yue Pan answered that the only reason he did not include them was that he did not find many articles that reported usable effect sizes for this variable (personal communication, January 22, 2008). The question still remains open, however, whether Pan \& Zinkhan really had all the relevant studies at their disposal, and whether the authors of the publications reviewed in the meta-analysis even considered including the comparatively new topic of loyalty programs in their respective studies in the first place. Furthermore, inclusion in the authors' study depended on what they considered a "usable" effect size. This problem of varying opinions among authors of what effect size is to be considered "usable" or "good enough," will be discussed in greater detail in Chapter 2.3.3.

Dowling \& Uncles's (1997) paper is the first in a row of publications that leave the reader with a negative impression of the effectiveness of loyalty schemes. What stands out about this work is that it is often referenced, despite a lack of its own empirical data. In fact, one might even go so far as to call the authors' work the starting point for modern research on the effectiveness of loyalty programs (next to Sharp \& Sharp 1997, possibly). In a review of behavioral loyalty research as well as then current events in the business environment, Dowling \& Uncles (1997) seem to have put future research on track. They found that loyalty is much more likely to come from other factors than the loyalty scheme itself. From this they concluded that most programs were not serving their purpose, despite agreeing that if properly designed, there are certain conditions under which they can be useful. 
In an attempt to determine its ability to create additional loyalty for brands taking part in the program, Sharp \& Sharp (1997) evaluated Australia's major coalition scheme Fly Buys. To detect a change from normal repeat purchase behavior, the authors developed Dirichlet estimates of expected repeat purchase loyalty from their own panel of 745 households, and compared them with the actual, observed behavior. They found that out of the six participating brands, only two showed substantial levels of excess loyalty, and further added that these deviations were likely to be at least partially linked to other loyalty efforts by the company, as both members and non-members exhibited the same alteration in behavior.

An example of an exploratory study relying on survey data is that of Wright \& Sparks (1999). From personal interviews with 150 people entering or exiting the main shopping center of the British city of Stirling, the authors concluded that people were tiring of loyalty cards. In explanation of the reasons behind this phenomenon, Wright \& Sparks stated that people no longer had space in their wallets, that they did not have the time or inclination to complete card applications, and that they would not need further cards which they were probably not going to use regularly. In addition, customers were found to join loyalty programs mostly out of rationality or greed, and not because they wanted to reinforce their sense of belonging. Furthermore, the authors retrieved only limited evidence to suggest that loyalty schemes possess the power to influence customer behavior.

Following the administration of an initial questionnaire, Smith et al. (2003) evaluated the results from a four month diary study covering 30 respondents in the United Kingdom. Despite finding that the average spend of non-cardholders equaled just slightly above $40 \%$ of what cardholders generated, the authors conceded that "there was no evidence to suggest that the cardholders were becoming more loyal over time" (p. 114). As far as the average spend is concerned, this can easily be explained by the fact that customers that are already very loyal are the ones most likely to sign up for the scheme, since they are the ones drawing the biggest benefits from their membership (Leenheer et al. 2007).

In Bellizzi \& Bristol's (2004) study, respondents were, among other things, asked to assess 28 items on a five-point scale and indicate how likely each factor would be to contribute to their store loyalty. With a mean of 2.67 ( 5 being highest), "store offers a shopper loyalty card" landed in place 18, followed by items like "store offers automobile oil change while you shop" in place 25 , or "store offers a beauty salon/barber shop inside" in the final slot. Obviously, one is tempted to say, customers placed factors such as "store offers quick-moving check-out lines," "store offers a variety of fresh produce," or "store is conveniently located" in the top positions. Also, they will naturally prefer immediate discounts over delayed ones, as indicated by the unnecessarily specific item "store does not have a loyalty card, but offers low prices in general, and has lots of two for one 
sales" in place number 7. Two things are important to note in this connection: (1) letting customers judge the importance of such factors can potentially yield inaccurate results, as they might not consciously perceive, acknowledge, or admit to the psychological effects underlying certain loyalty schemes (particularly when dealing with delayed rewards) (e.g. Mägi 2003), and (2) both academics and practitioners acknowledge that the potential impact is comparatively small (see Chapter 2.3.3 for a detailed discussion of these issues).

Preceding the series of similar articles by Meyer-Waarden $(2007,2008)$ that were mentioned in the section on positive evidence, Meyer-Waarden \& Benavent (2006) evaluated a sample of 50,000 purchases from a panel of 2,476 customers over a period of 24 weeks. Despite relying on the same panel that MeyerWaarden $(2007,2008)$ used, the authors retrieved predominantly negative evidence. According to their findings, stores with a loyalty scheme were not able to develop higher purchase frequency and also, no effect on an increase in customer penetration could be observed. Interestingly, Meyer-Waarden failed to properly comment on this outcome in his latter two articles, except for referencing his earlier work with Benavent while noting that some authors "contend it is difficult to change established behavioral patterns with the type of reward systems that are prevalent today" (Meyer-Waarden 2007, p. 224 and Meyer-Waarden 2008, p. 90).

\subsubsection{Possible Explanations for the Mixed Results}

It could be seen that some authors provided rather positive and others rather negative evidence, while yet others came up with mixed results even within their own studies. This ambiguous situation even reaches the extent that findings leave enough discretion to be interpreted in both directions. Indeed, certain articles are sometimes cited as positive and sometimes as negative examples, depending on what the authors considered "effective." For example, Leenheer \& Bijmolt (2008) referenced Mägi (2003) in relation to loyalty schemes when stating that "existing academic research [...] provided empirical evidence of their effectiveness" (p. 429), while Demoulin \& Zidda (2008) claimed that "Mägi (2003) did not show any convincing effect of loyalty cards on consumers' shares in grocery retail chains (i.e., share-of-wallet and share-of-visits)" (p. 387). A similar example concerns the paper of Lal \& Bell (2003), which was referenced by Gómez et al. (2006) following the statement that "papers focused on loyalty programs that compare the consumers' behavior before and after enrolling themselves in these programs show that there is virtually no difference between the two states regarding to number of visits to the retailer or purchase volume" (p. 388), while Taylor \& Neslin (2005) stated that the authors "found evidence for a sales increase during 
the redemption period, suggesting a rewarded-behavior effect" (p. 295). Interestingly, even the same author might provide different results. For instance, Meyer-Waarden \& Benavent (2006) wrote: "findings with regard to the effects of loyalty schemes on repeat purchase patterns in stationary markets are mitigated [...]. Our findings lead us therefore to reject hypothesis H1, according to which stores with loyalty schemes systematically develop higher purchase frequency" (p. 81). Working with the same source of panel data two years later, however, Meyer-Waarden (2008) noted that "our main findings show that loyalty programmes affect purchase behaviour for both market leaders and smaller retailers" (p. 101 f.).

One reason for these discrepancies could be that the authors were simply sloppy in their literature review. Evidence for this theory comes from the fact that Taylor \& Neslin (2005) referenced Lal \& Bell (2003) in a June 2002 edition of Quantitative Marketing and Economics, despite the fact that the article appeared in June 2003. Gómez et al. (2006) did no better, however. Apart from referencing the 2002 working paper instead of the published article from 2003 (which, after all, appeared a whole three years prior to their own work), they continuously misspelled the last name of poor Rajiv Lal. Still, this theory probably does not explain it all and is, moreover, a rather unkind allegation that was not meant too seriously. More likely, then, are the different interpretations due to the varying perceptions of what the authors considered to be "effective." In the course of the literature review employed in this paper, both the works of Mägi (2003) and Lal $\&$ Bell (2003) were mentioned as examples of positive evidence. If one attempts to read the corresponding statements of Demoulin \& Zidda (2008) and Gómez et al. (2006) with more care, one can discover the solution to this problem in little words embedded in these sentences. When the authors claimed that the loyalty programs "did not show any convincing effect" or made "virtually no difference," they interpreted the results according to their own standards.

But what is the principal reason that explains why these papers allow for such fundamentally different interpretations in the first place? It is argued that this is due to the fact that the positive effect that can be obtained by employing a loyalty scheme is comparatively small by nature. This is particularly true for the retailing industry, as it is generally characterized by a non-contractual setting, low consumer involvement, a high level of competition, low profit margins and consequently comparatively low reward values in the industry's loyalty programs. Grocery retailing probably serves as the most prominent example for this scenario. This realization is not only supported by academics (e.g. Meyer-Waarden \& Benavent 2009), but by practitioners alike. For instance, Humby et al. (2008) (the men behind Tesco's Clubcard scheme) explicitly note that these programs can only complement the marketing strategy of a retailer, after all other more important 
factors are delivered on. The impact these schemes can consequently have on turnover is comparatively small expressed in percentage points, but will nevertheless result in a significant absolute number - particularly in a retail sector such as grocery retailing, which is characterized by small margins, but high rates of turnover.

A further issue that interferes with these results is the ubiquity of loyalty cards (Capizzi \& Ferguson 2005). Indeed, marketers have found customers to be "cherry picking," with multiple memberships in different competing loyalty schemes forming the basis (Passingham 1998, Wright \& Sparks 1999, Bellizzi \& Bristol 2004). "I have accumulated nine 'loyalty' cards from various stores and supermarkets. Does this make me more loyal, or less," asks a reader in a letter to The Times in the UK (Wright \& Sparks 1999). Usage frequency of these cards is one factor that would have to be considered in order to judge whether customers are really promiscuous at all times, or merely keep a loyalty card of a second fuel retailer in their car in case their first choice is not around. Particularly in those instances where the program is configured so that it gives immediate discounts, consumers are likely to register for the free program. Another possible scenario is what Dowling \& Uncles (1997) and McGoldrick \& Andre (1997) called polygamous loyalty. As opposed to brand switching on the one extreme and promiscuity on the other, polygamous loyalty describes the loyalty to a small set of brands. A possible example for this would be a variety seeking customer who purchases a specific toothpaste or breakfast cereal $80 \%$ of the time, and another one $20 \%$ of time. The "just-in-case scenario" as well as that of polygamous loyalty would thus be two possible explanations for the negative effect that having a competing loyalty card has been found to have on share-of-wallet (e.g. by Mägi 2003). What remains true, though, is that cards are often not used in the long run. During a 12 month empirical investigation of the database of one Italian supermarket outlet, Mauri (2003) discovered that a very high percentage of card holders were not loyal to their card. In fact, out of the roughly 8,300 cards issued during that year, less than $40 \%$ were still in use in the last month.

The effect of competing loyalty programs is also one of the most important points of criticism with regard to these programs' effectiveness. Following the argumentation of Uncles (1994) and Dowling \& Uncles (1997), a loyalty scheme's effect will be cancelled out as soon as competitive offerings enter the market. Consequentially, as terminating a loyalty scheme is a problematic issue and not advisable in a setting where a competitor has already matched the program, retailers are expected to be left with additional costs, but no additional benefit. As some of the studies mentioned in Chapter 2.3.2 have shown, this is not necessarily true, particularly because quite often not all players in an industry do employ a 
loyalty scheme and furthermore, because they almost always differ in their setup (e.g. their reward structure).

Another possible explanation for the varying results relates to methodological deficiencies, of which Meyer-Waarden \& Benavent (2009) provide a valuable summary. While studies using aggregate panel data do not take customer heterogeneity into account and store level data fails to do so with respect to competitive information on buying behavior, declarative survey data is confronted with reliability problems. Most importantly, however, the explanatory power of virtually all existing studies is flawed in that they ignore purchase behavior prior to loyalty program membership. Unfortunately, this is a limitation that is hard to avoid. While for store-level data, purchase behavior can only be captured from the beginning of membership in a loyalty program, very few providers of panel data capture the sign-up date to a loyalty program and also what purchases the respective card has been used for. Finally, survey data might have difficulties capturing the minor changes in purchase levels or buying frequency that can be expected from loyalty program membership in certain industries. Different methodologies, data sources, sample sizes and observed time spans are just some of the issues that cause variations in the outcome, particularly because the effect that is to be measured is fairly small. Regarding the oscillating observations mentioned previously in a comparison of Meyer-Waarden \& Benavent (2006) and Meyer-Waarden (2008), for example, Lars Meyer-Waarden noted during personal communication that this was influenced by the data basis covering only 24 weeks in the first case, while it spanned 156 weeks in the later article (personal communication, December 7, 2008).

Next to these two main reasons that are often cited as interfering with the determination of the "true" effect of loyalty schemes, numerous other elements are obviously involved. For example, Meyer-Waarden also highlighted the lack of proper consideration of the distorting effect of self-selecting members in his papers as well as our personal communication. Except for Leenheer et al. (2007), who calculated that $86 \%$ of the effect of being a member on share-of-wallet is explained by this endogeneity, no other study to date has launched an attempt to control for this factor. In addition, different industries and even retailing subsectors are likely to lead to different results and the program configuration and reward structure can also be considered a major driver of loyalty scheme effectiveness (if not the most important one). A certain variance in the outcome of these studies is thus naturally given, as their setup is never similar in all respects. 


\subsubsection{Reflection}

It seems fair to say that studies regarding the effectiveness of loyalty schemes in generating or fostering loyalty face several limitations that need to be considered. As far as the problem of distinguishing between studies that prove and those that refute the effect of loyalty schemes is concerned, this paper does at least partly step into the same trap that other authors were criticized for falling into. The reason for the voluntary action of offering a "positive evidence chapter" and a "negative evidence chapter" is to provide an illustration for the dominance of research that leaves the reader with a positive aftertaste. Naturally there are some papers that were named in the negative category, but do not provide purely negative results (e.g. Sharp \& Sharp 1997 or Smith et al. 2003). The motivation for still putting them into that group is that they are predominantly negative, as opposed to those in the positive category, which are at least predominantly positive. Overall, however, literature tends to support a small, yet positive relationship between loyalty schemes and behavioral loyalty.

But what about attitudinal loyalty, one might ask. Unsurprisingly, opinions diverge in this case as well. Kumar \& Shah (2004), for example, argued that loyalty programs need to cultivate attitudinal in addition to behavioral loyalty in order to reap the benefits of some of the commonly believed effects of true loyalty (Reichheld 1996, Steyn et al. 2010):

- The costs of serving loyal customer are less.

- Loyal customers are less price-sensitive.

- Loyal customers benefit the company by passing on positive word-of-mouth.

The way in which this can be done, the authors proposed, is via a suitable configuration of the reward structure. Applicable only to pre-selected, profitable customers, this would mean targeting the customers' higher level goals in life, such as achieving social recognition, or visiting exotic places around the world. Likewise, Hart et al. (1999) suggested that loyalty schemes need to put more focus on their relational intent. In fact, the authors even asserted that the "future success of the schemes will depend on extended relationships as well as a move away from transactional intent" (p. 557). It needs to be added, however, that Hart et al. are referring to non-grocery retailing sectors only, which might constitute a key point in this discussion. Even Kumar \& Shah (2004) could only come up with examples for rewards they contended to be able to foster attitudinal loyalty, which are rather unlikely to see implementation in a food retailing setting. When credit card companies fly their elite customers around in a private jet or treat them to private time with a celebrity, one could imagine that this might work. Picturing a grocery chain doing so is disproportionally harder. In this regard, the 
question that Dowling \& Uncles (1997) brought up by asking whether customers really want a relationship for low-involvement products might be modified into asking whether a relationship can really be established for retail sectors characterized by low involvement. In all likelihood, it is maintained, creating attitudinal loyalty through a special loyalty scheme for the top customers in Prada stores is more probable to succeed than through a program targeting Tesco's best customers. This also supports Yi \& Jeon's (2003) proposition that loyalty marketing is a better fit for high-involvement products.

While some authors thus still purport that attitudinal loyalty is a goal that is achievable, many others believe the opposite. "A classic example of a misnomer: the loyalty card" is the title of an article by the academic Steve Worthington (2000), for instance. Similarly, Wright \& Sparks (1999) stated that “'loyalty card' is not perhaps the correct term to call many of the cards in use" (p. 431), and Weinstein (1999) quoted a managing partner of a retail consultancy talking about attitudinal loyalty with the words "in fact, there is one thing still lacking in frequent-shopper programs, and that is loyalty" (p. 89 f.). Indeed, even for studies that explicitly capture attitudinal loyalty (e.g. Noordhoff et al. 2004 or Gómez et al. 2006) it needs to be kept in mind that despite findings of loyalty program users being characterized by a higher level of attitudinal loyalty than non-members, a causal relationship has never been established.

Can a loyalty scheme generate loyalty? Logic would suggest that a smart shopper (i.e. well-informed and generally price-conscious consumer) will adopt such a program and adjust his behavior to his own benefit, but in practice, this will certainly not be true for all customers (Schnedlitz 2006, Liebmann et al. 2008). This question of whether a loyalty program can create loyalty has not received an ultimate answer yet, but for the effect on behavioral loyalty, the answer appears to be predominantly yes, though depending on industry and program structure, generally to a relatively small extent. As for attitudinal loyalty, the answer tends towards no, at least for a large part of the retailing landscape and again dependant on program and particularly reward configuration. 



\section{Loyalty Schemes}

Chapter 3 will be dedicated to a comprehensive discussion of loyalty schemes. Again, a section on definitions will mark the beginning of this overview (Chapter 3.1), after which the historical development and the current spread of loyalty programs in a sample selection of countries will briefly be touched upon (Chapter 3.2). Thereafter, the different types of loyalty schemes will be discussed (Chapter 3.3), the aspect of data collection broached (Chapter 3.4), and finally, the positive as well as the negative aspects commonly associated with these programs summarized (Chapter 3.5).

\subsection{Definition}

A chapter on definitions always seems to be a somewhat German endeavor and consequently, this work relies at least partly on German literature. By summing up the essential characteristics that the name alone does not always transmit, definitions certainly have an important role to play in any academic paper. In the case of loyalty schemes, this role is even more important, as the features that are commonly ascribed to such a scheme have changed somewhat in the recent past. Possibly due to that reason, a generally accepted definition of loyalty programs is still lacking.

"A customer club can be defined as an at least communicative union of people or organizations, which is initiated and operated by an organization in order to contact these members directly on a regular basis and offer them a benefit package with a high perceived value, with the goal of activating them and increasing their loyalty by creating an emotional relationship," Butscher (2002, p. 5) noted. Similarly, Diller (1997) defined customer clubs as an "association of actual and potential customers with a certain organizational degree, initiated, organized, or at least supported by one or more organizations" (p. 33, translated), and Poth \& Poth (1999) as "the association of users of certain products or services," whereby these clubs "are founded by producers, but particularly retailers and primarily serve the purpose of [engendering] customer loyalty" (p. 214, translated).

Following a review of classic German marketing handbooks, Holz (1997) added three further properties that characterize a loyalty scheme: (1) it needs to 
be seen as a marketing instrument, (2) it unites only a part of all current and potential customers, and (3) it implies an activity by the customer in order to become a member of the club. Furthermore, Liebmann et al. (2008) added, these schemes are used to develop loyalty particularly among customers "who have either identified themselves with the company or its products to a larger degree [than others] in the past, or those that are considered desired customers due to their turnover potential or their function as opinion leaders" (p. 630, translated).

While most of the characteristics mentioned by these authors are certainly correct, the constituting element of engenderment of true loyalty which, for instance, Poth \& Poth (1999) or Butscher (2002) imply, is mostly considered outdated. The plain stimulation of continued patronage among customers is its basic goal, which companies attempt to achieve through discounts, cash, free goods, or other special features and services (Berman 2006; see Chapter 3.5 for further information on goals of loyalty schemes). Direct, customized communication and a range of useful analyses made possible through extensive customer databases is the essential foundation for companies with sophisticated programs. "The effective use of loyalty card data is arguably the most significant benefit of scheme implementation," Byrom (2001, p. 334) noted.

The role of loyalty schemes is nowadays largely considered to be basically twofold, meaning (1) the programs' ability to generate data and (2) their function as a marketing tool which might be promotional in nature, though featuring unique characteristics (see e.g. Sharp \& Sharp 1997).

\subsection{Historical Development and Current Spread}

There are numerous points in the past to go back to in search of the roots of loyalty programs, depending on how closely one believes historic examples need to resemble today's loyalty schemes in order to be considered a historic example in the first place. It is probably due to that reason (and hopefully not bad research) that different dates marking the beginning of these schemes appear in the literature.

Generally speaking, frequency schemes reward loyal customers with a diverse range of monetary or non-financial benefits, expecting an overall positive impact on business. Did salesmen in the Middle Ages, ancient Rome, ancient Egypt, or even in times before that employ such practices in one form or another? Most probably, one is tempted to say, they did. Still, the earliest concrete date mentioned in relevant literature is 1844 . In that year, the Rochdale Society of Equitable Pioneers, one of the first consumers' cooperatives, was founded in Rochdale, England by William Cooper, Charles Howarth, and another 26 Lancashire weavers (Reeves 1944). Reportedly encouraged by a lecture by George 
Holyoake (a short-time lecturer at the Birmingham Mechanics Institute, greatly influenced by the ideas of the Welch socialist Robert Owen) on self-help, the "Equitable Pioneers" opened a small grocery shop (Cannon 2004). The underlying rules, which endured as the basic structure of consumers' cooperatives, encompassed two things: a fixed interest on invested capital as well as a distribution of profits depending on the amount purchased (Reeves 1944). Run by its members, the shop was initially open on only two evenings a week. By 1851 , however, this modest upstart had served as an inspiration for a total of 130 similar outlets, reaching an impressive 450 cooperative enterprises by 1862 (Cannon 2004) and serving as the basis for the foundation of a cooperative factory and a textile mill (Reeves 1944).

The basic element found in both this consumer cooperative as well as modern loyalty schemes is, of course, that of giving something back to the consumer based on his contribution to sales. What is arguably different, however, is the underlying motive. While customers in today's loyalty programs are rewarded for their patronage with the actual aim of increasing overall profit, the dominant idea of the Rochdale Society was simply to provide groceries without paying the additional profit margin to the retailer (in return for which the members of the society had to contribute their labor).

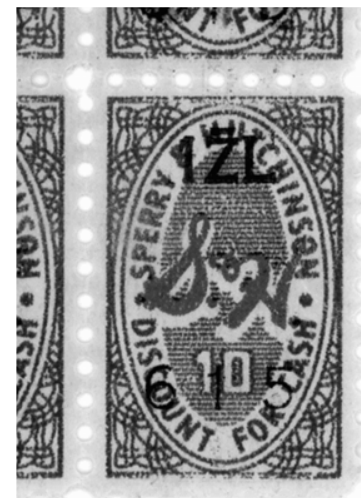

Figure 7: S\&H Green Stamp

Source: Wikipedia

Often called the first "actual" loyalty scheme, the S\&H Green Stamps (not to be confused with the S\&H Green Shield Stamps issued by a different company in the UK) were introduced in the USA as a reward currency by the S\&H Company in 1896 (S\&H 2009). Founded by Thomas Sperry and Shelly Hutchinson, the company sold these stamps to a whole range of supermarkets, fuel stations, and 
other retailers, which distributed them as a bonus to customers based on the amount purchased. Shoppers could then collect these stamps in collectors' books provided by $\mathrm{S} \& \mathrm{H}$ free of charge and eventually exchange filled in books for a variety of premiums and consumer products offered at local Green Stamps stores or via a special catalogue. According to the company's own declaration, by 1964 this catalogue had become the single largest publication in the USA, with S\&H printing three times as many stamps as the US Post Office. In the past decades, however, the popularity of the program has decreased steadily. In 2000, following two changes in ownership, the firm launched an electronic version of the Green Stamps, the greenpoints, with a supermarket chain in New York and New Jersey. By 2003, the greenpoints were used by a self-reported 3 million customers of three grocery chains in eleven US states, but have certainly failed to live up to their predecessor's glory.

Departing from the stamp-idea, American Airlines is often accredited with the initiation of the modern loyalty scheme. Following industry deregulation in 1979, the AAdvantage Program was introduced in 1981, converting unused capacity into a loyalty marketing tool (Gilbert 1996, O’Malley 1998). Only a few weeks later, United Airlines launched a similar program and today, many carriers have their own frequent flyer scheme in place.

Following an overview of the historical development, a few facts and figures about the current spread of loyalty programs will be given. This section is deliberately kept comparatively short, as these numbers change rapidly. Companies start up new programs, other schemes are shut down - large numbers of customers enroll in recently introduced programs in certain industries of particular countries, while somewhere else saturation and lethargy unfurl. Consequently, it needs to be kept in mind that the following selection of findings from a range of studies permits only a rough estimation of today's true geographic and industryspecific spread of loyalty schemes, as well as their customer penetration. The following numbers have been collected for the USA:

- By the end of the 1990 s, more than $30 \%$ of the supermarkets in the US had a program in place, with an additional $30 \%$ planning their implementation (Weinstein 1999). Mostly due to the emergence of computers, scanners, and other efficient ways of capturing, storing and analyzing customer purchase data, card-based loyalty programs have strongly increased their presence since the 1990s (Bellizzi \& Bristol 2004).

- Total US loyalty memberships have increased from 973 million in 2000 to 1,319 million in 2006 (Ferguson \& Hlavinka 2007). Figure 8 depicts the 2006 distribution of these memberships by industry.

- Calculating with a generous $80 \%$ of the United States' roughly 300 million inhabitants, this would translate to around 5.5 loyalty memberships per person. 
- Gartner analyst Adam Sarner calculated that US companies spent 1.2 billion USD on loyalty programs in 2003 (Kumar 2008).

- Regarding the current state of affairs, Capizzi \& Ferguson (2005) cannot help but describe loyalty schemes as ubiquitous. For example, the US Food Marketing Institute FMI (n.d.) revealed that approximately $75 \%$ of grocery retail customers in the US participate in a program of some sort, and indeed, some retailers disclosed that more than $95 \%$ of their total sales were generated by members of their loyalty scheme. Around five years earlier, Cigliano et al. (2000a) had found that only $53 \%$ of US grocery shoppers were enrolled in a loyalty program.

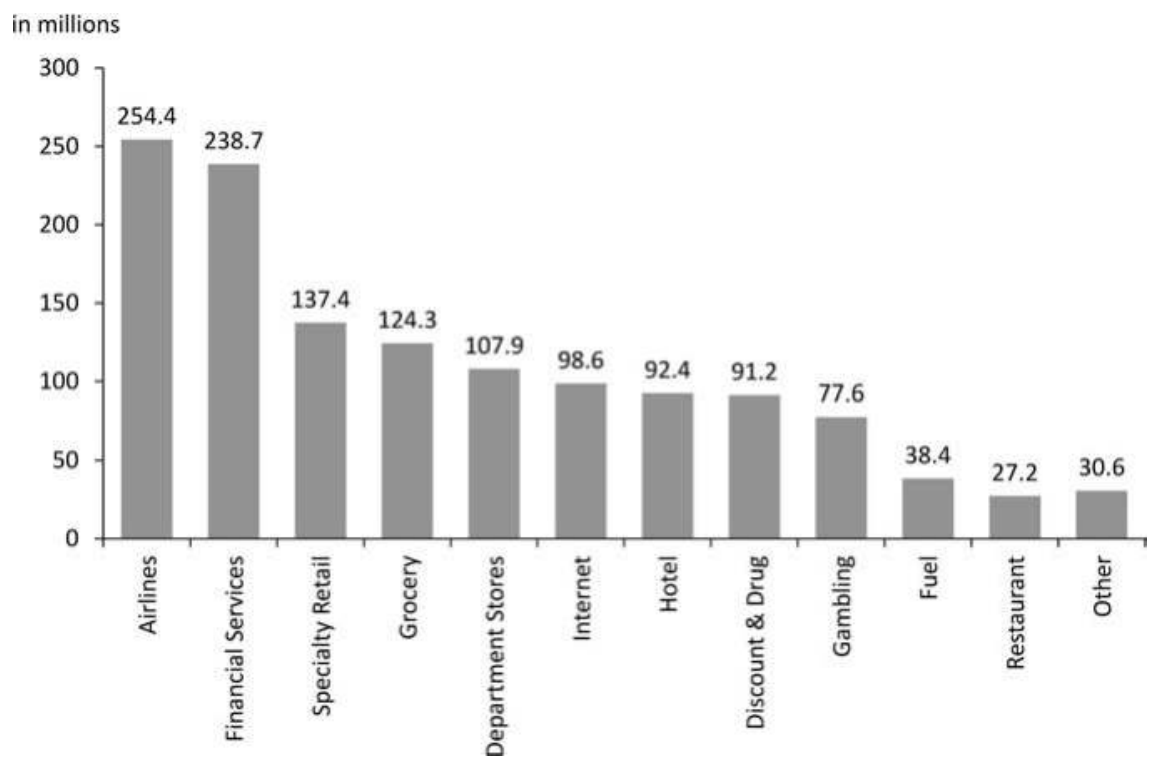

Figure 8: Number of US Loyalty Program Memberships by Industry (2006)

Source: $\quad$ Ferguson \& Hlavinka (2007)

Comparable enumerations could be assembled for many countries in the world. For instance, Capizzi \& Ferguson (2005) reported that more than $70 \%$ of Canadian households participated in at least one loyalty program. Similarly, to name a European example, Pressetext Austria (2006) announced that close to $80 \%$ of Austrian consumers were members of at least one loyalty program, following a $6 \%$ increase from the previous year.

Not everything seems to be home and dry, however. As previously mentioned, these numbers are all characterized by high volatility. To illustrate these 
rapid changes, one just needs to consider the developments in the British grocery retail market in the past decades. In the United Kingdom, probably the world's most mature market for loyalty programs, four out of the five biggest food retailers (Tesco, Sainsbury's, Safeway [acquired by Morrisons in 2003], ASDA, and Morrisons) had at some point employed a loyalty scheme. Today, Tesco remains as the only company still running its own program. Around the turn of the century, both Wal-Mart's subsidiary ASDA, as well as Safeway abandoned their trials or running schemes and pronounced them a failure (Humby et al. 2008). Eventually, Sainsbury's gave up its own loyalty program in 2002, joining the British coalition scheme Nectar (Thompson 2004).

The customer penetration of loyalty programs changes constantly and as far as predictions are concerned, one should never forget to distinguish between different geographical markets and different industries (see e.g. Demoulin \& Zidda 2009 for drivers of customers' adoption and adoption timing, which could, in line with Venkatesh et al.'s 2003 concept, possibly also be explained with a technology acceptance model). Despite some authors having augured a saturation in certain industries (e.g. Wright \& Sparks 1999 with a focus on retailing in the UK), the tendency in many areas still seems to be that of further growth (see e.g. Ferguson \& Hlavinka 2007 for more detailed sector-specific growth estimates for the US).

Following this introduction to the history and current spread of loyalty schemes, a comprehensive overview of the diverse types of programs will be given.

\subsection{Types of Loyalty Schemes}

Interestingly, particularly German literature seems preoccupied with the urge to classify the various types of loyalty schemes into as many groups as possible. Next to the classic loyalty program, Holz (1997) and Butscher (2002), for instance, differentiated between the following types of clubs:

- Book and music clubs: a meanwhile increasingly outdated form of distribution used particularly by book and music catalogue retailers. Hereby, customers are lured into the "club" by special offers, upon which the new members are obliged to buy a specific number of products in a given period of time.

- Fan clubs: clubs initiated and often run by consumers themselves, such as fan clubs of a particular soccer team, car brand or actress.

- Club companies: clubs that do not serve as a marketing instrument for a company, but that form the actual basis of the organization (e.g. the American Automobile Association in the US). 
- Warehouse clubs: a form of retailing where customers pay an annual fee for the club membership, enabling them to shop at the corresponding retail store, which usually offers no-frills settings and wholesale quantities for competitive prices (e.g. Costco or Sam's Club in the US).

- Rebate clubs: clubs based entirely on price discounts, whereby the payment of the membership fee entitles customers to a specific rebate for a particular period of time (e.g. the BahnCard of Deutsche Bahn, the German railway company; one available variation of this card, the BahnCard 25, can at the time of writing be purchased for 57 EUR and entitles its owner to a discount of $25 \%$ on all railway tickets in second class purchased within a year).

- Business-2-Business Clubs: marketing instruments similar to regular customer loyalty schemes, but aimed at partners in B2B transactions.

Categorization attempts go even further than that, however. In addition to the special variations mentioned above, Holz (1997) and Butscher (2002) tried to further distinguish between "customer clubs," "customer cards," and even "frequency programs." This categorization can still be found in modern retailing literature in the German-speaking area (e.g. Liebmann et al. 2008). From these authors' works, the following explanations could be distilled:

- Customer clubs: the main characteristic of this type of club, which might also distribute cards as a sign of club membership, is supposed to be the lack of price discounts as well as a payment function of the card. Club benefits are thereby reduced to things like special service, a club magazine, invitations to special events, or an exclusive product selection available to members (e.g. the Family Club of the Swedish furniture retailer Ikea).

- Customer cards: according to these authors' definitions, customer cards, as opposed to customer clubs, are loyalty programs that offer price discounts and/or a payment function of the card. Particularly with regard to price discounts, this category could probably be called the classic loyalty scheme of today's business environment.

- Frequency programs: the single differentiating feature of this type of program is their foundation on the collection of some form of bonus points.

As will be seen in the course of this chapter, there are numerous variations of loyalty programs in existence. Keeping that in mind, any categorization such as that into customer clubs, customer cards and frequency programs, appears random. Various possible categorizations are thinkable - consistent with the MECE principle (i.e. the categorization is mutually exclusive and collectively exhausted) and accurate, but quite frankly, all just more or less random. Furthermore, another point of criticism needs to be added with regard to Holz (1997), Butscher (2002), and Liebmann et al. (2008): giving these three categories names that are commonly 
known, but not commonly agreed upon, is highly problematic. In fact, a lot of people use these terms interchangeably, and who is to decide that a loyalty card giving its bearer $5 \%$ off the total purchase is a "customer card," while the loyalty card that does not is in fact an outflow of a "customer club" and should be referred to as such. Holz (1997) himself noted that a clear distinction of the terms "customer club" and "customer card" does not exist in literature and is problematic in practice. Is dialogue-oriented communication more dominant in this type of program and do the money- and payment-related advantages outweigh regular club benefits in that type of program? Not only does no clear-cut categorization spring from these variables, but the distinction is also superfluous. For the reasons stated above, it is thus believed that this discussion takes things too far.

The contributions of Holz (1997) and Butscher (2002) were, however, valuable in that they highlighted certain forms of customer clubs that are not to be mixed up with the various types of loyalty schemes that form the basis of this work. To be precise, book and music clubs, fan clubs, club companies, and warehouse clubs will not be further touched upon in this paper. As opposed to these four variations, the rebate clubs the authors referred to, possess all classical features of loyalty schemes. Likewise, B2B clubs are a form of loyalty scheme, despite being targeted at a different audience. In the course of this paper, the terms customer club, customer card, and frequency club will be considered synonyms together with other common names such as loyalty program, bonus program, frequency program, or reward program. For each of these, not the name, but a description of the program's particular configuration (e.g. the target group, cost of membership, etc.) will allow the reader to differentiate.

Finally, a few other examples of classifications will be presented here. None of these individually might be the one and only correct answer, but at least they do evade a previous point of criticism: the naming issue. For instance, Berman (2006) suggested the following typology of loyalty program types:

- Type 1: members receive additional discount at the register

- Type 2: members receive 1 free when they purchase $\mathrm{n}$ units

- Type 3: members receive rebates or points based on cumulative purchases

- Type 4: members receive targeted offers and mailings

Numbering the different kinds of loyalty schemes from Type 1 to Type 4 and sorting them by the level of sophistication from low to high, is arguably a much more elegant solution than that pursued by Holz (1997), Butscher (2002), and Liebmann et al. (2008). Hereby, Type 1 programs are nothing more than electronic coupons, while the other three types rely on psychological mechanisms that attempt to increase the customers' purchases by specifying a particular threshold that needs to be exceeded. Type 2, then, is a simple variation of that kind, 
while Type 3 programs demand a higher level of administrative effort. Finally, Type 4 solutions resemble the most refined form of reward programs. In addition to using the program as a different form of promotional tool, the company can analyze the generated data and use it to improve various aspects of the program as well as other parts of the organization.

A further example of categorization is that of Dowling \& Uncles (1997). The authors, no strangers to the field of loyalty program research, proposed a fundamentally different approach: a classification according to the timing of the reward on the one hand and the reward's support of the product or service value proposition on the other hand. By contrasting two variations of timing (immediate vs. delayed) with two variations of the type of reward (direct support of the product's value proposition vs. other indirect types of reward) on a 2 by 2 matrix, the authors ended up with four kinds of reward schemes:

- Retailer/brand manufacturer promotions: direct support of the product's value proposition coupled with an immediate reward (e.g. price promotions).

- Airline frequent-flyer clubs, coupons, and tokens: direct support of the product's value proposition coupled with a delayed reward (e.g. the GM card, allowing the card holder to accumulate a discount redeemable towards the purchase of a new General Motors vehicle).

- Competitions and lotteries: other indirect types of reward coupled with an immediate benefit (e.g. instant scratches).

- Multiproduct frequent-buyer clubs: other indirect types of reward coupled with a delayed benefit (e.g. the Australian coalition scheme Fly Buys).

Rowley (2004) took yet another path by presenting the following categorization:

- Retailer schemes: operated by or on behalf of individual retailers. These might also include shared schemes such as the Tesco Clubcard in the UK (see Chapter 3.3.2 for a distinction of program types by operating company).

- Coalition schemes: program management is independent from any of the partners.

- Financial services schemes: typically associated with credit or debit cards.

- Online schemes: seek to cultivate loyalty among online consumers.

- Frequent flyer or frequent travel schemes: reward frequent users of travelrelated services for their patronage.

- Geographically based schemes: rest upon repeated patronage of related outlets in a particular geographic area (e.g. shopping center or airport loyalty cards).

Unfortunately, Rowley's classification follows no clear pattern. Next to retailers and financial services, the author mentioned another very broad group (travel), which includes various components such as airlines (transportation) or hotels 
(accommodation), a special category for all online schemes (including retailers, service providers, etc.), one group based on the program's organizational structure (coalition schemes; while stand-alone and possibly also shared schemes are thrown into the group of retailer schemes), and finally one group that almost seems like it received its own category only because it did not fit anywhere else (the geographically based schemes).

It can be seen that many different categorizations and typologies are thinkable. None of them are necessarily incorrect (even though some provoke criticism more than others), but neither do any appear to be the ultimate answer either. In the following sub-chapters, a comprehensive overview of the range of options a company has when determining the structure of its loyalty program will be presented.

\subsubsection{B2C vs. B2B}

A fairly evident distinction of loyalty schemes is that into programs targeted at the individual end consumer and those aimed at business partners in B2B transactions. Possibly due to their less extensive spread, B2B programs have received far less attention in the literature and remain understudied. Professional users, companies purchasing goods for their own production, or resellers could all be the target of a B2B scheme (Butscher 2002, Lacey \& Morgan 2009). An example would be the Preferred Partner Program of the electronics manufacturer Toshiba. Retailers can enroll in this scheme to receive benefits such as increased rebates, demonstration units to be tested by their customers, or an option to register for special deal periods which allot additional rebate to the retailer if such is able to sell a particular amount of specified products within a given timeframe. Incentivizing a retailer with, say, a 5\% additional rebate if more than 50 of the manufacturer's laptops are sold within the next month, is not so very different from rewarding the individual customer with a $5 \%$ discount on yearly turnover upon reaching a threshold of 2,500 EUR at the same chain.

As far as B2C clubs are concerned, one can distinguish between retailer, manufacturer, and service provider schemes. Compared with B2B programs, consumer schemes certainly remain the dominating force both in research and practical application and are also the main focus of this paper.

\subsubsection{Stand-Alone vs. Shared vs. Coalition}

Any company developing a loyalty scheme faces the question of whether to finance and administrate it alone or to get partners on board. Furthermore, if the 
decision is taken in favor of partners, the initiating organization has the option of being the dominant sponsor who runs the scheme or to be one of many equals in a coalition, in which case the program is usually administrated by a specialized third party (see Chapter 4 for a detailed description of coalition schemes).

Describing what they considered the basic scheme options among which companies have to take their decision in the creation of a program, Stone et al. (2004) presented the following alternatives:

\section{- None}

- Solus: stand-alone programs (e.g. Safeway Club Card in the US)

- Shared: the main company lets customers collect points at a range of partner companies as well (e.g. Tesco Clubcard in the UK)

- Consortium: coalition schemes where an organization outside the circle of sponsors usually sets up and runs the program (e.g. Payback in Germany)

While the differentiation into stand-alone and coalition schemes is a very common one, the category of shared loyalty schemes is not so clear cut. Partnerships are generally defined by the ability to earn points with each partner. Whether they can be spent at these partners or for other companies' products or services does not play any role in this case. Stone et al. defined a coalition as a scheme where a third party sets up and runs the program. Reinartz (2006), on the contrary, suggested that all multi-firm variations may be run either by the dominant partner, any other partner, or a third party. Theoretically, Reinartz is certainly right in that coalitions need not necessarily be run by a third party as it is at least thinkable that a company in the circle of partners takes on this task (if data protection policies allow), but this is still usually the case in practice.

It is argued that the defining element is more likely to be that of the degree of dominance of the principal firm. As for shared schemes, for example, Stone et al. (2004) mentioned the Tesco Clubcard, because customers are able to collect points at other partner companies such as the UK department store Allders or the electricity giant E.ON. Indeed, becoming a partner in a strong loyalty scheme brand is also an option. It needs to be added, however, that in the case of Tesco, the percentage of points accrued via partner organizations is still comparatively small. For that reason, as well as due to the fact that certain companies allow their program members to collect points with other loyalty programs (e.g. many hotel groups give customers the option of either accruing points with their own scheme or air miles with some airline's frequent traveler program), classification might seem a bit difficult. While categorizations that are not guided by clear rules are generally problematic, this just might be the next best thing in this case. It does not matter who runs the loyalty scheme: a shared program will be given when a partnership is clearly dominated by a single firm (as is the case with the 
Tesco Clubcard), while a coalition scheme is present when the parties to the program are regarded as equal partners (as is the case with Payback in Germany, despite the fact that some of the partners in the scheme are naturally larger than others).

\subsubsection{Within Sector vs. Across Sector}

This question relates to partnerships (i.e. shared or coalition schemes) only. Any partnership might include firms from the same sector or only companies from different sectors (Reinartz 2006). Alliances encompassing various airlines within one frequent flyer scheme are famous examples of intra-sector partnerships. As far as retailing is concerned, however, most shared and coalition schemes include different non-competing sub-sectors. A typical coalition scheme might thus include a grocery, a fuel, and a sporting goods retailer, but not two competing food retailers.

\subsubsection{In-House vs. Outsourced Administration}

As far as program administration is concerned, there are generally two options for stand-alone loyalty schemes: running it in-house or outsourcing it to a specialized company. For shared schemes, the options are threefold: having it run by the dominant firm, any other partner, or a third party. Finally, companies employing a coalition scheme can decide whether the program is to be administrated by one of the partners or by a specialized company. As mentioned previously, shared programs tend be run by the dominant company, while, probably for both data protection reasons as well as the aim of creating an equal atmosphere among the partners, coalition schemes are usually run by a third party.

\subsubsection{Target Group}

Deciding on the target group of the loyalty scheme involves two basic questions: (1) should the program target all or only specific groups of current customers and (2) should it aim only at the current customers or at potential new customers as well?

Butscher (2002) accurately pointed out that any decision on the target group within the range of current customers naturally depends on the underlying goal of the loyalty scheme. If, for instance, the goal is to develop a comprehensive customer database in order to be able to reap the benefits of direct marketing, the target group will have to be very broad. If, however, the objective of the whole 
undertaking is to secure or intensify relations with the top customers, the target group needs to be adapted accordingly. Most importantly, the overall program structure and particularly the reward structure, needs to be matched with the strategic goals of the company. Eventually, it needs to be kept in mind that these goals that were mentioned merely as examples do not necessarily exclude each other. A program might, for instance, allow for points collection among the whole range of customers and at the same time offer special events to top customers only.

An interesting point in this discussion is the fact that both researchers and practitioners tend to focus on the logical target of heavy users. Why would it not make sense to put more effort into maintaining a relationship with those $20 \%$ of customers that generate $80 \%$ of the firm's revenues (as has been shown to be the case in many industries), as opposed to investing too much energy in sporadic customers who do not spend much? Pointing into that direction is research focused on coupling loyalty programs with a measure of profitability (e.g. Reinartz \& Kumar 2002, Kumar \& Shah 2004). Other authors take it for granted that "in order to maximize loyalty and profitability, a company must give its best value to its best customers" (O'Brien \& Jones 1995, p. 76) or that "the primary target group of your customer loyalty programme should be your most important customers, those who constitute the major portion of your business" (Butscher 2002, p. 6). Still, many organizations, including the best practice example Tesco (see Humby et al. 2008), have quite successfully employed the principle of treating all customers equally (despite having previously experimented with a different approach). In this respect, Wansink (2003) presented an interesting piece of research, featuring results from interviews with 41 managers of loyalty programs, as well as two surveys of 132 brand managers and 643 customers respectively. $80 \%$ of the brand managers thought that heavy users would be the most profitable user segment to target, while only $18 \%$ opted for the light users. Results from the customer survey showed that light users might even be an overlooked segment. In fact, implementing a high rewards program among heavy users was shown to be the least cost-effective in the scenario employed by the author. Instead, low and moderate reward programs targeting light customers may generate higher incremental sales and may be more profitable than initially expected. Still, authors like Wansink or Kumar \& Shah (2004) do have one thing in common: they suggest a loyalty program targeted at different user segments simultaneously, but tailored in terms of their reward values. Even though it will depend on the individual situation of the company, this seems like a sound suggestion, as long as it can be implemented in a profitable manner. In addition to that, a loyalty scheme can help to identify the valuable and the not so valuable customers in the first place!

As far as the question of whether the program should be aimed at current or new customers is concerned, Tomczak et al. (2008) made the point that customer 
relationship management demands a concentration of activities on the existing customer base. For Tomczak and his colleagues, new customers are consequently nothing but a positive side-effect. If one were to go with the strict meaning of the words, that is probably true. After all, one can only foster a relationship with existing consumers, while winning new ones is a different story. This might be true, but winning over new customers is always part of the project, be it that they are lured through positive word-of-mouth by current members or that they got wind of the benefits that await them in any other way. Not without reason is the acquisition of new customers usually part of success evaluation (e.g. at American Express, as O'Brien \& Jones 1995 explained) or part of the program development process (see e.g. Kumar \& Shah 2004). The amount of research on the effectiveness of programs to acquire new customers is still fairly small and mostly forms part of studies dealing with the effectiveness of loyalty programs overall, such as those reviewed in Chapter 2.3. To give just one example, in their study determining the effect of loyalty programs on repeat purchase behavior, Meyer-Waarden \& Benavent (2006) found they had "little effect on recruiting new customers" (p. 81). They supported this conclusion with the insight that $88 \%$ of the program members in their sample were already customers before subscribing. However, this still leaves $12 \%$ of the sample that were not customers before joining the loyalty program. This is certainly not the majority, but a number that feels fairly considerable nevertheless. As the authors also pointed out, the reward structure naturally drives the impact that loyalty schemes can have on the acquisition of new customers. While programs that are mostly used as promotional tools giving discounts on promotional items have a higher ability to attract new customers, things might look different when a large amount of points needs to be collected in order to receive a reward. Further information on customers' word-of-mouth behavior can, for instance, be found in Reinartz \& Kumar's (2002) or Ferguson \& Hlavinka's (2009) work.

\subsubsection{Open vs. Closed}

Customer loyalty schemes can be distinguished into open and closed programs. While open programs welcome any customer to the club, closed programs usually require a financial commitment in the form of an admission or membership fee, and/or particular customer-specific characteristics in order to participate. Thus, by setting up other preconditions for membership as well, creators of closed programs might actually be going one step further than just asking whether the scheme should be free or come at a cost.

As for their actual prevalence, open clubs have clearly gotten the upper hand, bringing with them large numbers of members, but also negative side-effects 
such as scattering loss through inactive members, for instance. What is important to note is that closed programs can naturally create a much tighter fit with the target group. Particularly with regard to the overall appearance and reward structure, closed schemes are much easier to tailor to customer preferences. By contrast, members of open programs will feature much more heterogeneous preferences (Hoffmann 2008). As for advantages and disadvantages of closed programs, Hoffmann extracted two notable points from Felser's (1997) and De Wulf et al.'s (2003) contributions: on the one hand, the creation of access barriers could create an impression of exclusivity and consequently fulfill a function of prestige for members, while on the other hand, high membership fees could deter otherwise valuable customers. What could be added to the negative aspects is that not just the fees, but also the simple existence of an exclusive circle from which they are excluded, could alienate customers. Furthermore, a smaller number of members does not necessarily help to make the program cost-efficient. On the upside, however, membership fees obviously help to cover the costs of closed clubs.

As is the case with many of the aspects revolving around decisions on program structure, the choice to operate either an open or a closed club is similarly guided by the strategic goal of the club. There are many variables interfering with this decision and Butscher (2002) presented a set of guidelines that may be useful to reflect upon. He summarized that open customer loyalty schemes tend to be the better choice for companies who

- possess little knowledge about their current and potential future customers

- prefer a rather general approach

- have a big, long-term budget at their disposal

- operate on unsegmented markets

- are set in consumer goods markets

- are retailing commodity products

On the contrary, closed programs tend to be better for organizations who

- primarily try to approach their top customers

- prefer a rather focused approach

- command a smaller budget

- operate in clearly segmented markets

- are not set in consumer goods markets

- have a relatively homogeneous target group

Keeping advantages and disadvantages in mind, these guidelines can certainly help, but are not free from criticism either. Would not a relatively homogeneous target group (similar to a clearly segmented market) speak for an open program as well, since standardized rewards are likely to meet rather homogeneous prefe- 
rences? Furthermore, why, without considering its capabilities, should it matter whether the company prefers a general or a focused approach? Should not the actual situation determine the appropriate approach?

\subsubsection{Member Limit}

As for this point it should be mentioned that it is rather theoretical by nature and finds practical application in extremely rare cases only. The reason why it is still discussed here is that it might in certain exceptional constellations be an interesting option to introduce a member limit to a loyalty program. In fact, it might even have the potential to introduce some element of novelty to what Capizzi \& Ferguson (2005) called a loyalty trend of the $21^{\text {st }}$ century: today's ubiquity of loyalty cards.

\subsubsection{Reward Structure}

Last, but certainly not least, the reward structure is probably the element most critical to the success of a loyalty program. Found to be the most important among the different elements of the operative structure of a loyalty scheme, Lara \& De Madariaga (2007) added that rewards were even considered more important among non-users than among loyalty scheme members. For the company, deciding on the reward structure is always a trade-off between what customers want and what the company can provide at a reasonable expense. From the customer perspective, there are five elements that determine a program's value (O’Brien \& Jones 1995):

- Cash value: the value of the reward in percent of the spending amount necessary to achieve the reward. For example, if a customer has to spend 2,000 EUR at a fuel station to earn enough points to trade in for a can of engine oil worth 20 EUR, this would equal a cash value of $1 \%$.

- Choice of redemption options: the variety of rewards a customer can choose from. For instance, members of Lufthansa's Miles \& More frequent flyer program can redeem their miles not only for airline tickets, but for a whole range of goods from wallets to designer garden furniture.

- Aspirational value: the desirability of the reward. For example, a top customer who is rewarded with a Ferrari for a weekend or a chance to meet the shoe designer Manolo Blahnik during a special off-hours shopping evening in an upscale department store might perceive this as more desirable than a simple voucher worth $3 \%$ of annual spending at the store - despite the fact that the cost of the reward might be the same in both cases. 
- Relevance: the ability of a program to be valuable to a customer in the first place. For instance, a program that lets members collect only air miles towards a long-haul flight is likely to be irrelevant to all but heavy customers of the organization, as it will probably take the majority of customers a very long time to accumulate enough air miles for the flight. A study by Sneed (2005) highlighted the importance of this factor by showing that $69 \%$ of those customers who stopped participating in a loyalty program cited the long time it took to receive a reward as the main reason for doing so.

- Convenience: the scheme's ease of use. For example, members of the loyalty program of the Austrian hypermarket chain Merkur can optionally use their bank card as a membership card, freeing up space in their wallets. Furthermore, the fact that most Austrians carry a bank card in their wallet at all times, makes this program very convenient to use.

Parker \& Worthington (2000) contributed to this discussion by noting that customers' loyalty towards a program is influenced by five things: (1) the degree of satisfaction the customer feels towards the rewards, (2) the offering of competitive loyalty schemes, (3) other customers' feelings towards the program, (4) the media, and (5) the social norms. Similarly, Stauss et al. (2005) noted in their study on customer frustration with loyalty schemes that programs should provide genuine value to the consumer and added that it should be possible to claim these benefits at any time and without additional effort.

Essentially, customers' wants need to be balanced with the cost of the rewards to the company. Deciding on the type of reward is only the first step, however. Should more important customers receive bigger rewards? Should customers receive them immediately or in the future? Should psychological mechanisms be exploited that take effect when customers need to reach a certain barrier to receive the reward? Should the company focus on financial benefits to the consumer or provide other non-financial benefits to its program members? The following sections will lead the way through the different elements that need to be considered when dealing with a program's reward structure.

\section{1) Financial vs. Tangible vs. Intangible}

Generally, rewards can be differentiated into so-called hard (i.e. tangible) and soft (i.e. intangible) rewards. Reinartz (2006) proposed that the first category consists of all financial and other tangible rewards, while the other contains rewards that are based on psychological or emotional benefits. Consequently, rebates, vouchers, free products, special promotions, and other non-financial benefits such as late check-out at the hotel, access to a special lounge at the airport, or a special check-out queue at the supermarket would all be considered hard re- 
wards. Reinartz's very narrow definition of soft rewards thus only refered to what the author called the "badge effect:" the psychological benefit of receiving special treatment or a special status (e.g. becoming a "Gold Customer" and later a "Platinum Customer" in a loyalty scheme). This, the author pointed out, usually comes in a package with actual tangible rewards, such as the access to a special lounge at the airport mentioned previously. Furthermore, Reinartz argued, soft rewards can become more important than hard rewards in cases where the buyer shows high involvement with the product or product category (e.g. members of Harley Davidson's owners group HOG enjoy the sense of being part of a community, but do not receive many hard rewards).

Reinartz's categorization is certainly an interesting one, but leads to a single dominant and heterogeneous group (i.e. that of hard rewards). To further dissolve this category into more homogeneous segments, the classification depicted in Table 2 is proposed.

\begin{tabular}{|l|l|l|}
\hline Category & Variations & Examples \\
\hline Financial & - & $\begin{array}{l}\text { Price promotions available to members, electronic coupons, } \\
\text { money-off vouchers }\end{array}$ \\
\hline Tangible & Utilitarian & $\begin{array}{l}\text { Products or vouchers for products catering to basic needs (e.g. } \\
\text { basic household, personal, or food items) }\end{array}$ \\
\cline { 2 - 3 } & Amusement/Luxury & $\begin{array}{l}\text { Airline tickets, theater tickets, jewelry, an evening at a high-end } \\
\text { restaurant }\end{array}$ \\
\cline { 2 - 4 } & Information & $\begin{array}{l}\text { Special hotline, exclusive check-out line at the supermarket, } \\
\text { preferential treatment, late hotel check-out, airport lounge access, } \\
\text { payment function of the card }\end{array}$ \\
\cline { 2 - 3 } & Social & $\begin{array}{l}\text { Early notice of upcoming promotions, customer magazine giving } \\
\text { background information on products and services }\end{array}$ \\
\cline { 2 - 3 } & Charity & $\begin{array}{l}\text { The psychological benefit of receiving special treatment (the } \\
\text { "badge effect"), sense of belonging, feeling of participation }\end{array}$ \\
\cline { 2 - 3 } & Environment & $\begin{array}{l}\text { Support of disadvantaged third parties such as the donation of } \\
\text { accumulated points to an NGO }\end{array}$ \\
\hline $\begin{array}{l}\text { Support benefiting the environment such as the donation of } \\
\text { points to green projects }\end{array}$ \\
\hline
\end{tabular}

Table 2: Classification of Reward Types

The first category depicted in Table 2 concerns all kinds of financial rewards. The customer might receive $5 \%$ off his purchase at the cashier or in the form of a voucher mailed at the end of the year (covering 5\% of the customer's total annual purchases). Other examples of financial rewards would be special promotions for program members, special electronic coupons stored on the customer loyalty card, or promotional money-off vouchers sent via direct mailings. The second category of rewards refers to all tangible benefits the customer might receive, 
such as tickets to an amusement park or a free product. The distinction into utilitarian and amusement/luxury rewards was made as this has important implications for customer acceptance (see e.g. O'Brien \& Jones's 1995 criteria of aspirational value in the opening paragraph of Chapter 3.3.8). In fact, Reinartz (2006) even considered the hedonic value of rewards as a separate criterion along which the reward structure can be described. A noteworthy contribution to this topic comes from Kivetz \& Simonson (2002). The authors investigated the impact of the level of effort loyalty program members had to invest to receive the reward on their preference for specific reward types. In a series of studies, they found that higher program requirements caused a shift in preference towards luxury rewards. In a way, customers felt like they earned the right to indulge. In addition to that, the authors added, this effect was even stronger among customers who tend to feel guilty about consuming luxury products and services. In the context of a loyalty scheme, that would mean that shoppers who need 30 instead of 15 shopping trips to obtain the reward are more likely to prefer a reward with hedonic value (for further information on this topic, see e.g. Hirschman \& Holbrook 1982, Berry 1994, Dhar \& Wertenbroch 2000, or, for research in a service setting, Daryanto et al. 2010).

Finally, loyalty programs can provide various kinds of intangible rewards to the customer. What Reinartz (2006) subsumed at least partly under the category of "hard rewards" (which arguably feels wrong when talking about an intangible reward), might involve special service or information, as well as social benefits such as those described by the author as soft rewards. As mentioned before, social benefits are often coupled with services or other types of rewards and might be considered a by-product of hard reward types. The two variations of charitable and environmental reward types are a comparatively recent trend. For example, members of Lufthansa's Miles \& More frequent flyer program can donate 20,000 miles to the SOS children's village, in return for which Lufthansa will cover the (unspecified) costs of enabling one young African to attend secondary school or of a vocational training center for a period of two months. Alternatively, miles can be donated to support projects that conserve endangered species, replant forests, or conserve habitats. It remains unknown, however, how many customers have already donated 10,000 of their hard-earned miles to mark and consequently protect one Chinese snow crane or to plant and protect five trees in South Africa.

\section{2) Firm-Related vs. Non-Firm-Related vs. Mixed}

Some discussion has been going on among researchers as to whether rewards should be linked to the products or services supplied by the firm, or whether they 
should be unrelated or, indeed, mixed. Frequent flyer programs, for instance, allow customers to collect miles and trade them in for an airline ticket or a business-class upgrade. Thereby, the airline directly supports the value proposition of its products. Several airlines have decided to offer a greater choice of redemption options to their customers, allowing for miles to be exchanged for other products like alcohol, perfume, or clothing. By doing so, Lufthansa falls into the mixed rewards category. Another example would be that of a supermarket that gives away points to be redeemed for an airline ticket. For obvious reasons, this type of reward cannot be considered to be supporting the value proposition of the company's products.

Dowling \& Uncles (1997) referred to these two options as offering either direct or indirect rewards (which he also used as classification criteria: see the beginning of Chapter 3.3) and suggested that rewards which directly support the value proposition of the product or service were preferable to indirect rewards. They arrived at this judgment after considering the findings of a previous study by Rothschild \& Gaidis (1981). Relating to something similar to what Mauri (2003) described as card loyalty, Rothschild \& Gaidis (1981) referred to what might be dubbed "deal loyalty." Leaning on behavioral learning theory, the authors pointed out that deals can lead to brand switching as "the deal is more likely to be reinforcing than the product" (p. 74). This can be particularly problematic for lowinvolvement products, where, as opposed to the product itself, the reward might become the primary incentive to purchase the product. The issue with this situation is, Dowling \& Uncles (1997) summarized, that once the incentive is taken away or copied by a competitor, the primary reason to buy the product disappears. That, then, is also the reason why many companies find themselves in a vicious cycle of ongoing promotions. By contrast, high-involvement products are often accompanied by a small incentive, but bought primarily because of the product. Consequently, the authors argued, direct (i.e. firm-related) rewards are preferable to indirect (i.e. non-firm-related) ones.

Yi \& Jeon (2003) followed this argument and further underlined that the concept of Dowling \& Uncles (1997) really is very similar to that employed by Rothschild \& Gaidis (1981). In fact, Yi \& Jeon (2003) argued that the direct and indirect rewards that Dowling \& Uncles (1997) mentioned were conceptually consistent with Rothschild \& Gaidis' (1981) "primary and secondary enforcers." According to Rothschild \& Gaidis' definition, primary enforcers such as the product, provide intrinsic utility to the customer, while secondary enforcers like coupons or loyalty program stamps need to be converted first. In other words, while the authors would advise a company to focus on promotions for products with $10 \%$ more content for a limited period of time (as opposed to handing out vouchers), Dowling \& Uncles (1997) would recommend letting customers exchange their points 
from ten purchases of a product against yet another product. It is probably unfair to claim that Dowling \& Uncles simply applied this idea from the field of promotions to that of loyalty schemes and gave it a different name. The difference lies in the fact that the determining element in the case of Rothschild \& Gaidis (1981) was that of "redemption" - which was only true for secondary enforcers. In Dowling \& Uncles' (1997) view on loyalty schemes, redemption always takes place, with the only question being for what type of reward (a direct firm/product-/service-related reward or an indirect non-firm-/product-/service-related one).

Either way, the praise of firm-related rewards has found other followers as well. Wansink \& Seed (2001) or Reinartz (2006), for instance, also concurred with Dowling \& Uncles (1997). Additionally, based on a contribution by Lobb (1997), Wansink \& Seed (2001) reminded their readers of the possible extension of the view from the product to the brand. Their example is that of a beverage company rewarding consumers with sports gear. While this might at first sight oppose Dowling \& Uncles' (1997) proposition, it might not entirely. It would, namely, not be true if this type of reward was chosen as part of a brand-building effort trying to establish a sportive brand image. This issue was also discussed by Roehm et al. (2002), who found that incentives that overlap with brand associations can help post-incentive loyalty. Thus, even rewards supporting the brand can be considered beneficial to the company.

Still, the reality is everything but consistent with these authors' views. Most, particularly point-based programs indeed offer mixed rewards in terms of their support of the value proposition of the product or service. Even the often-cited best practice example Tesco has concluded that the benefits of satisfying customers with a larger choice of redemption options outweigh the disadvantages of not offering direct rewards (Humby et al. 2008). Obviously, more simple forms of loyalty schemes such as the buy-n-get-1-free type or those programs that are functionally reduced to a simple form of price promotion (e.g. handing out storewide vouchers worth a certain percentage of annual purchases by the customer) rely on the proposed rule. Nevertheless, thorough empirical proof of whether this is applicable to all forms of loyalty schemes and whether it is really preferable to offering more choice to consumers is still outstanding. There are, after all, also authors who see the future in offering a large amount of reward options, made possible through partnerships and alliances (e.g. Kumar \& Shah 2004).

\section{3) Intrinsic vs. Extrinsic}

An issue that is fairly similar to that described in the previous section on the rewards' relation to the firm, is that of offering either rewards intrinsic or extrinsic 
for the consumer. Hereby, the critical question is whether the rewards create a good fit with the customer's natural purchase motivation (Meyer-Waarden \& Benavent 2008). An example that Meyer-Waarden \& Benavent gave was that of financial rewards: these would be considered intrinsic for a person who bases purchase decisions on price and extrinsic for a consumer whose main motivation to shop is pleasure. Consequently, the authors argued that extrinsic rewards would only buy the customer's loyalty for one transaction - or even worse, reduce the person's intrinsic motivation to make the purchase. Instead, intrinsic rewards would be considered valuable by the consumer and reinforce natural shopping behavior.

In a way, this question goes one step further than the previous section in taking the customer's perspective into account. For example, handing out vouchers to be exchanged at the supermarket where the underlying revenue was generated would be considered firm-related rewards, while offering free flights to customers of the supermarket would count as non-firm-related. However, both types of rewards could be intrinsic or extrinsic to a specific customer in that they reflect or do not reflect his actual buying motivation.

One problem with Meyer-Waarden \& Benavent's assertion is that offering only intrinsic rewards will impede any endeavor to cultivate cross-selling. This is also the reason why Tesco has decided to mail out customized vouchers partly valid for products that are part of the customer's regular buying behavior and partly for other products (e.g. in neighboring categories) that have never appeared on that customer's record of previous transactions (Humby et al. 2008). Following Meyer-Waarden \& Benavent's (2008) line of thought, the latter type of vouchers would be classified as extrinsic rewards. At the same time it is undisputed that these rewards are effective in establishing long-term purchase motivation in respect of the new product in at least some of the recipients. Thus, this just might be another one of those questions where neither extreme is desirable. Instead, a healthy mix of intrinsic and extrinsic rewards might best serve the purpose of providing both immediate value to the customer and the possibility to engage in successful cross-selling.

\section{4) Rate of Rewards}

A company developing a loyalty scheme must, as briefly touched upon in the section on reward types (financial, tangible, or intangible), also decide on the actual value of the reward. Thereby, the rate of rewards refers to its monetary value as a percentage of the sales volume necessary to receive it. In other words, the rate of rewards describes how much a customer gets in return for his purchases (Reinartz 2006). Naturally, the rewards are a big cost factor for the company and 
offering a rate of reward of $2 \%$ instead of $1 \%$ can have a big impact, particularly in low-margin industries. Certainly, the company will want to make sure that an increase in loyalty can be attained with these measures to a larger degree than the associated costs. One advantage for the company is that the price to end consumers is generally perceived as the value of the reward by the customer, while the direct reward cost of handing out a 10 EUR voucher redeemable at a supermarket's own chain resembles only the wholesale price of the items purchased with it (not taking other overhead costs into account). In this regard, an interesting point needs to be kept in mind: the cost component that lies behind these loyalty programs differs quite significantly between industries. For example, airlines employing a frequent flyer program can simply fill their otherwise empty seats with passengers redeeming their miles. In an article of the Financial Times (2002), an associate principal at McKinsey revealed that in 2000, sales of frequent flyer miles by the five biggest US airlines to retailers, hotel chains, credit card companies, and other organizations for use in their respective loyalty schemes totaled around 2 billion USD and accounted for an astonishing $40 \%$ of these airlines' combined operating profits. In a more recent example published in the Washington Post, Kralev (2009) reported that United Airlines sold miles worth around 1 billion USD to the US consumer and commercial bank Chase, its credit card partner, in 2008. In contrast to airlines, however, rebates on merchandise or other rewards that retailers offer their program members directly affect their profits.

Still, the basic question that companies face is that of deciding on the optimal rate of rewards. What rate do customers still perceive as valuable enough to influence their behavior, while it is at the same time not too costly for the company? For instance, would a change in the rate of rewards from $1 \%$ to $2 \%$ make sense for a supermarket? The answer is, yet again, that no universal answer can be given.

In a study investigating the rate of rewards of the later abandoned ABC Card of the former British supermarket chain Safeway (which has meanwhile been acquired and renamed Morrisons), Parker \& Worthington (2000) detected that the program did not operate in what they defined as a fair and equitable manner. This conclusion was primarily based on the finding that points reflected less value, the more a customer had to redeem for a product. In other words, the bestvalue products were available after a few visits. Furthermore, the authors showed that the value of a point was more than twice as much for the best offers than it was for the worst offers. This meant that the rate of rewards fluctuated between around $1 \%$ and $2 \%$. By comparison, at the same time, the value of a point offered by the Advantage Card of the British chemist Boots was significantly higher at over $4 \%$. While pointing out a structural problem that might be considered unfair by certain customers, Parker $\&$ Worthington also failed to provide an answer as to what the appropriate rate of reward would have been. 
What may be noticed, however, is that different industries can afford to provide different reward rates. The main reasons behind this are probably the particular margin structure in the different industries, as well as the differing costs associated with the rewards. Thus, while Safeway offered a reward rate of around $1-2 \%$ in value to its customers, Boots could afford to give away over $4 \%$. At the same time, a sandwich shop that gives away a free sandwich after the customer has already purchased 10 of them, is effectively handing out a discount of roughly $9.1 \%$.

To test customer reactions towards different reward rates, Wansink \& Seed (2001) conducted a survey study comparing programs with high, moderate, and low reward characteristics. The high-reward program featured a monthly booklet with information as well as a voucher worth 1 USD to be used for the purchase of any product in the product line. Additionally, sending in 10 proofs of purchase of a product in the product line (e.g. a coffee mug) would entitle the customer to a free product of that kind. By contrast, the moderate-reward program gave away quarterly booklets with vouchers worth 0.5 USD and the opportunity to exchange 20 proofs of purchase for a free product, while in the low-reward program only a quarterly one-page newsletter would be sent out, containing a 0.25 USD coupon and the option to mail in 20 proofs of purchase for a free product, which would, however, cost the customer an additional 5 USD in shipping and handling fees. Keeping in mind that the survey participants consisted of only 153 people (who were members of the not further specified "Brand Revitalization Consumer Panel"), the authors discovered that loyalty schemes offering moderate reward value had the most cost-effective impact on increasing purchases. One can learn from this, then, is that very generous loyalty programs may have trouble remaining profitable, while those providing too little reward value to the customer may be ineffective in fostering an optimal amount of behavior change among their program members. Again, this rule certainly does not have universal application, as companies operating in different settings and different industries are likely to arrive at unequal estimations of variables such as reward cost or sales uplift.

At the most basic level, Wansink \& Seed reminded their reader, the program will be profitable if the following function turns out positive:

$$
\text { Gain } / \text { Loss }=\left(\mathrm{U}_{\mathrm{n}} \mathrm{P}\right)-\left(\mathrm{U}_{\mathrm{o}} \mathrm{P}\right)-\mathrm{R}-\mathrm{A}
$$

Hereby, $U_{n}$ refers to the new number of units sold (i.e. following the implementation of the program) and $U_{o}$ to the old number of units sold (i.e. prior to the implementation of the program). Furthermore, $\mathrm{P}$ describes the price, $\mathrm{R}$ the cost of the rewards, and A the administrative expenses (please note a change to Wan- 
sink \& Seed's formula: the authors did not put the actual cost of the rewards into their calculation, but the "dollar amount of coupons or other incentives used" (p. 216); in most cases, however, the dollar amount would not be an accurate reflection of the underlying costs).

\section{5) Tiered vs. Non-Tiered}

Contrary to what Parker \& Worthington (2000) found that Safeway had practiced, companies who believe in rewarding their heaviest spending customers will provide them with more valuable rewards than their light spending customers. Briefly discussed in relation to the decision on the target group of the program (see Chapter 3.3.5), tiering was favored by a large amount of authors (e.g. O’Brien \& Jones 1995, Butscher 2002, Kumar \& Shah 2004), but not always employed in real life. Tesco, for instance, decided that treating all customers equally was the way to go, despite having experimented with a tiered reward structure (Humby et al. 2008). There are, however, also numerous examples of companies that successfully operate a tiered reward structure. Lufthansa's Miles $\&$ More program, for instance, consists of four tiers: basic members, frequent travelers, senators, and HON circle members - with tier-membership depending upon accumulating a specific number of miles in a certain period of time. Hereby, benefits range from a bonus of $25 \%$ on future miles collection (until the status is lost again after a while) to additional baggage weight allowances and access to lounges and special check-in counters. Naturally, benefits increase level by level. While frequent travelers can enter only business class lounges, HON circle members are allowed into first class lounges when traveling with a Lufthansa ticket of any fare class. Another goody granted to the heavy user group of HON circle members is that they are picked up with a luxury limousine at the airplane if their flight is not assigned a gate dock. Another famous example stems from the retail setting. At the time of writing, the InCircle program of the US upscale department store Neiman Marcus featured six tiers. If accumulated points are redeemed for gift cards, the rate of return equals $2 \%$ for the first four tiers and $5 \%$ for the last two tiers. To move up from the first to the second tier requires an annual turnover of at least 2,500 USD, while the shift from the fifth to the final tier (the so-called "chairman's circle") is dependent upon purchases valuing over 600,000 USD per year. In addition to the higher rate of return mentioned previously, other perks include off-peak shopping hours or special shopping events from tier 5 upwards, or unique experiences like a visit to the offices of Vogue including a glimpse into the magazine's famed fashion closet exclusively for members of the chairman's circle. "How will the customer get to the Vogue 
offices?" one might ask. Possibly by driving the new Lexus the InCircle member had previously traded in 1.5 million points for (Sherman 2007).

In what they considered the way of the $21^{\text {st }}$ century, Kumar \& Shah (2004) developed a noteworthy conceptual framework for building and sustaining customer loyalty. Incorporating different behavioral and attitudinal analyses via surveys, transaction data, profile data, and a measure for customer lifetime value, the authors proposed a two-tiered reward structure to operationalize the framework. Specifically, a simple and explicit baseline should be provided to all customers, ensuring general awareness and the ability to record a comprehensive set of transaction data. In addition to that, the authors suggested selectively awarding highly differentiated rewards at the individual customer level.

Apart from making heavy customers happy with special perks, tiering has a second major effect. Described in Chapter 2.3.1, Taylor \& Neslin (2005) found proof for the existence of what they termed "points pressure." Further examined by Kivetz et al. (2006), this effect describes a change in the behavior of loyalty program members due to the existence of a certain barrier that needs to be overcome to reach the reward. For instance, this effect caused customers to increase their purchase frequency the closer they came to the barrier. The authors did not explicitly investigate this impact in relation to a whole range of loyalty program tiers, but a similar effect is likely to exist.

In practice, companies employ both tiered and non-tiered loyalty schemes quite successfully (see e.g. Drèze \& Nunes 2009 for further details on the effect of program structure on the customers' perception of status). Nevertheless, all evidence considered, it seems that tiering might very well provide more advantages (e.g. being able to record transaction data on a broad basis while still giving special treatment to the most valuable customers) than disadvantages (e.g. higher reward and administrative costs). Which one to pursue, though, will again have to be determined based on the specific situation and the strategic goals of the company.

\section{6) Immediate vs. Delayed}

A further decision to be made in the context of reward structure is that on the timing of rewards. On the one hand, consumers naturally prefer immediate rewards or at least short accumulation periods. On the other hand, the company tends to prefer long accumulation periods, as they work as a switching barrier (Reinartz 2006). Customers who are building up points and accumulating turnover to reach a certain barrier thus, in addition to other possible changes in behavior (e.g. increased purchase frequencies), also find themselves in a form of lock-in (Kim et al. 2001). The reward that awaits them encourages customers to do busi- 
ness with the firm. Unfortunately for the company, Dowling \& Uncles (1997) highlighted, research had proposed that delayed rewards were less powerful. The authors added that companies often try to mitigate this problem by sending out regular mailings that remind the member of the aspirational value of the rewards. Taking a strong customer perspective, Dowling \& Uncles eventually suggested that immediate rewards were preferable to delayed ones.

Certainly, humans often place more value on short-term than on long-term desires (Soman 1998). The reasons why the future is often discounted in such a disproportionate manner are not fully understood (Ebert \& Prelec 2003). Ebert \& Prelec illustrated that in the first half of the $19^{\text {th }}$ century, Rae $(1905$, originally published in 1834) had already suggested that people perceive the distant future as pallid and remote as opposed to a more vivid and predictable near future. More recently, to name just one example, Becker \& Mulligan (1998) went a step further and analyzed how wealth, mortality, addictions, uncertainty, and other variables affected how consumers discount on future utilities. So while it is proven that this effect exists, is it worth foregoing the benefits of a delayed reward structure?

Interestingly, conducting research in a service setting, Keh \& Lee (2006) found a moderating effect of satisfaction on the timing of rewards. In fact, delayed rewards were discovered to work better than immediate ones if the service experience was satisfactory. Studying promotion options in general, Zhang et al. (2000) noticed that the sales impact and the sales on discount were always higher for immediate (or what they called front-loaded) promotional initiatives. At the same time, they showed in their two published empirical studies that rear-loaded (i.e. delayed) promotions may be the more profitable option under certain circumstances. The authors demonstrated that in markets characterized by high variety seeking behavior, delayed measures will be preferable, while the opposite will be true only for markets with high inertia.

To sum up, it is not fully understood how customers react differently to delayed as opposed to immediate rewards. Individual studies have identified particular situations in which one approach is preferable over the other, but no piece of research was able to give a well-grounded more general recommendation. What is known, however, are the advantages and disadvantages of each approach. Using immediate rewards might be preferred by consumers and result in higher redemption rates, but will not make use of valuable psychological effects resulting from points pressure or lock-in. Furthermore, one could theorize that customers have gotten increasingly used to being rewarded with delayed benefits, which in turn results in higher acceptance and appreciation of this reward type. 


\section{7) Proactive vs. Reactive}

This differentiation of loyalty rewards is a rather new one, rooted in the work of Kumar \& Shah (2004). The authors criticized the common practice of rewarding customers based on their purchase history (reactive) and instead suggested that rewards should at least to some extent be distributed based on the customers' future value (proactive). As an illustration, one of the authors talked about a personal experience with the frequent traveler program of an airline, which he had been patronizing for 17 years. In unrelated communication, both the author and his spouse received a letter offering a chance to upgrade to the next status tier, despite missing the requirements by a few thousand miles each. From this the authors concluded that the airline must have been selectively choosing valuable members from the database and furthermore, that the airline seemed to be "systematically targeting customers based on future revenue potential from the customer and not tenure or other considerations" (p. 324). While it generally seems to be an interesting notion to hand out rewards in a more proactive manner, this example suffers from a few deficiencies. Given that the author had been a member of that airline for 17 years, it appears a bit audacious to claim that tenure had nothing to do with his selection. Moreover, it is probably fair to say that any member who has fallen only a few thousand miles short of the highest status tier, is a valuable customer who deserves this upgrade, even if evaluated based upon his past purchase behavior alone. Maybe a better example would be that of a frequent business traveler who shifts jobs from a company in Germany to a new employer in the United States. Given that he will be in a similar position that requires a lot of national air travel, he will have to pick a new carrier with a new frequent traveler program. If, then, right when this person starts traveling on its planes for the first time, the US airline awarded him with an elite status upgrade (as the company knows his future value), this could really be considered a proactive distribution of rewards. In this rather extreme example, the only way for the airline to know about the customer's actual value would probably be to get access to information situated outside the company. At best, the company might choose to rely on the customer's self-assessment, but overall, this does not sound like a very reliable option. All that is left then, is to base decisions in that regard on the (albeit limited) transaction history of the customer.

Another example Kumar \& Shah use is that of the Wyndham hotel chain in the US which might surprise a high-value member of their loyalty scheme with a free round of golf upon arrival (given that the person noted golf as a leisure activity of interest). The question really is whether that customer was classified as high-value due to a future-looking exercise, because only then could the round of golf be considered proactive. In this respect, the difficulty of incorporating fu- 
ture-oriented variables is the fundamental issue. Kumar \& Shah approached this problem by applying an estimation of customer lifetime value (CLV), currently probably the most promising solution (see e.g. Gupta et al. 2006 for a thorough information basis on CLV). Customer lifetime value models, however, have clear limitations, making it hard to implement a truly proactive reward system. The need to estimate different variables such as purchase frequency or profit margin is just one (though the bigger) part of the challenge. In addition to that, the different available models themselves might lead to values that can vary quite significantly. Diller et al. (2008) called attention to this problem in a comparison of three CLV models (i.e. those by Dwyer 1997, Reinartz \& Kumar 2003, and Venkatesan \& Kumar 2004), whereby the authors calculated the value for each model using a comprehensive data set from a German retailer of sporting goods. Surprisingly, the results for the average CLV per customer turned out at 128, 184, and 244 EUR respectively. Accordingly, another crucial step in determining a correct (or more suitable) CLV for use in the context of loyalty schemes is the choice of an appropriate CLV model.

In the end, due to its difficult practical application, this undoubtedly intriguing approach by Kumar \& Shah (2004) is possibly something that is sufficiently taken into account when simply kept in mind. It would certainly be a preferable approach, but it is simply not easy to implement in practice. Furthermore, Reinartz \& Kumar (2002) have highlighted that just because a customer was profitable in the past, does not mean that he will be profitable in the future. Thus, if there is evidence that a customer will probably be worth more in the future than he has been in the past, or likewise, that a customer will not be as profitable in the future as compared to the past, the company can and should attempt to find a way to adequately reflect this in its loyalty program (and indeed, its marketing spend).

\subsection{The Value of Data}

Next to all other advantages that are commonly named in relation to customer loyalty schemes, the value of data is definitely among the most significant ones today. Not without reason did Schoenbachler et al. (1997) call it a major trend in consumer marketing or did Ferguson \& Hlavinka (2006) label the power of data one of the three loyalty trends for 2006 and beyond. Loyalty programs allow for highly detailed information on individual customers to be collected and thereby benefit various aspects of the company. Analyzing the available information generates the ability to take strategic, knowledge-driven decisions. Companies eventually have the opportunity to achieve what only mom-and-pop stores were 
able to do: to know their customers. In this chapter, the value of this source of knowledge will be elaborated on and several examples for its use in the business arena provided. An introduction to data mining will then be given (supplemented by an exemplary description of the data mining process in Chapter 3.4.1), and eventually the section closed with an excursion on retailing and shopping basket analysis (Chapter 3.4.2).

So what are the potential benefits of data analysis? The following points should serve as examples to demonstrate the power and business value of data (Clayton-Smith 1996, Hippner et al. 2001, Berman 2006, Kumar \& Reinartz 2006, Humby et al. 2008):

- The ability to minimize wasteful (marketing) spending.

- The ability to mass customize marketing communication to maximize the impact of the according marketing activity.

- The ability to identify customer segments with similar characteristics.

- The ability to engage in profitable customer acquisition by modeling expected customer potential.

- The ability to increase revenues through cross- and up-selling, based on a model of the customer's purchase likelihood of specific product sets or services.

- The ability to optimize store layout (e.g. product placement) following a better understanding of purchase behavior.

- The ability to promote follow-up products (e.g. razor blades for a particular razor).

- The ability to reduce churn with predictive models that identify customers who are likely to stop patronizing the company in the future.

- The ability to identify customers who were recently lost and to reach them with an action plan aimed at bringing them back.

- The ability to identify the profitability of the company's customers.

- The ability to identify and track trends.

- The ability to make qualified changes to the range of goods or services on offer.

- The ability to measure and evaluate the effect of marketing campaigns in a better and more efficient manner.

- The ability to improve the success of a necessary product recall by directly addressing affected customers.

- The ability to cheaply acquire new customers for new business areas developed by the company.

- The ability to support business decisions of various kinds (e.g. development of a new product line). 
Previously, companies could only rely on market research to facilitate at least some of the things mentioned above. However, market research is also costly, particularly when compared to the benefit yielded from the small sample sizes and imprecise results. Furthermore, market research can only answer particular questions and it falls short of offering the same potential benefits that the analysis of loyalty program data could provide. "...these data are exact: they are not based on a small-scale study, a focus group or instinct - they're actually what is happening. [...] In itself the data can become a high-value asset, as Tesco has proved," Humby et al. (2008, p. 12) summarized getting to the core of the matter. "The effective use of loyalty card data is arguably the most significant benefit of scheme implementation," Byrom (2001, p. 334) concluded - an opinion that many academics and practitioners share.

\subsubsection{Data Mining}

Unlike the manager of the mom-and-pop store, the CEO of a major retailer will not be able to store the knowledge about the company's customers in his head and draw any useful conclusions from it. The company needs to data mine the information stored in its databases. Customer cards with a magnetic stripe, bar code, chip, and the like, allow the company to capture the individual purchase transactions upon their use, usually during payment of the products or services. Consequently, statistical and other data analysis methods, often coupled with sophisticated reporting platforms (Kumar \& Reinartz 2006), allow the company to access this information and use the newly-won insights when taking business decisions. In essence, then, data mining describes the extraction of meaningful and actionable knowledge from a large amount of data through the application of traditional statistics, coupled with modern algorithms (Ravi et al. 2006, Reutterer et al. 2007).

Managing and analyzing the mountain of data is not easy. At the beginning of the 1990s, Blattberg et al. (1994) had pointed out that many companies will not be suffering from a lack of data anymore, but from its abundance instead. One only needs to imagine a major retailer, where $75 \%$ of customers regularly use their loyalty card when they make a purchase. That means that if the data were to be recorded, every single transaction of a good part of the customers' turnover would have to be saved down to the level of the individual article. Naturally, that would result in the accumulation of an enormous amount of raw data, minute by minute. A famous example of a company that failed to face this challenge is that of the former British grocery chain Safeway. When the company abandoned its ABC card in May 2000, executives noted that making sense of all the data was like drinking from a fire hose (Humby et al. 2008). Similarly, Humby et al. 
noted, the British supermarket chain Waitrose commented on the problem of the exuberant amount of data when it gave up its loyalty program attempt: "trying to analyse all the data is madness" (p. 6), the company was quoted. It certainly is a challenging task, but there are also notable examples of companies (such as Tesco, for instance) that were up to it.

So what does the data-mining process look like? A general overview is provided by Kumar \& Reinartz (2006) in Figure 9.

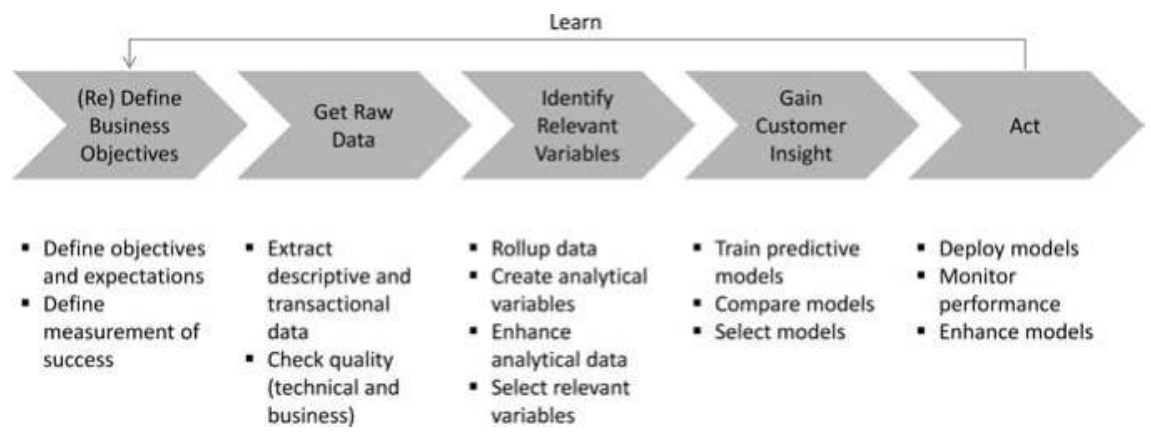

Figure 9: The Data-Mining Process

Source: Kumar \& Reinartz (2006)

\section{1) (Re) Define Business Objectives}

Let us imagine the simple example where a grocery retailer wants to increase turnover through targeted promotions. Different approaches exist to resolve this issue (see e.g. Reutterer et al. 2006 for a possible solution), but for now the process described by Kumar \& Reinartz (2006) will serve the purpose of illustrating a general path. As the retailer in this example has closed a deal with a manufacturer of products in the near-water category (e.g. mineral water flavored with an exotic fruit), the question is who to target with a coupon for this product. A straight-forward option might be to target those customers who purchase either still or sparkling water on a regular basis. Moreover, as the advertised product from the near-water category is an expensive, high-quality branded product, the target set could be further narrowed down to customers who regularly purchase up-market branded water. In addition to that, if a high turnout is the aim despite lower absolute numbers, one could even exclude all those water-buyers that have never had (exotic) fruit juices in their shopping basket.

As for the project management, in a more formalized setting, another task would include the setup of a project plan, including the determination of delivery dates for the final model and dates for the start and end of the supported cam- 
paign. Kumar \& Reinartz emphasized that it is important to carefully define the chosen experimental setup for the campaign. That might include forming two groups to enable success tracking: one control group with randomly selected (i.e. average) customers and another group with the customers selected by the model. Eventually, expected costs need to be compared with expected revenue gains and criteria for evaluating the success of the campaign defined. If high purchase rates are the goal, the measure of success could be "percentage of customers who redeemed voucher," while it could be "absolute number of flavored mineral water bottles sold during the campaign" if the increase in turnover is the most important aim. Additionally, it might be interesting to compare the success of the campaign based on a predictive model with that of past campaigns which had relied on traditional target measures (taking the different market settings, product offerings, etc. into account).

\section{2) Get Raw Data}

After objectives and expectations have been set and a measure of success agreed upon, the raw data needs to be gathered. Kumar \& Reinartz differentiated this phase into three sub-steps: (1) looking for data sources, (2) loading the data, and (3) checking data quality. In the mineral water example, the food retailer will own the corresponding data if a loyalty program that saves purchase transactions is employed. At first, it might be a good idea to start with the extraction of a small sample to make sure that the data fulfills the requirements. Then, the whole set of data necessary to answer open questions will be retrieved in a previously designed format (e.g. its native format or in XML/text format) from the company's databases and consolidated into an analytical database (often referred to as analytical data mart). Finally, data quality needs to be checked to ensure that business decisions remain unaffected by bad data quality. This check might concern problems such as duplicate records, missing values, conflicting entries (e.g. if the data is put together from various databases running in parallel), outdated information (e.g. addresses) or wrong information (e.g. incorrect information such as a customer's birth year entered as 2952 instead of 1952).

\section{3) Identify Relevant Variables}

Consequently, relevant predictive variables need to be identified. In the first phase, this will include a procedure which Kumar \& Reinartz called flattening the data. The basic idea is that the sourced data is transformed from its relational format into a customer-oriented one. In a flattened view, all data related to an individual will be contained in one observation (e.g. one row in the data table). From this data, descriptive statistics such as averages, medians, sums, etc. can be 
calculated. In our example one could, for instance, calculate the average monthly revenue generated in the mineral water category by each customer.

Following the flattening of the data, analytical variables might have to be created. This is the case when the variables generated in the previous data flattening step do not suffice. Possible examples would include interaction terms (e.g. variables resulting from the combination of values such as age and income), transformed variables (e.g. dates of each customer's transaction transformed into the number of days lying between them), or categorized variables (e.g. five defined income brackets from low to high). Finally, predictive variables need to be selected. As it is likely that the data set is now filled with a whole range of variables with different predictive capabilities, variables need to be sieved. For instance, salary might be a more important factor affecting the likelihood to purchase highpriced near-water brands than gender. To determine what variables show little correlation with the target value, Kumar \& Reinartz suggested carrying out tests such as linear correlation analyses, pair-wise chi-square tests, or pair-wise simple linear regressions, and proposed supporting the variable exclusion process with histograms, scatter plots, box plots, and frequency tables. What can definitely be excluded are variables that take on only one value, such as name, customer ID, or home address. In addition to that, variables where the level of missing values exceeds a certain threshold might be excluded. In either case, however, it is important to keep in mind that variables deemed unnecessary for the analysis should not be erased from the table, but instead marked as unnecessary. Name, customer ID, and address, for example, are not going to be needed for the analytic process, but will certainly be required to carry out the campaign later on.

\section{4) Gain Customer Insight}

Following this step, it is time to actually gain the customer insight. In case of the mineral water example, it would be useful to build the predictive model on a predefined test set which contains customers that have already bought the flavored mineral water. In the course of model construction, one would then try to estimate the purchase likelihood for all the selected customers (who are not yet buying the new product) in the analytical model. To find the best way of doing so, one might try out different approaches in order to arrive at the model with the highest predictive power. For instance, one could apply different statistical tests such as linear or logistic regression, neural networks, factor analysis, or clustering. After doing so, the alternative models are compared by looking at the misclassification rates resulting from their application on the test set and eventually, the best one will be chosen. The final decision down to which level of purchase likelihood customers will be targeted by the flavored mineral water campaign, however, is another business decision to be made, Kumar \& Reinartz pointed out. 
The ultimate step in the data mining process is an obvious one: to act on its results. The grocery retailer would proceed with his direct marketing campaign, mailing out vouchers for a specific brand of flavored mineral water to the selected customers. In addition to that, the company would monitor its campaign and learn from its evaluation. Furthermore, the outcome of the data mining process needs to be fed back into the company databases, with all results properly archived. As Kumar \& Reinartz highlighted, possible information that requires documentation for future use or reference could include the following:

- Raw data used

- Transformations for each variable

- Formulas for creating derived variables

- Train, test, and score data sets

- Target variable calculation

- Models and their parameterizations

- Score threshold levels

- Final customer target selections

Needless to say, Kumar \& Reinartz are not the only authors to write about data mining, but their work was chosen as one good example illustrating a general data mining process. In this regard, Reutterer et al. (2007) provided a helpful, compact literature overview, despite their actual focus on basket analysis. Fayyad et al.'s (1996) or Berry \& Linoff's (2004; originally published in 1997) contributions, for instance, are two established pieces of literature that should not go unmentioned. Alternatively, authors such as Tan et al. (2006), Chiu \& Tavella (2008), Hastie et al. (2008), or Olson \& Delen (2008) offered more recent publications.

Still, what needs to be added in relation to the data mining process described by Kumar \& Reinartz (2006) is that it is often automated. Discussing the future of decision support systems in the marketing environment, Bucklin et al. (1998) made a staunch pledge for automation on the basis of increasing both efficiency and effectiveness. The two variables determining the possible degree of automation are the novelty of the product and the stability of the market, whereby existing products and stable markets would consequently allow for full automation. One only needs to picture all the information the grocery retailer from our example will have access to following interpretation of the loyalty program data. The decision about who to target in a single direct marketing campaign is certainly only one among many decisions the company needs to take, and most importantly, only one of numerous interesting possible analyses that also happen on a frequent basis. Indeed, setting up a formal project for every single analysis really does not 
seem like a very efficient approach. For that reason, it will definitely make sense to automate a good part of the analyses.

\subsubsection{A Look at Retailing and Market Basket Analysis}

Having established the use of data in general, the chapter on the value of data will now be concluded with a closer look at retailing, as this industry is the most prominent user of loyalty programs. Interestingly, findings show that retailing is also the industry which can draw the biggest benefit from its loyalty program data due to the large amount of information that is potentially available to these companies (Wood 2003). Wood reported findings from a telephone and email survey among marketing professionals of UK's top 1,000 companies, concluding that retailers were able to gain the biggest commercial value from their customer and prospect databases. Focused on local marketing initiatives, Byrom (2001) and Byrom et al. (2001) similarly praised the value of loyalty program data.

Among the different possible analyses that a retailer might undertake with the data of its loyalty program, a dominant part of that can be subsumed under the term basket analysis. While the company might also possess other information such as demographic or psychographic data perhaps, a good part of the value of the loyalty program lies in its ability to provide the company with transaction data for every single shopping incident of its members (i.e. information about their shopping basket). For that reason, a brief introduction to the research field of basket analysis will be given.

The basic idea is that the selection of products from different categories is based on related decisions. Understanding these can naturally be of great support to any marketing decision. Russell et al. (1999), for instance, highlighted the importance of including the influence from other products on the consumer's choice decision in the then possibly oversimplified consumer choice models. As far as basket analysis models are concerned, a whole range has been developed over time, trying to grasp the relationships among products and product categories. Referencing an early contribution by Agrawal et al. (1993) from the association rules category (see Table 4), Chen et al. (2005) exemplarily summarized a possible process as follows: between two individual product categories $\mathrm{X}$ and $\mathrm{Y}$, an association rule such as $\mathrm{X} \rightarrow \mathrm{Y}$ would indicate a pattern where $\mathrm{Y}$ is bought by the customer when $\mathrm{X}$ is purchased. The authors described "support" and "confidence" as the two selection measures for the association rule. In this context, support signifies how often both $\mathrm{X}$ and $\mathrm{Y}$ are recorded in the database, while confidence refers to the number of consumer shopping baskets comprising both $\mathrm{X}$ and $\mathrm{Y}$, as compared to those with only product category $\mathrm{X}$. In other words, confidence works as a measure of accuracy for the rule. 
As mentioned before, several different models have been developed in order to better understand these patterns. Notable introductions to and overviews of these models include those by Russell et al. (1999), Seetharaman et al. (2005), and, in German-speaking literature, Boztu \& Silberhorn (2006). As usual, the applied categorization method varies among these papers. Russell et al. (1999) can be considered as a sort of starting base. The authors began by defining "category" in the first place and went on to explore different types of choice dependence, which they used to develop a research agenda. Understandably, Russell et al. argued that it would be necessary to understand the goals driving consumers in order to be able to develop adequate models. While the authors discussed crosscategory consideration, cross-category learning (i.e. from earlier choices), and product bundling as the three types of cross-category choice dependence, Boztu \& Silberhorn (2006) found the three factors of complementarity, heterogeneity, and coincidence to be driving cross-category choices.

\begin{tabular}{|c|c|c|}
\hline & Models & Sub-Groups \\
\hline \multirow{6}{*}{ 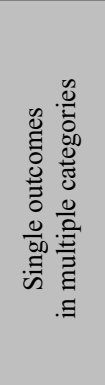 } & \multirow[t]{3}{*}{ Models of incidence outcomes } & Models capturing "whether to buy" \\
\hline & & Models capturing "when to buy" \\
\hline & & Models capturing bundle choice \\
\hline & \multirow[t]{2}{*}{ Models of brand choice outcomes } & $\begin{array}{l}\text { Models capturing correlated mar- } \\
\text { keting mix sensitivities across } \\
\text { categories }\end{array}$ \\
\hline & & $\begin{array}{l}\text { Models capturing correlated brand } \\
\text { preferences across categories }\end{array}$ \\
\hline & Models of quantity outcomes & - \\
\hline \multirow{3}{*}{ 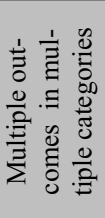 } & $\begin{array}{l}\text { Models of incidence and brand choice } \\
\text { outcomes }\end{array}$ & - \\
\hline & $\begin{array}{l}\text { Models of incidence and quantity } \\
\text { outcomes }\end{array}$ & - \\
\hline & $\begin{array}{l}\text { Models of incidence, brand choice, and } \\
\text { quantity outcomes }\end{array}$ & - \\
\hline
\end{tabular}

Table 3: Multi-Category Models of Consumer Purchasing

Source: Seetharaman et al. (2005); illustration adapted

Probably inspired by Russell et al.'s (1999) suggestion to advance from singlecategory models to multi-category models, Seetharaman et al. (2005) undertook a literature review of these multi-category models in order to establish a statusquo. As depicted in Table 3, the authors distinguished the models by the number of outcomes that were modeled: either one of the three purchase decisions inci- 
dence, brand choice, or quantity, a combination of two of them (i.e. incidence and brand choice or incidence and quantity), or all three.

Based on the methodological approach employed rather than the modeled element of consumer purchasing, Boztu \& Silberhorn (2006) adopted the categorization illustrated in Table 4. As for the exemples in literature as well as the explanations, the contributions by Mild \& Reutterer (2003) and Reutterer et al. (2007) were used to complement the elaborations of Boztu \& Silberhorn (2006).

\begin{tabular}{|c|c|c|c|}
\hline & Method & Example References & Explanation \\
\hline \multirow{6}{*}{ 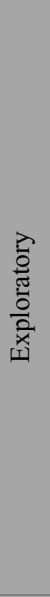 } & $\begin{array}{l}\text { Pair-wise } \\
\text { associations }\end{array}$ & $\begin{array}{l}\text { Dickinson et al. (1992), } \\
\text { Julander (1992) }\end{array}$ & $\begin{array}{l}\text { Use of a } 2 \times 2 \text { matrix to determine pair-wise } \\
\text { measures of association }\end{array}$ \\
\hline & Association rules & $\begin{array}{l}\text { Agrawal \& Srikant } \\
\text { (1994), } \\
\text { Chen et al. (2005) }\end{array}$ & $\begin{array}{l}\text { Calculation of correlations between two or } \\
\text { more items }\end{array}$ \\
\hline & $\begin{array}{l}\text { Cluster analysis/ } \\
\text { vector quantization }\end{array}$ & $\begin{array}{l}\text { Schnedlitz et al. } \\
(2001) \text {, } \\
\text { Decker (2005) }\end{array}$ & $\begin{array}{l}\text { Clustering of products or product groups } \\
\text { based upon them being purchased together }\end{array}$ \\
\hline & $\begin{array}{l}\text { Autologistic } \\
\text { model }\end{array}$ & $\begin{array}{l}\text { Moon \& Russell } \\
(2004)\end{array}$ & $\begin{array}{l}\text { Mapping of customers according to their } \\
\text { common preferences }\end{array}$ \\
\hline & $\begin{array}{l}\text { Collaborative } \\
\text { filtering }\end{array}$ & $\begin{array}{l}\text { Breese et al. (1998), } \\
\text { Mild \& Reutterer } \\
(2003)\end{array}$ & $\begin{array}{l}\text { Prediction of a new customer's behavior based } \\
\text { on the behavior of known customers }\end{array}$ \\
\hline & $\begin{array}{l}\text { Multidimensional } \\
\text { scaling }\end{array}$ & $\begin{array}{l}\text { Böcker (1978), } \\
\text { Merkle (1981) }\end{array}$ & $\begin{array}{l}\text { Visualization of meaningful underlying di- } \\
\text { mensions that enable an explanation of simi- } \\
\text { larities and dissimilarities in data }\end{array}$ \\
\hline \multirow{2}{*}{ 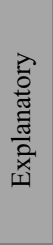 } & Logit models & $\begin{array}{l}\text { Hruschka et al. (1999), } \\
\text { Russell \& Petersen } \\
(2000)\end{array}$ & $\begin{array}{l}\text { Modeling of inter-category choice decisions } \\
\text { following utility theory }\end{array}$ \\
\hline & Probit models & $\begin{array}{l}\text { Ainslie \& Rossi } \\
\text { (1998), } \\
\text { Manchanda et al. } \\
\text { (1999) }\end{array}$ & $\begin{array}{l}\text { Modeling of inter-category choice decisions } \\
\text { according to utility theory, but in contrast to } \\
\text { logit models with correlated disturbance } \\
\text { variables }\end{array}$ \\
\hline
\end{tabular}

Table 4: Approaches to Basket Analysis

Source: Boztu \& Silberhorn (2006), supplemented by Mild \& Reutterer (2003) and Reutterer et al. (2007); illustration adapted

Based on Mild \& Reutterer (2003), Boztu \& Silberhorn (2006) differentiated between explanatory and exploratory models in their detailed, though not exhaustive overview. As Mild \& Reutterer (2003) explained, exploratory models are focused on exposing the relationship patterns that exist among multiple product categories. By contrast, explanatory models try to discover and measure inter-category choice effects caused by the company's marketing efforts (e.g. 
price or promotions), thereby considering external variables interfering with the customer's purchase decisions.

Comparing the contributions of Russell et al. (1999), Seetharaman et al. (2005), and Boztu \& Silberhorn (2006), it seems fair to say that they almost perfectly complement each other. The first one gave a good introduction to the topic, outlining issues that needed to be resolved, while the second one gave a solid overview of the different approaches to solving these problems, categorizing them according to what the models try to capture. Eventually, the third contribution supplemented the previous works by looking at how the models worked, classifying them by their methodological approach.

\subsection{Characteristics of Loyalty Schemes}

It is relatively clear why customers join and patronize a loyalty program. Predominantly, they join to receive different types of rewards, such as discounts, increased status, or increased service (see e.g. Smith \& Sparks 2009). To make this decision, they weigh these benefits (more or less consciously) against the membership's disadvantages directly affecting them (e.g. usage of wallet space for the new loyalty card, privacy issues, etc.). The company does so in a similar, though (hopefully) more conscious and structured manner. Just like the consumer, the organization also tries to reach its respective goals by exploiting the characteristics (i.e. advantages) of customer loyalty programs. At the same time, the firm has to consider the disadvantages and dangers and make a trade-off with the expected positive effects. In this chapter, the goals the organization is commonly trying to achieve with its loyalty scheme will briefly be discussed by reviewing two established frameworks (found in the current section), upon which the commonly claimed positive effects (Chapter 3.5.1) as well as the negative effects and problems associated with loyalty schemes will be covered from the company perspective (Chapter 3.5.2).

As depicted in Figure 10, Butscher (2002) categorized the companies' goals into three hierarchical levels: core goals, primary goals, and secondary goals. Most importantly, the author argued, the company is interested in increasing its turnover, profit, or market share. This can be achieved in the medium to long run by realizing the goals from the lower hierarchical levels.

Butscher's rather self-explanatory model begs two comments: firstly, it is (as ever so often in these cases) unclear why these particular goals were chosen and arranged in this specific way. Why, for instance, is the increase of purchase frequency a secondary goal, while it is actually an outcome of customer loyalty (which is, however, placed at a higher hierarchical level)? At the same time, other secondary goals really are a target in their own right, as they are not linked to the fulfill- 
ment of a previous objective (e.g. the support of the company's public relations). Secondly, Butscher equalized the goal of customer loyalty with the aim of developing a relationship with the customer. It was established in Chapter 2, however, that the ability of customer loyalty schemes to establish true, possibly life-long relationships (as the author describes them) is rather unlikely. At best, an average retailing loyalty scheme can alter behavioral loyalty to a certain extent, manifesting itself in a change of purchase frequencies, basket sizes, share-of-wallet, etc.

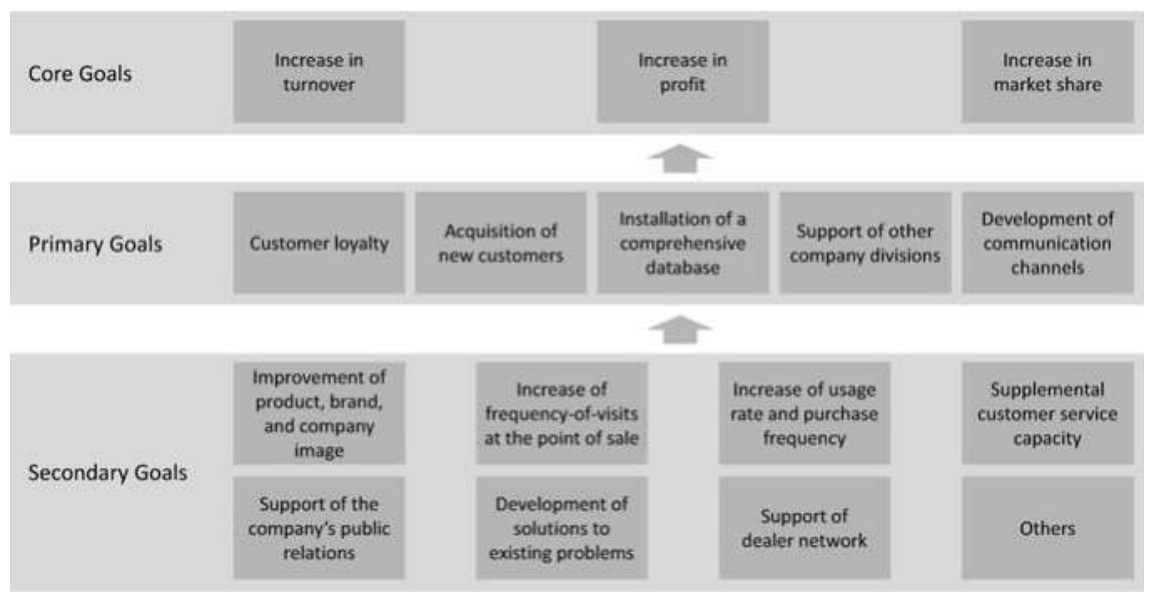

Figure 10: Loyalty Program Goals - Framework 1

Source: Butscher (2002); illustration adapted

Another, slightly less straight-forward framework is that suggested by Diller (1997). As seen in Figure 11, the author has also applied some form of hierarchy to his version. Following Diller's line of thought, the customer loyalty program creates different types of effects via its rewards. Interestingly, three of the effects mentioned by the author (i.e. customer selection, knowledge, and interaction/integration) mean roughly the same thing. By signing up to the scheme, customer selection takes place in the sense that the members are now known by name and can be targeted individually. The company possesses information about areas such as personal data or shopping behavior, which it uses to improve interaction with the customer to better integrate him with the organization. All these things, including improved image, then lead to the realization of strategic goals such as the identification of the customer with the company, increased commitment, satisfaction, and trust, as well as positive word-of-mouth. In the end, then, these effects impact turnover and protect the company from disloyal customers and 
competitive action (the security aspect), which in combination with the cost factor, results in improved profits and secures the organization overall.

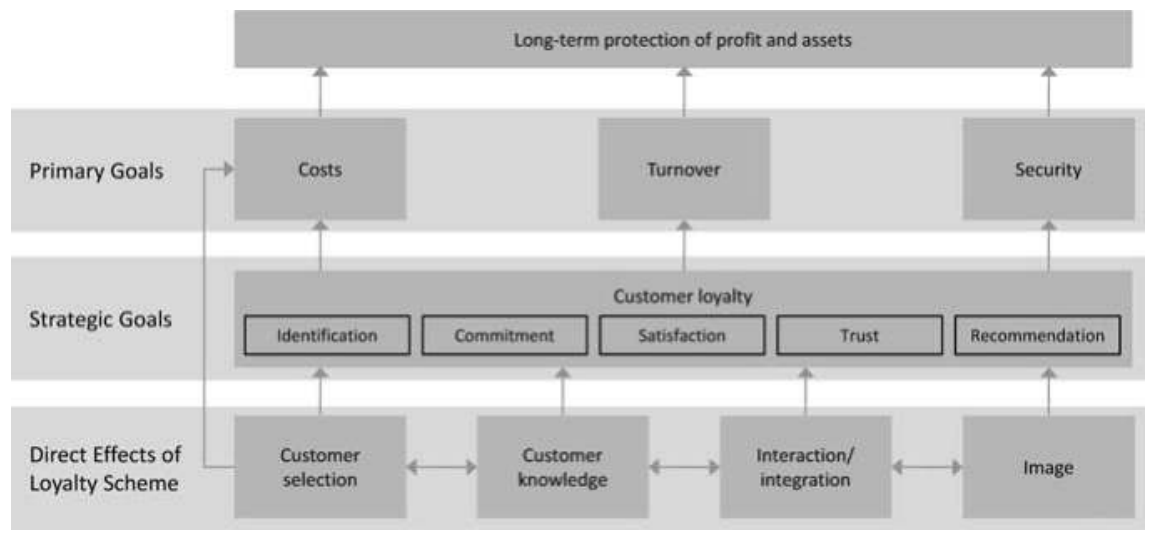

Figure 11: Loyalty Program Goals - Framework 2

Source: Diller (1997); illustration adapted

It seems fair to say that, apart from the inclusion of costs, Diller's framework appears more homogeneous than Butscher's (2002). This is probably due to the fact that Diller (1997) refrained from including the actual drivers of turnover increase, such as the aforementioned changes to purchase frequencies and the like. Moreover, it is appealing that the author made profitability the final stage in his model, anticipating the outcry of authors such as Reinartz \& Kumar (2002) or Kumar \& Shah (2004) who found the issue of profitability neglected in relation to loyalty schemes.

Certainly, different illustrations of this framework are possible, and despite some criticism, these two examples hopefully helped to provide an interesting introduction particularly to the following summary of positive effects, but also negative effects and issues commonly associated with loyalty programs.

\subsubsection{Benefits}

Several of the advantages have already been named, be it in relation to the value of data, the goals that companies try to achieve with loyalty schemes, or in other chapters of this paper. Those already cited benefits will be repeated and integrated into the following list. The aim of this section is to provide an extensive, though not necessarily exclusive laundry list of positive effects commonly attributed to loyalty programs, followed by a critical reflection, as some of these positive effects have been criticized and were shown not to apply in every setting (to 
name just one example, Frisou \& Yildiz 2011 demonstrated how program effectiveness is dependent on consumer learning).

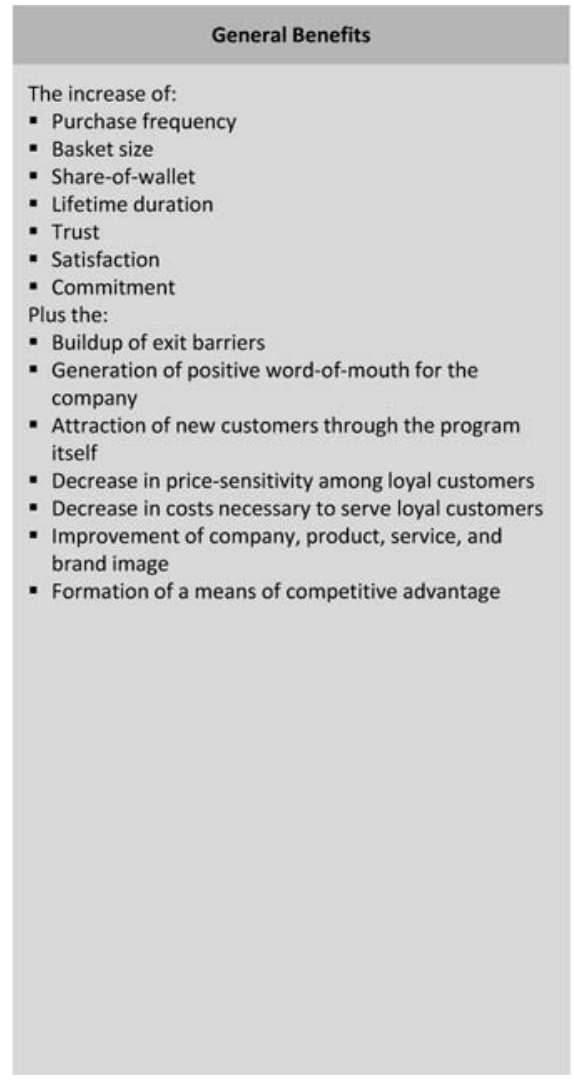

\begin{tabular}{|c|}
\hline Data Collection-Specific Benefits \\
\hline $\begin{array}{l}\text { The ability to: } \\
\text { - Minimize wasteful (marketing) spending } \\
\text { - Mass customize marketing communication to } \\
\text { maximize the impact of the corresponding marketing } \\
\text { activity } \\
\text { - Identify customer segments with similar } \\
\text { characteristics } \\
\text { - Engage in profitable customer acquisition by } \\
\text { modeling expected customer potential } \\
\text { - Increase revenues through cross-and up-selling, } \\
\text { based on a model of the customer's purchase } \\
\text { likelihood of specific product sets or services } \\
\text { - Optimize store layout (e.g. product placement) } \\
\text { following a better understanding of purchase } \\
\text { behavior } \\
\text { - Promote follow-up products (e.g. razor blades for a } \\
\text { particular razor) } \\
\text { - Reduce churn with predictive models that identify } \\
\text { customers who are likely to stop patronizing the } \\
\text { company in the future } \\
\text { - Identify customers who were recently lost and to } \\
\text { reach them with an action plan aimed at bringing } \\
\text { them back } \\
\text { - Identify the profitability of the company's customers } \\
\text { - Identify and track trends } \\
\text { - Make qualified changes to the range of goods or } \\
\text { - } \text { - Mervices on offer } \\
\text { campaigns in a better and more efficient manner } \\
\text { - } \text { Improve the success of a necessary product recall by } \\
\text { areas developed by the company } \\
\text { development of a new product line) } \\
\text { - Support business decisions of various kinds (e.g. } \\
\text { - }\end{array}$ \\
\hline
\end{tabular}

Figure 12: Proclaimed Benefits of Loyalty Schemes

Source: Clayton-Smith 1996, Diller 1997, Hippner et al. 2001, Butscher 2002, Berman 2006, Kumar \& Reinartz 2006, Humby et al. 2008, Mimouni-Chaabane \& Volle 2010, Morrisson \& Huppertz 2010

As the relationships between these different points are not always clear, the list of generally claimed benefits in Figure 12 was presented in an unspecified order. The enumeration does, however, encompass a good part of the characteristics that are commonly claimed to be positive effects of loyalty schemes. Still, it should be noted that some of these effects have found themselves subject to criticism. In particular, the following associations with loyal customers have been increasingly called into question: 
- The decrease in costs necessary to serve loyal customers

- The decrease in price-sensitivity among loyal customers

- The generation of positive word-of-mouth for the company

Going back to a series of publications by Frederick F. Reichheld (see e.g. Reichheld et al. 2000), director at the management consultancy Bain \& Company, these claims have essentially been criticized for not being universally applicable. Building on a discussion set off by Dowling \& Uncles (1997), today's best-known critics that need to be named in this regard are probably Reinartz \& Kumar (2002). Studying company data of a US high-tech corporate service provider, a US mailorder company, a French food retailer, and a German direct brokerage house, the authors analyzed the shopping behavior, revenue streams, and profitability of over 16,000 individual and corporate customers over a period of four years.

Firstly, the authors found no evidence for the claim that it costs less to serve loyal customers. At best, they concluded, this link between loyalty and lower cost was industry-specific. The idea that gave rise to the claim for the existence of this link was that the initial customer acquisition cost could be distributed over a longer retention period in case of loyal customers. Furthermore, these customers were expected to incur a lower amount of service costs as they were more experienced with the product (and consequently with the trouble-shooting necessary). This, the idea went, would also cause customers to use cheaper communication channels, such as the internet instead of calls to the service center. Reinartz \& Kumar found that in none of the four companies analyzed were longterm (i.e. loyal) customers cheaper to serve than short-term customers throughout the observed time period. For instance, experienced customers of the mailorder company who did actually use the internet instead of another more expensive channel to place their orders expected lower prices in that channel in return (thereby neutralizing any cost savings). In case of the high-tech corporate service provider, costs to serve loyal customers were even higher than those associated with short-term customers due to higher price pressure by the big and loyal corporate customers as well as increased costs for dedicated service teams.

Secondly, Reinartz \& Kumar discovered that loyal customers were not paying higher prices. While it might sound reasonable that loyal customers are more likely to pay higher prices as they face higher switching costs or a switching barrier due to the associated uncertainty (e.g. as far as product or service quality is concerned), this was not found to be the case in practice. Loyal customers of the corporate service provider as well as the other three companies serving consumer markets were all demanding a tangible return for their loyalty or, in the best case, expected the same as short-term customers. In fact, long-term customers of the corporate service provider paid between 5-7\% lower prices than short- 
term customers, with loyal customers of the mail-order company paying up to $9 \%$ less in a specific product category. As for the grocer and the brokerage house, the prices charged to each type of customer were equal. Possibly due to the loyal customers' better knowledge of the product and its value, the authors concluded that these consumers are actually more price-sensitive and not the other way around.

Thirdly, the authors highlighted that measuring behavioral loyalty alone was not sufficient to judge the effect on positive word-of-mouth. They did not necessarily prove the claim wrong that loyal customers speak more positively about the company, but pointed out that only behavioral loyalty combined with attitudinal loyalty is truly helpful in generating new customers. This conclusion was drawn from a separate study with a sample of customers from the French food retailer, where both the passive and active word-of-mouth behavior was tested with two questions. In this study, customers were first asked to recommend a particular food retailer (i.e. to test passive word-of-mouth) upon which they were asked whether they ever tell friends or family about positive experiences with the French grocer under review (i.e. to capture active word-of-mouth). In addition to that, their actual behavioral loyalty was looked up in the company database and finally, their attitudinal loyalty captured through a telephone survey. Interestingly, customers who exposed high levels of both attitudinal and behavioral loyalty were $54 \%$ more likely to engage in active and 33\% more likely to participate in passive word-of-mouth behavior (for a more recent and detailed investigation of word-of-mouth activity among reward program participants see e.g. Ferguson \& Hlavinka 2009).

As mentioned in the introduction to Reinartz \& Kumar's (2002) elaborations, it is important to keep in mind that the truth of these claims is clearly dependent on the industry and the individual customer or customer segment. For instance, industries where loyal customers tend to pay more certainly do exist. An example would be a highly competitive market for mobile telephone services such as that in Austria. The different providers are constantly creating and advertising new, cheaper phone plans to attract new customers. Old customers, then, very soon find themselves paying for a more expensive phone plan than all the new customers have access to. Kumar \& Reinartz (2006) later added that the case where customers become more profitable over time is when a contractual relationship is given, while it would not hold true in a non-contractual setting. In the case of the mobile phone services market, however, the contractual obligation is often not the only factor causing customers to stick to the more expensive phone plan. Next to being affected by the minimum period of contract duration (usually 18 24 months in Austria), they often simply show too little involvement or fear uncertainties with regard to things like network coverage or service quality to 
switch to a new provider with better offers. Furthermore, providers in many countries often do not give customers the option to transfer their old phone number to a new provider (Austrian legislation has enabled this procedure since 2004, Germany since around two years earlier), which might pose an additional, significant exit barrier. Thus, even if they are not contractually bound, loyal customers in certain industries might very well find themselves paying more than new customers.

Apart from the industry, profitability also varies by the individual customer or customer segment. For instance, Reinartz \& Kumar (2002) found that longterm customer segments who were only marginally profitable actually made up between $15 \%$ and $21 \%$ of the four analyzed companies' customers, while around the same percentage were highly profitable, though short-term customers. For that reason, the correlation between customer lifetime duration and profitability was only found to be weak to moderate.

It was already determined that it depends on the industry and the individual customer whether loyal patrons are cheaper to serve than short-term customers. Similarly, it is difficult to generalize in the case of price-sensitivity, although it is certainly less common that loyal customers can (and perhaps should) be exploited by the company in that regard. Eventually, the last point of criticism will be addressed. It was concluded in the end of Chapter 2 that despite an ultimate answer being outstanding, retailing loyalty programs, dependent on industry and program configuration, are generally not able to create or foster attitudinal loyalty. At least within a retail setting it seems safe to say, then, that the true power of positive word-of-mouth (which comes from a combination of both behavioral and attitudinal loyalty) cannot fully be capitalized on. In other words, the increase in positive word-of-mouth caused by loyalty schemes will be visible, but is not expected to be very big.

\subsubsection{Drawbacks}

Next to the positive effects associated with loyalty schemes, there are, of course, also a range of alleged negative effects and general problems associated with such programs. The following enumeration in Figure 13, like that in the previous chapter, is not characterized by a specific order. 
- Loyalty schemes merely bribe customers to patronize the company

- Customers would prefer generally lower prices over a loyalty scheme

- Loyalty programs are often easy to reproduce, eliminating any competitive advantage and leaving behind an industry with lower margins

- Handling and analyzing all the data generated from such a program is like drinking from a fire hose

- Customers are concerned by privacy issues

- Following an initially visible sales bump, it is difficult for the company to measure the ongoing success of the program

- Common rewards worth around 0.5 - $3 \%$ of sales are not enough to sway customer behavior

- Once the loyalty program is started, the company will be committed, as it is extremely difficult to take it away from customers

- In most programs where customers accrue points, it takes them far too long to achieve a desirable reward

- Customers often hold multiple cards from competing firms, allowing them to engage in cherry picking

- Competing loyalty schemes are often similarly structured, resulting in too little differentiation to be effective in a competitive setting

- Customers' wallet space is limited, making it impossible to carry a membership card of every store around at all times

- A good part of the rewards goes to customers who were already loyal to the company in the past and would have remained loyal even without the program

Figure 13: Proclaimed Drawbacks of Loyalty Schemes

Source: $\quad$ Dowling \& Uncles 1997, Passingham 1998, Wright \& Sparks 1999, Parker \& Worthington 2000, Dowling 2002, Berman 2006, Leenheer et al. 2007, Meyer-Waarden 2007, Humby et al. 2008, Lacey 2009, Cedrola \& Memmo 2010

These points will now be elaborated on one after another. Firstly, it was claimed by some authors that loyalty schemes merely bribe customers. For instance, Humby et al. (2008) reported that the chairman of the British grocery chain ASDA was a renowned advocate of this view (the Wal-Mart subsidiary had abandoned the four-year pilot trial of its loyalty scheme around the turn of the century). The authors further highlighted that it was not uncommon to find a magazine comparing the rewards of different competing loyalty schemes almost like mobile phone plans, which contributes to the confirmation of this belief. Humby et al. did not go on to fundamentally refute this argument, but indicated that this does not mean that loyalty schemes were unable to generate loyalty in an emotional and not simply logical sense (such as the reaction towards bribery). It was determined previously that it is very difficult for loyalty schemes to generate attitudinal loyalty, implying that this point of criticism might essentially be cor- 
rect. The question is, however, whether this is a bad thing. After all, any marketing action advertising special discounts or other types of promotion could be called bribery. The reward part, then, might well be considered another form of such bribery, without affecting the actual strengths of the loyalty scheme mentioned in the previous chapter.

Is it true that customers prefer generally lower prices over a loyalty scheme? This was the primary reason the aforementioned British grocer ASDA brought forward when abandoning its loyalty program pilots. Following an Every Day Low Pricing (EDLP) strategy, the company reasoned that the money would be better spent on a reduction of prices than on a loyalty scheme. Next to the overall strategy the company follows, other factors such as competitive actions or the characteristics of the industry will certainly affect this lower prices vs. loyalty program decision. Essentially, however, one factor will have the greatest influence: how cost-effective the loyalty program can be operated. Let us imagine a company facing two options: (1) to take 20 million EUR and invest the money in a loyalty scheme or (2) to decrease prices to an equal extent. Given that the loyalty scheme is profitable (i.e. it produces an increase in like-for-like sales which contribute to profit in excess of the costs of the program), the company has made a good investment. Similarly, if the decrease in prices leads to an increase in volume large enough to outbalance the turnover lost through this decrease, the company has made a good decision as well (other consequences of either move left aside). In the end, then, it will depend on the specific situation which one of these two options is the better one, or in other words, it cannot be generally stated that either one way is the right one (Tsao et al. 2010 take this one step further by discussing how a company should distribute its marketing budget between promotions and its loyalty program). Especially because while it might be true that all customers want low prices, only some of them shop exclusively on that basis (Humby et al. 2008). Furthermore, Humby et al. added, the loyalty scheme helped the company to minimize the cost of price cutting while maximizing competitive impact at the same time.

Parker \& Worthington (2000) attested that the most common cause of failure is the ease with which competitors can imitate the loyalty scheme - something, that will inevitably happen to good programs in a competitive market. This would result in a return to the initial situation before the introduction of the first scheme, but with increased marketing costs for everyone (Meyer-Waarden 2007). Is the key, then, to have a differentiated program that cannot be easily copied? Would a sophisticated program characterized by high costs serve as an entry barrier for competition and conserve that program's competitive advantage? Let us consider Tesco's Clubcard, for instance. This loyalty scheme has helped to build up a considerable amount of know-how since its launch in 1995 (and the 
start of trials some time earlier), which undoubtedly makes it extremely difficult to copy. In fact, for precisely that reason the US grocery chain Kroger decideed to hire dunnhumby, the company that devised and still manages Tesco's loyalty scheme, when it attempted to set up its own program. This point of criticism consequently only applies to simple programs - the ones which are used as nothing more than a plain promotional tool. Similar to how any competitor can easily start sending out promotional leaflets or give $5 \%$ discount on all frozen pizzas to copy his competitor's move, it will be possible to imitate such a basic loyalty scheme. This is true, but no different with respect to any other promotional action.

The problem of handling and making sense of the large amount of data available to many companies, particularly in the retailing industry, has already been discussed in Chapter 3.4.1. This definitely is a challenging task, but one that many companies have successfully faced. In addition to that, the number of external service providers willing to assist companies in this endeavor is growing continuously.

"Food retailing loyalty schemes - and the Orwellian Millennium," Evans (1999) titled his article on the privacy issue associated with loyalty programs. Schemes that capture each customer's purchase history give the company access to detailed information about the shopping behavior of every person using his loyalty card. As many customers have a fear of this intrusion into their privacy, sometimes even coupled with an uncertainty about whether this data will be sold to a third party, this factor does play an important role for some customers in their decision to opt for a loyalty card. For example, using focus groups and semi-structured, qualitative interviews, Noble \& Phillips (2004) discovered two different types of concern among the study participants: fraudulent use of the data (e.g. going as far as "identity theft" by someone inside or outside the company) or just simply the emergence of a "big brother is watching" feeling (see e.g. Sayre \& Horne 2000 for further information on this topic). Apart from the extreme case of a misuse of data, the fact that companies are able to monitor behavior was in itself considered intrusive by some respondents. It needs to be kept in mind, however, that this matter is to a large extent strictly regulated by data protection laws, limiting the leeway given to companies. Still, organizations need to make sure that they communicate clearly to customers about this issue and adhere to their statements. Examples of problems include that of the US pharmacy chain CVS, where a lack of password protection enabled anyone with the membership number (which could, for example, be retrieved from old sales slips which the number was printed on), zip code and last name to have online access to that person's possibly sensitive purchase history. Another example was disclosed by Humby et al. (2008) in relation to Tesco's UK Clubcard. In this case, an upset woman complained about the company promoting condoms in the 
targeted mailing she had received, stating that this must be a mistake as neither she nor her husband had ever purchased such an item. In reality, the husband must have done so, of course, but the call center agent reportedly acted in a sensitive manner and blamed it on a defect of the computer system. In either case, at least at a theoretical level, the potential for intrusion and infringement of privacy or possibly even manipulation is considerable, Rowley (2004) highlighted. Even though some of the advice may be taking things a little too far, a set of guidelines for companies to consider can be found in a publication by the US Food Marketing Institute (FMI n.d.).

Another problem that companies are facing is that of measuring the effectiveness of their loyalty scheme. Stating that is was impossible following the sales bump caused by the launch of the program is not entirely correct. Given that the scheme captures transaction data, the company can at least track things like purchase frequency or turnover development on a customer level, and also, new promotional activities associated with the program can be analyzed without much difficulty. Ziliani (2005), for instance, offered an interesting way to measure the effectiveness of promotions with the help of a loyalty scheme. At the same time, it is naturally difficult to separate the contribution of the loyalty program to the development of an indicator of success (e.g. turnover) from that of other interfering variables. A possible solution would be a comparison with a control group of non-members, which is tracked from program launch onwards. As Butscher (2002) suggested, this comparison would ideally be based on both quantitative and qualitative indicators which were selected to best judge the achievement of one or a set of previously determined goals the company was aiming to achieve with the help of its loyalty program. At the same time, it is important not to forget to take other positive effects into account that are not captured by these indicators.

A voucher worth $2 \%$ on annual sales of 500 USD might not be deemed worth much in absolute terms, particularly not if compared with the $25 \%$ to $40 \%$ discounts which are not uncommon in retailing promotions, Cigliano et al. (2000b) noted. This might sound logical, but nevertheless, a large number of retailers successfully runs a loyalty scheme offering even less reward value than this $2 \%$. Despite these low percentages, certain customers still seem to respond to them particularly, but not only, if the industry competitors do not offer their own scheme. It needs to be added, however, that focusing exclusively on monetary rewards is not necessarily a good thing (see Chapter 3.3.8 for a discussion of reward types and the rate of reward). Berman (2006), for instance, called a focus on financial rewards a potential pitfall of loyalty schemes. This is even more important as customers might perceive non-financial rewards to be of much greater value than they actually are expressed in monetary terms (i.e. stated as the under- 
lying cost to the company). All in all, it can be said that numerous loyalty programs even with such low reward values have in fact been successful in practice.

It is true that loyalty schemes are not particularly easy to cancel or cut back on, as customers seem to perceive the receipt of rewards almost as their given right a while after the program is launched. Thus, apart from the sunk cost associated with the scheme, the company has to cope with the reaction of the customers when abandoning their program. Still, many companies have "successfully shut down" their programs. Consequently, it is certainly a point that managers will need to consider before committing to a loyalty scheme, but at the same time it is not one that cannot be overcome if the program really needs to be shut down at some point in time.

Some critics argue that it takes far too long for customers to achieve a truly desirable reward in most loyalty schemes where a specific number of points or amount of turnover needs to be reached in order to redeem that reward. Companies naturally are limited in the degree of reward value they can hand out to each customer. It is obvious that even if, for instance, a consumer pools all his fuel expenses at a particular retailer (e.g. 1,500 EUR per year, arising from an average distance of $18,750 \mathrm{~km}$ [11,650 miles] traveled with a vehicle consuming 8 liters per $100 \mathrm{~km}$ [29.4 miles per gallon] and a theoretical fuel price of around 1 EUR per liter [3.8 EUR per gallon]), he will not be receiving a holiday weekend in Paris as a reward every year. To illustrate the time it takes to achieve a reward worth 50 EUR, the strategy consultancy Roland Berger (2003) compared four German reward programs (Lufthansa's Miles \& More scheme, the coalition program Payback, the then still active stand-alone scheme of the fuel retailer Aral, and the loyalty program of the shoe retailer Görtz), based upon average usage frequencies and sales. Achieving that 50 EUR reward took Lufthansa frequent flyers 6.5 months, Payback users 11 months, Aral customers 12.5 months, and Görtz patrons a whopping 6.5 years. In a way, this discussion is linked to the choice of reward type and reward rate. As was previously established, companies have a wide range of options when it comes to rewards and should strive to optimize impact. Practice has shown that customers also find low-value rewards desirable and these do not always have to be monetary either. As far as rewards resembling a bigger value are concerned, multi-partner schemes can serve as a way out. In Roland Berger's study, for example, the two programs with the shortest time to reward redemption were coalition schemes (Lufthansa's Miles \& More and the German Payback program), allowing customers to collect points at a range of partners, leading to a quicker accumulation of the reward currency.

"I have accumulated nine 'loyalty' cards from various stores and supermarkets. Does this make me more loyal, or less," asked a reader in a letter to the UK 
newspaper The Times cited by Wright \& Sparks (1999, p. 429). Indeed, many customers, even within the same industry, are members of multiple loyalty programs (Dowling \& Uncles 1997, Passingham 1998, Bellizzi \& Bristol 2004, Liu $\&$ Yang 2009). To name just one example, Haeberle (2004) quoted a study by Forrester Research, according to which $54 \%$ of grocery shoppers were members of two competing loyalty schemes, $15 \%$ had joined three different programs, and $4 \%$ held membership cards of four or five food retailers. Altogether, that leaves only $27 \%$ of respondents who were members of only one program. Multiple card-ownership certainly does not have a positive influence on the effectiveness of the individual retailer's loyalty program. For instance, Mägi (2003) discovered that having a competing loyalty card had a negative impact on share-of-wallet and Meyer-Waarden (2007) found that multiple memberships of geographically close retailers lead to a reduction of lifetime duration. This problem has already been touched in Chapter 2.3.3, with the naturally given presence of polygamous loyalty through variety seeking customers or the "just-in-case scenario" (i.e. customers possess a competing loyalty card to take advantage of that program just in case they are once in a while unable to patronize their preferred company) named as possible explanations. Nevertheless, it can never be excluded that certain customers are members of competing schemes only to engage in cherry picking. This is a disadvantage that just needs to be accepted, but one whose effects can at least be mitigated by differentiating the program from competitive offerings and applying a more effective reward structure. In addition to that, a first mover advantage such as that often quoted in relation to the introduction of new products or the entry of new geographical markets might exist as well. Despite the lack of empirical proof for this effect in relation to the introduction of loyalty schemes, this scenario is not unlikely if a reward structure creating a barrier of exit is present. Once the customer has advanced to a higher tier of the program or is half way into the collection of points for a desired reward, it is less likely that the customer significantly redistributes his share-of-wallet.

The claim that programs are often similarly structured and consequently ineffective in a competitive setting might apply to certain industries in particular countries, but cannot be considered generally true. Many companies, such as the ever so often named best practice case Tesco, have indeed managed to differentiate themselves from competition and created a competitive advantage. The following passage stems from a research report issued by the investment bank JP Morgan Cazenove on August 31, 2005 (quoted by Humby et al. 2008, p. 271): "contrary to popular belief, Tesco's most significant competitive advantage in the UK is not its scale. We believe Clubcard, which conveys an array of material benefits across virtually every discipline of its business, is Tesco's most potent weapon in the ongoing battle for market share." The wide range of options avail- 
able to structure a loyalty program enables every company to optimally match such to its own, the given industry's, and the customers' characteristics and demands. Particularly if the organization has a lead on its competitors in doing so, it will be less likely to end up ineffective in the competitive arena.

Another point of concern is that customers' wallet space is limited, while the number of loyalty cards available to stick into these wallets seems to be just the opposite. This is definitely an, interestingly often underestimated problem that loyalty programs face. There are, however, various ways around this issue. For instance, some companies optionally offer key fobs (e.g. UK's grocery retailer Tesco), others provide stickers with the bar code to be stuck on whatever the customer wants (e.g. the US textile retailer American Eagle Outfitters), while again others enable the loyalty program to be stored on the chip of any national bank card (e.g. the Austrian grocery chains Billa and Merkur). Alternatively, companies often allow for the customer to be looked up in the firm's database, making it unnecessary to bring the card along, but increasing the time (and thus the cost) of the payment or service process for the company. A final example is that where organizations have arranged for the customer service centers to issue a temporary card with a validity of, say, one day, in case the customer has forgotten the original (e.g. the Austrian department store Kastner \& Öhler). All in all, it can be seen that this is certainly an issue that can be resolved with an according portion of creativity. Furthermore, as will be discussed in Chapter 4.2.1, coalition schemes can also serve as a mean to reduce the number of loyalty cards in customers' wallets.

As far as the problem of rewarding already loyal customers who would have continued to patronize the company even without the loyalty program is concerned, the critics seem to have a point. Interestingly, with very few exceptions such as Leenheer et al. (2007), authors who attempted to empirically measure the effectiveness of loyalty schemes have not taken the effect of such self-selecting members into account. Customers who are already heavy spending and loyal customers of the organizations, critics argue, are the ones who would derive the greatest benefit of a loyalty program membership. Consequently, these are the ones who are most likely to sign up for the scheme. In an analysis of seven loyalty programs of Dutch food retailers, Leenheer et al. discovered a small, yet positive influence of the loyalty scheme on share-of-wallet and added that this effect would have been seven times as large had they not accounted for this endogeneity in program membership. Nevertheless, the overall impact of the program remained positive. In light of this problem, simple, promotion-like loyalty schemes do face the same difficulty as any other form of untargeted promotion would encounter. Sophisticated loyalty schemes, however, can compensate for this in that they allow the company to develop each customer individually - even the ones who were al- 
ready considered loyal. Be it that they are successfully influenced by a crossselling incentive or that they improve the coupon redemption rate among loyal customers: the concern regarding self-selecting members is not always justified.

All in all, it can be said that most of these presumed problems or negative effects of loyalty schemes will not always be applicable. In fact, it will depend on the specific internal and external factors acting on the company whether these downsides have to be perceived as an issue in the first place. Particularly sophisticated programs can provide significant benefits to an organization and it will be up to its leaders to judge whether these outweigh expected costs and other disadvantages. Furthermore, if these problems really are encountered, there will be numerous ways to approach them available to the organization. 



\section{Coalition Schemes}

"Coalitions represent both the natural evolution and the future of loyalty marketing programs, both within the USA and abroad" (Capizzi \& Ferguson 2005, p. 76).

"The efficiencies inherent in coalition loyalty models [...] make coalitions the natural endgame for loyalty evolution” (Ferguson \& Hlavinka 2006, p. 297).

"According to Frequency Marketing Inc., there are 3 trends to watch for in card marketing in the new millennium: [...], and 3. coalition programs" (Barlow 1999, p. 1).

"The 22 major factors that will shape the future of customer loyalty: [...] 3. An explosion of loyalty coalitions and networks" (Clark 2006, p. 1 f.).

Weighing the advantages that characterize coalition schemes against their disadvantages, several practitioners and academics have proclaimed that multi-partner programs are an ongoing trend, and indeed, the next evolutionary step of loyalty schemes. Loyalty coalitions are, as compared to stand-alone programs, a relatively recent development. While the latter have existed at least since 1896 with the origination of the S\&H Green Stamps (S\&H 2009), it is possibly the founding of Air Miles in the United Kingdom in 1988 that marked the birth of coalition schemes operating on a grand scale (Air Miles 2009). Since then, several other programs have been introduced in different parts of the world, ranging from the United States and the United Kingdom to South Africa and South Korea. Still, several countries well penetrated with stand-alone programs and other regional or otherwise differentiated schemes (e.g. the US) have yet to witness the development of a strong nation-wide coalition.

This chapter will offer an overview of the different scheme types (Chapter 4.1), advantages and disadvantages associated with coalitions (Chapter 4.2), notable success factors relating to these programs (Chapter 4.3), as well as studies on impact, spread and customer perceptions (Chapter 4.4). Finally, Chapter 4.5 will bridge the way to the empirical section of this paper, in which further questions concerning these schemes will be elaborated on. 


\subsection{Scheme Types}

As far as a possible classification of coalition schemes is concerned, different approaches can be taken. One option would be the categorization into sectorexclusive schemes on the one hand and non-sector-exclusive programs on the other hand. Another possibility would be to differentiate by geographical spread (e.g. international vs. national vs. regional), possibly supplemented by an indicator of size to capture the "true presence" of the scheme. Furthermore, one could classify schemes by reward type offered (e.g. UK's Air Miles focusing on flight rewards only vs. UK's Nectar offering a whole range of rewards), by the underlying goal of the scheme (e.g. Nectar offering benefits only to consumers, while the regional SmartTown Alliance in the USA is aimed at benefiting both the consumer and a non-profit organization of choice), or by whether the scheme is internet-based or a "regular" program. Just as well, however, existing programs could be grouped by industry (e.g. retailing, airlines, etc.).

Among the numerous forms of coalition schemes, the following two subchapters will be centered on the most common variations: multi-partner programs focused on retailing and airline alliances. Finally, a brief overview of other special types of coalitions will be given in the third sub-chapter.

\subsubsection{Retail-Oriented Coalitions}

For obvious reasons, the number of national coalition programs a market can accommodate is a lot smaller than that of stand-alone programs. Possibly because of the ability of retailing partners to generate the volume required for the customer to maintain interest in the scheme, retail-oriented, typically sectorexclusive coalitions represent a good proportion of the already limited number of coalitions in existence. At least for strong, national programs, it is a plain necessity to get one of the biggest retailers of each of the most important sub-sectors on board. In particular a big grocery retailer will be necessary to guarantee these short purchase frequencies that keep the customer involved with the program.

It needs to be added, however, that these coalitions do not rely exclusively on retail partners. In fact, next to being able to collect points at, say, a grocery, fuel, clothing, and book retailer, customers can often beef up their point balance by generating turnover at a bank, insurance company, travel agency, car rental company, or electricity provider - to name just a few examples. The partner mix is obviously different in every scheme, but as a general rule, it seems fair to say that despite including partners from other industries, these schemes remain retailoriented. Table 5 shows a sample list of a number of more or less well known programs falling into that group. 


\begin{tabular}{|c|c|c|c|}
\hline Category & Program & Geographical Presence & Website \\
\hline \multirow{15}{*}{$\begin{array}{l}\text { Regular Retail- } \\
\text { Oriented } \\
\text { Schemes }\end{array}$} & BonusLink & Malaysia & www.bonuslink.com.my \\
\hline & DeutschlandCard & Germany & www.deutschlandcard.de \\
\hline & Dotz & Brasil & www.dotz.com.br \\
\hline & eBucks & South Africa & www.ebucks.com \\
\hline & $\begin{array}{l}\text { FlyBuys/ } \\
\text { Fly Buys }\end{array}$ & $\begin{array}{l}\text { Australia } \\
\text { New Zealand }\end{array}$ & $\begin{array}{l}\text { www.flybuys.com.au } \\
\text { www.flybuys.co.nz }\end{array}$ \\
\hline & HappyPoints & Germany & www.happypoints.net \\
\hline & i-mint & India & www.imintpoints.com \\
\hline & Malina & Russia & www.malina.ru \\
\hline & Nectar & UK & www.nectar.com \\
\hline & OKCashbag & South Korea & www.okcashbag.com \\
\hline & Payback & Germany & www.payback.de \\
\hline & Premium Club & Poland & www.premiumclub.pl \\
\hline & $\mathrm{R} \& \mathrm{R}$ & Kenya & www.rr.co.ke \\
\hline & s'miles & France & www.smiles.fr \\
\hline & SuperShop & Hungary & www.supershop.hu \\
\hline \multirow{2}{*}{$\begin{array}{l}\text { Retail-Oriented } \\
\text { Schemes } \\
\text { Focused on } \\
\text { Travel Rewards }\end{array}$} & Aeroplan & Canada & www.aeroplan.com \\
\hline & $\begin{array}{l}\text { Air Miles/Travel } \\
\text { Club }\end{array}$ & $\begin{array}{l}\text { UK } \\
\text { Canada } \\
\text { Spain } \\
\text { Netherlands } \\
\text { UAE, Qatar, Bahrain }\end{array}$ & $\begin{array}{l}\text { www.airmiles.co.uk } \\
\text { www.airmiles.ca } \\
\text { www.travelclub.es } \\
\text { www.airmiles.nl } \\
\text { www.airmilesme.com }\end{array}$ \\
\hline \multirow{7}{*}{$\begin{array}{l}\text { Regional Retail- } \\
\text { Oriented } \\
\text { Schemes }\end{array}$} & Kärnten Power Card & Austria & www.kaernten-power-card.at \\
\hline & Powercard & USA & www.powercard.com \\
\hline & S\&H greenpoints & USA & www.greenpoints.com \\
\hline & SelektPoints & Lebanon & www.selektpoints.com \\
\hline & SmartClub & China & www.smartclub.com.cn \\
\hline & Thank You & USA & www.thankyou.com \\
\hline & Wedge & UK & www.wedgecard.co.uk \\
\hline $\begin{array}{l}\text { Retail-Oriented } \\
\text { Internet Schemes }\end{array}$ & Maximiles & UK & www.maximiles.co.uk \\
\hline
\end{tabular}

Table 5: Retail-Oriented Coalition Schemes

It needs to be kept in mind that this list is by no means exhaustive. In particular the group of regional schemes is, for obvious reasons, just a brief selection. Nevertheless, this enumeration hopefully provides a good pool of examples to examine in further detail if interest has been sparked. Some of them are more dominant in terms of size, while others were created on a smaller scale. Especially the United States is an example of a loyalty card market where no truly big, national scheme managed to strike root. S\&H greenpoints and the Thank You program are mentioned as two examples of regional brands, which despite boast- 
ing a notable presence (in contrast to the Powercard in the US, for example), have not reached a significant nation-wide presence comparable to, say, the Nectar scheme in the UK.

As far as the categorization in Table 5 is concerned, four sub-categories of retailoriented coalitions emanated: (1) "regular" schemes, making up the majority of this coalition type, (2) programs with a focus on travel-related rewards (i.e. a slightly different form of "regular" schemes), (3) regional programs with limited geographical reach and/or only small program sponsors, and (4) internet schemes focused exclusively on points collection with online retailers. In particular the second group might require some further explanation. The idiosyncrasy of this kind of coalition is probably best explained with an example. Air Miles, a type of franchise present in various countries of the world, was wholly-owned ever since soon after its launch in the UK in 1988 by British Airways (British Airways 2008). As discussed in the fourth sub-section of Chapter 3.3.8, airlines have a clear cost advantage over regular retail-oriented schemes, as they can simply fill their otherwise empty seats with passengers travelling on redeemed miles. The additional variable cost incurred by such a passenger is likely to stand in no relation to the value of the reward as perceived by the customer. Naturally, this constellation only works if the airline owns the program, because otherwise the frequent flyer miles need to be purchased from the airlines - eating up at least part of the cost savings. On the downside, the target group of potential customers will be smaller with such travel-reward-oriented schemes, as not everyone is attracted by this type of reward. In addition to that, a wider choice of rewards is preferred by all customers - even by those who like to travel.

\subsubsection{Airline Coalitions}

Airline coalitions are, as opposed to most retail-oriented programs, not sector exclusive. While several small alliances exist as well, three coalitions dominate the airline industry (see Table 6). Of course, these alliances comprise much more than just loyalty programs which allow customers to collect and redeem miles with all the different member airlines. An extended network through code sharing agreements or cost advantages through common booking systems or sales offices are a few notable examples.

Still, the loyalty scheme is a significant part of these alliances, with the distinctive feature of these coalitions being that most of these alliance members operate their own, branded loyalty scheme. At the same time, the alliance is advertised to certain degree. This naturally makes for a few differences in terms of the advantages and disadvantages commonly associated with retail-oriented 
loyalty coalitions. The airlines Austrian and Lufthansa are two of the rare exceptions in the industry which use the same loyalty scheme brand (i.e. Miles \& More). Since September 2009, Austrian has also been owned by the German Lufthansa, but the decision to adopt the same loyalty scheme in addition to being in the same alliance was implemented long before. It can thus be seen that different alliance governance structures are thinkable (see e.g. Gudmundsson et al. 2002 for further information on this topic).

\begin{tabular}{|c|c|c|c|}
\hline Category & Program & Member Airlines ${ }^{1}$ & Website \\
\hline \multirow[t]{3}{*}{ Airline Schemes } & Oneworld & $\begin{array}{l}\text { American Airlines, British Airways, } \\
\text { Cathay Pacific, Finnair, Iberia, } \\
\text { Japan Airlines (JAL), LAN, Malév, } \\
\text { Mexicana, Quantas, Royal Jordanian, } \\
\text { S7 Airlines }\end{array}$ & www.oneworld.com \\
\hline & SkyTeam & $\begin{array}{l}\text { Aeroflot, Aeromexico, Air Europa, } \\
\text { Air France, Alitalia, China Southern } \\
\text { Airlines, Czech Airlines, Delta Air } \\
\text { Lines, Kenya Airways, KLM, } \\
\text { Korean Air, TAROM, Vietnam } \\
\text { Airlines }\end{array}$ & www.skyteam.com \\
\hline & Star Alliance & $\begin{array}{l}\text { Adria Airways, Aegean, Air Canada, } \\
\text { Air China, Air New Zealand, ANA, } \\
\text { Asiana Airlines, Austrian, Blue1, } \\
\text { bmi, Brussels Airlines, Continental } \\
\text { Airlines, Croatia Airlines, Egyptair, } \\
\text { LOT Polish Airlines, Lufthansa, } \\
\text { Scandinavian Airlines, Singapore } \\
\text { Airlines, South African Airways, } \\
\text { Spanair, Swiss, TAM, TAP Portugal, } \\
\text { Thai, Turkish Airlines, United, } \\
\text { US Airways }\end{array}$ & www.staralliance.com \\
\hline
\end{tabular}

1 As of February 2011

Table 6: Airline Coalitions

Source: Company Websites

\subsubsection{Other Variations}

While no large retail-based scheme has gained a foothold in the US to date, other smaller, creative programs managed to do so. Generally, these schemes are characterized by a set up similar to that of their larger archetypes. Customers receive a discount on their turnover or collect some form of points at a range of retailers, restaurants, financial service providers, and other partner companies. What is 
special about these programs is, however, what these savings are used for. In case of college saving schemes, any discount or accumulated points will be used to pay for college tuition. BabyMint, for instance, offers members one dollar off tuition expenses for every reward dollar earned at around 175 colleges and universities across the US. Similar to BabyMint, Upromise also allows for a transfer of accumulated rewards to a college saving plan of the customer's choice (these so-called " 529 college savings plans" are tax-free in the US and can be opened at a range of financial service providers).

Another interesting variation is that of schemes supporting non-profit organizations. In case of the SmartTown Alliance, for example, customers can choose a non-profit organization they want to support from a list provided. Any savings made with participating program sponsors are then split between the customer and the selected non-profit organization. Lastly, Stockback is an example of a program putting these rewards savings into an investment plan, while the Canadian Futura Rewards scheme represents a coalition allowing the customer to choose between several of these options. In this case, program members can use the rewards for education savings, retirement savings, charity, or cash payouts.

Somehow one is tempted to ask whether these programs are not simply regular retail-oriented schemes with a different range of reward options. In a way they are, but at the same time their different range of rewards goes hand in hand with such a fundamentally different positioning of the program, that it seems justified to set them apart in a special category.

\begin{tabular}{|c|c|c|c|}
\hline Category & Program & Geographical Presence & Website \\
\hline \multirow{2}{*}{$\begin{array}{l}\text { College Saving } \\
\text { Schemes }\end{array}$} & BabyMint & USA & www.babymint.com \\
\hline & Upromise & USA & www.upromise.com \\
\hline \multirow{2}{*}{$\begin{array}{c}\text { Schemes } \\
\text { Benefiting } \\
\text { Non-profits }\end{array}$} & $\begin{array}{l}\text { Rainbow } \\
\text { Rewards }\end{array}$ & USA & www.rainbowrewards.com \\
\hline & $\begin{array}{l}\text { SmartTown } \\
\text { Alliance }\end{array}$ & USA & www.smarttownalliance.com \\
\hline \multirow{2}{*}{$\begin{array}{l}\text { Variable } \\
\text { Schemes } \\
\text { and Others }\end{array}$} & Futura Rewards & Canada & www.futurarewards.ca \\
\hline & Stockback & USA & www.stockback.com \\
\hline
\end{tabular}

Table 7: Other Coalition Types 


\subsection{Differences to Stand-Alone Programs}

\subsubsection{Advantages}

Coalition schemes offer several distinct advantages over their single-sponsor counterpart to both companies and consumers. Given the lack of literature on this topic, Clark \& Clark (2009) have provided a useful basis, which has been restructured and further supplemented:

\section{- Lower cost:}

- Instead of having to bear the cost of constructing and maintaining a program by themselves, the partner companies can share the development, promotion, communication, and other administrative costs. As far as development costs are concerned, Clark \& Clark added that these are in practice sometimes covered by the third-party operator of the program (possibly with the support of a venture capitalist, as it was the case with Nectar in the UK), increasing the operator's freedom from the partner companies, but decreasing the degree of commitment by coalition members. With regard to the lower individual promotional costs it can be added that this constellation allows for more frequent and coherent promotional activities.

- In addition to that, having a third party develop the scheme will prevent the capacity of existing partner company staff from being consumed.

- Finally, these generally larger programs are often able to exploit economies of scale when purchasing the rewards that are to be distributed to consumers. Passing this benefit on to the customer can naturally help to increase the perceived value of the rewards.

\section{- Card more likely to be carried:}

- As only one card needs to be carried for use at several different companies, the often-cited problem of limited wallet space becomes less of an issue.

- This is even more important as cards carried in the wallet are more likely (if not a precondition) to be used. In this regard, In-Store (2008) reported results from a study finding that over a third of customers felt they had too many cards to carry, with another $27 \%$ plagued by regularly carrying the wrong card when making a purchase. In Germany, for example, TNS Emnid (2006) found that the Payback coalition card was carried by $32 \%$ of Germans in their wallet at all times, coming only behind a bank card and the health insurance card (and thus, together with a credit card at tied third place). By comparison, the stand-alone card carried by the highest percentage of respondents was that of a major food retailer, the REWE Haushaltskarte with $9 \%$. 


\section{- Better and faster rewards for the customer:}

- Due to the possibility of collecting points at different companies, coalition schemes allow for faster points accrual. Consequently, it becomes easier for customers to earn enough points for a bigger, more aspirational reward. While the regular purchase behavior would, for instance, amount to a total of four small rewards at the patronized grocery, fuel, sporting goods, and drug retail chains if they each operate a separate scheme, pooling these expenses with a single multi-partner program could add up to one big reward for the customer.

- Furthermore, as compared to a single stand-alone program, the time it takes until the reward can be redeemed will be significantly lower when several partners of a coalition scheme are patronized.

- Since coalitions are usually much bigger in size than stand-alone programs, they can offer a greater choice of rewards to the consumer. When selected according to the product assortment of the program partners, a broader selection of rewards might even satisfy both the customer's desire for variety and at the same time exploit the often-mentioned positive effects of offering firm-related rewards (in this case at least within the circle of partners). Dowling \& Uncles (1997), for example, argued that handing out rewards unrelated to the firm could become a problem for low involvement products, as the reward might turn into the primary incentive to buy the product. Once the reward was copied by a competitor or simply taken away, the main purchase reason would disappear. In the case of coalition schemes, however, companies could offer rewards related to any of the coalition members' products or services, with the program offering protection to the firms from competitive moves.

\section{- Improved pool of data:}

- Limited by national data protection legislation as well as data protection agreements among program sponsors, the operating company of a coalition has access to a much broader and richer data set than that of a standalone program, due to the availability of a purchase history which covers different retail sectors. Consequently, it might, for instance, be possible to segment customers not only by what they bought at the grocery store, but by their purchase behavior displayed in a whole range of retail sectors.

- Moreover, the database is more likely to be run by dedicated professionals, as data management and analysis is a core element of the coalition operator's business. While that, of course, does not mean that the same level of professional standards could not be found in a firm running a stand-alone scheme, it is simply less likely to be the case. 
- Ability to increase the customer base of every program sponsor:

- As loyalty coalitions are usually made up of a range of prominent representatives from different retailing sub-sectors, customers might be persuaded to redirect their share-of-wallet to the chain of a program member, after previously having collected points at some of the other sponsors.

- This effect could be supported by special coalition marketing campaigns. Clark \& Clark (2009) reported an example from the Canadian franchise of Air Miles, which had once offered a 50\% reduction in miles required for a free flight to every customer who had collected points with at least five coalition sponsors.

\section{- Higher penetration rate:}

Coalitions can often boast a quick achievement of a high customer penetration rate through broad appeal, a generally higher media presence, as well as the other advantages benefiting customers. For example, Clark \& Clark highlighted that UK's Nectar had signed up more than 11 million members within 12 months and 13 million within 18 months following its launch (which corresponds to a penetration rate of around $21 \%$, given a total population of roughly 61 million people). By comparison, Germany's Payback (2001) reported 10 million active cards 16 months after launch (equating to a $12 \%$ penetration rate based on a total population of around 82 million). Apart from coalitions, such high numbers can really only be achieved by very large and long-standing stand-alone programs.

- Generation of appeal for a wider range of companies:

Particularly firms offering products characterized by a low purchase frequency might be more successful participating in a coalition program than operating a stand-alone scheme. While it might become a problem that customers will not maintain interest in a stand-alone scheme, this issue would likely be mitigated in the case of a coalition. In addition to that, Clark \& Clark (2009) noted, customers used to collecting low point volumes often look forward to scoring a big chunk of points at once.

- Firm-related benefits through industry exclusivity:

Another point that makes coalitions appealing to organizations is the possibility of keeping the program sector-exclusive. This practice is employed by most retailing coalition schemes, giving the first firm to enter exclusivity within its sub-sector. Once the program reaches a high level of penetration, this could even act as a source of competitive advantage.

\section{- Greater simplicity for the customer:}

Due the fact that only one account needs to be tracked and taken care of, complexity for the customer is reduced to some extent. 


\subsubsection{Disadvantages}

Coalition schemes boast several advantages, but this does not mean that they are free from disadvantages. Naturally, there are downsides associated with these schemes as well. The following list aims to cover the most important ones (Humby et al. 2008, Clark \& Clark 2009):

\section{- Issues regarding ownership of data:}

Similar to consumers, partner companies of coalition schemes might also be concerned by privacy issues. In this case, the concern revolves around company-related data being handled by a third party. Adding up to this is the fact that each company's data is pooled together with that of other companies. Within every loyalty coalition, there will be contracts dealing with the topic of data ownership. Clark \& Clark reported that for retailers, article-level basket data is typically both held and owned by the partner companies. Therefore, coalition operators would only hold customer information and data on the number of points collected by location and date. In practice, however, it differs from case to case whether coalitions really do not have access to detailed purchase histories, particularly to undertake valuable inter-industry customer segmentations based upon buying behavior. At any rate, the issue of data ownership is definitely a significant one. For instance, Nicolai (2003) reported that the negotiations between Shell Germany and the coalition scheme Payback failed because the fuel retailer did not want to leave control over customer data to a third party. It needs to be added, however, that Shell was at that time operating its own loyalty scheme and that negotiations only took place because Shell took over the German DEA chain, which was then part of the Payback coalition. Given this scenario, it might be argued that the outcome was predetermined to a certain extent. In addition to that, Nicolai wrote, Shell was unwilling to give up the flexibility that only its own scheme could provide.

\section{- Target of customers' loyalty unclear:}

In case of coalition schemes, the question remains whether customers are actually becoming loyal to the partner company or to the program instead. In other words, it is unclear whether the link between customer and program sponsor is strengthened at all. An interesting report on this problem comes from Humby et al. (2008), who described the switch of the UK's grocery retailer Sainsbury's from the long-established Air Miles coalition to the then new Nectar coalition in 2002. Upon this change, Tesco decided to take Sainsbury's space in Air Miles and allowed for a conversion of its own Clubcard points to Air Miles. A week into the new partnership, Tesco claimed to have experienced a $450 \%$ increase in the use of its online store finder and a $300 \%$ increase in enquiries about home shopping. Furthermore, Tesco de- 
clared that one million new Clubcards were distributed. Ultimately, Humby et al. (2008) pointed out, Sainsbury's attributed a loss of $1 \%$ of sales volume to the decision to leave Air Miles - equal to what the authors calculated to be around 60,000 valuable customers lost to Tesco. On the one hand, this shows that coalition schemes really do work in creating lock-in with a range of customers, but on the other hand it also shows that for some consumers this lock-in relates to the program and not the company. What is particular about this situation is that the change was not from one existing to another existing coalition, but one from an existing to a new one. In such a constellation, there is no opportunity to immediately replace the lost customers with members from the new coalition. Still, since its launch, Nectar has long overtaken Air Miles in terms of the number of collectors and it can very well be argued, that Sainsbury's has meanwhile had a chance to compensate for this loss (Johnson 2002 reported that Air Miles had 6.5 million members in 2002; by contrast, Clark \& Clark 2009 stated that Nectar had signed up 11 million members within a year from its launch). In fact, Loyalty Management UK, the company administrating the Nectar scheme, reported that it overtook Air Miles in terms of active cardholders within four weeks from its launch (Voyle 2002).

\section{- Loss of control for program sponsors:}

Naturally, every company joining a coalition scheme as a partner will have to give up some control. Humby et al. (2008) highlighted that this will reduce the chance to quickly introduce tactical marketing initiatives and limit innovation, because all decisions have to be agreed on by the program sponsors. While this might be of particular concern for program-wide changes or marketing campaigns, this will be less significant for individual, companyspecific promotions. Still, as far as program-specific activities are concerned, the different sponsors will have to cooperate even when their agendas and priorities differ. In addition to that, involvement in the general program design will also be limited and the ability to "bind the program in to the business," which Humby et al. considered to be such an important feature for Tesco, constrained.

\section{- Imbalance concerning partner contribution:}

One problem that might arise is that some of the program partners will become net contributors to the program, while others become net beneficiaries. In other words, some companies might distribute more point value than customers spend at their outlets, while the opposite situation might be given for other program sponsors. While this is a fairly natural situation, it can be expected that coalition operators have measures in place to adjust for this imbalance. 


\section{- Coalitions virtually impossible to pilot:}

Due to specificities inherent to program structure, coalitions are pretty much impossible to pilot on a small scale. In order to work properly, multi-partner schemes require a certain size and, in case of retailing programs, sector coverage.

\section{- Bad experiences with program attributed to sponsors:}

When a customer encounters a problem with the coalition scheme that is located within the scope of the operator (e.g. points were not accredited, long waiting time in the customer service hotline, etc.), these negative experiences might be attributed to the program sponsors.

- Expanding grocers limit space for new partners:

A final point brought forward by Clark \& Clark (2009) is that grocers in many countries have started to expand their activities not just into the retailing of other non-food items, but also into other non-retailing sectors such as financial services. Since, however, a food retailer is essential to any retailing coalition as it brings the necessary purchase frequencies with it, this might (together with the usually present exclusivity agreement) restrict the coalition in terms of the other partners it can select.

\subsection{Success Factors}

As with all other aspects of coalition schemes, research is scarce on this subject. Despite lacking empirical proof, Clark \& Clark's (2009) list of four success factors associated particularly with coalition schemes shall nevertheless be reproduced here as it still represents a valuable contribution (see also Furinto et al. 2009 for a different approach to the subject). Certainly, there are other variables contributing to success as well, but the ones mentioned here might serve as a basic guideline.

Firstly, operators of a coalition scheme need to make sure that a high rate of penetration is reached fairly quickly. Most of the big programs have adhered to this principle and made sure that a major player from each key sector in retailing and possibly also financial services was on board to build up turnover right from the beginning. Furthermore, details were usually kept secret during the planning phase, possibly with a few bits of information leaking out towards launch date to build momentum. The launch itself, then, was accompanied by a massive media campaign to create awareness and immediately sign up a large number of new members.

Secondly, particularly in the case of coalition schemes, being first is a significant advantage. Not only will the second player in the market have lost his chance to sign up the most suitable partners (i.e. generally each sector's market leader), but in addition to that, customers will already have started to patronize one 
scheme and might have become locked in or be unwilling to join a second scheme. For instance, Payback was launched as Germany's first coalition in March 2000. The second biggest player on the market today is HappyPoints, which was introduced as the loyalty program of the telecom provider Deutsche Telekom in October 2001 and expanded into a comparable, classic retail-oriented coalition in the years thereafter. Possibly the lack of first mover advantage combined with the lack of a big launch with many partners right from the beginning were what has kept the program in second place ever since. According to a study by GfK (2007) covering 8,000 households, in September 2007 60.8\% of German households held a Payback card, while only $41.8 \%$ possessed a HappyPoints card.

Thirdly, coalitions need to make sure that they offer aspirational rewards that can be earned in a reasonable amount of time. As was mentioned before, this factor is one of the big advantages of multi-partner programs and its operators should make sure not to give that edge away.

Finally, coalitions need to emphasize the right choice and a suitable standard of communication channels. Pooling all program-related communication at the operator creates cost advantages, but at the same time, any negative experiences at the operator's customer touch points might fall back on the partner companies.

\subsection{Impact, Spread, and Customer Perception}

The number of academic papers on this subject is fairly limited. Out of the 23 studies on the success impact of loyalty schemes that were reviewed in Chapter 2.3, only one dealt with a coalition scheme. In their evaluation of the Australian FlyBuys coalition, Sharp \& Sharp (1997) observed a trend towards a weak level of excess loyalty, although the expected deviation was not consistently observed for all program sponsors under review. In fact, only two of the six participant brands showed substantial excess loyalty deviations and even this variance in repeat-purchase loyalty was observed for both members and non-members of the coalition. The authors explained these findings at least partly as the result of other loyalty efforts. In the end, then, Sharp \& Sharp's study can be categorized as one supporting those who claim that it is very difficult for loyalty schemes to alter customers' purchase patterns. The overall majority of evidence points in the opposite direction, however. As was previously discussed, it is clearly possible for loyalty programs to alter purchase behavior, at least to a small degree. Ultimately, it probably boils down to the same problem observed with other studies on the effectiveness of loyalty schemes: the definition of success. Sharp \& Sharp themselves noted that "... the results are mixed" and that "the markets [...] remain close to 'normal' repeat purchase markets after the introduction of the 
loyalty program" (p. 483). Things did not look the same before and after program launch, but were observed to be "close to" normal. Without changing the content of this statement, one could easily rephrase this to resemble the conclusion drawn in Chapter 2.3: the loyalty programs caused change, but on average only to a small extent.

Moore \& Sekhon (2005) conducted a more recent study of coalition schemes by administering a survey of 153 members of the UK's Nectar program. The authors posed a range of general questions relating to a wide range of topics such as customers' scheme-related knowledge or use of the card, and attempted to draw conclusions on the program's success in influencing behavior. Due to the similarity of this study's goals at least to the general questionnaire part of the present work, findings will be reviewed in greater detail. The following points were discovered by the authors:

- Customers were generally satisfied, found the scheme easy to understand, convenient and easy to use, reliable, and trustworthy (although the level of trust remained at a basic level), and were happy with the service.

- Respondents preferred financial rewards when asked directly, though particularly aspirational rewards created high levels of involvement, resulting in customers taking on what the authors described as "a role of planners," saving 2-3 times more points than people with low involvement.

- Program members valued the fact that they were able to collect more points at a quicker rate.

- Contact between the program and its members was found to be limited, with communication being confusing, complicated, and thereby discouraging attention.

- Despite a high level of targeted communication, respondents still felt that their expectations were not met in that regard.

- Customers found no differentiation between Nectar and its competitors.

- Except for the major retailer (i.e. most likely the grocery chain Sainsbury's), consumers exhibited a clear lack of awareness as far as other program sponsors are concerned. This resulted in many customers perceiving the scheme to be that of the lead retailer.

- $97 \%$ have never had problems with the program.

- No special treatment as a result of being a program member was experienced by customers.

- The card was used with the majority of transactions with the two biggest retailers, while usage figures were clearly lower with the other coalition sponsors. 
- The rate of redemption for acquired points was described as low by the authors (and not further defined).

- Customers usually carried competitive cards as well and appeared to be using the scheme out of habit and not so much because of a preference for the program.

Apart from a few exceptions such as that of poor communication, use out of habit, or a lack of knowledge of program sponsors, it seems fair to say that the outcome is generally what can be expected from coalition schemes. A good part of this study's abstract nevertheless leaves the reader with a rather grim feeling about coalitions. At the same time, however, the authors titled their article "Multi-Brand Loyalty Cards: A Good Idea" and closed their summary stating that “... there is evidence to suggest consumers perceive real benefits in coalition schemes and that there is a willingness to alter their behavior if the motivation is sufficient" (p. 625).

The importance of rewards as a motivator has already been discussed in previous sections of this paper, with its last point of mention in Chapter 4.3 on success factors associated with coalition schemes. Lara \& De Madariaga (2007) dealt with this topic in a study focused exclusively on multi-sponsor programs. In their telephone survey of 521 members and 540 non-members of Spanish coalition schemes, the authors attempted to shed some new light on the research subject of loyalty rewards. Among a range of different elements associated with coalition schemes (e.g. number of participating companies, effort, exclusiveness, etc.), rewards were singled out as the most important factor by both members and non-members. As far as the type of reward is concerned, an association of satisfaction with intangible amusement rewards (e.g. games, raffles, etc.) and services was noticed for non-members and one with discounts and intangible amusement rewards for members. Particularly ecology and charitable rewards were found to be a very attractive element of the reward structure, which has long been disregarded in practice. Furthermore, the authors highlighted the importance of tailoring reward types to consumers and the goal the company tries to achieve. For instance, Lara \& De Madariaga found that intangible amusement rewards would be particularly useful to acquire new participants, while rewards relating to benefits such as exclusiveness or special preference could help to strengthen the present member base.

Next to academic papers, studies by market research specialists serve as another source of information on coalition schemes. A notable contribution in this category comes from TNS Emnid (2006), which posed a range of general questions to a sample of 1,000 consumers. Despite having been commissioned by the German Payback coalition and therefore calling for a healthy bit of caution (particularly 
in relation to what questions were asked and how the outcome is presented), the findings might nevertheless be useful:

- When respondents were asked about the type of cards carried in their wallet at all times, the bank card finished first with a penetration rate of $82 \%$, followed by the health insurance card with $77 \%$, and the Payback card together with a credit card tied at third place with $32 \%$. The card of the second largest German coalition HappyPoints was carried by $15 \%$ of people, with cards of stand-alone programs failing to surpass the $10 \%$ mark.

- Consumers were further confronted with a list of loyalty program names and asked which ones they know by name. $80 \%$ answered that they had heard of Payback, $50 \%$ were familiar with HappyPoints, $41 \%$ with the Family card of the Swedish furniture retailer Ikea, and 39\% with the Lufthansa Miles \& More frequent flyer program. With the exception of Ikea's Family card, no stand-alone program managed to surpass the $35 \%$ mark.

- Requested to judge the importance of a range of loyalty scheme features, $76 \%$ found the ability to use the card at different shops to be either very or rather important. That it offers services, special offers, or advantages the customer does not have access to without the card followed with $63 \%$ and that it offers coupons which provide savings and advantages upon purchase as well as access to a wide range of reward types followed with a tied $51 \%$. Having access to a reward within a short amount of time was judged very or rather important by $46 \%$ of survey respondents, the card being usable for online shopping by $43 \%$, that rewards exclusive to the program are available by $38 \%$, that the card offers a payment function by $22 \%$, and that it offers a credit card function by $12 \%$.

- Asked directly whether their purchase behavior has changed since they became a member of the respective loyalty scheme, 34\% said they buy/book more flights and $38 \%$ that they are more likely to buy/book flights since joining Miles \& More. The values for Payback in these two categories ("buy/book more" and "buy/book more likely") came in at $26 \%$ and $32 \%$, these for the program of the perfumery chain Douglas at $25 \%$ and $35 \%$, for HappyPoints at $20 \%$ and $30 \%$, for the Haushaltskarte of the grocery retailer REWE at $20 \%$ and $26 \%$, and for the Ikea Family card at $9 \%$ and $18 \%$.

- Finally, respondents were questioned as to which one of the nine programs presented in a list gave them the biggest personal benefit. Payback came in a clear first with $34 \%$, followed by HappyPoints with $7 \%$ and the Ikea Family card, Miles \& More, as well as bahn.comfort (a point-based frequent traveler scheme of the German railway company Deutsche Bahn) with 6\% each. Four other stand-alone programs attracted the favor of between $1 \%$ and $5 \%$ of respondents, 
complemented by $12 \%$ stating that none of the programs would give them personal benefit and $18 \%$ saying that they do not know.

Within the range of findings presented by TNS Emnid, Payback scored a conspicuously high number of first and second places. Given that the study was commissioned by Payback's operator Loyalty Partner, it seems fair to challenge the survey's outcome in a few regards. A very obvious point is the question asking people to judge the importance of a range of loyalty scheme features. Coming even before items such as the program's ability to provide savings and benefits, the possibility to use the card at different shops took a surprising first place (and this characteristic is, after all, a great advantage of Payback). Leaving aside the issue of whether respondents might have been confused as to whether the question really meant different companies or simply different stores from the same chain, this ranking is most likely explained by the fact that both the answer category "very important" and "rather important" were combined in generating it. In other words, it is not unlikely that, as opposed to the ability to use the card at different shops, a much bigger percentage of respondents judged the rebate function to be very important. In addition to that, it remains unclear why this specific range of programs was chosen for the list to be presented to respondents and whether the findings presented were not simply a flattering selection. Nevertheless, given an appropriate sense of caution, these findings still provide a few interesting insights, for instance, supporting the general view that multi-partner schemes are able to reach a much higher penetration rate than stand-alone programs.

This fact is also supported by further research on behalf of the Payback operator Loyalty Partner. GfK (2007) investigated the possession and use of loyalty cards in Germany by surveying 8,000 households. As mentioned in Chapter 4.3, in September 2007 60.8\% of Germany's 34.3 million households held a Payback card. By comparison, $41.8 \%$ possessed a HappyPoints card, $11.7 \%$ a Shell Clubsmart card, and $8.7 \%$ a Lufthansa Miles \& More card. As far as the use of these loyalty programs is concerned, $56.5 \%$ of respondents stated that they always use their Payback card, while $32.4 \%$ did so with their HappyPoints, $44.7 \%$ with their Clubsmart, and 30.9\% with their Miles \& More card. In addition to that, another $38.5 \%$ used the Payback card occasionally, 54.7\% did so with their HappyPoints card, $38.7 \%$ with their Clubsmart, and $49.7 \%$ with their Lufthansa Miles \& More card. What remains unclear is whether these usage rates refer to category spending or simply use with the program operators or, in case of coalitions, their partners. After all, a rate of only around 31\% showing their Miles \& More card on every flight taken with Lufthansa seems very low. By contrast, it seems more likely that Miles \& More members were using their card on virtually every flight with Lufthansa, but that they selected this airline for only $31 \%$ of 
their flights. Further background information on this issue is not provided, but one thing is in any case certain: among the programs surveyed, customers of Germany's largest coalition Payback showed the highest rates of both possession and usage.

\subsection{The Next Evolutionary Step?}

As was mentioned in the introduction to this Chapter 4, several academics and practitioners consider coalition schemes to be some sort of evolutionary step. Naturally, this program type has drawbacks as well, but overall, advantages were often found to overweigh.

What is so striking, then, is the blatant deficit of literature on this topic. Some ground is covered by studies from market research organizations (usually commissioned by coalition operators, however; e.g. TNS Emnid 2006 or GfK 2007) and in fact, some of the academic literature has also been written by practitioners from research organizations (e.g. Capizzi \& Ferguson 2005 or Ferguson \& Hlavinka 2006). Next to a few current or former practitioners (e.g. Humby et al. 2008 or Clark \& Clark 2009), the truly academic view on coalition schemes remains extremely limited (and includes only a handful of publications such as those by Sharp \& Sharp 1997 or Lara \& De Madariaga 2007). At best, authors from an academic background have mentioned examples of coalition schemes in the course of a study on a different aspect of loyalty schemes (e.g. Stone et al. 2004 referring to UK's Nectar coalition in a general evaluation of loyalty schemes or Rowley 2005 in a case study of Tesco's Clubcard).

Scientific information on this topic is consequently still scarce, with unbiased, empirical evidence of the purported superiority of coalition schemes still outstanding. For that reason, this paper will attempt to contribute another, muchneeded piece to this puzzle with the following empirical section. 


\section{Empirical Study Design}

Within Chapter 5, an overview of the study configuration will first be given (Chapter 5.1), followed by a description of the preparatory work necessary to conduct this research endeavor. The first steps in developing a conceptual framework will be discussed (Chapter 5.2) together with an elaboration on potential theoretical reference points for hypotheses formulation (Chapter 5.3). Lastly, the finalization of the conceptual framework (Chapter 5.4) and the process of construct operationalization will be examined (Chapter 5.5).

\subsection{Study Configuration}

To answer the research questions outlined in the introductory chapter to this paper, this study on customer loyalty schemes in retailing relied on both an empirical qualitative as well as an empirical quantitative component (see Figure 14). As was discussed in detail in Chapter 1.2, Germany was selected as the place to conduct this research, with the focus being put on the fuel retailing market. To be precise, Aral (as a partner company of Payback - Germany's biggest multipartner program) and Shell (with the industry's major stand-alone scheme Clubsmart) were selected as two subjects of study that ensure good comparability due to their similarities in terms of size and strength.

In Chapter 5.1.1, the qualitative aspect of the study will now be described, with an elaboration of the quantitative element following in Chapter 5.1.2. 

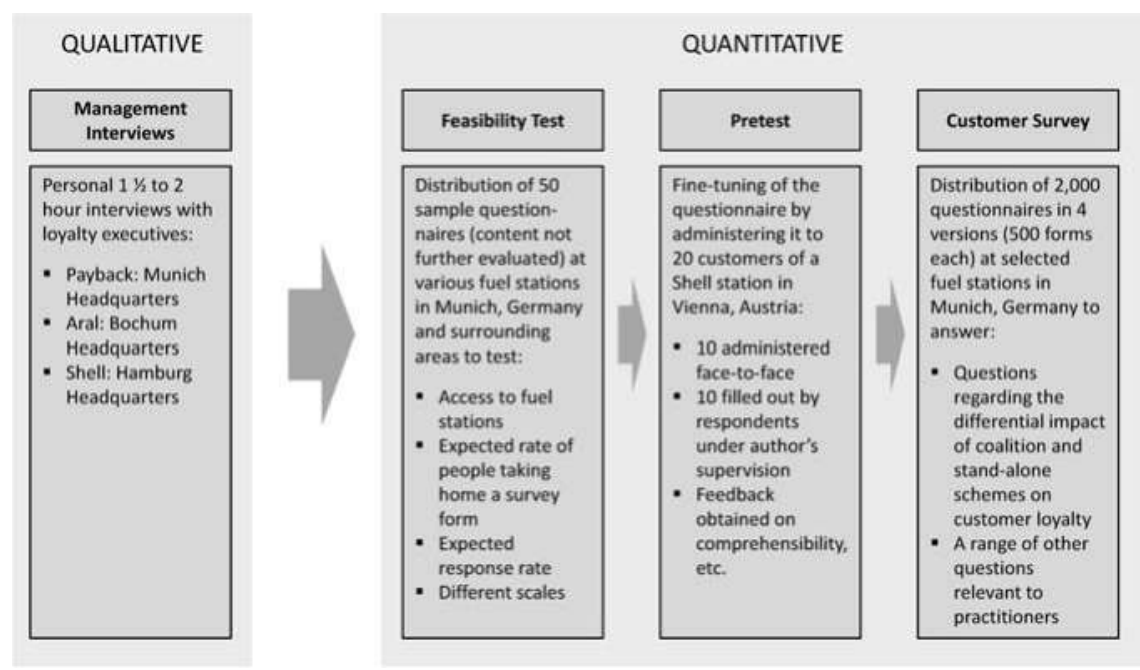

Figure 14: Overview of the Study's Qualitative and Quantitative Components

\subsubsection{Qualitative Component}

First, qualitative interviews were conducted with the management of the Payback coalition, as well as Aral's and Shell's loyalty department prior to the main quantitative survey. While this certainly had the side-effect of helping the formation of the study framework, the main goal of this exercise was twofold: (1) to assist the formulation of questions relevant to practitioners and (2) to hear about these loyalty executives' views and decisions regarding their programs. Hereby, the following managers were interviewed over a period of 1.5 to 2 hours each:

- Payback: Walter Lukner, Chief of Payback Partner Management, interviewed on location at the Payback headquarter in Munich on 04 June 2009.

- Aral: Björn Schaaf, Loyalty Campaign Manager, interviewed on location at Aral Germany's headquarter in Bochum on 21 July 2009.

- Shell: Jan-Christian Kempin, Loyalty Marketing Manager D-A-CH (Germany/ Austria/ Switzerland), interviewed on location at Shell Germany's headquarter in Hamburg on 07 October 2009.

Next to other company-specific issues, the following topics were discussed during these interviews: advantages and disadvantages of multi-partner and stand-alone schemes, ability of loyalty programs to alter customer behavior, ability to alter customer attitude, goals of the program, success measurement and indicators 
used, specific effects of loyalty schemes at the interviewees' companies, financial cost (multi-partner solution compared with a stand-alone program created from scratch, a stand-alone version adapted from an existing scheme in a foreign market, and regular promotions), co-determination rights of program sponsors in a multi-partner platform, specifics of data analysis (level of detail for analyses, outsourcing of analyses, ownership of data, privacy issues, departments that profit from customer data, etc.), use of promotions parallel to operating a loyalty program, success factors for creating a loyalty scheme, ease of copying a program, reasons for choice of loyalty scheme type (in Germany and other markets), use of partnerships in loyalty schemes, differences between industries and companies of different sizes, penetration rates of the program, number of employees, and thoughts about tiering.

Subsequently, the quantitative component of this study was taken on and open questions emanating from these interviews - in part to challenge the established, sometimes contrary views of the interviewed loyalty managers - were taken up.

\subsubsection{Quantitative Component}

To generate the data necessary to contrast the effect of multi-partner and standalone schemes on loyalty, a consumer survey was selected as the appropriate research method for the study's quantitative component. The reasons behind this decision will be laid out in the following sub-section, followed by a brief discussion of sampling as well as a section describing the two test-runs preceding the consumer survey.

\section{1) Reasons for Choosing a Consumer Survey}

The decision to administer a questionnaire to consumers was taken in a twostage approach: first, the established literature on the success of loyalty programs was reviewed in respect of the method employed. In a second step, the advantages and disadvantages of each approach were summarized, and keeping the goals of this study in mind, the decision was made to use a consumer survey.

The literature review comprised the 23 publications analyzed in Chapter 2.3. As seen in Figure 15, surveys and company data served as the dominant methods of data collection, with each one employed in around one third of these investigations. Panels, diary studies, and experiments followed at considerable distance, being used in only around $14 \%, 11 \%$, and $4 \%$ of these studies, respectively. 


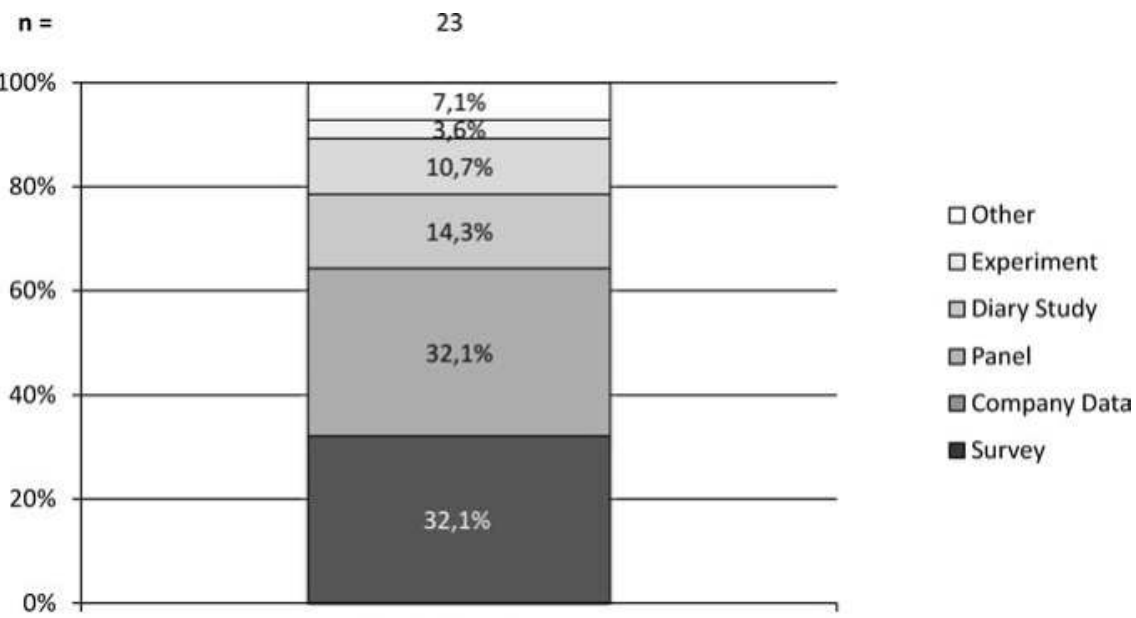

Research Method

Figure 15: Research Methods Used in Loyalty Scheme Success Research

It needs to be noted beforehand, however, that next to the previously mentioned success research component, the study also aimed to answer a range of practically relevant questions. For that reason, a survey element was deemed unavoidable in any case. The comparison of advantages and disadvantages featured in Table 8 was thus primarily undertaken to decide whether to add an additional source of data. Apart from issues revolving around gaining access to company data, the fundamental problem associated with this approach is that despite offering an accurate data set, information will be limited to purchases made with that company. As, however, share-of-wallet will be used as an indicator of behavioral loyalty (see Chapter 5.5), and furthermore, a control group with no loyalty program membership was to be addressed, company data dropped out of the race. As far as household panels are concerned, the two big players active in the German market were consulted via telephone. Unfortunately, both Nielsen and GfK do not collect data on loyalty schemes anymore (while previously only ownership of a small range of cards was captured, without matching these to the purchase acts). Developing a separate diary study would, of course, have been an option to reduce the reliability problems inherent in survey designs. Still, this alternative was dismissed due to the enormous effort a diary study with a significant amount of participants would have required, particularly because the potential benefits were not perceived to justify these efforts (and given, also, that a survey was to be conducted either way). Eventually, an experimental setup was rejected due to concerns about problems connected with its theoretical setting. In addition 
to that, an experimental setup would have required a different study design and corresponding research questions in the first place.

\begin{tabular}{|c|c|c|c|c|c|}
\hline & Survey & Company Data & Panel Data & Diary Study & Experiment \\
\hline+ & $\begin{array}{l}\text { Essential to } \\
\text { answer whole } \\
\text { set of ques- } \\
\text { tions } \\
\text { - When work- } \\
\text { ing with com- } \\
\text { pany data, ne- } \\
\text { cessary to } \\
\text { supplement } \\
\text { information } \\
\text { on competi- } \\
\text { tors }\end{array}$ & $\begin{array}{l}\text { Offers access } \\
\text { to an accurate } \\
\text { record of } \\
\text { purchase } \\
\text { transactions } \\
\text { (where the } \\
\text { loyalty card } \\
\text { has been } \\
\text { used) }\end{array}$ & $\begin{array}{l}\text { - If available, } \\
\text { features } \\
\text { access to an } \\
\text { accurate } \\
\text { record of } \\
\text { purchase } \\
\text { transactions } \\
\text { across com- } \\
\text { petitors }\end{array}$ & $\begin{array}{l}\text { If available, } \\
\text { features } \\
\text { access to an } \\
\text { accurate } \\
\text { record of } \\
\text { purchase } \\
\text { transactions } \\
\text { across com- } \\
\text { petitors }\end{array}$ & $\begin{array}{l}\text { - Allows for } \\
\text { the evaluation } \\
\text { of a range of } \\
\text { scenarios in a } \\
\text { well-control- } \\
\text { led setting }\end{array}$ \\
\hline - & $\begin{array}{l}\text { Declarative } \\
\text { survey data } \\
\text { suffers from } \\
\text { reliability } \\
\text { issues }\end{array}$ & $\begin{array}{l}\text { - Allows for } \\
\text { only limited } \\
\text { use of com- } \\
\text { petitive infor- } \\
\text { mation about } \\
\text { purchase } \\
\text { behavior } \\
\text { - Does not } \\
\text { provide } \\
\text { access to } \\
\text { control group }\end{array}$ & $\begin{array}{l}\text { - Aggregated } \\
\text { panel data } \\
\text { does not take } \\
\text { customer he- } \\
\text { terogeneity } \\
\text { into account } \\
\text { - Unavailable } \\
\text { for Germany } \\
\text { at both of the } \\
\text { large panel } \\
\text { operators }\end{array}$ & $\begin{array}{l}\text { - Lengthy and } \\
\text { complex data } \\
\text { collection } \\
\text { process } \\
\text { - Bad ratings } \\
\text { in terms of } \\
\text { "cost-benefit } \\
\text { ratio" }\end{array}$ & $\begin{array}{l}\text { - Suffers from } \\
\text { limitations } \\
\text { due to the } \\
\text { theoretical } \\
\text { nature of an } \\
\text { experimental } \\
\text { setup } \\
\text { - Unfit to fulfill } \\
\text { the require- } \\
\text { ments of the } \\
\text { planned study }\end{array}$ \\
\hline Verdic & & & & & \\
\hline
\end{tabular}

Table 8: Advantages and Disadvantages of Possible Research Methods

Naturally, other methods are also thinkable, but were not considered in the comparison of advantages and disadvantages due to their underlying inability to answer the research questions evaluated by this study. In addition to that, they also proved unfit for application in previous success research, except for very few, special cases. As for the chosen survey method, associated reliability issues certainly constitute a limitation. Compared with the alternatives, however, a survey was still considered to be the best option.

Following the choice of what survey design to employ, the next question was what kind of survey to use. In this respect, the decision was made to approach respondents in person at selected fuel stations of the respective chains and to hand them the questionnaire with a self-addressed, postage-paid envelope to fill out at home. This procedure was chosen for the following reasons: 
- The notoriously low response rate to mail surveys was expected to be optimized by personal contact and the commitment given to take a questionnaire home.

- A take-home survey was considered likely to yield a higher response rate as compared to face-to-face interviews. Especially at a fuel station where people generally do not wish to lose much time, customers would have been unlikely to participate in a comprehensive survey on location.

- Other communication channels (e.g. internet survey, telephone survey, etc.) would not have provided such an efficient access point to potential respondents (i.e. customers of Aral or Shell fuel stations, with or without loyalty card membership).

\section{2) Sampling}

Respondents in the different sampling groups were directly approached at specifically selected fuel stations, which represents a quota rather than a convenience sample. With true national representativeness not being the goal of this study and to avoid interference from further covariates, Munich was chosen as the single place to hand out the survey forms. Within the city itself, access to fuel stations was kindly provided by Aral and Shell, as well as the respective tenants. Consequently, almost every Aral and Shell station within the city's boundaries was visited and their adequacy as a location evaluated. The main criteria underlying this evaluation were customer frequency, geographic location, proximity to an autobahn onramp, and heterogeneity of the customer base. Following this assessment, two Aral and two Shell stations (in each case with one in the northern and one in the southern part of town) were selected as the places to hand out the questionnaires:

- Aral, Garmischer Straße 138, 80807 Munich, Germany

- Aral, Tegernseer Landstraße 174, 81539 Munich, Germany

- Shell, Leopoldstraße 140, 80804 Munich, Germany

- Shell, Liesl-Karlstadt-Straße 25, 81476 Munich, Germany 


\begin{tabular}{|c|c|c|}
\hline & Aral AG & Shell Deutschland Oil GmbH \\
\hline Sample Type & \multicolumn{2}{|c|}{$\begin{array}{c}\text { Quota sample } \\
\text { (subjects approached at the fuel station) }\end{array}$} \\
\hline Survey Groups & $\begin{array}{l}\text { - Group 1: Aral customers with } \\
\text { loyalty program membership } \\
\text { (Payback) } \\
\text { - Group } 2 \text { (control group): Aral } \\
\text { customers without membership }\end{array}$ & $\begin{array}{l}\text { - Group 3: Shell customers with } \\
\text { loyalty program membership } \\
\text { (Clubsmart) } \\
\text { - Group } 4 \text { (control group): Shell } \\
\text { customers without membership }\end{array}$ \\
\hline Sample Size & \multicolumn{2}{|c|}{$\begin{array}{l}500 \text { questionnaires per group handed out } \\
=\mathbf{2 , 0 0 0} \text { questionnaires in total }\end{array}$} \\
\hline
\end{tabular}

Table 9: Sampling Approach

At each fuel station, customers were approached while waiting for their vehicle to be filled up and asked personally by the study author whether they wanted to participate in an anonymous survey for a doctoral thesis on loyalty schemes and fuel-related purchase behavior. For each fuel retailer, two questionnaire versions were procured: one for customers with loyalty program membership (four pages in length; see appendix) and one for customers without program membership (three pages in length; see appendix). For each of these two groups at each of these two fuel retailers 500 questionnaires were provided, resulting in a total of 2,000 distributed survey forms. As for the time of this distribution, three nonconsecutive periods of 6, 5, and 4 days respectively were chosen in March 2010 with attendance at the fuel stations between around 7 a.m. and 8 p.m. Alternation between the selected locations took place on a regular basis in an attempt to minimize the potentially disruptive effect of different weekdays, the weather, or the time of the day.

\section{3) Feasibility Test and Pretest}

Prior to the actual consumer survey, a feasibility test was conducted. In order to evaluate access to fuel stations, to test different scales, to estimate the number of people who take home a survey form, and to get a feeling for what response rate to expect, 50 sample questionnaires were distributed to Payback members at a range of Aral fuel stations in and around Munich on 04 June 2009. These survey forms were handed out in the same manner as the main consumer survey was intended to take place (i.e. handed out along with a self-addressed, postage-paid envelope). Compared to the main survey, the appearance of these forms was less professional, however (e.g. in terms of graphical layout or use of simple white envelopes, instead of envelopes with the university logo), and furthermore, they 
were shorter in length. Taking this into account, the response rate of exactly $50 \%$ was nevertheless surprisingly high. Overall, the feasibility test led to two things: (1) the decision to proceed with the described way of administering the questionnaires also in the main consumer survey and (2) the refinement of the scales to be used (e.g. with respect to capturing declarative survey data such as shareof-wallet).

After the draft of the final questionnaire had been created by adhering to the standards of marketing research (e.g. Black 2005) and naturally taking all advice such as that by Temme et al. 2009 for an optimal measurement method into account, the obligatory pretest took place on 25 February 2010 at a Shell station in Vienna (Heiligenstädter Straße 60, 1190 Vienna, Austria). Altogether, 20 questionnaires were completed -10 of them in a face-to-face interview and 10 by the respondents themselves under the author's supervision. As far as the selection of participants is concerned, it was ensured that both male and female, as well as participants with different social backgrounds (which, despite the limitations associated with this approach, had to be judged by observing external appearance) were represented in the small convenience sample. While the surveys were filled out, behavior was observed (e.g. where respondents hesitated, etc.) and the elapsed time recorded. After the survey form was completed, the participants were asked for their opinion on comprehensibility and clearness of the questions, layout, length, and for any further remarks they had. Needless to say, insights from this pretest were incorporated into the final questionnaire version used during the main consumer survey in Munich.

\subsubsection{Overview of the Subjects of Study}

Finally, a more detailed overview of the subjects of study will be given. First, Table 10 will illustrate the key facts regarding these two subjects and the loyalty program they have in place, upon which Table 11 will provide some background information on Loyalty Partner (the administrator of the Payback coalition, which Aral is a partner company of). 


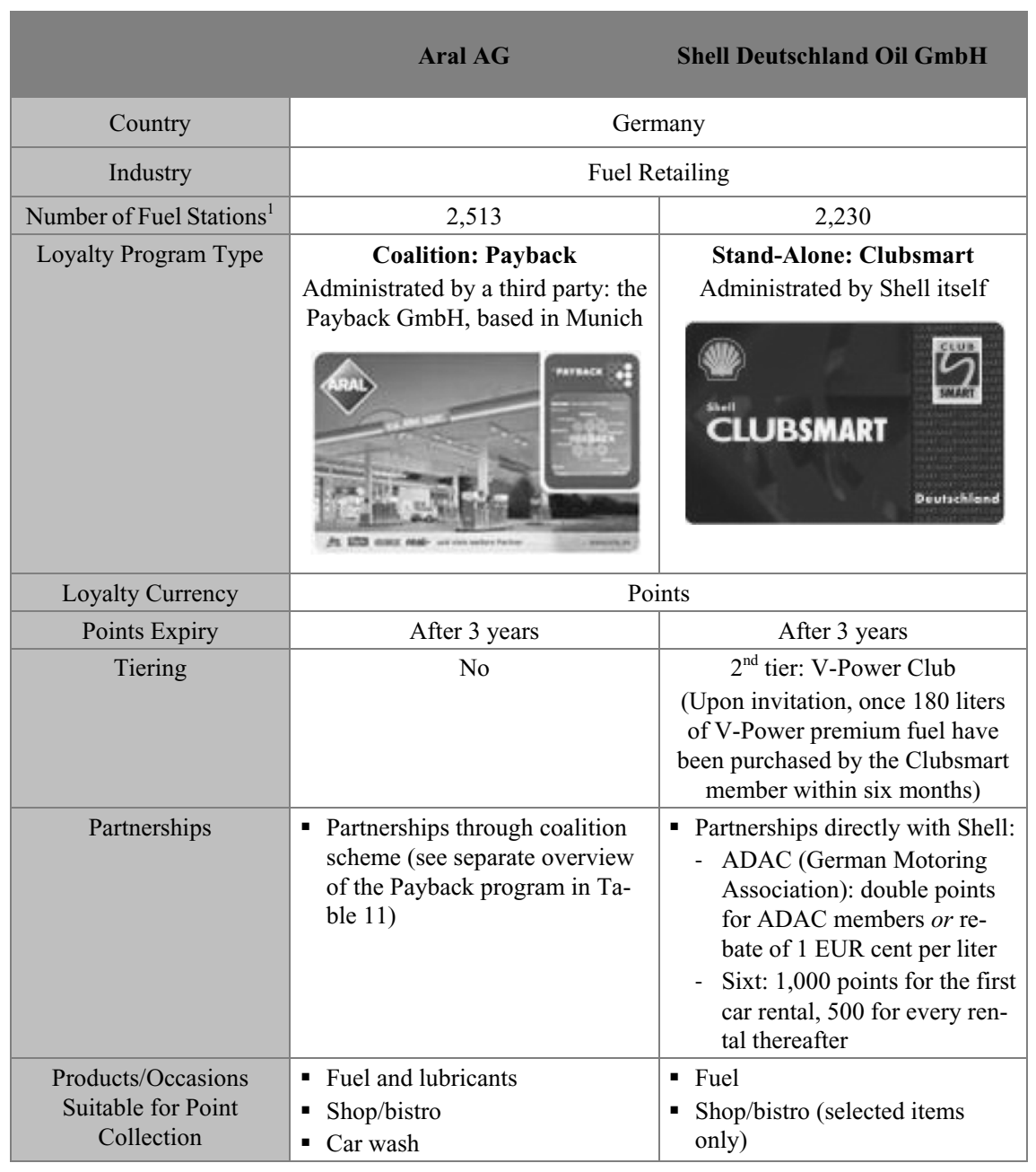




\begin{tabular}{|c|c|c|}
\hline $\begin{array}{l}\text { Number of Points } \\
\text { Earned }\end{array}$ & $\begin{array}{l}\text { - At every participating station: } \\
\text { - } 1 \text { point per } 2 \text { full liters of fuel } \\
\text { or per } 1 \text { full kilogram of nat- } \\
\text { ural gas } \\
\text { - At most participating stations: } \\
\text { - } 1 \text { point per EUR of turnover } \\
\text { made at the shop/bistro or car } \\
\text { wash }\end{array}$ & $\begin{array}{l}\text { - At every participating station: } \\
\text { - Clubsmart members: } 1 \text { point } \\
\text { per full liter of fuel } \\
\text { - V-Power Club members: } 1 \\
\text { point per full liter of regular } \\
\text { fuel and } 5 \text { points per full liter } \\
\text { of V-Power premium fuels } \\
\text { - At most participating stations: } \\
\text { - Points for selected shop } \\
\text { items } \\
\text { - ADAC (German Motoring } \\
\text { Association) members receive } \\
\text { further specials (see above) }\end{array}$ \\
\hline Redemption Options & $\begin{array}{l}\text { - At the fuel station: } \\
\text { - Payment with points (made } \\
\text { optional in February 2010): } \\
100 \text { points for a rebate of } \\
1 \text { EUR } \\
\text { - Car wash: } 200 \text { points plus } \\
3 \text { EUR } \\
\text { - Sandwich and coffee at the } \\
\text { bistro: } 200 \text { points plus } \\
1 \text { EUR } \\
\text { - Directly via Payback: } \\
\text { - A range of options, to be } \\
\text { mailed home (e.g. via } \\
\text { www.payback.de) }\end{array}$ & $\begin{array}{l}\text { - At the fuel station: } \\
\text { - A range of options from a ca- } \\
\text { talogue to take away imme- } \\
\text { diately } \\
\text { - A range of options from a ca- } \\
\text { talogue to be picked up at the } \\
\text { station at a later point in time } \\
\text { - At the fuel station or via Shell } \\
\text { website: } \\
\text { - A range of options to be } \\
\text { mailed home }\end{array}$ \\
\hline $\begin{array}{c}\text { Point Value } \\
\text { (Exemplary Calculation) }\end{array}$ & $\begin{array}{l}\text { Optional payment with points } \\
\text { (directly at the cashier): } 1 \text { EUR } \\
\text { cent per point }=\mathbf{0 . 5} \text { EUR cent } \\
\text { per liter (special promotions } \\
\text { not taken into account; note dif- } \\
\text { ference in number of points } \\
\text { earned per liter) }\end{array}$ & $\begin{array}{l}\text { Optional payment with points } \\
\text { (via redemption option for a } \\
\text { prepaid voucher): } 0.5 \text { EUR cent } \\
\text { per point } 0.5 \text { EUR cent per li- } \\
\text { ter (special promotions and V- } \\
\text { Power Club or ADAC members } \\
\text { not taken into account) }\end{array}$ \\
\hline Employees & - 3.5 in loyalty department & $\begin{array}{l}\text { - } 10 \text { in loyalty department (with a } \\
\text { downward trend) }\end{array}$ \\
\hline
\end{tabular}

1 Aral: as of the end of 2009; Shell: as of the middle of 2009

Table 10: Overview of Subjects of Study

Note: $\quad$ Prepared in April 2010

Source: Personal interviews and company homepages 


\begin{tabular}{|c|c|}
\hline Pand & $\begin{array}{l}\text { Loyalty Partner GmbH } \\
\text { (Payback GmbH) }\end{array}$ \\
\hline Start of Operations & - March 2000 \\
\hline $\begin{array}{l}\text { Organizational } \\
\text { Structure }\end{array}$ & $\begin{array}{l}\text { - Loyalty Partner with three subsidiaries (acquired by American Express in } \\
\text { 2011): } \\
\text { - Payback GmbH: loyalty program operator } \\
\text { - emnos GmbH: CRM consultant } \\
\text { - Loyalty Partner Solutions GmbH: IT consultant and service provider }\end{array}$ \\
\hline Purpose & $\begin{array}{l}\text { - Developing and promoting the Payback platform as a whole (Payback) } \\
\text { - Offering communication channels/options to partner companies (Payback) } \\
\text { - Offering services regarding data analysis (generally at Payback, but given } \\
\text { a special mandate, also at emnos) or IT support (Loyalty Partner Solu- } \\
\text { tions) }\end{array}$ \\
\hline $\begin{array}{l}\text { Partner } \\
\text { Companies }\end{array}$ & $\begin{array}{l}\text { - } 4 \text { main partners (distributing the physical cards next to Payback itself): } \\
\text { - Aral: fuel retailer } \\
\text { - dm-drogerie markt: drugstore } \\
\text { - real,-: grocery retailer } \\
\text { - Galeria Kaufhof: department store } \\
\text { - Currently } 27 \text { further partner companies from different industries } \\
\text { - A range of around } 150 \text { online shops } \\
\rightarrow \text { Altogether, } 8,000-10,000 \text { physical outlets across Germany }\end{array}$ \\
\hline $\begin{array}{c}\text { Partner Company } \\
\text { Membership } \\
\text { Types }\end{array}$ & $\begin{array}{l}\text { - Different contract types for partner companies (e.g. platinum or gold), } \\
\text { highly correlated with size and determining that partner's rights (e.g. per- } \\
\text { mission to issue cards, offer redemption options, etc.) and voice in the ad- } \\
\text { visory council } \\
\text { - Typical contract length (though individual arrangements possible): } 5 \text { years } \\
\text { - Partner involvement via Payback advisory council (consisting of partner } \\
\text { representatives) and several smaller, focused committees (e.g. for strategy) }\end{array}$ \\
\hline $\begin{array}{l}\text { Turnover } \\
\text { (excluding point- } \\
\text { related revenues) }\end{array}$ & $\begin{array}{l}\text { - Loyalty Partner: } 209 \text { million EUR (2009), thereof } \\
\text { - Payback: } 161 \text { million EUR } \\
\text { - emnos \& Loyalty Partner Solutions: } 48 \text { million EUR } \\
\text { - Components: } \\
\text { - Fixed management fee (no transaction fees, except in case of a few } \\
\text { partners with older contracts) } \\
\text { - Payment for individually booked communication channels (e.g. direct } \\
\text { mailings, one of the } 12 \text { coupons attached to the account statement which } \\
\text { is sent out four times a year, etc.) } \\
\text { - No earnings resulting from unredeemed points (i.e. no fees for points } \\
\text { included in the turnover figures above) } \\
\text { - } 15 \text { billion EUR in revenues processed via Payback cards (2008) }\end{array}$ \\
\hline $\begin{array}{l}\text { Cost per Point for } \\
\text { Partner Company }\end{array}$ & $\begin{array}{l}\text { - } 1 \text { EUR cent minus the included } 19 \% \text { German value-added tax }=0.84 \text { EUR } \\
\text { cent }\end{array}$ \\
\hline Redemption Rate & - $90 \%$ of total points handed out \\
\hline Point Clearance & $\begin{array}{l}\text { - Point balance created once a year by external unincorporated association: } \\
\text { the Payback Rabattverein e.V. }\end{array}$ \\
\hline
\end{tabular}




\begin{tabular}{|c|c|}
\hline $\sin$ & $\begin{array}{l}\text { Loyalty Partner GmbH } \\
\text { (Payback GmbH) }\end{array}$ \\
\hline & $\begin{array}{l}\text { - Each point handed out is linked to its issuer and upon redemption treated } \\
\text { on a first-in, first-out basis at each customer's account } \\
\text { - Payback partners pay for every point they hand out, but render account for } \\
\text { every point that was redeemed at their company, but originally handed out } \\
\text { by another partner } \\
\text { - The value of all unredeemed points (the so-called "breakage") is paid back } \\
\text { to the partner companies }\end{array}$ \\
\hline Additional Services & $\begin{array}{l}\text { - Payback Credit Card } \\
\text { - Payback Maestro Bank Card }\end{array}$ \\
\hline Employees & $\begin{array}{l}\text { - Loyalty Partner: 500-600, thereof } \\
\text { - Payback: } 130-180 \\
\text { - emnos \& Loyalty Partner Solutions: } 370-420\end{array}$ \\
\hline $\begin{array}{l}\text { Communication } \\
\text { Activities }\end{array}$ & $\begin{array}{l}\text { - } 96 \text { million direct mailings ( } 2008) \\
\text { - } 8 \text { million variations per mailing possible } \\
\text { - } 1.3 \text { million SMS } \\
\text { - } 167 \text { million email newsletters } \\
\text { - } 40 \text { million visits per year to the Payback website }\end{array}$ \\
\hline Penetration Rate & $\begin{array}{l}\text { - Close to } 40 \text { million cards handed out } \\
\text { - } 22 \text { million users (in } 60 \% \text { of Germany's households; each account is linked } \\
\text { to } 1.4 \text { cards on average) } \\
\text { - } 80 \% \text { of users active (note: time over which this was measured is unknown) } \\
\text { - } 3-4 \text { partner companies patronized per Payback member } \\
\text { - } 4 \text { card usages per month }\end{array}$ \\
\hline
\end{tabular}

Table 11: Overview of the Multi-Partner Program Operator

Note: Based on self-reported information!

Source: Personal interviews, company PowerPoint slides, and company homepages

\subsection{The First Stage of Developing a Conceptual Framework: A Look at Satisfaction}

In the course of this chapter, a conceptual framework will be developed to support the formulation of hypotheses because, as Funk (2005) put it, this helps to structure the perceptions of reality. To avoid an aftertaste of randomness in the process of hypotheses formation, it is necessary to ground one's approach in accepted theory. "To explain a particular circumstance means to derive it from theoretical rules and certain ancillary conditions in a logical-deductive manner," Bea et al. (2000, p. 85, translated) noted. In order to capture, explain, and predict a problem, one can turn to one or several of these theories (Chalmers 2007). Based upon Sir Karl Raimund Popper's idea of critical rationalism, these even- 
tually formulated hypotheses, which Popper used to describe with a metaphor by the German philosopher Novalis as "nets we cast out to capture reality" (Kaas 2000, p. 57), then need to be tested in an empirical setting. Unless falsified in repeated examinations, this will count as established knowledge (Popper 1972).

Interestingly, the majority of papers on the success of loyalty schemes reviewed in Chapter 2.3 lack an explicit theory foundation, even when the paper was published in a renowned, first-class international academic journal. This conclusion was confirmed by a similar analysis by Hoffmann (2008), who found that particularly articles published in English-speaking journals did not contain a description of their theoretical underpinning. In fact, only one of 18 papers in English language papers made reference to a particular theory. By contrast, two out of four reviewed German publications made such a reference - a finding which can be explained by the fact that precisely these two were publications of a doctoral thesis. Whether international English journals simply do not attribute as much importance to a solid, theoretical foundation, or whether these are just not elaborated on in the paper due to space constraints, remains an open question.

In any case, like Hoffmann (2008) concluded when talking about the acceptance of loyalty schemes, the behavior resulting from stimulation by a loyalty program is a phenomenon which cannot be directly observed in its entirety. In line with Hoffmann, the S-O-R paradigm was thus introduced in Chapter 2.2.2 as a useful tool to explain measurable consumer behavior by integrating intervening, not directly observable variables.

The S-O-R model is commonly ascribed to what the German literature refers to as the "neobehavioral paradigm" (as opposed to the "neoclassic" one developed by Erich Gutenberg in the 1950s and the comparatively younger "neoinstitutional" one; see Kaas 2000 for a detailed overview of these paradigms rooted in microeconomic theory). The neobehavioral paradigm is centered on consumer research and dates back to the beginning of the 1970s, when Werner KroeberRiel (1975) brought English-speaking behavioral research to German literature in a contest of the neoclassical paradigm. As far as its characteristics are concerned, it can be described as interdisciplinary, empirical-positivistic, and is applied in that it attempts to provide decision guidance to marketing managers (KroeberRiel et al. 2009). It incorporates theories and methods from sociology, social psychology, behavioral biology, and physiological behavioral sciences and examines consumer behavior as a reaction to a particular stimulus (Kaas 2000). Most importantly, however, this approach is based on the perception that this stimulus does not have a direct effect, but that it functions through intervening processes and variables.

Partly illustrated in Figure 16, neobehavioral research streams include latent variables such as emotions, motivations, or attitudes, as well as perception, deci- 
sion, and learning processes as a predecessor to actual (i.e. observable) behavior. Furthermore, the model shows that, preceding the final step to an actual response, the decision processes within the consumer lead to the formation of an intended behavior. As everyone has probably experienced first-hand, intended behavior (which could be inquired about with the help of a questionnaire or a personal interview, for example) does not necessarily resemble actual behavior. Naturally, what ultimately counts for an organization is actual behavior. On this account, the empirical customer survey described in this paper focuses on questions regarding past purchase behavior.

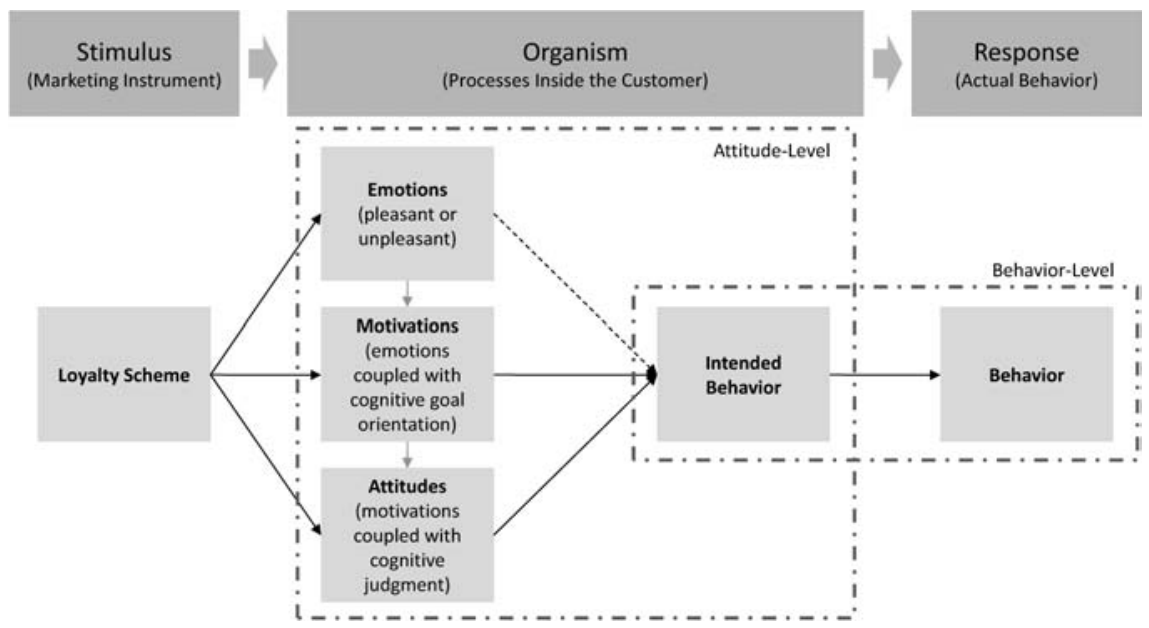

Figure 16: Customer Loyalty from a Behavioral Standpoint

Source: Hoffmann (2008)

The next step in the process toward developing a conceptual framework for this survey is to transform the general model presented in Figure 16 into a more concrete one (depicted in Figure 20 at the end of this section). Given the stimulus of a customer loyalty program as a marketing instrument, the first question was which indicators to consider as response. Based on the discussion in Chapter 2, loyalty in its true sense can only be captured by including both behavioral and attitudinal indicators. While a battery of established scales would suffice for the construct of attitudinal loyalty, it was initially unclear what behavioral indicators should best be used for the purpose of this study. Indicators applied in past publications included the following: share-of-wallet, frequency of purchase, frequency of visits, basket size, lifetime duration, likelihood to defect, and word-of-mouth (e.g. Jones \& Sasser 1995, Sharp \& Sharp 1997, Nunes \& Drèze 2006, Reichheld \& Seidensticker 2006, 
Meyer-Waarden 2007, Bridson et al. 2008). In addition to that, the ability to acquire new customers is also generally considered to be a valuable success indicator for loyalty schemes. The question of what marker to use was resolved with the help of management interviews conducted with Aral, Shell and Loyalty Partner (see Chapter 5.1.1). The respective executives concluded that the three most important indicators for program success in fuel retailing were

- the increase in share-of-wallet with existing customers,

- the increase in basket size of existing customers through up- and/or crossselling, and

- the attraction of new customers.

With respect to other commonly used indicators, particularly the frequency of purchase of fuel is unfit to serve as a success marker without an indication of share-ofwallet. Unlike in grocery retailing or the car wash business in itself for example, it is highly unlikely that it will be possible to increase the frequency of purchase through a loyalty card without essentially affecting the share-of-wallet (fuel retailers commonly differentiate between revenues stemming from (1) the sale of fuel, (2) the shop attached to fuel stations, and (3) the car wash business). In other words, it is improbable that a loyalty card owner would consume more fuel than he normally would, just because of the benefits the program has to offer. Consequently, any increase in frequency of purchase will come at the expense of a competitor and result in a shift of share-of-wallet and thus the company's market share (leaving market growth unconsidered). A similar peculiarity of fuel retailing has to do with basket size. As the capacity of the fuel tank is limited, basket size can only be increased through up- or cross-selling in one of yet another three ways:

- up-selling customers to premium fuel (fuel business),

- selling customers more goods from the station's store (shop business), and

- getting the customer to wash his car more often (car wash business).

For the reasons mentioned above, share-of-wallet was chosen as the principal indicator of behavioral loyalty, coupled with frequency of purchase as a backup measure and a range of complementary questions to capture the program's ability to acquire new customers as well as the ability to induce up- and/or crossselling. In addition to that, following the line taken by Reichheld \& Seidensticker (2006), word-of-mouth was measured. Striving to find a good measure for loyalty, Reichheld came up with what he termed the ultimate question: Would you recommend the product/service/firm/etc. to your friends? This, he argued, resembles the definitive measure of positive attitude and indeed, it sounds reasonable that one would only recommend something to a friend, when truly convinced by it. This argument suffers from one deficiency, however: a recommen- 
dation to a friend might just as well be given for reasons unrelated to a positive attitude (e.g. because of a good offer). As this measure appears useful nonetheless, the ultimate question was also included in the questionnaire to supplement behavioral and attitudinal indicators.

With both stimulus (i.e. program membership) and response (i.e. loyalty) agreed upon, the most difficult task was to decide on what to include in the organism category. Figure 4 in Chapter 2.2.2 presented an overview of the different possible factors exerting influence within the "black box" - the consumers" organism. Considered the most important driver of loyalty (see e.g. Oliver 1997, Homburg 2006, Kumar \& Reinartz 2006), satisfaction was an obvious choice to be examined in the new light of the planned study.

Among many definitions of the term satisfaction, one by Homburg \& Giering (2001) was chosen: "customer satisfaction is defined as the result of a cognitive and affective evaluation, where some comparison standard is compared to the actually perceived performance. The satisfaction judgment is related to all the experiences made with a certain supplier concerning his products, the sales process, and the after-sales service" (p. 45). The authors summarized that earlier research, largely resting on the confirmation/disconfirmation paradigm, used to regard satisfaction as a "postchoice evaluative judgment concerning a specific purchase decision" (p. 44). This view, represented by authors such as Oliver (1980), Churchill \& Surprenant (1982), or Bearden \& Teel (1983), was extended by later research in that it included affective processes when attempting to explain customer satisfaction (see e.g. Fornell \& Wernerfelt 1987, Westbrook 1987, or Oliver 1997). Furthermore, Homburg \& Giering (2001) noted, authors soon concluded that looking at satisfaction in a transaction-based manner was cutting things a little too short. Instead, particularly with regard to the relationship between satisfaction and loyalty, authors began to view satisfaction as the outcome of cumulative experiences (see e.g. Bayus 1992, Anderson et al. 1994, Fornell et al. 1996).

In order to better understand the purported links that customer satisfaction has with other constructs such as loyalty, Anderson \& Mittal (2000) provided an illustration of what they termed the satisfaction-profit chain (depicted in Figure 17 in the slightly modified form developed by Kumar \& Reinartz 2006). 

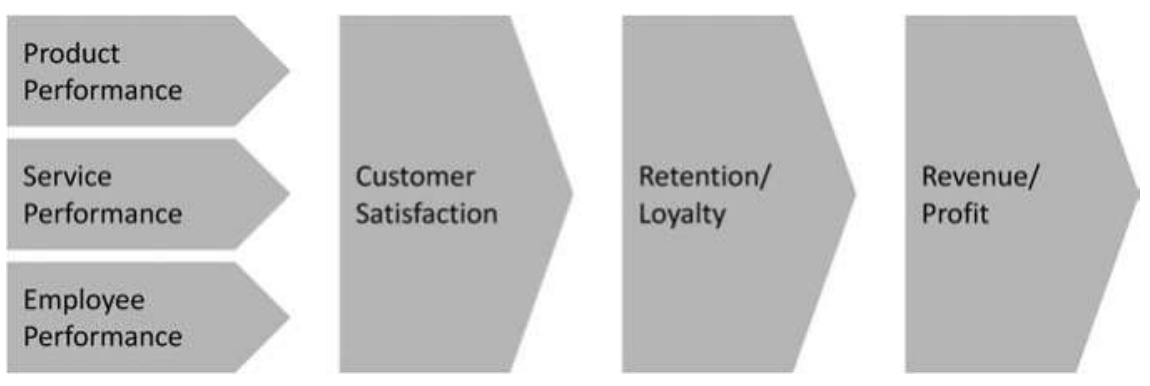

Figure 17: The Satisfaction-Profit Chain

Source: Anderson \& Mittal 2000, Kumar \& Reinartz 2006

This concept has been popular since the beginning of the 1990s, as Kumar \& Reinartz highlighted (as can be witnessed in articles such as that by Heskett et al. 1994). The basic idea of this rather self-explanatory chain seems intuitive: by increasing performance variables related to products, service, or employees, companies can improve customer satisfaction, which leads to increased customer retention (i.e. loyalty), which in turn eventually results in higher revenue and profit.

As far as the literature on the relationship between satisfaction and loyalty is concerned (i.e. the segment of the chain which is most relevant for the present study), three groups of publications can be distinguished (Homburg \& Giering 2001):

- those that analyze this relationship without further elaboration,

- those that examine the functional form of this relationship, and

- those that explore the effects of moderating variables.

The first category includes numerous studies which have confirmed a positive correlation between satisfaction and repurchase intentions (e.g. Bitner 1990, Fornell 1992, Anderson et al. 1994, Rust et al. 1995, Hallowell 1996, Jones et al. 2000), as Homburg \& Giering (2001) and Mägi (2003) noted. Empirical results for this link have been mixed and it is meanwhile acknowledged that satisfaction does not necessarily result in purchase behavior (e.g. Reichheld 1993, Mägi 1995, Oliver 1999, Mittal \& Kamakura 2001, Khatibi et al. 2002). Kumar \& Reinartz (2006) pointed out that one issue with many of the studies exploring this relationship is that they concentrated on aggregate, firm-level results. Specifically, these studies looked at satisfaction indices and their link to firm-level performance, while the chain should ideally be implemented on the individual customer level (as resources are also allocated on that level). Kumar \& Reinartz eventually concluded that "although one would expect a correlation between 
firm-level and individual-level results, it is not clear how strong this correlation really is" (p. 158).

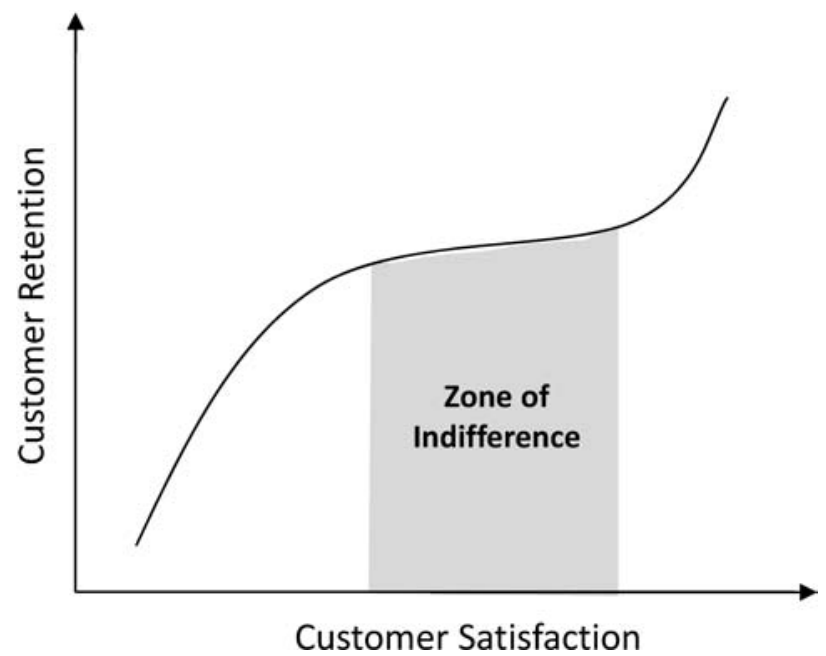

Figure 18: The Asymmetric Link Between Customer Satisfaction and Customer Retention

Source: $\quad$ Anderson \& Mittal (2000), Kumar \& Reinartz (2006)

Another reason for the differing results is the focus of the research stream represented by the second group. When talking about the relationship between satisfaction and loyalty, it needs to be taken into account that this link is generally asymmetric (Jones \& Sasser 1995, Auh \& Johnson 1997, Anderson \& Mittal 2000, Kumar \& Reinartz 2006; see Figure 18). Oliva et al. (1992) highlighted that this relationship can be both linear and nonlinear, depending on transaction costs, but a significant amount of evidence points to its general nonlinearity. This can largely be explained by the fact that a major variable influencing this relationship is that consumers in today's modern world often have many options when making a purchase. In other words, even a high level of satisfaction with a particular product will not guarantee customer retention, as another product might be similarly satisfactory. Apart from the extremes, where the impact of satisfaction on retention has a bigger influence, the flat part of the curve stands out in the illustration. Also referred to as the zone of indifference, Kumar \& Reinartz (2006) summarized that the extent of this area (and indeed, the shape of the whole curve) is influenced by a number of factors, including the aggressiveness of competition, the degree of switching costs, and the level of perceived risk.

Particularly the competitive environment needs to be considered when trying to understand why the observed relationship between satisfaction and loyalty 
differs between studies. Jones \& Sasser (1995) illustrated this discovery with the graph reproduced in Figure 19.

Noncompetitive Zone:

- Regulated monopoly or few substitutes

- Dominant brand equity

- High cost of switching

- Powerful loyalty program

- Proprietary technology

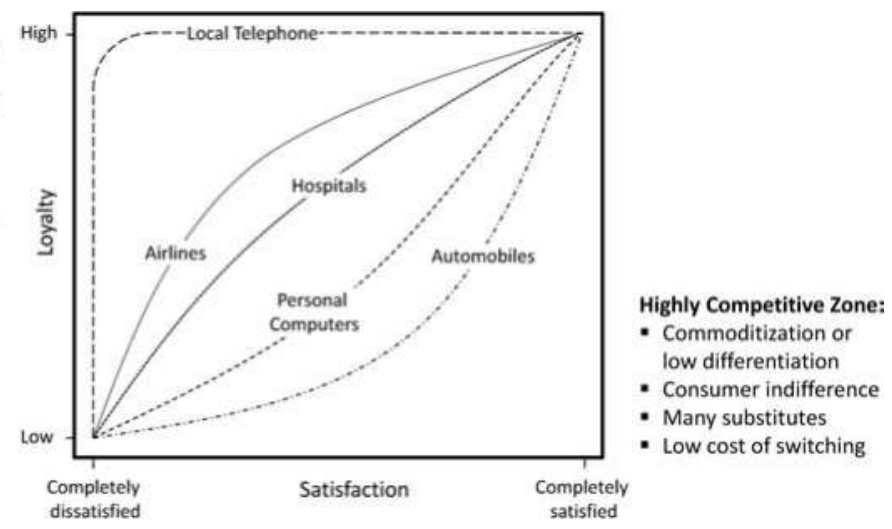

Figure 19: The Influence of the Competitive Environment on the Satisfaction-Loyalty Relationship

Source: Jones \& Sasser (1995)

Despite the fact that the competitive conditions within the industries described in Figure 19 are changing constantly and vary from country to country, the basic message remains the same: the characteristics of the satisfaction-loyalty relationship depend on the competitive framework.

At any rate, Mägi (2003) was right in saying that the link between satisfaction and store loyalty demands further attention. A positive relationship between these two was identified in a number of studies. For instance, Reynolds \& Arnold (2000) identified this relationship in a survey of customers at two upscale department stores, while Bloemer \& de Ruyter (1998) found that satisfaction mediated the influence of store image on store loyalty. One of the newest studies where the satisfaction construct was included in connection with loyalty schemes, is that of Bridson et al. (2008). In a survey of 200 customers of an Australian health and beauty retailer, the authors found that satisfaction was indeed a precursor to loyalty. In addition to that, the loyalty program was confirmed to be a significant predictor of store loyalty. Lastly, Dagger \& O'Brien (2010) evaluated this relationship in the context of services and noted significant differences between novice and experienced customers.

Apart from satisfaction, no other factor mentioned in Figure 4 in Chapter 2.2.2 was reported to have such a significant relationship with the development of loyalty. Since, however, evidence for this link is partly negative, further attention seems required. Mägi (1995) discovered, for instance, that $15 \%$ of those customers who gave a particular store the highest satisfaction rating, did not 
regard it as their primary store. In any case, given some of the negative evidence on this relationship, as well as the differences relating to the study setting, satisfaction was taken up as the main variable in the organism category.

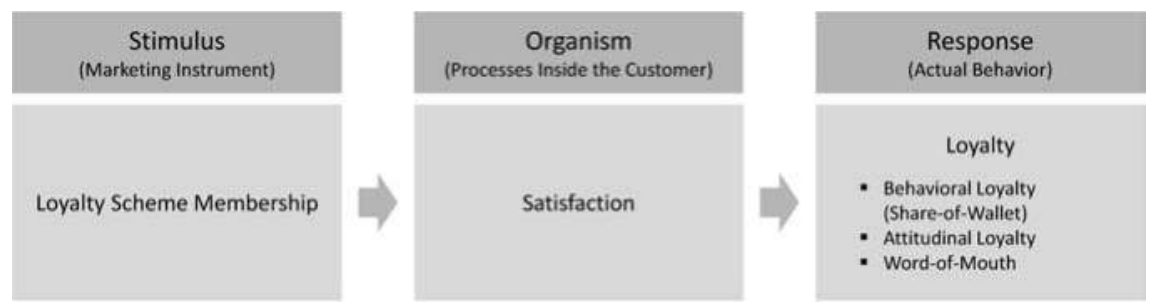

Figure 20: Transforming the General S-O-R Model into the Conceptual Framework's Core Piece

Nevertheless, the first step towards a concrete conceptual framework (see Figure 20) appears incomplete in its current form. In order to finalize the model and formulate the corresponding hypotheses, it will be necessary to identify potential reference points for a theoretical underbody.

\subsection{Theoretical Reference Points}

Before turning to the development of the final model, different theoretical perspectives rooted in the study of human behavior will be presented in this chapter. This excursion on consumer behavior seems useful when illustrating the overall path from external stimuli to the generation of loyalty. In addition to a short description of each theory, a reflection on their explanatory value in the context of hypotheses generation will be provided. All these theories have proven their value in marketing research, and in fact, most of them have previously been used in studies related to customer loyalty schemes (see e.g. Hoffmann 2008). In any case, those theories that appear useful for the formulation of hypotheses will be adopted for the underlying study (following Fischer \& Wiswede 2009). In that sense, this paper relies on theoretical pluralism, as the questions covered in this study cannot be explained by a single theory. The actual selection of theories presented in this chapter was inspired by the contributions of Künzel (2002), Hoffmann (2008), and Homburg \& Bruhn (2008).

\subsubsection{Motivational Theories}

At the very basic level, theories of motivation explain what it is that drives human behavior. There are numerous theories in this category, including that of Maslow 
(1943), Herzberg et al. (1959; originally published in 1957), or Alderfer (1969). Together with a more business-oriented approach by Hanna (1980), these three will briefly be described. Subsequently, they will be joined together in an integrative categorization and evaluated based upon their connection with loyalty programs.

Probably the most famous of the three, Abraham Harold Maslow's (1943) hierarchy of human needs categorized these needs into five layers and postulated that each has to be at least partly satisfied, before a person can advance to the next category. These needs, listed from the lowest to the highest hierarchical layer, are:

- Physiological needs (e.g. for water, air, or shelter)

- Safety needs (e.g. for order, stability, or health)

- Belongingness needs (e.g. for love or friendship)

- Esteem needs (e.g. for recognition or respect)

- Self-actualization needs (i.e. for self-realization)

Herzberg et al. (1959) looked at human motivation from a worker's point of view and concluded that satisfaction and dissatisfaction were unrelated in that they develop based on two categories of influencing factors:

- Hygiene factors which influence dissatisfaction (e.g. salary or working conditions)

- Motivators which, mostly immaterial by nature, influence satisfaction (e.g. recognition or success)

Another example is that of Alderfer (1969) who, building on Maslow's hierarchy of needs, found only three distinct motivational groups:

- Existence motives, physiological or material by nature (e.g. food, water, shelter, or material security)

- Belongingness motives (e.g. friendship or love)

- Growth motives (e.g. self-actualization)

A final example that shall be presented is the motivational theory of Hanna (1980), who took a more focused approach in examining the motivations behind consumer behavior. Hereby, the author distilled seven different kinds of motives:

- Physical safety motives (i.e. the product needs to be safe)

- Material safety motives (i.e. the product has to match the consumer's expectations)

- Material comfort motives (i.e. the product has to fulfill the desire for material comfort)

- Acceptance motives (i.e. products are bought in an attempt to reach a feeling of belongingness or acceptance)

- Influence motives (i.e. consumers want to influence other consumers in their purchase decisions) 
- Self-confirmation motives (i.e. products are bought for recognition)

- Personal growth motives (i.e. products are bought to improve self-esteem)

To ascertain the explanatory value of these motivational theories for a study on customer loyalty schemes, Künzel's (2002) useful approach of grouping these authors' categories into another four clusters will now be applied:

(1) Elementary motives encompass both physiological and safety needs (i.e. they include Maslow's (1943) first two categories, Alderfer's (1969) existence motives, and Hanna's (1980) first three groups) and are rather unlikely to have an effect on the link between loyalty program participation, satisfaction, and loyalty.

(2) Social motives include needs such as those for friendship and belonging (i.e. they comprise Maslow's (1943) and Alderfer's (1969) belongingness as well as Hanna's (1980) acceptance and influence motives) and might have some effect on loyalty program participation, as membership in a club is a classic example of this motivational category. This effect is expected to be rather small, however, as loyalty schemes usually do not stipulate personal contact with other members of the program (with the exception of customer clubs, such as the Harley Davidson Owner's Club, for example).

(3) Recognition motives are driven by the customer's desire for recognition by other people (i.e. they contain Maslow's (1943) esteem and Hanna's (1980) self-confirmation needs) and might have some effect on loyalty program membership, particularly when these schemes appear in a tiered form. Especially frequent flyer programs fall into this category, being a strong example of a loyalty program where the ability to use the business lounge, a special check-in, the provision of a particular leather baggage tag, or preferred boarding might evoke a feeling of recognition. Within retailer loyalty schemes, this effect can be expected to be smaller in tiered programs, as there tend to be fewer possibilities to provide recognition. In untiered programs where everyone can be a member, this effect is likely to wear off almost completely.

(4) Self-actualization motives, characterized by the customers' wish for selffulfillment (i.e. they include Maslow's (1943) self-actualization, as well as Alderfer's (1969) and Hanna's (1980) growth motives), are rather unlikely to have a significant influence on the loyalty program-loyalty relationship. Künzel (2002) argued that an effect might be given when a feeling of self-satisfaction results from the decision to participate in the program - a rather improbable and rare occasion. Another possibility would be an effect arising from the redemption of a big reward, which somehow contributes to the self-fulfillment of the customer. All in all, however, it might be taking things a little too far to expect an influence of loyalty schemes on the customers' need for self-actualization. 


\subsubsection{Transaction Cost Theory}

A possible external stimulant to customer behavior is transaction cost theory. Initially devised by Coase (1937) in an attempt to define the firm in relation to the market (e.g. the reason for its existence, its characteristics, its size, etc.), Williamson (1975, 1985; to name just two examples) remains its most famous ambassador in the more recent literature. Largely focused on contracts, this theory propagates that initiating, executing, controlling, adapting, and dissolving contracts creates transaction costs, which are further augmented by opportunity costs (Homburg \& Bruhn 2008). The underlying idea is that these costs will rise in a disproportionate manner, depending on the frequency of the transaction, its specificity, and increasing uncertainty. This in turn has various implications on both internal (e.g. organizational or investment-related) and external issues (e.g. relationships with other firms or the competitive positioning in the market) affecting the firm. As all action underlying transaction cost theory is tailored to the dominating principle of minimizing the bespoken costs, they eventually determine the development of business relations (Plinke \& Söllner 2008). Consequently, transaction cost theory predicts that customers will be loyal to that company, where the transaction costs appear to be the lowest.

In order to understand the explanatory value of transaction cost theory for the underlying study, it is necessary to realize that all costs associated with the change of a business partner are also part of transaction costs. These can be differentiated into the following groups: costs to build up or enter a business relationship, contract-related costs, psychological costs, and continuity costs (i.e. costs related to the fact that the new business partner of a company might not know about the needs and wishes of the customer) (Künzel 2002). As far as membership in a loyalty scheme is concerned, it is indeed possible that these costs could hinder a change from one program to another (Kim et al. 2001, Kopalle \& Neslin 2003). Particularly programs that involve the collection of points are often argued to form a barrier of exit, as the current point balance would be forfeited once customers switch to another loyalty scheme (see e.g. Caminal \& Claici 2007 for a general discussion on loyalty schemes serving as a barrier of exit). At the same time, the question remains under what conditions customers consider switching costs to be significant. After all, the current point balance could simply be used up to receive a reward, upon which the point balance would be zero at both the old and the new loyalty scheme. Still, this is a danger the company may face, with the exception of the small group of customers that simply like to collect points and are happy about a high point balance without ever redeeming them for a reward. Likewise, a company could, for example, insulate itself from this danger by designing the program in a way that the relative value of big rewards appears to be higher to 
the customer than that of a small reward. In any case, the role of costs associated with a change of the business partner seems to demand further attention.

\subsubsection{Social Exchange Theory}

Social exchange theory is another example of what is theorized to be influencing the development of loyalty. Contrary to what Homburg \& Bruhn (2008) suggested, it was not developed by one team of authors alone, however. Instead, as Emerson (1976) noted, credit is due to four people: Homans (1958), Thibaut \& Kelley (1967; originally published in 1959) and Blau (1992; originally published in 1964). Still, these authors took different routes in approaching this topic, and in line with Homburg \& Bruhn's (2008) perception, Thibaut \& Kelley's (1967) work is probably best suited to explain this theory. Social exchange theory makes use of concepts such as rewards (i.e. satisfaction, pleasures, and gratifications) and costs (e.g. energy invested in the relationship or rewards forfeited by taking one action over another). The outcome of a relationship (such as satisfaction or discontent) is what remains after the incurred costs are subtracted from the received rewards. In order to judge the relative degree of this outcome, the authors created the concept of comparison levels (CL). Individuals enter a relationship possessing a particular comparison level which has been influenced by previous experiences. The type of outcome is then determined by an evaluation against this comparison level, thereby essentially representing what the person believes he or she "deserves."

Following this assessment, the individual makes another one: that against what has been called the comparison level for alternatives $\left(\mathrm{CL}_{\mathrm{alt}}\right)$. Constituting the lowest level of outcome that is acceptable given other alternatives, this contrast is what determines whether to leave the relationship or to remain loyal. Herkner (2001) summarized that this could lead to one of three particular scenarios (see Figure 21):

- Scenario 1: the comparison level is lower than the comparison level for alternatives, which in turn is lower than the actual outcome $\left(\mathrm{CL}<\mathrm{CL}_{\text {alt }}<\mathrm{O}\right)$. The relationship is thus attractive, but not characterized by total dependence, as the alternative is still better than the expected outcome.

- Scenario 2: the comparison level is lower than the actual outcome and higher than the comparison level for alternatives $\left(\mathrm{CL}_{\text {alt }}<\mathrm{CL}<\mathrm{O}\right)$. Consequently, the relationship is attractive and designated by a high level of dependence, as the alternative would provide a worse than expected outcome.

- Scenario 3: the comparison level is higher than the actual outcome, which in turn is higher than the comparison level for alternatives $\left(\mathrm{CL}_{\text {alt }}<\mathrm{O}<\mathrm{CL}\right)$. 
The relationship is unattractive, and nevertheless, a high level of dependence present, as the alternative would provide an even worse outcome.

Of course, another three scenarios are thinkable given the possible combinations of three variables, but Herkner's limited elaboration illustrates the main idea: relationships are denoted by different levels of attractiveness and dependence, contingent upon the status of the perceived comparison level, the comparison level for alternatives, and the actual outcome.

\section{Scenario 1:}

relationship attractive and without dependency
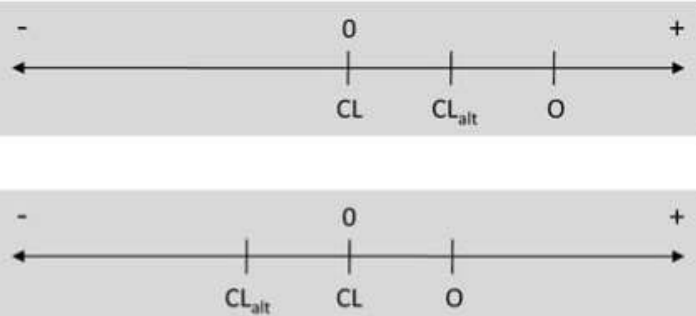

Scenario 3:

relationship unattractive and with dependency

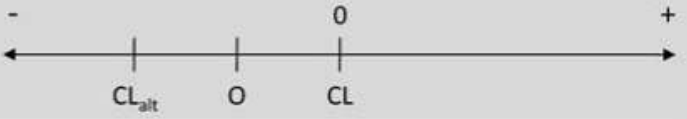

Figure 21: Attractivity and Dependence in Business Relationships

Source: Herkner (2001)

As was witnessed in Chapter 2.2, there are more factors than just satisfaction and a comparison against alternatives that influence the development of a relationship and consequently its intensity. Still, social exchange theory might be viewed as a sort of essential, elementary basis in the quest for decoding customer loyalty. The idea is that customers become members of loyalty programs, because they perceive the benefits associated with this membership to be higher than the costs (with costs forming a part of this theory, a certain overlap with transaction cost theory is present). In addition to that, the relationship will not be endangered, as long as their expectations as well as the perceived benefits from a competitive program are lower than the actual outcome.

\subsubsection{Learning Theory}

A whole range of different theories has developed over time, trying to permeate the complexities surrounding the process of human learning (Bower \& Hilgard 
1981, Kroeber-Riel et al. 2009). For a brief overview, four distinct mechanisms of learning will be presented (Sheth et al. 1999):

- Cognitive learning is based on the idea that learning takes place whenever people acquire information, be it in an active or passive manner, through their eyes or ears, or deliberately or incidentally. This type of learning can be further differentiated into plain memorization as well as problem solving.

- Classical conditioning is probably best known from Ivan Petrovich Pavlov's dog, but applicable to humans as well (see e.g. Shimp et al. 1991). By repeatedly experiencing two paired stimuli (e.g. as it is the case in certain television advertisements where the product is coupled with a distinct jingle), people learn an association between them.

- Instrumental conditioning is a process proven by yet another well-known experiment conducted with animals. Pigeons were taught that pushing a button mounted in their cage dispenses food (Skinner 1965). In that they are equally motivated by the promise of rewards, humans are not so very different. Be it through promotions that lure us to a particular supermarket, or delicious food that promises good value for money at a certain restaurant, instrumental conditioning is constantly taking place.

- Modeling is a way of learning that refers to the imitation of someone else. Miller \& Dollard (1947) discovered that there were four classes of people which are most prone to being imitated: those superior in terms of age, social status, intelligence, or technological competence. Culture, Sheth et al. (1999) complemented, is, among other things, influencing which one of them is more likely to be chosen as a model.

Among these theories of learning, instrumental conditioning might very well be the most useful one for understanding customer loyalty at least in its behavioral sense, Homburg et al. (2008) mentioned by pointing to Engel et al. (1995). It is often either a reward or some form of negative consequence that shapes human behavior. After all, Engel et al. noted, is this form of conditioning "concerned with how the consequences of a behavior will affect the frequency or probability of the behavior performed again" (p. 539). Accordingly, repurchase behavior can at least to some extent be explained by learning theory. Customers receive a reward or a discount, consequently use their loyalty card, and learn that this behavior will lead to another reward in the future. Unfortunately, Künzel (2002) summarized, does the consumers' interest in these rewards decline over time, creating a situation where the company is forced to regularly provide more or at least new rewards to their customers. For the context of this study, this would mean that customer loyalty schemes can only work if customers perceive the rewards to be interesting and attractive. Following the withdrawal of the rewards, customers were generally found to resume their original pre-reward behavior 
(Rothschild \& Gaidis 1981). Evidence for both other extremes has been found as well, however. Kohn (1999), for instance, emphasized that a so-called "contrast effect" might occur in some cases (i.e. behavior even more negative than originally), while Taylor \& Neslin (2005) found evidence for what they termed "rewarded behavior" (i.e. behavior more positive than originally).

At least with regard to the insight that rewards work as a stimulator for behavior, it seems important to investigate the common claim that multi-partner schemes are more appealing to customers, because it is arguably easier for members of such programs to accumulate enough points for a big, attractive reward. If program participants were really found to consider the rewards the multipartner program has to offer to be more attractive than those of the comparable stand-alone scheme, learning theory would imply a higher usage rate and hence, a better basis for program success.

\subsubsection{Theory of Perceived Risk}

Bauer (1967; first published in 1960) is considered by many to be the founding father of the theory of perceived risk (Ring et al. 1980). The basic idea is that humans try to minimize risk in their daily action. Naturally, risk propensity varies among individuals (Sitkin \& Weingart 1995, Sharma et al. in press) and is further influenced by the individual's level of commitment (Beatty et al. 1988). Every human is, in addition to that, subjective in the way that risk is experienced. Two factors exert influence on this perception: the amount at stake and the feeling of subjective certainty (i.e. how safe a person feels regarding the occurrence of that risk).

Regarding a classification of the types of risk, Kuß \& Diller (2001) shall be exemplarily named. As one possible solution, they distinguished between functional (e.g. malfunction of a product), financial (e.g. loss of money), physiological (e.g. threat to personal health), and social risk (e.g. mismatch with the accepted social norm). By relying on trusted and proven products, services, or retail outlets, and thereby reducing the risk of dissatisfaction, Homburg et al. (2008) summarized, can loyal buying behavior serve as a way to minimize these risks. Somehow interlinked with the theory of cognitive dissonance, this would be equally applicable to loyalty program members. In fact, it might even be viewed as preceding transaction cost theory, when the costs of changing to another program are unclear, and consequently posing a risk. In that sense, following the idea of theoretical pluralism, the theory of perceived risk could be viewed as complementary. 


\subsubsection{Theory of Cognitive Dissonance}

Developed by Festinger (1970; first published in 1957), the theory of cognitive dissonance proposes that humans are continuously seeking to reduce dissonance in their cognitive system. The basic idea is that dissonance is perceived as so psychologically uncomfortable, that individuals attempt to keep their cognitive system (as Raffée et al. 1973 described it: the sum of knowledge, beliefs and experiences, as well as the relationship they have with each other) in a state of balance. Furthermore, when faced with a state of dissonance, human beings will avoid any further information or situation that has the potential to increase this dissonance (Festinger 1970).

Loyalty - attitudinal or behavioral - can assist in maintaining a state of balance, as any deviation from loyal behavior creates the risk of dissatisfaction, and consequently, cognitive dissonance (Hennig-Thurau et al. 2000). As far as loyalty schemes are concerned, the risk persists that customers could be disappointed if they were unable to accumulate enough points for a reward they had expected to be able to get. A possible source of dissonance would thus be to think "I am a member in loyalty program X" and "loyalty program X does not offer attractive rewards." Furthermore, consonance is at risk once information about a superior competitive program is processed by the customer or if friends or other people whose opinion the customer values do not favor the program membership (Raffée et al. 1973, Künzel 2002). Raffée et al. (1973) described four ways to reduce any form of dissonance:

- Changing the scope

- Adding new cognitive elements to reduce the impact of the dissonance (e.g. a program member frustrated by rewards seeks information about competitive schemes and finds out that rewards there are not attractive either)

- Forgetting, ignoring, or blocking out the cognitions causing the dissonance (e.g. a program member frustrated by rewards simply does not think about their unattractiveness anymore)

- Changing the content

- Interpreting existing cognitions differently (e.g. a program member frustrated by rewards starts to focus more on other positive effects of the scheme, such as special services, for example, and at the same time attaches less importance to the rewards)

- Changing cognitive elements by changing own behavior (e.g. a program member frustrated by rewards cancels the membership or stops buying from the company)

From a practical point of view, there are many things to take away from Festinger's (1970) theory of cognitive dissonance. Partly, these concern the actual development of the program, but to a larger extent, they have to do with commu- 
nication policies. At any rate, it will be interesting to explore how customers value the rewards of a multi-partner and stand-alone scheme differently and to find out, whether a status of cognitive dissonance might be present.

\subsubsection{Other Theories}

Apart from the major theories mentioned so far, other ones have also been brought in connection with loyalty and customer loyalty schemes. As they provide only limited additional explanatory value, only a brief description will be provided:

- Attribution Theory: developed and advanced by authors such as Heider (1958), Jones (1972), and Kelley (1973), this theory in concerned with the way people attribute (i.e. explain) their own or other people's behavior to some reason. At the most basic level, people attribute events either to external causes or internal ones (i.e. to oneself). In addition to that, Weiner (1985) explained, is it possible to further differentiate into stable (i.e. remaining unchanged over time) and unstable factors (e.g. coincidence), as well as controllable (e.g. by making an effort) and uncontrollable factors (e.g. talent). Interestingly, positive experiences are often self-attributed, while negative experiences are attributed to external causes such as the organization - probably the most important realization to consider in the context of loyalty programs.

- Theory of Psychological Reactance: dating back to the work of Brehm (1966), this theory focuses on how people react to limited personal freedom. Specifically, Brehm defined it as the "motivational state directed toward the reestablishment of the free behaviors which have been eliminated or threatened with elimination" (p. 9). As far as loyalty schemes are concerned, Hoffmann (2008) summarized that the build-up of barriers of exit or a perceived intention to influence the customer might provoke a negative reaction. By contrast, exclusivity, for example in tiered programs, might lead to positive reactions in terms of a wish to participate.

- Organizational Theory: stemming, among others, from the works of Barnard (1938) and Simon (1948), the initial purpose was to evaluate the decisionmaking process. Later, the authors tried to determine how organizations can motivate their employees to work and make a contribution (March \& Simon 1976). This idea of incentive and contribution feels fairly intuitive and can easily be transferred to the topic of customer loyalty programs. As, however, organizational theory almost appears to be an early version of social exchange theory, it will also not be further elaborated on in this paper.

- Confirmation/Disconfirmation Theory: covered by various authors such as Olshavsky \& Miller (1972), Oliver (1980), Churchill \& Suprenant (1982), Bearden \& Teel (1983) or Oliver \& DeSarbo (1988), the confirmation/dis- 
confirmation theory suggests that people compare their actual experience with their expectations. If the actual experience equals or exceeds the expectations, a status of confirmation or positive disconfirmation, respectively, will be given. This will then lead to satisfaction, while negative disconfirmation (i.e. the actual experience falls short of expectations) would result in dissatisfaction (Homburg et al. 2008).

\subsection{Finalizing the Conceptual Model and the Hypotheses}

With the first steps in creating a conceptual model presented in Chapter 5.2 and different theoretical reference points elaborated on in Chapter 5.3, the model will now be finalized and the corresponding hypotheses penned (for an overview, please refer to Figure 22).

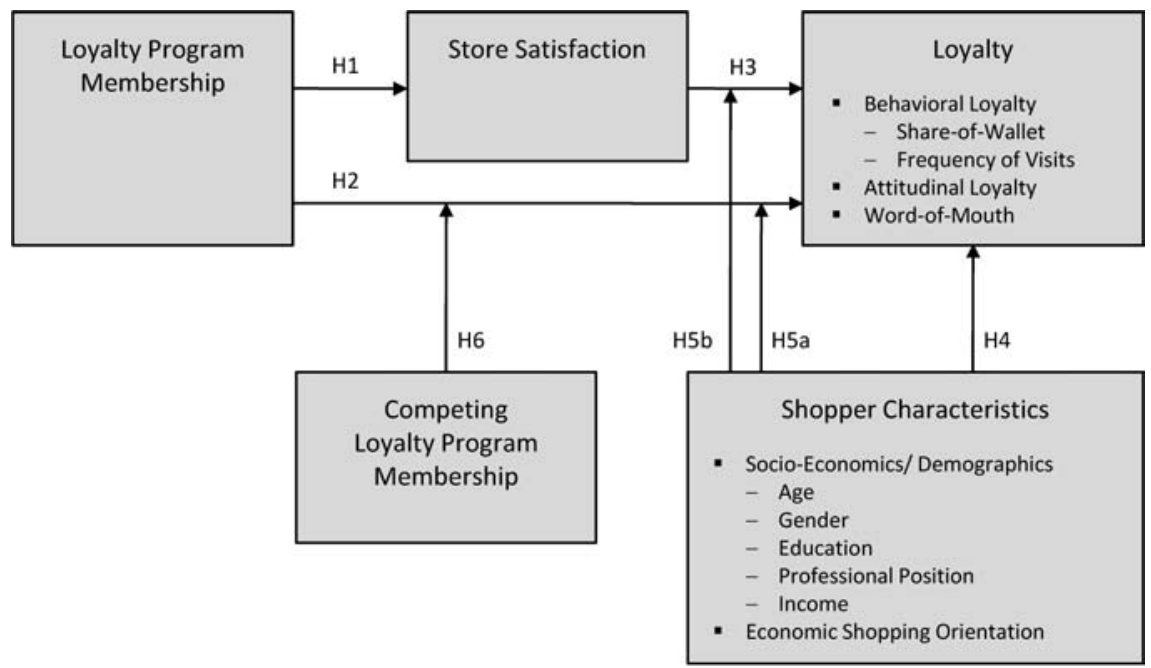

Figure 22: Study Framework

\subsubsection{The Relationship between Loyalty Program Membership, Store Satisfaction, and Loyalty}

As was established in the elaboration on satisfaction in Chapter 5.2, satisfaction is commonly cited to precede loyalty (Homburg \& Giering 2001, Homburg et al. 2008). While this relationship has received a lot of attention (see e.g. Homburg et al. 2008 for an extensive literature review), the opposite is true for the impact 
of loyalty program membership on satisfaction. Given the varying empirical results for loyalty scheme participation on loyalty (see Chapter 2.3), Bridson et al. (2008) argued that "the benefit of these programs perhaps lies first in their impact on customer satisfaction" (p. 367). While this view might be taking things a little too far, it seems at least appropriate to investigate this relationship. To a limited extent, social exchange theory, but even more so the confirmation/disconfirmation theory might help to understand the link between loyalty program membership and store satisfaction. Both theories share the notion that customers possess a particular comparison level (i.e. expectation) to which the actual outcome is matched. Given that customers value the loyalty scheme (i.e. find the rewards attractive, etc.), confirmation/disconfirmation theory proposes that this will lead to customer satisfaction. At this stage, customer satisfaction might be present both with regard to the loyalty scheme (see e.g. Hoffmann 2008 for an empirical test of this relationship), as well as the store itself. Following Homburg \& Giering's (2001) definition, "the satisfaction judgment is related to all experiences made with a certain supplier concerning his products, the sales process, and the after-sale service" (p. 45). This gives reason to believe that the loyalty scheme as a marketing tool also has some effect on store satisfaction. This shall be further explored in this study's context.

Hypothesis 1: Loyalty program membership has a positive effect on store satisfaction.

Excluding the role of satisfaction, the direct relationship between loyalty program membership and loyalty has almost traditionally been part of the majority of studies on the effectiveness of loyalty schemes such as those featured in Chapter 2.3. It was concluded in that section's review, that a lot of the differences can be explained either by the particular definition of success, the set-up of the program, or the specific conditions in the investigated industry. Influenced by the basic notion of social exchange theory which postulates that customers will remain loyal to the company if the actual outcome exceeds their comparison level, it can be assumed that loyalty program membership has a positive effect on loyalty. This idea is naturally based on the assumption that customers find the program and its rewards attractive - a factor that was also included in the study. Furthermore, transaction costs (especially in the form of switching costs) are thought to create a barrier of exit, thereby fostering loyalty if they are perceived to be significant enough. In addition to that, learning theory as well as the theory of perceived risk (e.g. when facing the decision to cancel the membership or switch to a competitive program) would similarly explain why consumers remain loyal to the company, while the theory of cognitive dissonance purports that 
customers would have already ended their membership or stopped using the loyalty card if they had found the rewards unattractive. As this study is again set in different conditions and includes a comparison of multi-partner and standalone solutions, this proposition - explainable with a whole range of theoretical reference points and as old as research on loyalty schemes - shall also be tested.

\section{Hypothesis 2: Loyalty program membership has a positive effect on loyalty.}

Lastly, the final relationship which has already been proposed in the first development stage of the conceptual framework (see Chapter 5.2), is that between store satisfaction and loyalty. As was previously mentioned, this link has received a lot of attention (see e.g. Homburg et al. 2008) and emerging evidence yielded mixed results. This relation may not be present under specific conditions, but it seems fair to say that satisfaction and loyalty appear together more often than not. Given the presence of satisfaction, Festinger's (1970; first published in 1957) theory of cognitive dissonance predicts that customers will not deviate from their loyal behavior and risk a state of cognitive dissonance created by potential dissatisfaction (a prospect overlapping with the theory of risk's projection). To name a few examples from a loyalty program setting, Mägi (2003), Bridson et al. (2008), and Vesel \& Zabkar (2009) analyzed this relationship and found support for a positive link. Interestingly, however, the strength of this effect varied noticeably. Mägi (2003), who conducted her study in the context of grocery retailing in Sweden found this effect to be much lower than Bridson et al. (2008), who carried out their research with customers of an Australian health and beauty retailer, or Vesel \& Zabkar (2009) who addressed customers of a DIY retailer in a Central European country. To determine the strength of this effect in yet another industry, the following hypothesis shall be tested:

Hypothesis 3: Store satisfaction has a positive effect on loyalty.

\subsubsection{The Effect of Shopper Characteristics}

Shopper characteristics have been examined on various occasions in terms of their influence on customer loyalty. Particularly in studies on store patronage behavior, these variables are a common sight. McGoldrick \& Andre (1997), for example, found that age and income were among the major determinants of loyalty (next to travel times). To be more specific, married customers in the middle age bands, who belong to a higher social class and income group and who have a large family and shop by car in large quantities, are more likely to be loyal shoppers. Interestingly, East et al. (1995) found no relationship between loyal- 
ty and income, while discovering a tendency for loyal consumers to stem from the 25-44 year-old age group. In a later study, East et al. (2000) concluded that loyalty (measured as first-store loyalty, i.e. loyalty to the store most of the study participant's category expenditures go to) rises with income and falls with age. Given that this study featured only three age groups $(<45,45-64$ and $65+)$, the findings related to age conformed to the older study. The authors speculated that this might be due to the fact that older customers have more time to allot to shopping and picking the best store, which consequently results in the selection of different stores. As far as monetary means are concerned, Knox \& Denison (2000) ascertained that customers with a smaller budget were more loyal than those with a bigger one. In fact, customers with fewer resources spent twice as much at their preferred store (again, first-store loyalty was measured). While the budget allotted to a particular category expense is certainly a different indicator to income, it seems intuitive to presume a positive correlation between these two. If this was true, findings would be contradictory to those in East et al.'s $(1995,2000)$ work.

In a more recent study, Mägi (2003) evaluated the influence of both age and purchase volume on loyalty to the primary store and, in addition to that, examined how various shopper types differed in their purchase behavior. For the three kinds of shopping orientation the author used, Mägi relied on the work of Stone (1954), who identified a range of customer types, which were later adapted in studies such as that by Laaksonen (1993): the first, the consumer's economic shopping orientation, presumes that price-conscious customers are less likely to be loyal, as they will compare prices across stores and shop wherever they get the best deal (see e.g. Kim et al. 1999). The second, consumer's apathetic shopping orientation, implies that apathetic customers (i.e. those who show low involvement with shopping) will be more likely to remain loyal to one store as they seek to reduce the effort put into the process of shopping (Williams et al. 1978). Finally, consumer's personalizing shopping orientation assumes that customers who enjoy the social aspect of building up relationships with store personnel will remain loyal to one store (Laaksonen 1993). Out of all these shopper types as well as the variables of age and purchase volume, only the economic shopping orientation proved to have a significant direct effect on loyalty in Mägi's (2003) investigation.

Given the varying outcomes in previous studies, the influence of demographic and socio-economic indicators shall be reevaluated (building on East et al. 2000 , among others) and in addition to that, an attempt will be made to corroborate Mägi's (2003) findings on the influence of the economic shopping orientation by exploring their external validity in the new setting of this study.

Hypothesis 4: Shopper characteristics influence the degree of developed loyalty. 
Of even greater importance for the core objective of this study - namely to determine the influence of loyalty schemes on loyalty - is a potential moderating effect of shopper characteristics on this relationship as well as that between store satisfaction and loyalty. Mägi hypothesized that it is indeed "plausible that any effects of loyalty cards would be moderated by consumer characteristics since consumers could be expected to react differently to the loyalty program once enrolled" (p. 99). An example the author brings forth is that of a price-conscious shopper who, despite having become a member of a loyalty scheme, might still be less likely to change his behavior than a customer with low economic shopping orientation (an argument that works just as well with store satisfaction). Mägi continued to point out that no previous research on the moderating role of customer characteristics was to be found and justified the inclusion in her study with the benefits of identifying such moderators. Out of the factors included (age, purchase volume, and gender, as well as the three shopper types), however, none proved significant. Again, this shall be reevaluated in a new context, but while building on the work of Mägi, with an adjusted focus. On the one hand, emphasis shall be placed on the economic shopping orientation as the one shopper type that proved important in the examination of the direct effect on loyalty. On the other hand, the range of factors to be included in the research process will be extended by three further variables (income, education, and professional position), while purchase volume shall be excluded for the sake of concentrating on demographic and socio-economic characteristics only (after all, it has been shown that loyalty schemes impact purchase volume; in other words, the direction of the relationship of this particular variable would be a different one). It is thereby hypothesized that:

Hypothesis 5a: Shopper characteristics moderate the effect of loyalty program membership on loyalty.

Hypothesis 5b: Shopper characteristics moderate the effect of store satisfaction on loyalty.

\subsubsection{The Influence of Competing Loyalty Program Memberships}

In the discussion section of her article on the effects of customer satisfaction, loyalty cards, and shopper characteristics, Mägi (2003) noted that "taking into consideration the large number of multiple-card holders the results indicate that the effects of competing loyalty programs may well cancel each other out. From a firm perspective these results suggest that it is necessary to take into account cardholders" "card portfolios" when evaluating the effectiveness of loyalty programs" 
(p. 104). The author based this notion on the study's finding of a significant negative effect on share-of-wallet being caused by the possession of a competing loyalty card. This problem has received a good deal of attention in the relevant literature (e.g. in Dowling \& Uncles 1997, Passingham 1998, Wright \& Sparks 1999, Bellizzi \& Bristol 2004, Meyer-Waarden \& Benavent 2006, MeyerWaarden 2007) and has already been discussed in both Chapter 2.3.3 and Chapter 3.5.2. Uncles (1994) and Dowling \& Uncles (1997) hypothesized that as soon as competitive offerings enter the market, this will eventually lead to a loyalty scheme's effect being cancelled out. Except for the contributions by Mägi (2003) and Meyer-Waarden (2007), however, the other papers are limited to untested hypotheses or simple statistics on card possession. Still, the two pieces of empirical evidence known to the author, both underpin the view that the possession of multiple competing loyalty cards will have a negative influence on each of these cards' performance. Next to Mägi's (2003) conclusions mentioned previously, Meyer-Waarden (2007) noticed that multiple memberships of geographically close retailers lead to a reduction of lifetime duration.

It should not be forgotten, however, that programs often do differ to some extent in practice, causing customers to prefer one over the other. Furthermore, next to the case of customers exhibiting polygamous loyalty, other settings are thinkable to explain why customers hold multiple cards (e.g. the "just-in-case scenario" where a consumer possesses a competing loyalty card to take advantage of that program just in case he is once in a while unable to patronize his preferred company; see Chapter 2.3.3).

Social exchange theory argues that customers become members of loyalty programs, because they perceive the benefits associated with this membership to be higher than the costs. According to this theory, membership will not be endangered as long as their expectations as well as the perceived benefits from a competitive program are lower than the actual outcome. What remains unanswered, is how customers perceive the benefits and the costs that characterize multi-partner programs (as opposed to stand-alone solutions). Relying on social exchange theory, a conclusion about the relative effectiveness of these two program types can be drawn if a significant difference between them can be made out. Likewise, it might be possible to determine whether cognitive dissonance theory has effect in this case. In order to better understand consumer behavior when membership with multiple competitive cards is given, it will further be necessary to capture the usage frequency in respect of these other loyalty schemes. Enhancing previous studies in that regard, it is hypothesized that:

Hypothesis 6: Memberships in competing loyalty programs have a negative effect on the relationship between loyalty program membership and loyalty. 


\subsection{Construct Operationalization}

When operationalizing the constructs of the study framework, particular attention was paid to building on previous literature and using established scales that have proven their worth in a similar study setting. Furthermore, following the movement initiated by authors like Jacoby (1978), Churchill (1979), and Peter (1979), multi-item measures were used wherever necessary. In fact, for this study, a uniformly 3-tiered design has been employed for all multi-item measures (see e.g. Sarstedt \& Wilczynski 2009 or Fuchs \& Diamantopoulos 2009 for criteria to assess where single-item measures can be feasible).

As far as the different constructs are concerned, in particular store satisfaction, loyalty (i.e. attitudinal loyalty and word-of-mouth), and the economic shopping orientation demand special consideration, as these are constructs that were operationalized by three-item measures. By comparison, loyalty program membership was examined with a simple question asked verbally when handing out the survey, while socio-economic and demographic shopper characteristics, as well as competing loyalty program memberships were captured with brief questions as part of the questionnaire.

\subsubsection{Store Satisfaction}

No general agreement exists among authors on how to measure satisfaction. In an article on measurement scales in customer satisfaction/dissatisfaction, Hausknecht (1990) identified more than 30 different measures that have previously been used. Reporting on a national product-related customer satisfaction barometer in Sweden that covers more than 100 companies in 30 industries, Fornell (1992) summarized that this barometer was intended to measure three distinct components of satisfaction: (1) The degree of general satisfaction (see e.g. Westbrook 1980, Oliver 1981), (2) the degree of confirmation of expectations (see e.g. Oliver 1977, Swan et al. 1981), and (3) the distance from the customer's hypothetical ideal product (see e.g. Sirgy 1984, Tse \& Wilton 1988). Similarly, the American Customer Satisfaction Index described by Bryant \& Cha (1996), encompassed 200 companies in 40 industries when it was first conducted in 1994 and included questions regarding the same three categories: overall satisfaction, confirmation or disconfirmation of expectations, and the comparison to an ideal.

Viewing satisfaction as the outcome of cumulative experiences (see e.g. Bayus 1992, Anderson et al. 1994, Fornell et al. 1996) and not in a transactionbased manner as authors had previously done, Mägi (2003) adopted the approach used by the American and the Swedish satisfaction indices. Characterized by a 
good Cronbach's alpha of 0.84, the following three items were employed: (1) how satisfied are you with your primary grocery store (very dissatisfied - very satisfied)? (2) How well does your primary grocery store match your expectations (not at all - completely)? (3) Imagine a perfect grocery store. How close to this ideal is your primary grocery store (not at all close - very close)?

Given the myriad of options when it comes to operationalizing customer satisfaction, it was decided to adjust Mägi's items for the purpose of this study, particularly because the quality of this approach has been demonstrated not only in the context of the author's examination of loyalty schemes, but also in two extensive, nation-wide studies on customer satisfaction. After an important modification in that the questions were adapted to match with the uniform Likert scale employed throughout the study, the following items were eventually chosen for the survey (note: the English statements were translated from the German original):

- I am satisfied with XYZ fuel stations.

Ich bin mit XYZ Tankstellen zufrieden.

- XYZ fuel stations match my expectations.

XYZ Tankstellen entsprechen meinen Erwartungen.

- XYZ fuel stations come close to my image of a perfect fuel station.

XYZ Tankstellen sind nah dran an meiner Vorstellung einer perfekten Tankstelle.

\subsubsection{Loyalty}

\section{1) Behavioral Loyalty}

In Chapter 5.2, the different components of the loyalty construct were agreed upon, and following the discussion in Chapter 2, both behavioral and attitudinal measures were included (see e.g. Day 1969, Jacoby \& Chestnut 1978, Oliver 1997). The more difficult part was then to decide on how to operationalize the behavioral measure. Trying to capture behavioral loyalty in apparel stores and supermarkets, De Wulf et al. (2001), for example, successfully employed measures which directly asked for an estimation of share-of-wallet and frequency of visits. The three items the authors used were: (1) What percentage of your total expenditures for clothing do you spend at this store? (2) Of the 10 times you select a store to buy clothes at, how many times do you select this store? (3) How often do you buy clothes in this store compared to other stores where you buy clothes? In a similar study, De Wulf \& Odekerken-Schröder (2003) reduced the number of items to two, and likewise, Noordhoff et al. (2004) employed such an approach, asking for the percent of budget spent in the store as well as the number 
of visits to the store out of 10 shopping trips. A final example in this sample listing of authors is that of Bowman \& Narayandas (2001), who asked customers to determine the number in ten purchases of a particular brand during a telephone interview (see e.g. Verhoef 2003 or Wirtz et al. 2007 for further examples).

To determine first-hand how customers would react to such direct questions, a separate sample study has been carried out. To this end, 50 questionnaires were distributed to customers in the same way the main survey was to be undertaken (see Chapter 5.1.2 for a description of this sample study). In addition to that, the possibility of letting customers freely note down the average number of visits per month, as well as the percentages of their budget spent at different fuel stations was explored (as opposed to forcing them to determine the number of visits out of 10 , for instance). With a response rate of exactly $50 \%$, the 25 usable questionnaires suggested good acceptance of these questions. In fact, many respondents distributed their budget in a very detailed manner (e.g. one customer allotted $95 \%$ to one fuel chain, as well as $2 \%, 2 \%$, and $1 \%$ to three others). Naturally, the reliability of such answers is not bulletproof. In order to gain access to more detailed information, other possibilities such as company or panel data were explored, though eventually rejected, as neither fuel retailers, nor administrators of household panels had access to a full set of information themselves. The only other real option, a diary study, was rejected for a lack of feasibility (see Chapter 5.1.2 for a full explanation of the reasons for choosing this study design).

Building on the experiences of prior studies as well as the aforementioned separate sample study, share-of-wallet was selected as the principal measure for behavioral loyalty (note: the English statements were translated from the German original):

- Share-of-wallet:

Please estimate how your total expenditure for fuel is divided up among the following fuel stations. Please distribute $100 \%$ among the different chains (leave fuel chains you do not visit blank).

Bitte schätzen Sie, wie sich Ihre gesamten Ausgaben für Treibstoff auf die folgenden Tankstellenketten aufteilen. Teilen Sie hierzu bitte 100\% auf (nicht besuchte Tankstellenketten frei lassen).

In addition to that, the survey included a measure of frequency of visits, the absolute amount spent on fuel per month, and an estimate of the price of an average tank of fuel. Thus, it was possible to assess both the "monetary attractiveness" of the customer, as well as to evaluate the congruence of different estimates (i.e. the amount of money spent on fuel per month should ideally equal the price of an average tank times the frequency of visits per month). 


\section{2) Attitudinal Loyalty}

Following the line of argumentation in Chapter 2, an attitudinal measure complemented the behavioral one in order to be able to capture loyalty to its full extent. Similar to the other constructs, operationalization was primarily attempted by building on existing literature and using established and proven scales. As quite a significant amount of literature exists on the measurement of attitudinal loyalty (see e.g. Jacoby \& Chestnut 1978 or Hill \& Alexander 2006), particular attention will be given to studies in the field of CRM and loyalty schemes. Verhoef's (2003) work is one publication falling into that category. The author focused on what he called "affective commitment," which, following Bhattacharya et al. (1995) and Gundlach et al. (1995), he described as "the psychological attachment, based on loyalty and affiliation, of one exchange partner to the other" (Verhoef 2003, p. 31). This, authors such as Hallberg (2004) or Kumar \& Shah (2004) argued, is also what customer loyalty schemes ought to achieve, although the ability of loyalty programs to do so remains largely in doubt. In any case, Verhoef (2003) went on to explain that this commitment, a term used by various authors synonymously with attitudinal loyalty (see e.g. Bloemer \& De Ruyter 1998, De Wulf \& Odekerken-Schröder 2003, or Bridson et al. 2008), has a positive effect on behavioral loyalty (see also Morgan \& Hunt 1994, Garbarino \& Johnson 1999). Testing this relationship, Verhoef (2003) used three items to operationalize the affective commitment construct (Cronbach's alpha =0.77): (1) I am a loyal customer of XYZ. (2) Because I feel a strong attachment to XYZ, I remain a customer of XYZ. (3) Because I feel a strong sense of belonging with $\mathrm{XYZ}$, I want to remain a customer of XYZ. De Wulf \& Odekerken-Schröder (2003) applied a scale with two similar items and extended it by two further questions (comparable to Bridson et al. 2008): (1) Even if this retailer would be more difficult to reach, I would still keep buying there. (2) I am willing to 'go the extra mile' to remain a customer of this retailer.

It is argued that it will not be possible to measure pure attitudinal loyalty with the latter two items, as the motivation to overcome the geographical distance to a retailer does not necessarily result from a positive attitude. For that reason, Verhoef's (2003) items were adopted with minor adjustments (note: the English statements were translated from the German original):

- I feel I am a loyal customer of XYZ.

Ich fühle mich als loyale/r XYZ-Kunde/in.

- Because I feel a strong attachment to XYZ, I remain a customer of XYZ.

Weil ich eine starke Verbundenheit zu XYZ empfinde, bleibe ich Kunde/in von XYZ. 
- Because I feel a strong sense of belonging with XYZ, I want to remain a customer of XYZ.

Weil ich ein starkes Zugehörigkeitsgefühl zu XYZ empfinde, möchte ich Kunde/in von XYZ bleiben.

\section{3) Word-of-Mouth}

Wirtz \& Chew (2002) provided a good overview of word-of-mouth research, dealing, among other things, with satisfaction as an important antecedent (see e.g. Engel et al. 1969, Bitner 1990, Reichheld \& Sasser 1990). Interestingly, Wirtz \& Chew (2002) summarized that this relationship between satisfaction and word-of-mouth is u-shaped in that consumers' engagement in word-of-mouth is higher when they are extremely satisfied or extremely dissatisfied, as opposed to being moderately satisfied (see also Anderson 1998).

As far as the measurement is concerned, it has already been mentioned in Chapter 5.2 that Reichheld \& Seidensticker (2006) have provided an interesting method of measuring loyalty by capturing word-of-mouth behavior via what they termed the ultimate question: "Would you recommend the product/service/firm/ etc. to your friends?" Following the principle of using multi-item measures (Sarstedt \& Wilczynski 2009), this question shall be further amended to fit the pattern of three-item-scales. Bridson et al. (2008), for instance, utilized the following questions in their study (Cronbach's alpha $=0.90)$ : (1) I often find myself telling people about the positive experiences I have had with this retailer. (2) Because of my experiences with this retailer, I try to convince friends, family, and co-workers to switch to this retailer. (3) I say positive things about this retailer to other people. (4) I would recommend this retailer to someone who seeks my advice. (5) I encourage others to do business with this retailer.

Out of these items, the following three were chosen (note: the English statements were translated from the German original):

- I often tell friends, family, or colleagues about the positive experiences with XYZ.

Ich erzähle häufig Freunden, Familienangehörigen oder Kollegen über die positiven Erfahrungen mit XYZ.

- Because of my experiences with XYZ, I try to convince friends, family, or colleagues to switch to XYZ.

Wegen meiner Erfahrungen mit XYZ versuche ich Freunde, Familienangehörige oder Kollegen davon zu überzeugen, zu XYZ zu wechseln.

- I would recommend XYZ to someone who seeks my advice.

Ich würde XYZ jemandem empfehlen, der meinen Rat sucht. 


\subsubsection{Economic Shopping Orientation}

To operationalize the construct of economic shopping orientation, a variation of Laaksonen's (1993) shopping orientation scales have been used. While the author based his work on Stone's (1954) shopper typologies, Mägi (2003) has in turn slightly adapted and enhanced Laaksonen's scales for use in her study on customer loyalty schemes. Characterized by a solid Cronbach's alpha of 0.76 , Mägi formulated a four-item scale with the following questions: (1) I choose to shop at the grocery store that has the best deals at the time. (2) I compare what I get for my money at different stores. (3) You profit from comparing prices across stores. (4) I choose what store to go to on the basis of where I find what I need for the best prices.

As other constructs of this study were also measured by three-item scales and as they were furthermore expected to lead to a better customer response, the first three items used by Mägi were chosen over the fourth one for their succinct phrasing. Furthermore, the items were slightly adapted for their use in the underlying study, resulting in the following statements (note: the English statements were translated from the German original):

- I refuel at the fuel station which currently has the lowest prices.

Ich tanke an der Tankstelle mit den aktuell niedrigsten Preisen.

- I compare what I get for my money at different fuel stations.

Ich vergleiche an verschiedenen Tankstellen was ich für mein Geld bekomme.

- You profit from comparing prices across fuel stations.

Man profitiert vom Preisvergleich bei unterschiedlichen Tankstellen.

Following the conception of the study framework, the formulation of the hypotheses, and the operationalization of the constructs employed, the questionnaire was finalized and the study conducted. The findings of this investigation will now be discussed in Chapter 6 . 



\section{Empirical Study Results}

In the course of this chapter, findings from the empirical study will be presented. Specifically, a description of the sample and data cleansing processes will be given (Chapter 6.1), followed by a comprehensive section on descriptive statistics (Chapter 6.2), where those survey questions not included in the main model test will also be addressed. Subsequently, a documentation of the main model test will be provided (Chapter 6.3), with a quick roundup of the qualitative study component concluding the chapter (Chapter 6.4).

\subsection{Sample Description and Data Cleansing Processes}

Table 12 gives an overview of the key data associated with the sample of this customer survey. Altogether, 8,260 people were approached to hand out the 2,000 questionnaires. Next to the quota of people willing to participate in the study, the quota of loyalty program members acted as the second important driver of the number of people that had to be addressed. 1,149 of the 2,000 distributed survey forms were returned, resulting in a surprisingly high response rate of $57.5 \%$. Out of those returned, 65 questionnaires had to be excluded for one of two reasons: (1) either because the respondent turned out to belong to the wrong target group (e.g. the possession of a Clubsmart card was indicated on a Shell control group form meant for non-members - despite the fact that the membership status was checked verbally when handing out the questionnaires) or (2) because a significant segment of the questions was not answered (i.e. when more than $50 \%$ of a whole section of the survey, and not just individual answers, were omitted; see Backhaus \& Blechschmidt 2009 for further details on possible ways of handling missing values). Ultimately, 1,084 filled-out forms were used for this study.

Prior to all statistical evaluations, a systematic process of data cleansing was conducted. Hereby, the following five issues were addressed (see appendix for the original questionnaires):

(1) Affected Question: "Which type of loyalty scheme do you like best?" Problem: Some respondents indicated more than one answer.

Solution: All answer pairs of a specific kind were selected (e.g. all instances where both Type 1 and Type 2 were indicated) and one of these two answers 
deleted in an alternating manner. This process was conducted separately for each of the four sample groups and applied to all answer pair variations.

(2) Affected Question: "Please estimate how your total expenditure for fuel is divided up among the following fuel stations. Please distribute $100 \%$ among the different chains (leave chains you do not visit blank)."

Problem: The sum of percentages allocated by respondents did not always add up to exactly $100 \%$.

Solution: The allocated percentage values were reduced (if the sum exceeded $100 \%$ ) or increased (if the sum turned out to be below $100 \%$ ) according to their proportions to reach a total of $100 \%$.

\begin{tabular}{|c|c|c|}
\hline Overview & Aral & Shell \\
\hline Survey take-home quota (eligible) ${ }^{1}$ & $34.8 \%$ & $31.9 \%$ \\
\hline Loyalty program membership quota & $42.7 \%$ & $32.1 \%$ \\
\hline Number of surveys distributed & 1,000 & 1,000 \\
\hline Absolute number of people approached & 3,364 & 4,896 \\
\hline Survey take-home quota (overall) ${ }^{2}$ & $29.7 \%$ & $20.4 \%$ \\
\hline
\end{tabular}

\begin{tabular}{|c|c|c|c|c|c|}
\hline & Response Rate & Aral & Aral Control & Shell & Shell Control \\
\hline 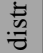 & Number distributed & 500 & 500 & 500 & 500 \\
\hline \multirow{4}{*}{$\begin{array}{l}\text { 己. } \\
\stackrel{\Xi}{E} \\
\text { D. }\end{array}$} & Number returned & 312 & 267 & 299 & 271 \\
\hline & Response rate & $62.4 \%$ & $53.4 \%$ & $59.8 \%$ & $54.2 \%$ \\
\hline & Number returned (total) & \multicolumn{4}{|c|}{1,149} \\
\hline & Response rate (total, returned) & \multicolumn{4}{|c|}{$57.5 \%$} \\
\hline \multirow{7}{*}{ 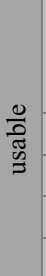 } & & 8 & 25 & 6 & 26 \\
\hline & Number excluded wrong target & 7 & 15 & 4 & 15 \\
\hline & p - signiı & 1 & 10 & 2 & 11 \\
\hline & Number usable & 304 & 242 & 293 & 245 \\
\hline & Response rate & $60.8 \%$ & $48.4 \%$ & $58.6^{\circ}$ & $49.0 \%$ \\
\hline & Number usable (total) & \multicolumn{4}{|c|}{1,084} \\
\hline & Response rate (total, usable) & \multicolumn{4}{|c|}{$54.2 \%$} \\
\hline
\end{tabular}

1 Percentage of eligible people that was willing to take the questionnaire home (i.e. only non-members were eligible to receive a control group survey form, while program members were the target for the main group questionnaires)

2 Taking all approached people into account; calculation based on two variables: (1) the quota of eligible people that was willing to take the questionnaire home and (2) the loyalty program membership quote (i.e. as this quota is below $50 \%$ for both Aral and Shell, control group questionnaires were distributed faster than those for program members)

Table 12: Study Sample Description 
(3) Affected Question: "Please indicate your highest, already completed level of education."

Problem: Some respondents indicated more than one answer.

Solution: As the different answer options were considered ordinal, all but the highest indicated level of education were removed.

(4) Affected Question: "Please indicate the professional position you currently hold."

Problem: Some respondents indicated more than one answer.

Solution: In cases of answer pairs where only one generates income (e.g. student and employee, homemaker and freelancer, etc.), the professional position which generates income was selected as the single answer. In cases where the answer pair includes two types of professional position that the respondent gets paid for, the same process used for issue 1 was applied (i.e. within all instances of each type of answer pairs, one answer was deleted in an alternating manner).

(5) Affected Question: "Lastly, please indicate your approximate monthly netincome (= income at your disposition after taxes and social insurance contributions are deducted)."

Problem: Some respondents indicated very high monthly net-incomes (i.e. among the 1,149 returned questionnaires, 22 out of the 1,024 respondents who had answered this question indicated net-incomes of more than 15,000 EUR per month. Answers ranged from 17,000 to 180,000 EUR).

Solution: It was decided to treat all answers above 15,000 EUR as missing values to prevent these few extreme cases from interfering with the analysis. This decision was made, as it was unclear whether the respondents had unintentionally indicated their yearly instead of monthly net-income, whether they indicated their household instead of their personal net-income, whether any other error caused this outcome, or whether they really made that much money.

\subsection{Extended Descriptive Statistics}

In the course of this chapter, descriptive statistics contrasting all four survey groups will be presented covering all questions of the survey form. As far as the sequence is concerned, demographic and socio-economic characteristics will be dealt with first (Chapter 6.2.1), followed by the other questionnaire segments in the order found on the survey form (Chapter 6.2.2-6.2.4). The only exceptions to this approach are the questions exclusive for the main groups (i.e. page 2 of the main group questionnaires), which will be the last ones to be attended to. In that specific case, a comparison will be made across the two main groups wherever 
possible (Chapter 6.2.5), followed by simple frequency tables for coalition scheme-specific (Chapter 6.2.6) and stand-alone scheme-specific items (Chapter 6.2.7). Depending on the nature of the question, classical examinations of distribution, central tendency, and/or dispersion will be performed, with a test of significance supplementing these evaluations (which is why this chapter on descriptive statistics is called "extended"). Contingent upon the explaining variable, either a one-way ANOVA or a ${ }^{2}$ test will be used for comparisons across four groups, while either a t-test or a ${ }^{2}$ test will be employed when two groups are contrasted (Freedman et al. 2007). Furthermore, a post hoc test (i.e. a Duncan test) will be performed in addition to the one-way ANOVA to determine the differences between groups.

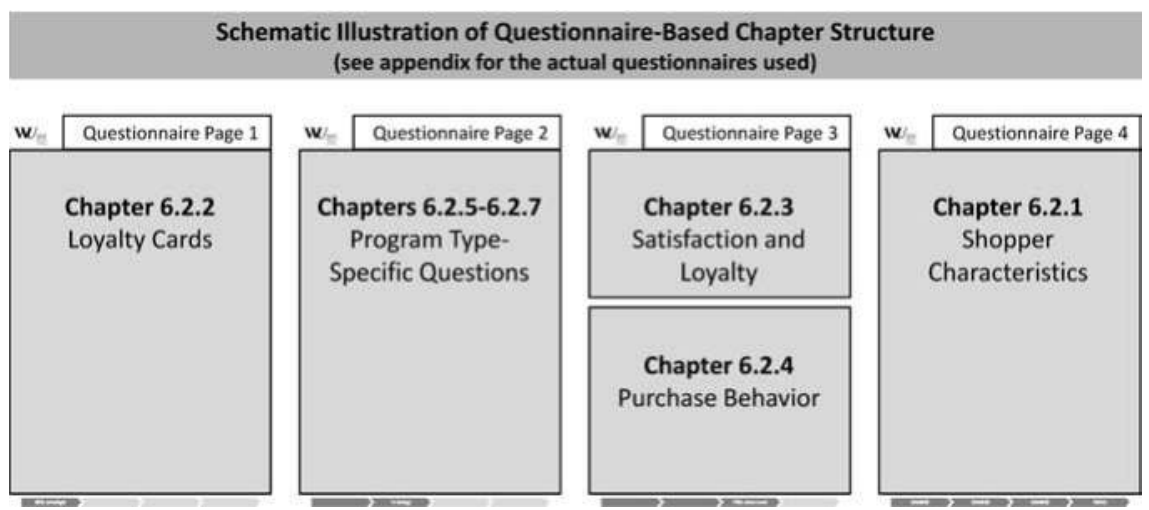

Figure 23: Schematic Illustration of Chapter Structure

Note: $\quad$ Main group questionnaire depicted

\subsubsection{Demographic, Socio-Economic, and Other Shopper Characteristics}

\section{1) Gender}

"Please indicate your gender."

While the various sample groups should preferably not differ with regard to the demographic variables, this is the case with gender in the underlying survey. It seems a fair assessment that men generally are the more dominant customer group when it comes to fuel retailing virtually anywhere on earth. This is also reflected within the two control groups with a comparatively similar distribution of men and women between the groups, but things are not quite that clear when it comes to the two main groups (see Figure 24). The principal reason for the 
above-average dominance of men in the Shell main group is that the Clubsmart loyalty program is primarily positioned for men, while the opposite is true for the Payback scheme. Furthermore, the higher representation of women in the latter group has certainly also been influenced by the fact that most of the Payback coalition partners are retailers that are generally patronized by a higher share of women than fuel stations (e.g. drug store, grocery store, etc.). Naturally, that highly significant difference between the survey groups (Pearson's ${ }^{2}$ test: $p<$ 0.001 ) has the potential to interfere with the study results - that is, if men and women really were to behave differently when it comes to a membership in a fuel retailing loyalty scheme. Whether or not (and if yes, to what extent) this is the case is unknown and thus remains a possible limitation to keep in mind.

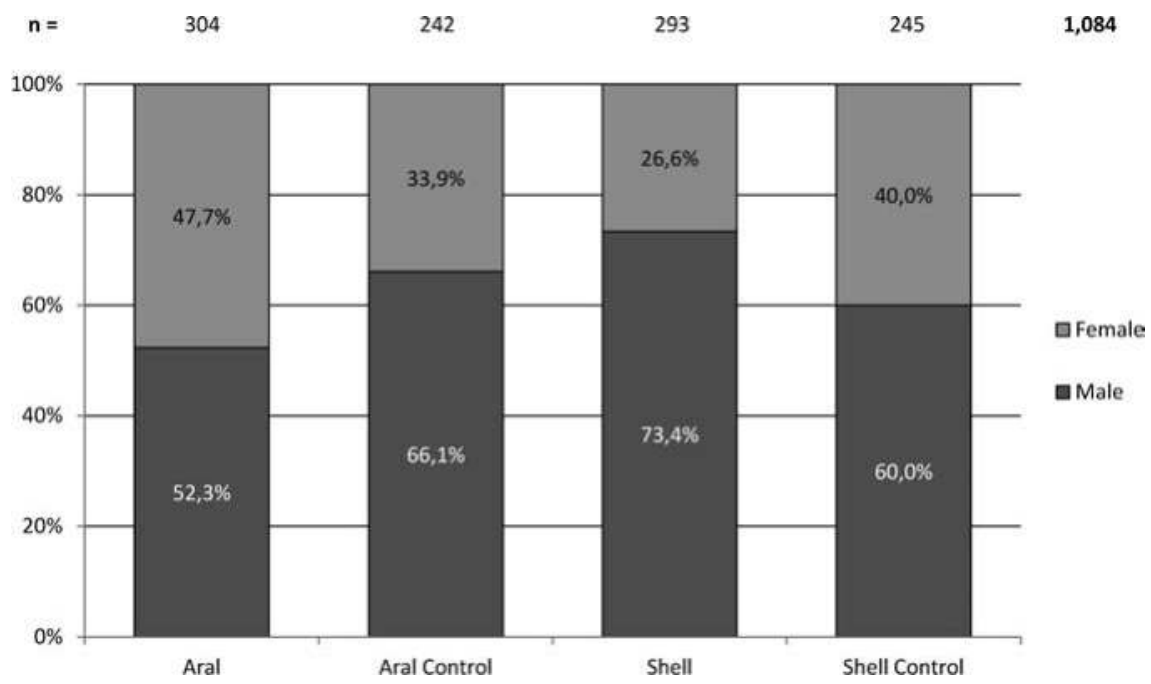

Figure 24: Descriptive Statistics - Gender

2) Age

"Please indicate your age."

In the questionnaire, age has been captured on a metric scale, but for a better visual comparison, categories were introduced ex post (see Figure 25). Within all four groups, 40 to 49 year olds form the largest group of respondents, followed by the 30 to 39 year olds. Notable differences include a comparatively bigger dominance of the 40-49 year old age bracket at Shell, as well as a greater percentage of up to 29 year olds in the Aral control group as compared to the Shell control group. In return, the Shell control group is characterized by a few more 
respondents aged 60 and above. Calculated across all four groups using the original metric data, the one-way ANOVA led to a significant result $(\mathrm{p}=0.005$; Duncan test-group assignment: Group 1: Aral Control, Aral - Group 2: Aral, Shell - Group 3: Shell, Shell Control).

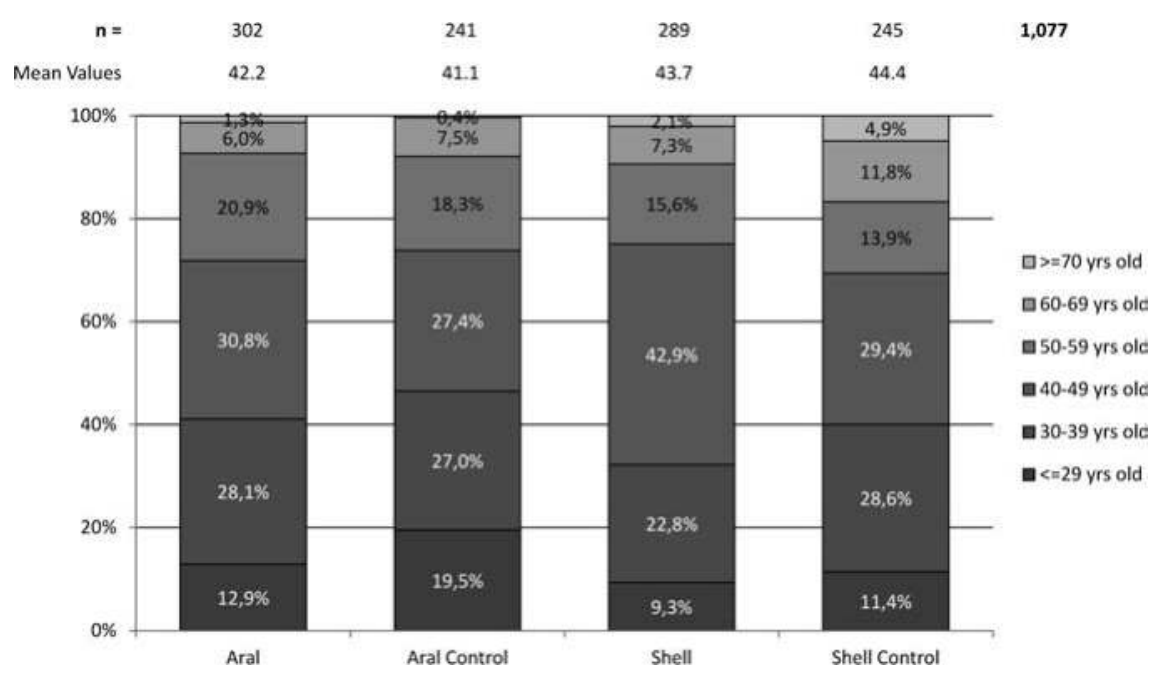

Figure 25: Descriptive Statistics - Age

\section{3) Education}

"Please indicate your highest, already completed level of education."

In the customer survey, respondents were asked to indicate their highest, already completed level of education. The different options, ranging from compulsory schooling to a doctoral degree, were considered ordinal. The clear majority of respondents marked a diploma degree as the highest completed level of education. While the low quota of bachelors and masters (which might be surprising to readers from the Anglo-American educational system) can easily be explained by the fact that these degree types were only recently established in the German educational system, the same is not true for the high overall quota of people having completed tertiary education (i.e. bachelor, diploma, master's, or doctoral degree holders). For all four groups, these values lie well above national average. The most likely explanation for this is this study's focus on fuel stations within the city of Munich - as compared to the rest of Germany an area with aboveaverage levels of education and income. While the process of selecting the specific stations where the survey forms were handed out was aimed at reducing the 
negative influence of covariates and making the sample as representative as possible, it should be noted that it is unclear whether absolute generalizability is given. The Pearson's ${ }^{2}$ value turned out to be significant $(\mathrm{p}=0.020)$ across all groups.

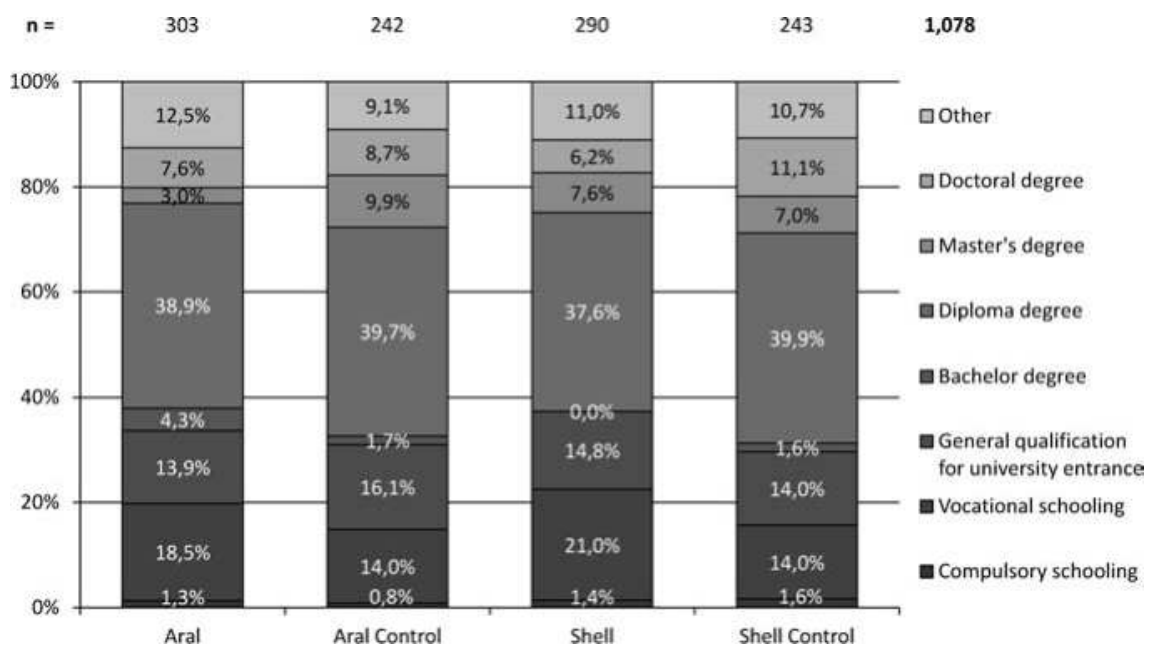

Figure 26: Descriptive Statistics - Education

\section{4) Professional Position}

"Please indicate the professional position you currently hold."

As illustrated in Figure 27, employees and civil servants with leadership responsibility made up the majority of respondents, followed by those without leadership responsibility and freelancers. Together, these three groups encompassed roughly $88 \%$ of study participants. It should further be noted that some of the six categories displayed in Figure 27 are actually an aggregation of further categories that were part of the original questionnaire. Altogether, respondents had ten options to indicate their current professional position, of which some have been consolidated for this illustration due to their small size. The Pearson's ${ }^{2}$ value was found to be highly significant $(\mathrm{p}=0.001)$. 


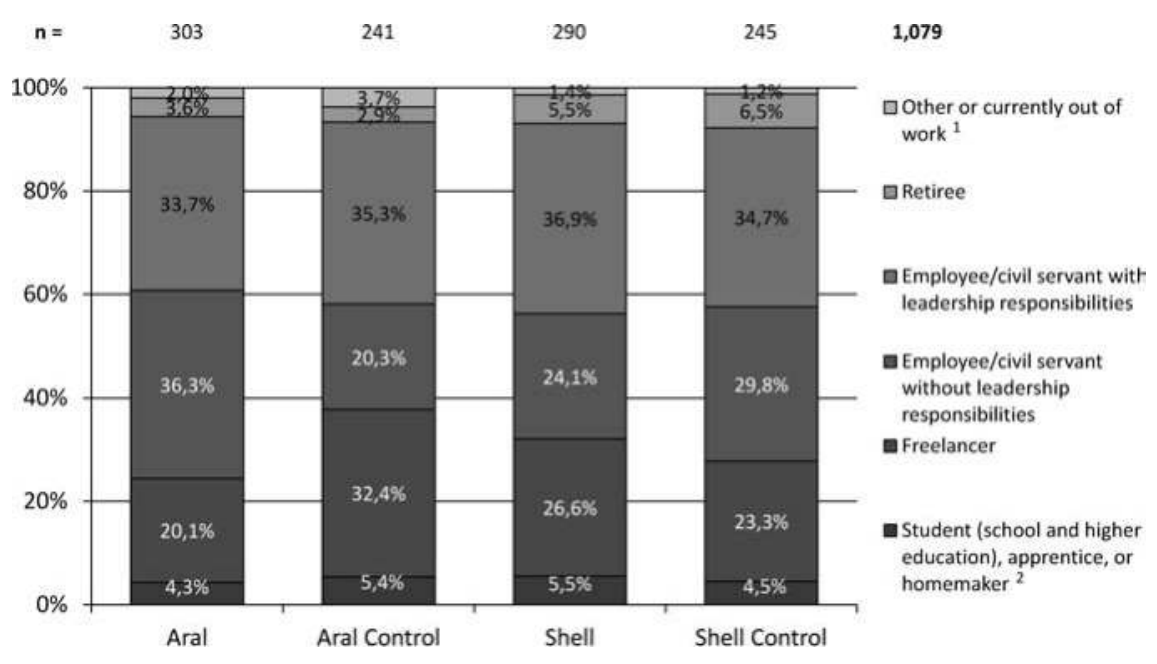

1 Originally captured as two separate categories

2 Originally captured as four separate categories

Figure 27: Descriptive Statistics - Professional Position

\section{5) Income}

"Lastly, please indicate your approximate monthly net-income (= income at your disposition after taxes and social insurance contributions are deducted)."

Next to gender, age, educational background, and professional position, customers were asked for their monthly net-income. Due to a couple of well-earning outliers, the median remains consistently below the average. It can be seen that overall, the income of Shell patrons is higher than that of Aral customers. Still, the difference between the median of the Aral and the Shell main group turned out to be 500 EUR, while that between the corresponding control groups equaled only 200 EUR and goes in the opposite direction. In addition to the overall mean and median, Table 13 also includes an overview based on gender in order to check whether this disparity has been caused by a differing composition of the customer base in terms of that variable. When looking at the gender-specific median, differences between the two Aral groups disappear. The two Shell groups still differ by 200 to 300 EUR, while interestingly, a discrepancy between the Aral and Shell main group exists only for male customers. Nevertheless, a consistent discrepancy of 200 EUR between the two control groups confirms the impression of Shell having customers with a slightly higher income. Overall, the one-way ANOVA proved to be significant $(\mathrm{p}=0.006$; Duncan test-group assignment: Group 1: Aral, Shell Control - Group 2: Shell Control, Aral Control, Shell). 


\begin{tabular}{|c|c|c|c|c|c|c|c|c|}
\hline & \multicolumn{2}{|c|}{ Aral } & \multicolumn{2}{|c|}{ Aral Control } & \multicolumn{2}{|c|}{ Shell } & \multicolumn{2}{|c|}{ Shell Control } \\
\hline & $\mathbf{m}$ & $\mathbf{f}$ & $\mathbf{m}$ & $\mathbf{f}$ & $\mathbf{m}$ & $\mathbf{f}$ & $\mathbf{m}$ & $\mathbf{f}$ \\
\hline Median & 3,000 & 2,000 & 3,000 & 2,000 & 3,500 & 2,000 & 3,200 & 2,200 \\
\hline Median (total) & \multicolumn{2}{|c|}{2,500} & \multicolumn{2}{|c|}{2,800} & \multicolumn{2}{|c|}{3,000} & \multicolumn{2}{|c|}{3,000} \\
\hline Mean & 3,679 & 2,149 & 4,021 & 2,238 & 4,062 & 2,276 & 3,763 & 2,631 \\
\hline Mean (total) & \multicolumn{2}{|c|}{2,954} & \multicolumn{2}{|c|}{3,438} & \multicolumn{2}{|c|}{3,626} & \multicolumn{2}{|c|}{3,328} \\
\hline $\mathrm{n}$ & 141 & 127 & 142 & 69 & 189 & 61 & 136 & 85 \\
\hline n (total) & \multicolumn{2}{|c|}{268} & \multicolumn{2}{|c|}{211} & \multicolumn{2}{|c|}{250} & \multicolumn{2}{|c|}{221} \\
\hline
\end{tabular}

Table 13: Descriptive Statistics - Income

Note: $\quad$ Mean values in EUR per month; listed by gender

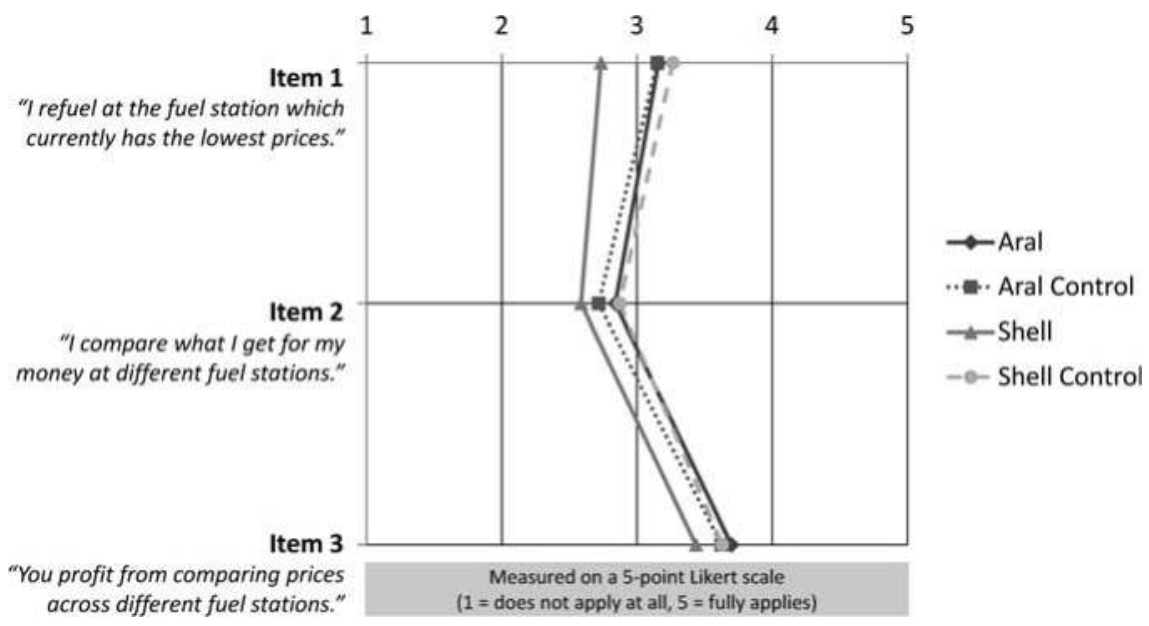

Figure 28: Descriptive Statistics - Economic Shopping Orientation

\section{6) Economic Shopper Orientation}

The construct of economic shopper orientation was operationalized with three items and measured on a 5-point Likert scale to complement the demographic and socio-economic shopper characteristics. Figure 28 provides an illustration of the mean values calculated for the four study groups. Surprisingly, only the Shell main group sticks out from the crowd. As its values differ significantly from the Shell control group (at least as far as statement 1 is concerned), it can be assumed that either the varying gender structure (possibly coupled with the underlying income levels) or the Clubsmart membership caused these different attitudes in terms of 
economic shopper orientation. Across all four groups, the one-way ANOVA showed highly significant values for Item 1 ( $\mathrm{p}<0.001$; Duncan test-group assignment: Group 1: Shell - Group 2: Aral Control, Aral, Shell Control), while Item 2 $(\mathrm{p}=0.053$; Duncan test-group assignment: Group 1: Shell, Aral Control - Group 2: Aral Control, Aral, Shell Control) and Item 3 were significant only at the $10 \%$ level ( $\mathrm{p}=0.060$; Duncan test-group assignment: Group 1: Shell, Aral Control, Shell Control - Group 2: Aral Control, Shell Control, Aral).

\section{7) Convenience Orientation}

Mixed into the latter three items operationalizing economic shopper orientation was one statement concerning the convenience orientation of customers, or specifically, a question asking customers whether they usually refuel at the fuel station with the most convenient location. Both control groups demonstrated a significantly higher level of agreement with the statement than the main groups. In addition to that, both Shell groups turned out to be slightly less convenienceoriented than their respective Aral counterpart (though not by a significant margin). Overall, the one-way ANOVA returned a highly significant value $(\mathrm{p}<$ 0.001; Duncan test-group assignment: Group 1: Shell, Aral - Group 2: Aral, Shell Control, Aral Control).

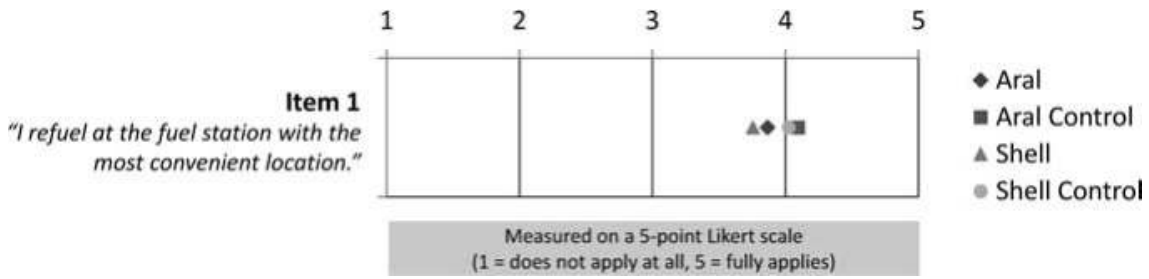

Figure 29: Descriptive Statistics - Convenience Orientation

\subsubsection{Loyalty Cards}

\section{1) Memberships in Loyalty Schemes in the Industry}

"Which one of these fuel station loyalty cards do you possess and/or at which of these campaigns do you collect sticker points (multiple answers possible)?”

It can be seen in Figure 30, that while all respondents in the Aral and Shell main group were naturally members in their respective loyalty scheme, around $86 \%$ of the Aral control group and $79 \%$ of the Shell control group possessed no loyalty card at all. Another noteworthy point is that while only $14 \%$ of the main Aral 
group and $9 \%$ of the Aral control group were members in the Clubsmart scheme, $33 \%$ of the main Shell group and 19\% of the Shell control group were members in the Payback coalition - clearly illustrating the fact that a high penetration rate is one of the key strengths of multi-partner schemes. The undoubted dominance of Payback and Clubsmart in the German fuel loyalty market, coupled with this study's focus on customers encountered at Aral and Shell fuel stations, was destined to lead to comparatively lower possession rates of other competitive loyalty cards. Still, the average membership rate with each of the remaining programs turned out at a surprisingly low $1.2 \%$ across all four groups.

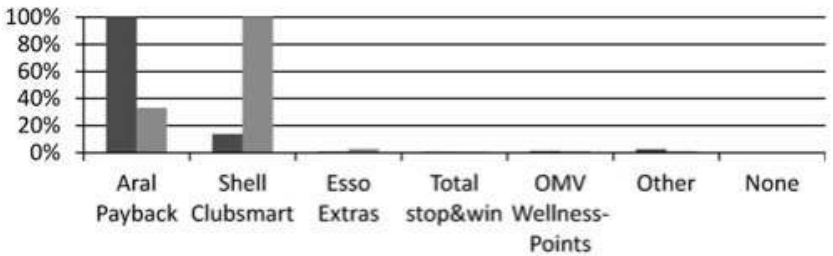

\begin{tabular}{|l|c|c|c|c|c|c|c|}
\hline Aral (absolute) & 304 & 42 & 3 & 2 & 4 & 8 & 0 \\
\hline Aral (relative) & $100.0 \%$ & $13.8 \%$ & $1.0 \%$ & $0.7 \%$ & $1.3 \%$ & $2.6 \%$ & $0.0 \%$ \\
\hline Shell (absolute) & 97 & 293 & 8 & 2 & 3 & 3 & 0 \\
\hline Shell (relative) & $33.1 \%$ & $100.0 \%$ & $2.7 \%$ & $0.7 \%$ & $1.0 \%$ & $1.0 \%$ & $0.0 \%$ \\
\hline
\end{tabular}

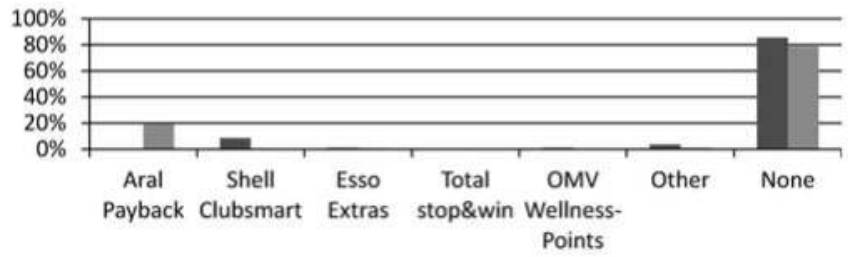

\begin{tabular}{|l|c|c|c|c|c|c|c|}
\hline $\begin{array}{l}\text { Aral Control } \\
\text { (absolute) }\end{array}$ & 0 & 21 & 3 & 0 & 3 & 9 & 207 \\
\hline Aral Control (relative) & $0.0 \%$ & $8.7 \%$ & $1.2 \%$ & $0.0 \%$ & $1.2 \%$ & $3.7 \%$ & $85.5 \%$ \\
\hline $\begin{array}{l}\text { Shell Control } \\
\text { (absolute) }\end{array}$ & 47 & 0 & 2 & 0 & 1 & 3 & 193 \\
\hline $\begin{array}{l}\text { Shell Control } \\
\text { (relative) }\end{array}$ & $19.2 \%$ & $0.0 \%$ & $0.8 \%$ & $0.0 \%$ & $0.4 \%$ & $1.2 \%$ & $78.8 \%$ \\
\hline
\end{tabular}

Figure 30: Descriptive Statistics - Memberships in Loyalty Schemes in the Industry 


\section{2) Memberships in Other Coalition Schemes}

"Which one of these two loyalty cards do you possess (multiple answers possible; please skip question if you possess neither one)?"

In addition to memberships in other fuel station schemes, the customers' participation in Germany's two other big, national coalition schemes was captured. In that regard, HappyPoints (formerly known as HappyDigits, the country's second largest multi-partner program) clearly outrivaled the Deutschland Card (the number 3 in the market). Roughly a quarter of the Aral main group and $18 \%$ of the Shell main group also holds a HappyPoints card, as compared with $4 \%$ in the Aral control group and an unexpected 10\% in the Shell control group (see Figure 31). By contrast, only a rounded $9 \%$ of the Aral main group, $8 \%$ of the Shell main group, $3 \%$ of the Aral control group, and $2 \%$ of the Shell control group are members of the Deutschland Card program.

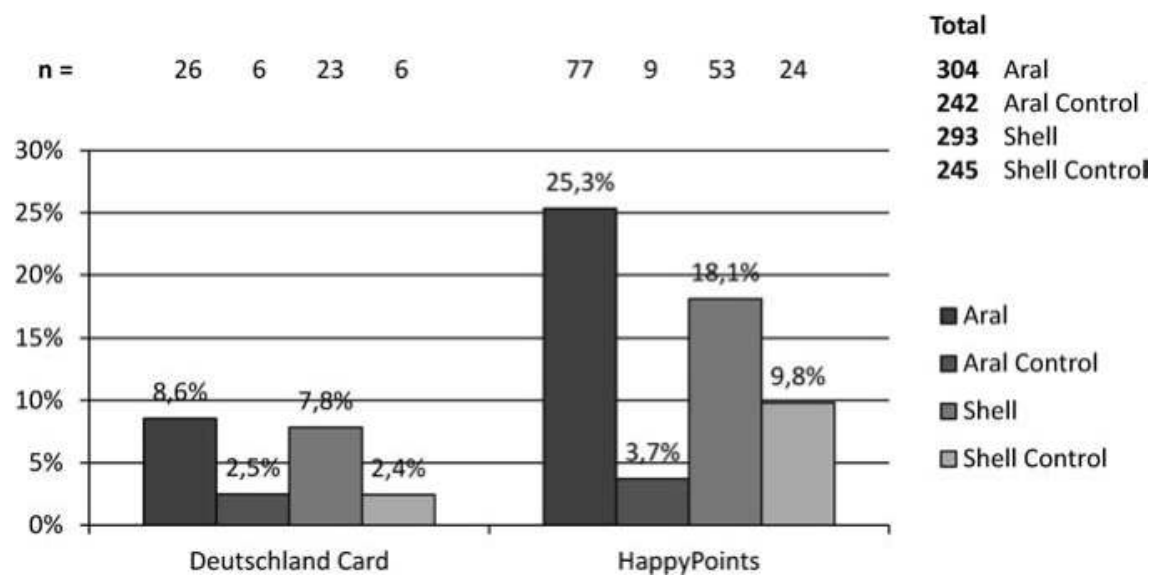

Figure 31: Descriptive Statistics - Memberships in Other Coalition Schemes

\section{3) Number of Loyalty Cards Carried}

"Altogether, how many loyalty cards do you usually carry with you (e.g. in your wallet; including all loyalty cards, not only those of fuel stations)?"

Broadening the scope to loyalty schemes in general, customers were asked how many cards they usually carry with them. While the figures for the two main groups look fairly similar at first sight, it can still be noticed that the segment of customers carrying no card at all is considerably larger at Shell than it is at Aral. Taking the common complaint of wallets overflowing with loyalty cards into consideration, this finding supports the claim that, as compared to stand-alone solu- 
tions, members of coalition schemes are more likely to carry the loyalty card (and hence have the opportunity to use it in the first place). Why, however, the amount of respondents in the Aral control group carrying no card exceeds that in the Shell control group by such a large extent is unclear. Unsurprisingly, the Pearson's 2 value turned out to be highly significant $(\mathrm{p}<0.001)$ across all groups.

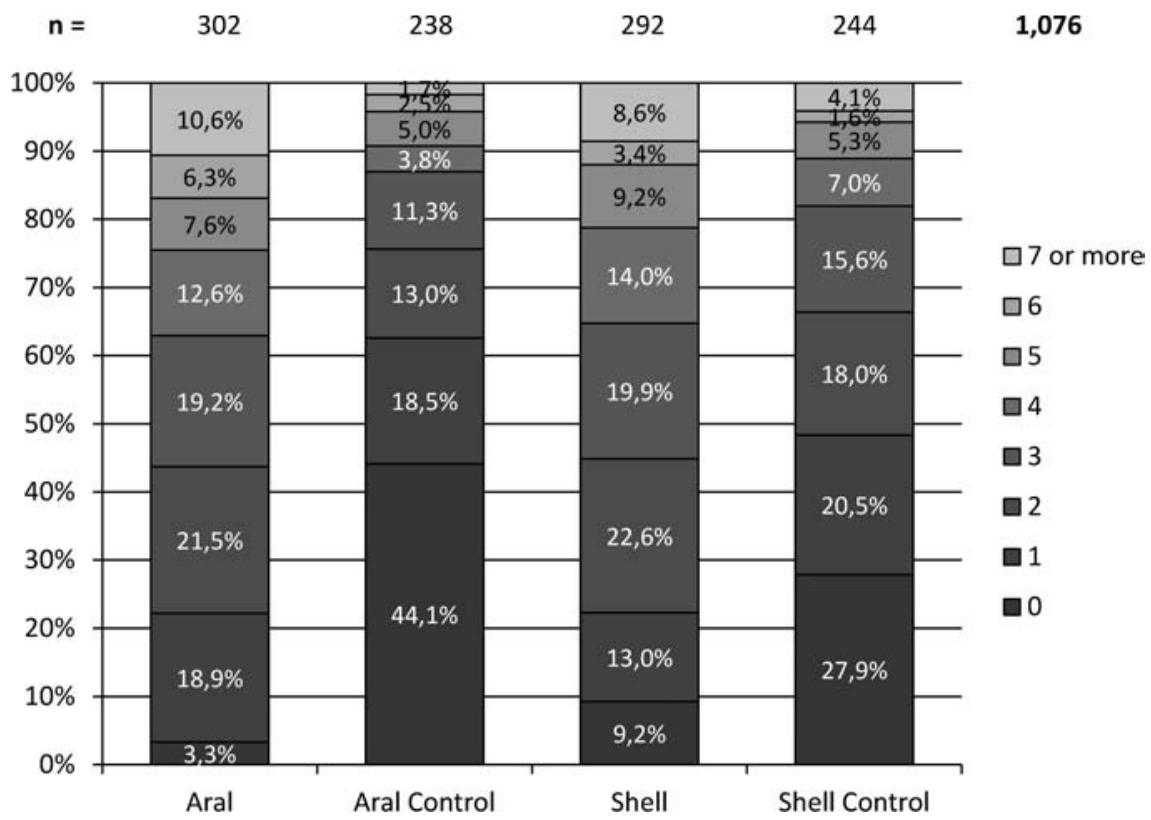

Figure 32: Descriptive Statistics - Number of Loyalty Cards Carried

\section{4) Preferred Type of Loyalty Scheme}

"Which type of loyalty program do you like best?"

Asked for their preference of one of the three basic types of loyalty scheme (sticker point/stamp collection, electronic points accumulation, or immediate discount), customers generally preferred those with immediate discount. That in itself might not have been such a surprising finding, but interestingly, in neither study group did more than $54 \%$ show a preference for that type. Whether points are redeemed for a free product or other rewards, in practice they rarely match a direct discount in terms of its monetary value (i.e. the point value of most retail loyalty schemes hovers around 0.5 to $1 \%$, while direct discounts given with a loyalty card often reach $2 \%$ and more; likewise, stamp cards frequently feature higher discount rates when completed - for instance, $9.1 \%$ in case of a "buy ten, 
get one free" stamp card). Taking that and the low diffusion of stamp cards in retailing into account, the amount favoring direct discounts still appears fairly low. Two other noteworthy points include the following: (1) the quota of respondents favoring point collection schemes is obviously biggest among the Aral and Shell main groups, but significantly larger at Shell than at Aral (even outmatching the segment preferring a direct discount). (2) The amount of people favoring a classic stamp or sticker collection scheme reaches only around $3 \%$ in the main groups, but $8-9 \%$ in the control groups (possibly due to fewer privacy issues associated with stamp cards). Across all groups, then, the Pearson's 2 value turned out to be highly significant $(\mathrm{p}<0.001)$.

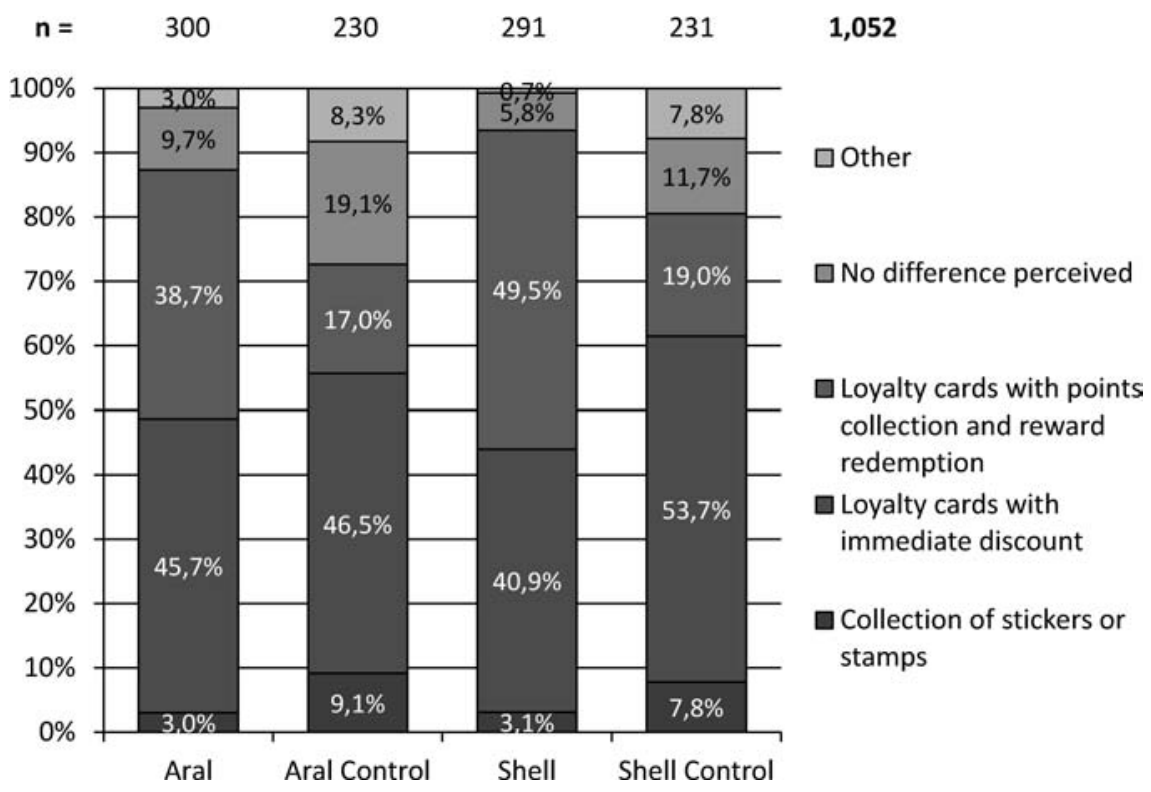

Figure 33: Descriptive Statistics - Preferred Type of Loyalty Scheme

\section{5) Barriers of Exit}

The barriers of exit construct, although not included in the main study framework, has been accommodated in this study to find out how significant loyalty card users and non-users perceive costs of change to a competitive loyalty card to be. Loyalty scheme advocates do not tire of praising point accumulation programs for their ability to create such barriers of exit. Mean values between 2 and 2.3 on the 5-point Likert scale indicate that customers are not really convinced that a switch to another fuel station loyalty card would incur a high loss of points 
and consequently rewards. While a minor difference between the main and control groups exists, it is not significant. Despite the fact that a coalition scheme might arguably be able to establish higher exit barriers as customers have higher point balances in their accounts and might consequently be aiming for a bigger reward, Shell came out slightly better than Aral in this respect. On the other hand, however, customers might have thought that with a coalition scheme, points are not entirely lost as they can still be used (and indeed, the balance further increased) with their regular purchase activity at other partner companies. As mentioned before, however, the differences between the groups proved to be non-significant (though in case of question 1 , only by a small margin), with a one-way ANOVA returning a p-value of 0.051 for Item 1 (Duncan test-group assignment: Group 1: Aral Control, Shell Control, Aral - Group 2: Shell Control, Aral, Shell) and 0.070 for Item 2 (Duncan test-group assignment: Group 1: Aral Control, Shell Control, Aral - Group 2: Shell Control, Aral, Shell).

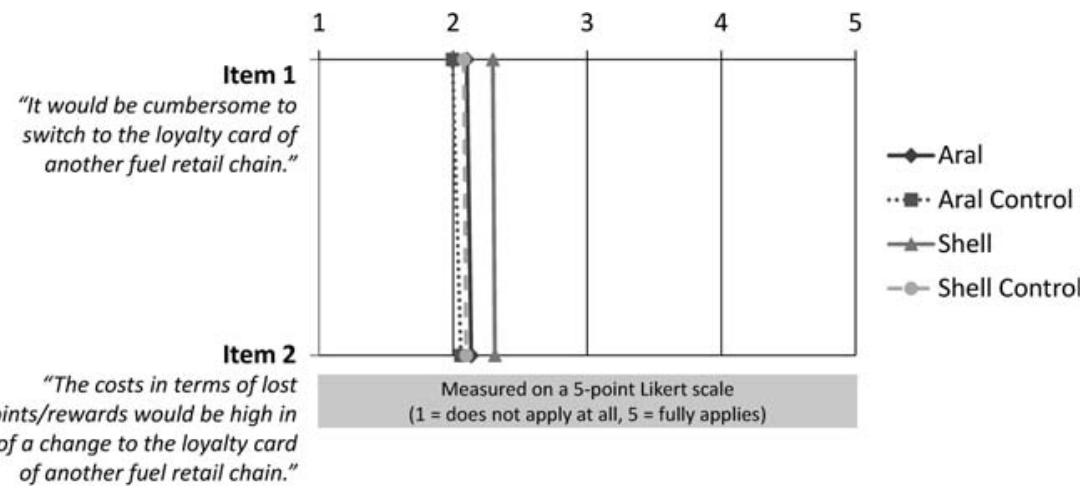

Figure 34: Descriptive Statistics - Barriers of Exit

\section{6) General Attitude Towards Loyalty Programs}

What is presented here under the headline "general attitude" is an accumulation of questions revolving around general attitudes customers have towards loyalty schemes. As seen in Figure 35, the differences between the groups are highly significant. While the mean values of respondents from the Aral and Shell main groups are almost identical, these from the two control groups vary slightly. In any case, members of the Aral or Shell program turned out to be significantly more convinced than their non-member counterparts, that loyalty cards are generally good and a good way for companies to show their appreciation to customers, as well as that they help a company to get customers committed. They also found loyalty cards less annoying and are less bothered by carrying cards of 
different companies with them. While these results were again fairly predictable, a look at both the average level of agreement with these statements as well as the differences between the main and control groups yields some remarkable insights: (1) the difference between the main and control groups is smaller for statements regarding the effect of the loyalty schemes on the issuing company (i.e. Item 1 and 3 ) as opposed to effects on the customers (i.e. Items 2, 4, and 5). (2) Across all four groups, the statement about loyalty cards helping companies to get customers committed found the highest agreement with mean values around 4 on the 5-point Likert scale. In other words, both members and nonmembers of loyalty schemes are convinced that they do indeed work. (3) The largest difference between the main and the control groups exists with regard to the statement pair "loyalty schemes are good/annoying" (Items 2 and 4). (4) The statement attracting the single highest amount of agreement is that concerning the annoyance felt when having to carry around many cards of different programs. In this case, both control groups clearly surpassed the threshold of a mean value of 4 on the 5-point scale with an average of around 4.2. The p-values calculated by the one-way ANOVA proved highly significant $(\mathrm{p}<0.001)$ across all groups for all five statements (Duncan test-group assignment - Item 1: Group 1: Aral Control, Shell Control - Group 2: Aral, Shell; Item 2: Group 1: Aral Control - Group 2: Shell Control - Group 3: Shell, Aral; Item 3: Group 1: Aral Control, Shell Control - Group 2: Shell Control, Aral - Group 3: Aral, Shell; Item 4: Group 1: Shell, Aral - Group 2: Shell Control - Group 3: Aral Control; Item 5: Group 1: Aral, Shell - Group 2: Shell Control, Aral Control).

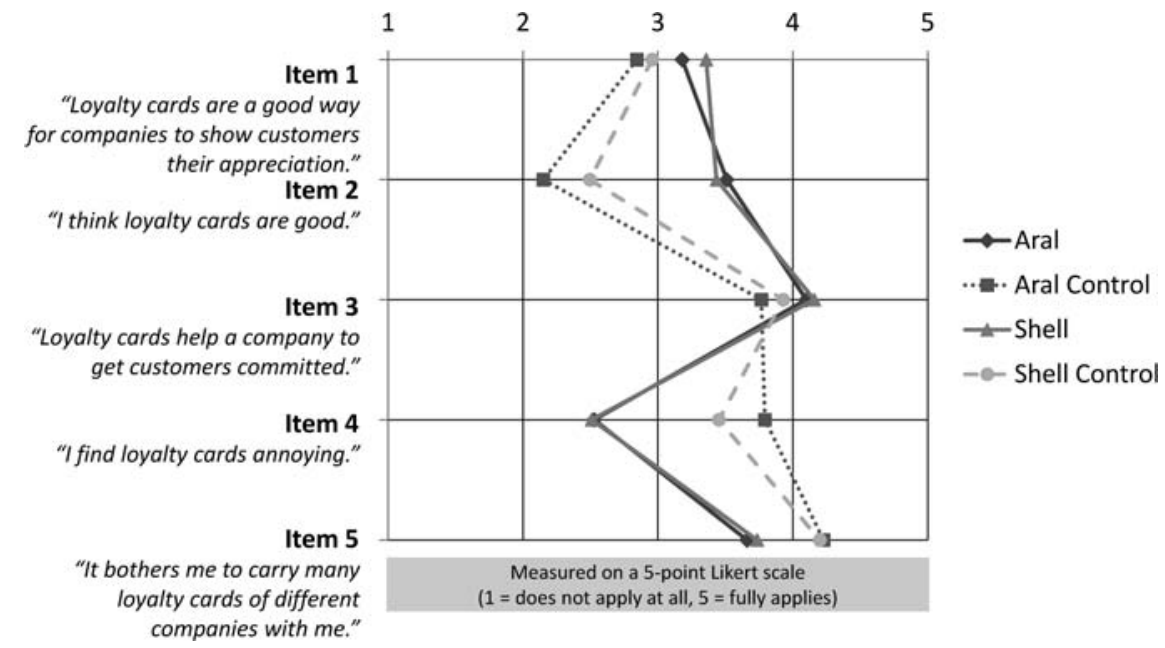

Figure 35: Descriptive Statistics - General Attitude Towards Loyalty Programs 


\section{7) Privacy Concerns}

Ending the general segment on loyalty cards, customers were asked whether (1) they are and whether (2) program members generally should be concerned about their privacy. Again, two distinct groups can be made out in Figure 36, with respondents of the control groups naturally being the bigger skeptics with regard to the privacy issue. Interestingly though, even within the main groups respondents indicated a privacy concern more often than not (with mean values between 2.5 and 3 for Item 1 and between 3 and 3.5 for Item 2). Moreover, customers were more likely to agree with the statement that holders of loyalty cards should generally be afraid, as opposed to the statement that they themselves are afraid. Most likely, however, this discrepancy can be explained by the disrupting effect of social desirability - giving room to the speculation that the responses to Item 2 are the more accurate ones. The one-way ANOVA yielded highly significant $p$-values $(p<0.001)$ for both items (Duncan test-group assignment - Item 1: Group 1: Aral, Shell - Group 2: Shell Control, Aral Control; Item 2: Group 1: Aral, Shell - Group 2: Shell Control, Aral Control).

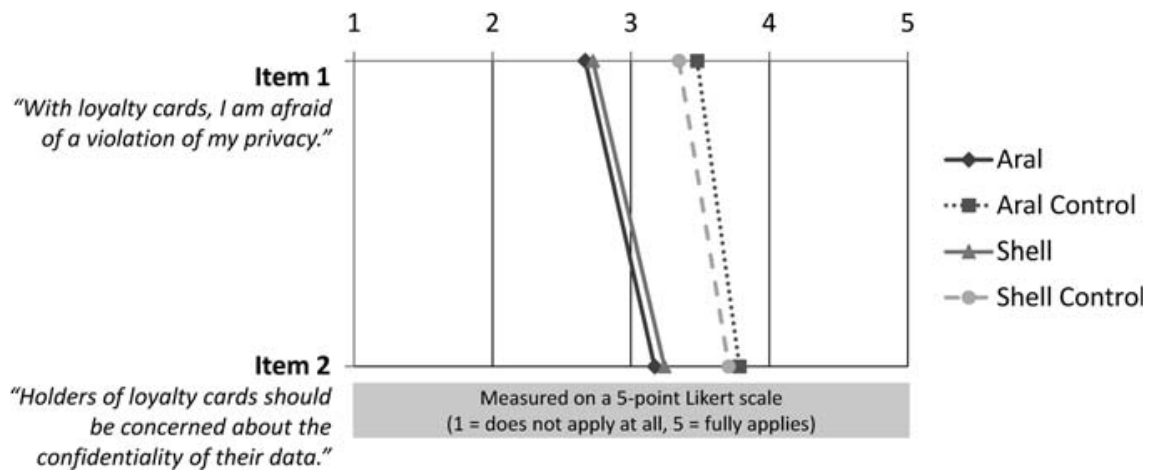

Figure 36: Descriptive Statistics - Privacy Concerns

\subsubsection{Satisfaction and Loyalty}

\section{1) Store Satisfaction}

Following the introductory section on loyalty cards in general (and a special segment for the main groups covered in Chapters 6.2.5 to 6.2.7), a passage on store satisfaction and loyalty was presented to respondents. Satisfaction was operationalized with three items, largely based on Mägi's (2003) work (see Chapter 5.5). As illustrated in Figure 37, answers were very similar within the 
main and within the control groups, but significantly different between these two. The slight drop for Item 3 can probably be explained almost entirely by the rather extreme wording used (a "perfect" fuel station), but also here, the absolute difference between the mean values for the main and control groups remains the same. Specifically, loyalty program members were found to be consistently more satisfied than non-members across all items. Whether or not this excess in satisfaction is entirely due to the loyalty program, however, is unclear. A possible explanation would be the same as often cited in relation to loyalty: customers who are already very loyal to a retailer are the ones most likely to become members of the loyalty program, as they draw the biggest benefit from it. Given, then, that satisfaction is a precursor to loyalty, it could be the case that customers within the main group have already been more satisfied in the first place. While this might be true at least for a part of the respondents, it is not unlikely, however, that the loyalty program indeed played a role. As for the result of the one-way ANOVA across all groups, values proved to be significant (Item 1: $\mathrm{p}=0.002$, Item 2: $\mathrm{p}=0.001$, Item 3: $\mathrm{p}=0.008$; Duncan test-group assignment - Item 1: Group 1: Aral Control, Shell Control - Group 2: Aral, Shell; Item 2: Group 1: Aral Control, Shell Control - Group 2: Aral, Shell; Item 3: Group 1: Shell Control, Aral Control - Group 2: Aral, Shell).

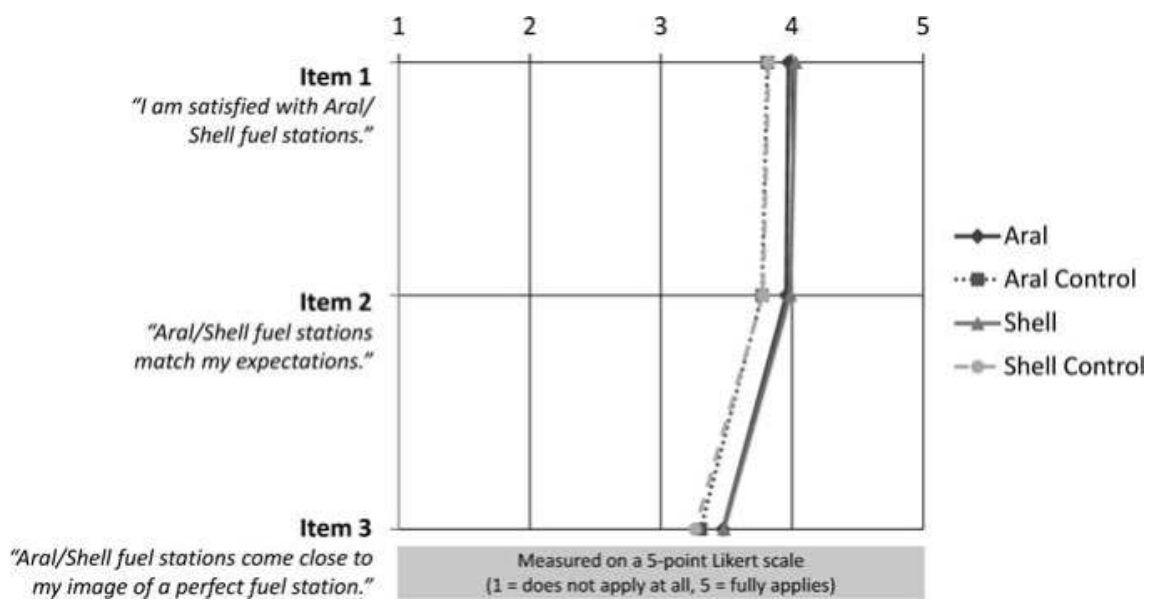

Figure 37: Descriptive Statistics - Store Satisfaction

\section{2) Attitudinal Loyalty}

In the questionnaire, attitudinal loyalty represented the first component of the loyalty construct to be checked. In order to determine the attitude (i.e. feel- 
ing/mind-set) customers have towards the company, they were asked to indicate their answer to three statements relating to their loyalty. This led to a couple of interesting findings: (1) members of the loyalty schemes were found to be significantly more loyal than members of the control group. (2) Members of the standalone program turned out to be significantly more loyal than those of the coalition scheme, while no significant difference was to be found between the two control groups (see Chapter 6.3.8 for a more detailed discussion of these findings). (3) The agreement with the attitudinal loyalty statements was clearly lower than that with the satisfaction statements. In other words, satisfaction did not fully translate into attitudinal loyalty. As far as the one-way ANOVA is concerned, $\mathrm{p}$-values proved to be highly significant for all three statements $(\mathrm{p}<$ 0.001; Duncan test-group assignment - Item 1: Group 1: Aral Control, Shell Control - Group 2: Aral - Group 3: Shell; Item 2: Group 1: Aral Control, Shell Control - Group 2: Aral - Group 3: Shell; Item 3: Group 1: Aral Control, Shell Control - Group 2: Aral - Group 3: Shell).

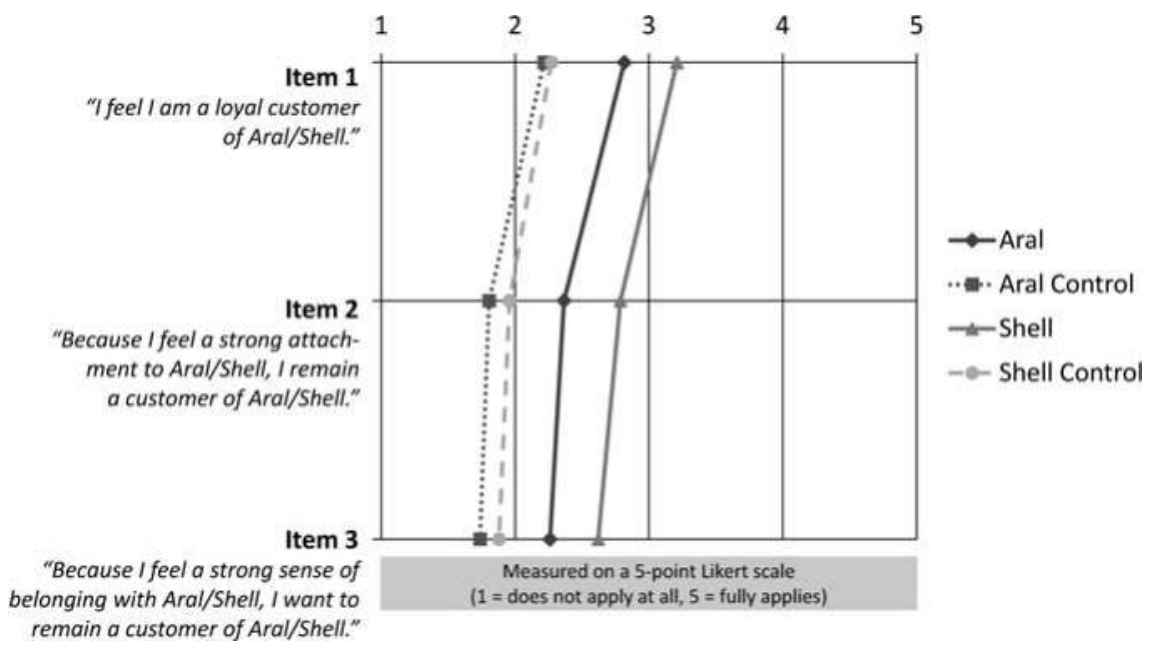

Figure 38: Descriptive Statistics - Attitudinal Loyalty

\section{3) Word-of-Mouth}

As part of the loyalty construct, word-of-mouth was operationalized as a threeitem construct. Particularly the first and third items, adopted from the work of Bridson et al. (2008), were naturally destined to lead to low levels of agreement with customers of a fuel retailer. While owners of the newest sports car or electronic gadget would clearly have been more likely to "tell friends, family, or 
colleagues about the positive experiences" with their recent purchase, patrons of a fuel stations probably would not. Nevertheless, even Item 2, which queried customers whether they would recommend the fuel station upon being asked, led to rather low levels of agreement (with mean values of around 1.8 within the control groups and 2.4 within the main groups). Still, the data revealed some noteworthy differences. Similar to the attitudinal loyalty construct, both control groups were well below the Shell main group. This time, however, the Aral main group was only able to gain significant ground over the control groups with regard to Item 2. All in all, then, the Aral group received a significantly better response than the control groups (albeit by a comparatively low margin), but clearly failed to achieve the high levels of Shell. Altogether, the one-way ANOVA delivered highly significant $p$-values for all three items $(p<0.001$; Duncan test-group assignment - Item 1: Group 1: Aral Control, Shell Control, Aral Group 2: Shell; Item 2: Group 1: Aral Control, Shell Control - Group 2: Aral Group 3: Shell; Item 3: Group 1: Aral Control, Shell Control - Group 2: Shell Control, Aral - Group 3: Shell).

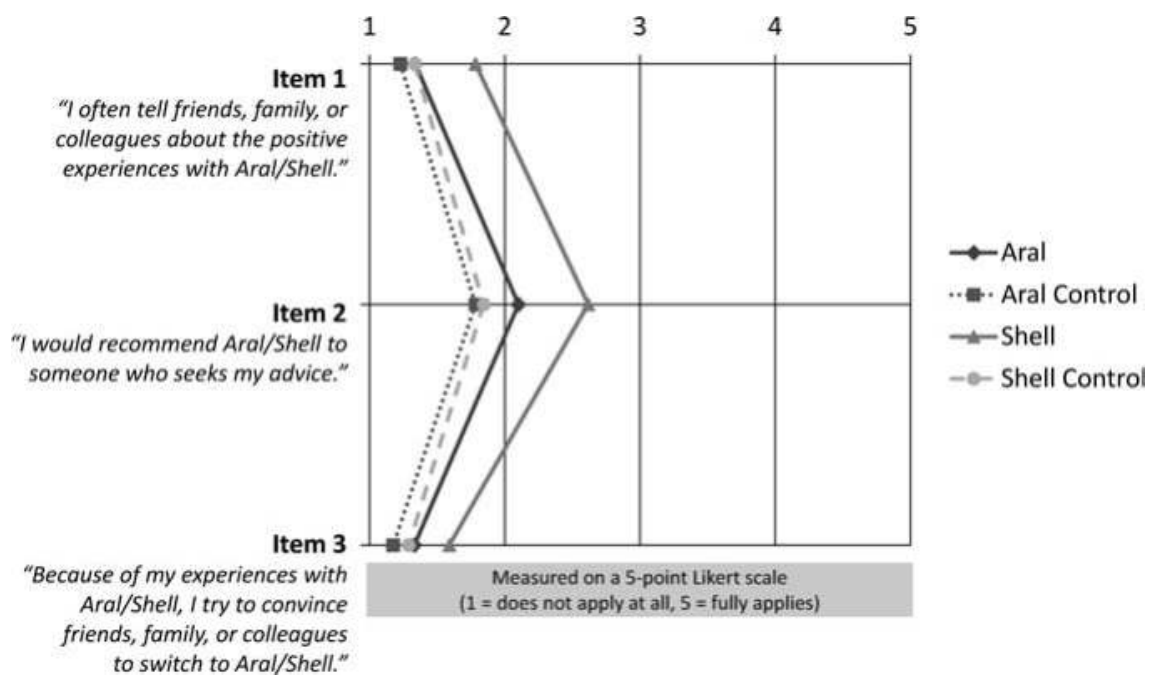

Figure 39: Descriptive Statistics - Word-of-Mouth

\section{4) Loyalty Scheme-Related Loyalty}

Mixed into the section containing the items of the satisfaction, attitudinal loyalty and word-of-mouth construct was a single direct question asking customers whether they would continue to patronize the fuel station even if the loyalty 
program did not exist. For control purposes (and despite the loss of content-wise relevance), this question was also included in the control group survey forms. Yet again, the values of the two control groups turned out to be fairly similar, with Aral one step and Shell two steps ahead. In this case, however, a high level of agreement signifies a lower dependency on the loyalty scheme, or in other words, a higher level of non-scheme-related loyalty. One possible source of error, discovered only after the collection of data, is that the phrasing of the statement asks whether customers would still "prefer" to refuel at the station, instead of "continue to patronize it the way have done so far" (which could be a problem for respondents who did not prefer to refuel there before either). This, in fact, is also the most probable reason for the low mean values within the control groups. To test this hypothesis, a one-way ANOVA was performed only with those respondents who had a share-of-wallet of $50 \%$ or higher at their respective chain. A p-value of 0.824 confirmed that all behaviorally loyal customers really do behave the same, as far as this issue is concerned. Only when using the full data set, did the one-way ANOVA return a highly significant $\mathrm{p}$-value $(\mathrm{p}<0.001$; Duncan test-group assignment: Group 1: Shell Control, Aral Control - Group 2: Aral Group 3: Shell) - supporting the hypothesis that it is indeed in relation to the behaviorally less loyal customers that the difference comes into play, as it is they who would have been affected by this phrasing problem. In any case, these limitations simply need to be kept in mind when interpreting the result that program members were characterized by a fairly high level of scheme-related loyalty.

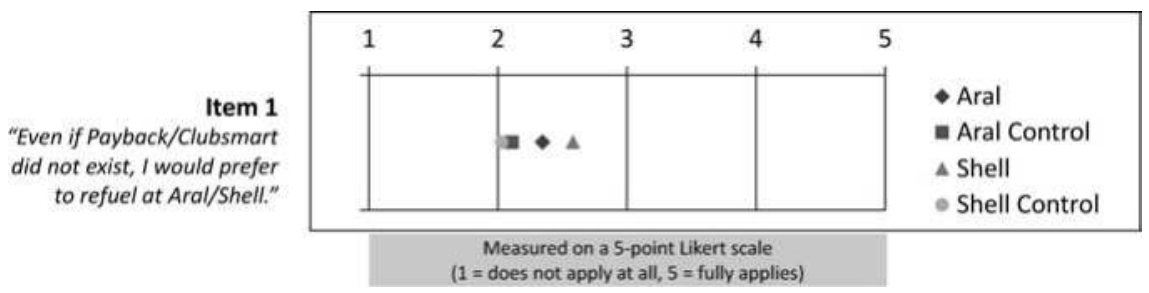

Figure 40: Descriptive Statistics - Loyalty Scheme-Related Loyalty

\subsubsection{Purchase Behavior}

1) Share-of-Wallet

"Please estimate how your total expenditure for fuel is divided up among the following fuel stations. Please distribute 100\% among the different chains (leave chains you do not visit blank)." 
To determine the purchase behavior across the whole category, customers were asked to indicate how their spending on fuel is divided up between the different fuel chains. Next to the eight largest national competitors, respondents also had the option of picking an "other" category, summing up the remaining small, regional and other independent fuel chains or individual stations. Similar to the share of around 9\% that Aral program members spent at Shell stations, Shell program members spent roughly $12 \%$ of their category expenditure at Aral stations. As far as the patronization of the own chain is concerned, things look different though. While the share-of-wallet allotted by the Aral main group to Aral stations equals $49 \%$ on average, members of the Shell main group spend a stunning $66 \%$ of their budget at Shell stations. Between the two control groups, only minor differences could be discovered (see Table 14) and it should also be emphasized, that no significant discrepancy in the availability of competitive options between the fuel stations where the survey was conducted could be noted.

\begin{tabular}{|l|c|c|c|c|c|c|c|c|c|c|c|}
\hline \multicolumn{3}{|c}{ Aral } & \multicolumn{2}{c}{ Shell } & \multicolumn{2}{c|}{ Esso } & \multicolumn{2}{c|}{ Jet } & \multicolumn{2}{c|}{ Avia } & \multicolumn{2}{c|}{ Total } & \multicolumn{2}{c|}{ Agip } & OMV & \multicolumn{2}{c|}{ Other } & TOTAL \\
\hline Aral & $48.9 \%$ & $9.3 \%$ & $5.5 \%$ & $8.8 \%$ & $1.0 \%$ & $1.2 \%$ & $4.7 \%$ & $6.9 \%$ & $13.8 \%$ & $100 \%$ \\
\hline Shell & $12.1 \%$ & $65.6 \%$ & $3.3 \%$ & $4.7 \%$ & $0.5 \%$ & $1.1 \%$ & $4.0 \%$ & $2.1 \%$ & $6.8 \%$ & $100 \%$ \\
\hline $\begin{array}{l}\text { Aral } \\
\text { Control }\end{array}$ & $31.9 \%$ & $13.7 \%$ & $8.2 \%$ & $9.9 \%$ & $1.5 \%$ & $3.4 \%$ & $6.9 \%$ & $8.9 \%$ & $15.4 \%$ & $100 \%$ \\
\hline $\begin{array}{l}\text { Shell } \\
\text { Control }\end{array}$ & $17.4 \%$ & $30.9 \%$ & $8.3 \%$ & $9.1 \%$ & $0.8 \%$ & $1.6 \%$ & $7.4 \%$ & $5.9 \%$ & $18.6 \%$ & $100 \%$ \\
\hline
\end{tabular}

Table 14: Descriptive Statistics - Share-of-Wallet

Note: $\quad n=1,065$ (Aral: 297, Shell: 291, Aral Control: 236, Shell Control: 241)

\section{2) Purchase Frequency}

"Please estimate how often per month you visit a fuel station to refuel your vehicle."

In addition to share-of-wallet, purchase frequency was measured as another indicator for behavioral loyalty, with the data gathered revealing an unexpected picture. While the frequency of purchase was lower in the Shell control group as compared to the Shell main group, the opposite was found to be the case for Aral. At the same time, a notable difference turned out to exist between the two control groups - suggesting interferences by other variables. What is particularly startling about this is the fact that the purchase frequency is higher at the Shell main group as compared to the Aral main group, but lower at the Shell control group as compared to the Aral control group. 


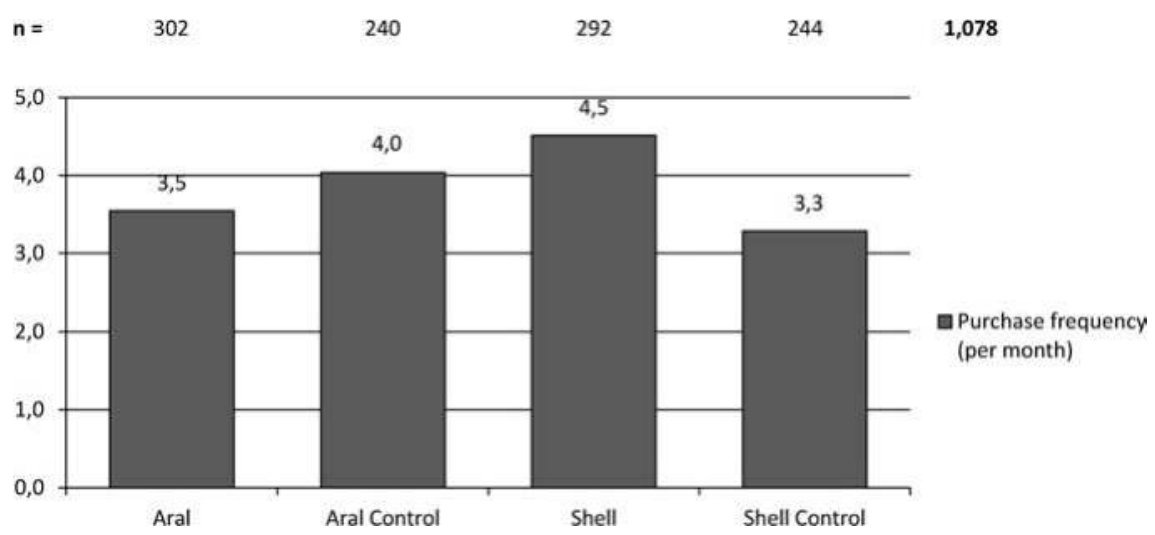

Figure 41: Descriptive Statistics - Purchase Frequency

\section{3) Monthly Category Spend and Cost per Tank}

"Please estimate how much money you currently spend on fuel per month."

"Please estimate how much you currently pay for an average tank of fuel."

Similar to the frequency of purchase, the mean values for the Shell main group clearly exceeded those of both the Aral groups as well as the Shell control group, while at the same time, the Aral control group exceeded the Shell control group. Although at least part of the high monthly spend of members of the Shell main group can be explained by the higher average fuel cost per tank in combination with the higher frequency of purchase, there appears to be more to it. This becomes apparent when looking at the Aral control group, where, as compared to the other three groups, the multiplication of purchase frequency times average fuel tank leads to the outcome with the biggest difference to the declarations for monthly fuel spend. It should be noted that while this calculation is never far from accurate (i.e. the difference equals around 14 EUR for all, except the Aral control group), individual respondents might nevertheless have misunderstood the question in that some indicated the average amount of fuel they usually fill into their tank (e.g. somebody might refuel exactly 20 liters every visit, no matter how empty the tank is), while others indicated the amount it would take to fill up a completely empty tank. 


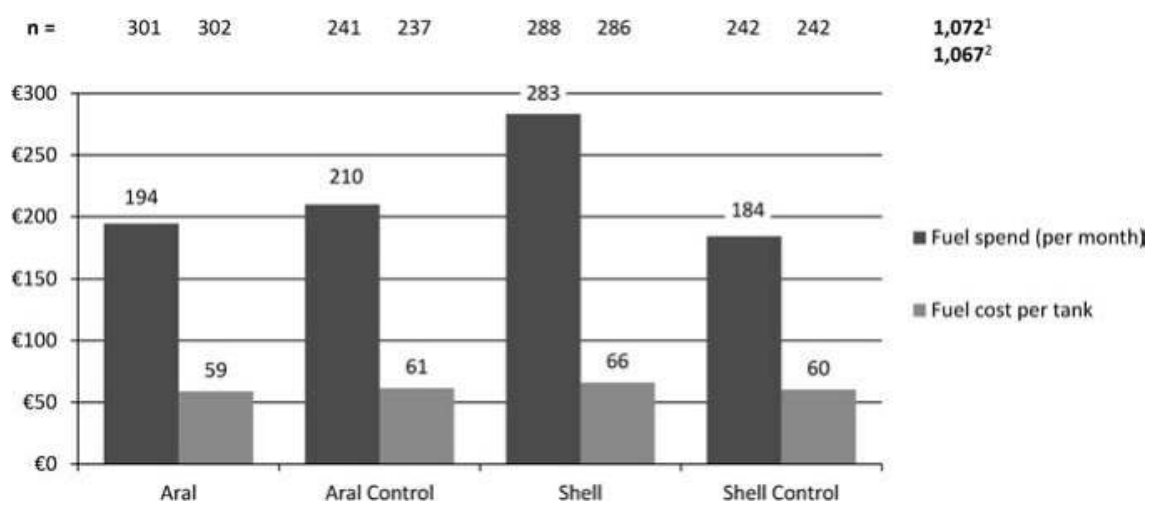

1 Fuel spend

2 Fuel cost per tank

Figure 42: Descriptive Statistics - Monthly Category Spend and Cost per Tank

\subsubsection{Common Loyalty Program Member-Specific Items}

While the questions covered so far were the same for all four groups, there were some that only the survey form for the main group contained. Out of those questions on the "extra page" (control group forms were 3 pages and main group forms 4 pages long), some were tailored to the respective loyalty program, while others were identical for both main groups and thus allow for a comparison. This comparison will be presented in this section.

\section{1) Place Where Loyalty Card is Kept}

"Where do you usually keep your Payback/Clubsmart card?"

The wallet is, with $92 \%$ for Aral and $69 \%$ for Shell, the clear number 1 place to keep the loyalty card. Compared to Aral, however, Shell customers were significantly more likely to keep the card in the car. Two factors are assumed to be responsible for this: (1) the Aral Payback scheme is a loyalty coalition with other partner companies where customers do not necessarily go to shop at with their car. Keeping the loyalty card of a fuel station in one's personal vehicle, however, ensures that it is always there when a purchase is made (with the exception of people owning more than one car). Furthermore, no wallet space is used up in that case. (2) The quota of women participating in the Payback scheme is higher than that in the Clubsmart program, and as women generally do not carry their 
wallet in a pocket of their pants, they are also less likely to be bothered by a purse bloated with loyalty cards. Finally, it should be noted that the "other place" category also includes respondents who do not use the card anymore and, for instance, have it lying around somewhere at home. With 3.3\% for Aral and 4.5\% for Shell, these groups are not very large, however. Across both sample groups, the Pearson's ${ }^{2}$ value turned out to be highly significant $(\mathrm{p}<0.001)$.

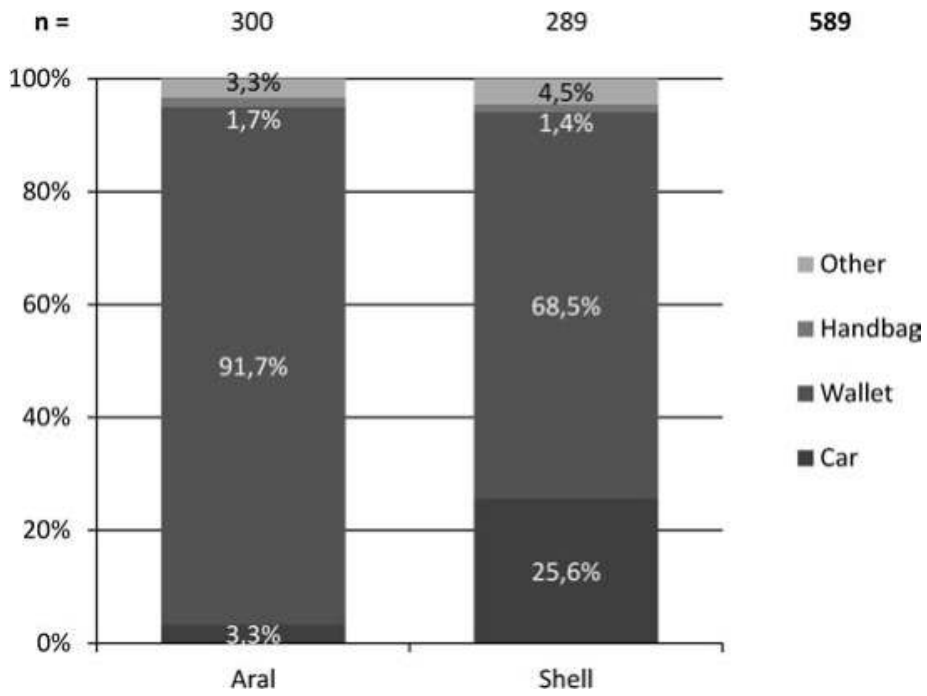

Figure 43: Descriptive Statistics - Place Where Loyalty Card is Kept

\section{2) Reward Redemption Behavior}

"Have you ever redeemed Payback/Clubsmart points for a reward?"

In the questionnaire, customers had to pick from the answer options presented in Figure 45 and thereby indicate both whether and where they had ever redeemed points for a reward. As these answer options are not comparable, however, yes/no categories were introduced ex post in order to engage in at least some degree of comparison. This comparison, illustrated in Figure 44, shows that the percentage of respondents in the Aral group who had at least once redeemed points for a reward exceeds that of Shell by a small, albeit significant margin. Specifically, the Pearson's ${ }^{2}$ test delivered a p-value of 0.045 . While the Payback scheme offers a wider range of redemption options without connection to fuel retailing (due to its connection with a range of different partner companies), 
Shell offers an narrower set of items overall with more (though not exclusively) firm-related rewards. Even more important, however, is the fact that Aral offers only three firm-related options to be redeemed at the fuel station (i.e. payment with points, a car wash, or coffee and a sandwich; see Table 10 in Chapter 5.1.3), while the majority of Shell's rewards can be picked up at the station. While firmrelated rewards have been found to generally be the better choice for a company running a loyalty program (see Chapter 3.3.8), the coalition scheme still appeared to be able to convince more customers to redeem their points (which customers did primarily via Payback directly or other Payback partners). Next to other things, different communication activities might have helped as well, of course, leaving it open how big a role the redemption options themselves really played.

$n=$

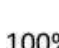

$100 \%$

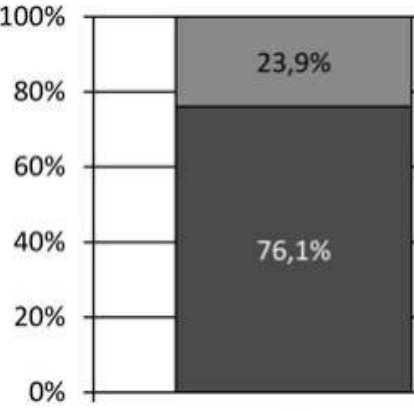

Aral

301
291

592

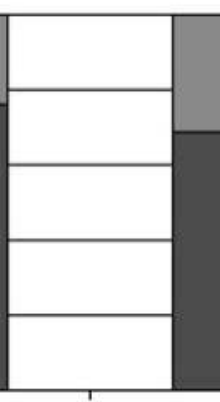

Shell

Figure 44: Descriptive Statistics - Reward Redemption Behavior

Note: $\quad$ Customers were asked whether they have ever redeemed points for a reward 


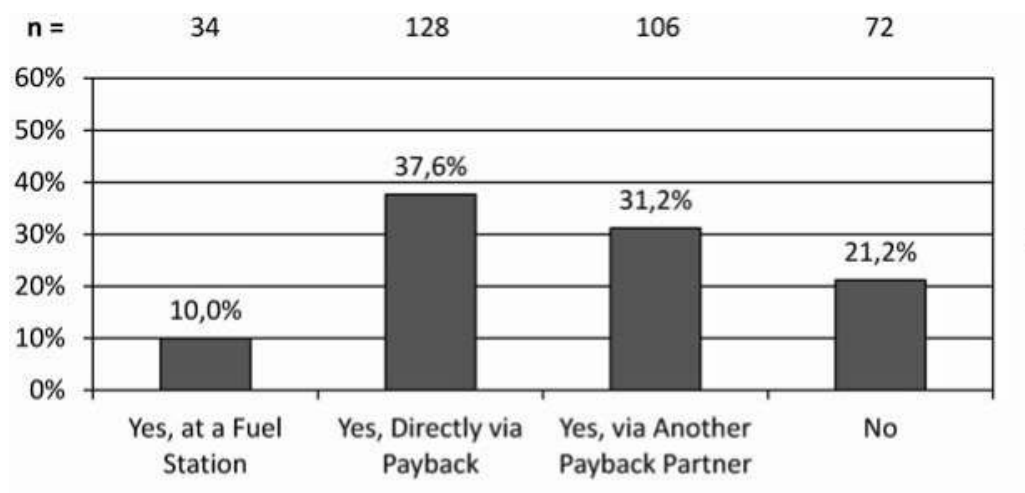

$340^{1}$

$301^{2}$

Aral

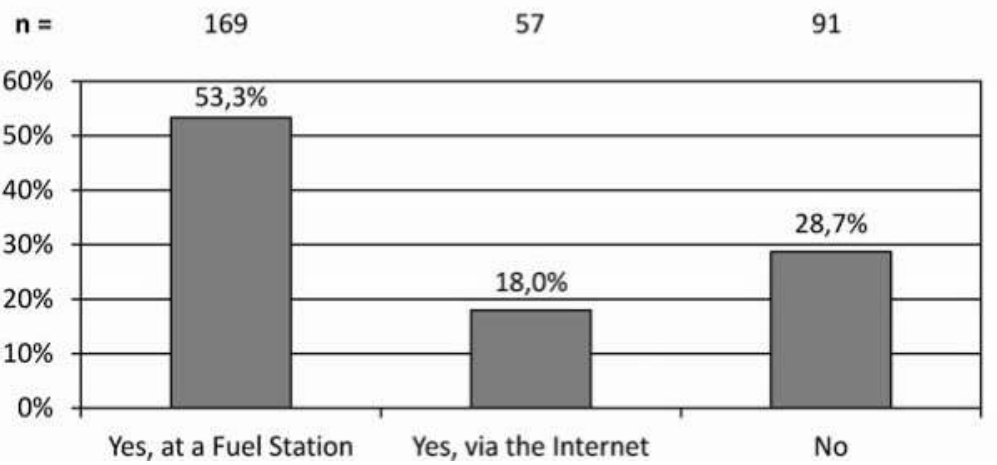

1 Including multiple answers (= number of answers given)

2 Excluding multiple answers (= number of respondents)

Figure 45: Descriptive Statistics - Reward Redemption Behavior (Details)

Note: $\quad$ Customers were asked whether and via what channel they have ever redeemed points for a reward

\section{3) Patronization Prior to Program Membership}

"Did you already visit Aral/Shell stations to refuel before you became a member of Payback/Clubsmart?"

"If yes (otherwise please skip question): Compared to today, did you refuel there ... in the past?" [options: rather less frequenlyt, about the same amount of times, rather more frequently]

Respondents were faced with these questions to determine two things: (1) whether the loyalty program might have caused them to start patronizing the fuel station and (2) whether the membership might have caused them to intensify the 
patronization of the fuel station (e.g. by increasing the share-of-wallet). In case of question 1, no significant difference could be made out between the two groups. Within both the Aral and Shell main group, around 6\% of respondents declared that they had not refueled their vehicle at these fuel stations prior to their loyalty program membership. In other words, roughly $6 \%$ of the chains' customers can be considered new customers that were acquired through the loyalty program.

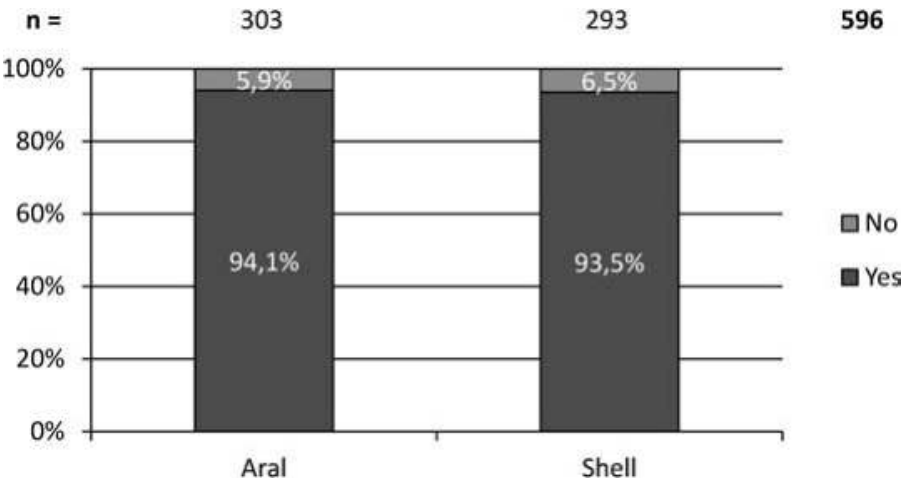

Figure 46: Descriptive Statistics - Patronization Prior to Program Membership

In case of question 2, significant differences do exist, however. While the amount of people indicating more frequent purchases in the past was found to be similar for both groups with a value of around 10\%, 27\% of Aral customers stated that they had purchased there rather less frequently in the past, as compared with $38 \%$ of Shell customers. The p-values calculated by Pearson's ${ }^{2}$ equaled 0.783 for question 1 and 0.012 for question 2 .

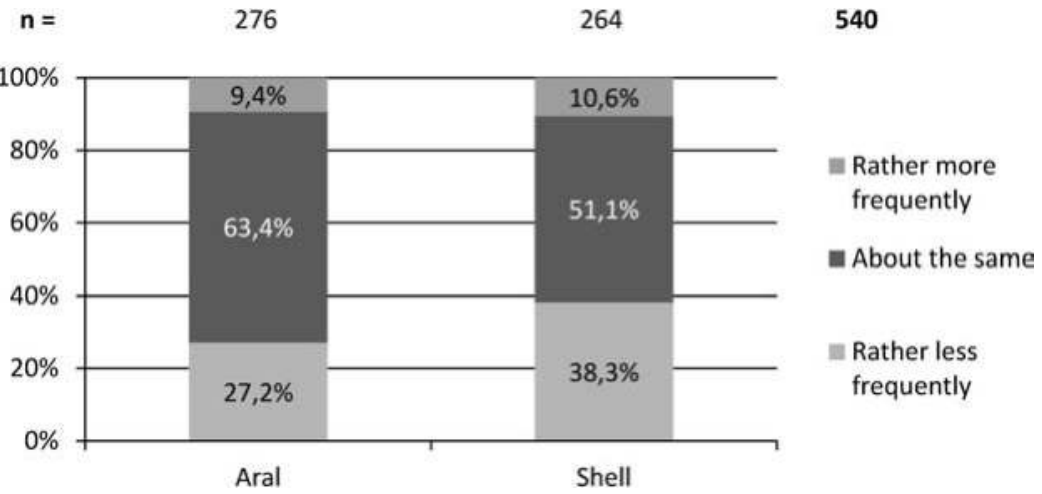

Figure 47: Descriptive Statistics - Past Purchase Frequency 


\section{4) Reaction to Up-Selling Incentives}

"Have you ever been motivated by extra Payback/Clubsmart points to refuel with Ultimate 100 or Ultimate Diesel/V-Power Racing 100 or V-Power Diesel, even though you would have normally purchased regular fuel or diesel?"

It should be noted that the original Shell survey form contained an additional category for V-Power 95, which was listed separately to permit a clean comparison [V-Power 95 is a premium version of its regular fuel, but with the same octane number. Specifically, Shell offers (1) regular 95 octane fuel and (2) regular Diesel, plus (3) a premium fuel with 95 octane, (4) a premium fuel with 100 octane, and (5) a premium Diesel. Except for the premium fuel with 95 octane, Aral offers the same range at most fuel stations.]. It can be seen in Figure 48 that as compared to the Aral main group, significantly more members of the Shell loyalty program declared that they had previously been persuaded by extra points to try out a premium fuel $(26 \%$ as opposed to $7 \%$ at Aral). The Pearson's value turned out to be highly significant $(\mathrm{p}<0.001)$ across these two groups.

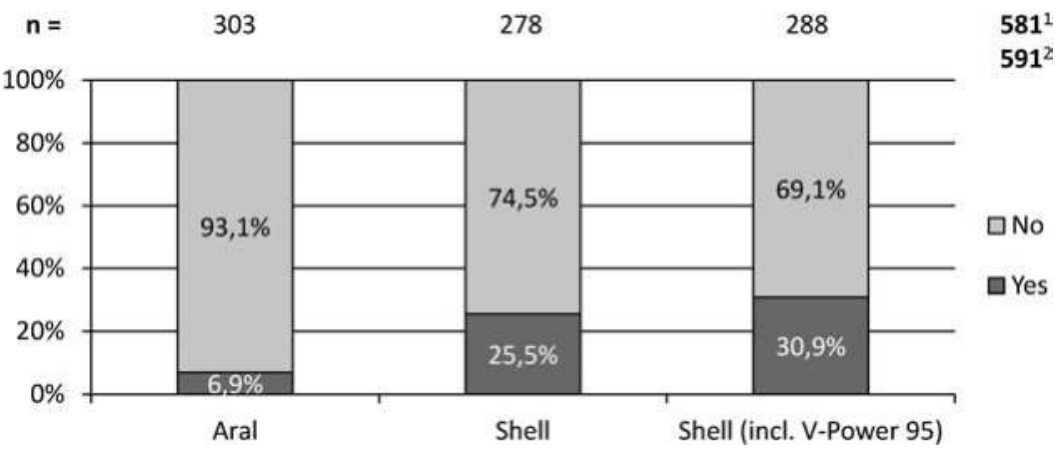

1 Excluding V-Power 95 (= clean comparison)

2 Including V-Power 95

Figure 48: Descriptive Statistics - Reaction to Up-Selling Incentives

In addition to the comparison given above, further details about (1) the answers of the Shell main group, as well as (2) the response to a follow-up question also belong in this paragraph. The more detailed view available for the Shell main group is presented in Figure 49. With around 20\%, V-Power Diesel is clearly Shell's most successful premium product, followed by V-Power 95 and Shell's most expensive product - V-Power Racing 100. These figures need to be interpreted with care, however, as no information about the type of fuel the respondents' cars require was captured. The only thing that can be added to this analysis are the statistics prepared by Germany's Federal Motor Transport Authority (Kraftfahrt- 
Bundesamt). The Kraftfahrt-Bundesamt (2010) reported that the share of diesel cars on the road on January 1, 2010, equaled $25.9 \%$, compared with $73 \%$ powered by regular fuel and $1.1 \%$ by gas, electricity, or a hybrid. Given the dominance of vehicles powered by regular fuel, the high proportion of people purchasing premium diesel is thus fairly impressive.

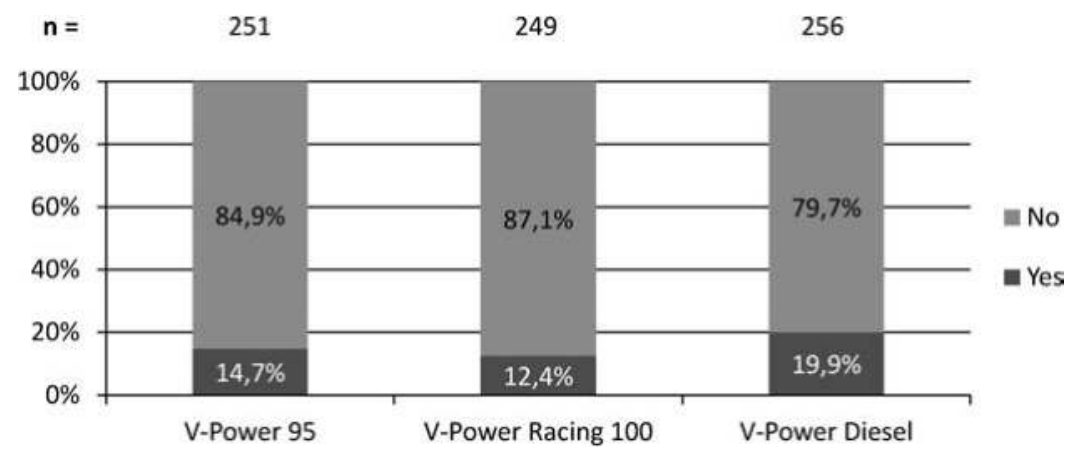

Figure 49: Descriptive Statistics - Reaction to Up-Selling Incentives (Details Stand-Alone Program)

"If yes (otherwise please skip question): Did you permanently stick with Ultimate/V-Power fuels afterwards?"

The follow-up question mentioned in the previous paragraph was whether customers who tried out premium fuels due to a point incentive continued to purchase them afterwards. The number of respondents listed in Figure 50 corresponds to those in Figure 48 who have tried out premium fuels (e.g. $303 * 6.9 \%=$ 21 in case of Aral). Like the higher percentage of customers persuaded to try these fuels at Shell, a larger percentage did stick with them later on. In the direct comparison with premium 100 octane fuel and premium diesel only (left two columns in Figure 50), Shell again clearly outrivaled Aral. 31\% of Shell customers, as opposed to around 5\% of Aral patrons who have tried out the fuels (note: which equates to only one customer, due to the small sample of 21 users), decided to also buy them afterwards. A further point that should be noted is the fact that customers did not seem to be as convinced of V-Power 95 as they were of the other two types of premium fuels. While the overall sample size increases with the inclusion of V-Power 95 (see right column in Figure 50), the quota of people continuing to buy premium fuels decreases. 


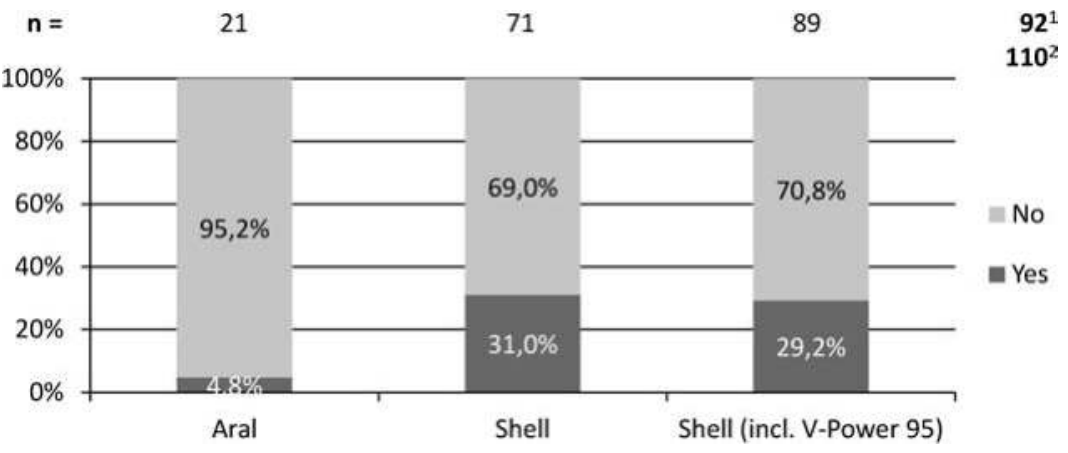

1 Excluding V-Power 95 (= clean comparison)

2 Including V-Power 95

Figure 50: Descriptive Statistics - Permanent Change to Premium Product

\section{5) Rating of Own Program}

It can be seen in Figure 51 that as compared to the stand-alone solution, members of the coalition scheme were significantly more convinced of the quality of their loyalty program and the benefits it has to offer. Still, with values between 3.0 and 3.5 in the case of Shell and 3.5 and 4.0 in the case of Aral, both programs attain rather high levels of agreement to these statements on the 5-point Likert scale. The t-test delivered highly significant $p$-values $(p<0.001)$ for both statements.

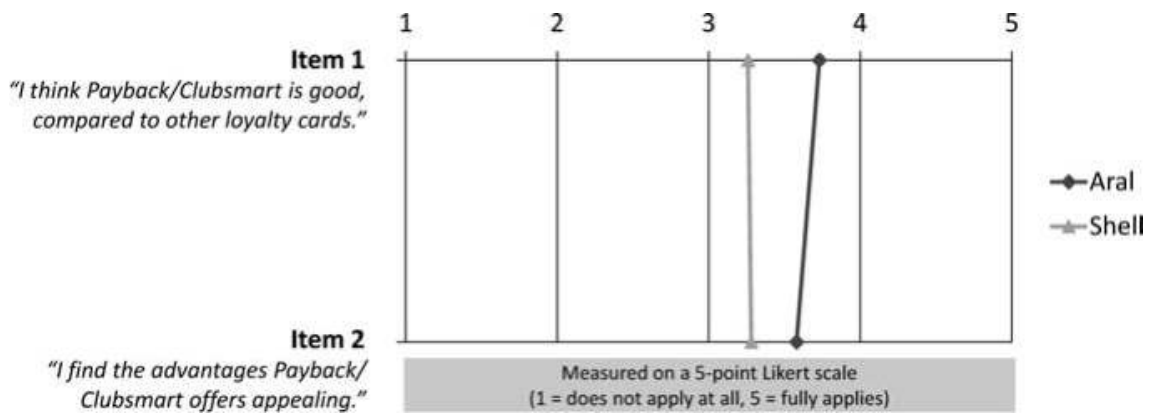

Figure 51: Descriptive Statistics - Rating of Own Program 


\section{6) Assessment of Point and Reward Structure}

In all four areas - reward attractiveness, fairness of amount of points received, speed with which a good reward can be attained, and strenuousness of collecting points - the coalition scheme had the edge over the stand-alone program. For the first two statements, however, the difference proved to be insignificant. With mean values between 3.0 and 3.5 for both Aral and Shell, perception of reward attractiveness as well as the fairness of the amount of points received average to rather positive ratings. Clearer differences between the two groups become evident when looking at the latter two statements regarding the speed with which good rewards can be obtained and concerning the effort required to collect points. Members of the coalition scheme found it significantly easier to collect points and to quickly attain a good reward. Across these two groups, insignificant $\mathrm{p}$-values for Item $1(\mathrm{p}=0.078)$ and Item $2(\mathrm{p}=0.150)$, but highly significant values for Item $3(p<0.001)$ and Item $4(p=0.002)$ were calculated by the t-test.

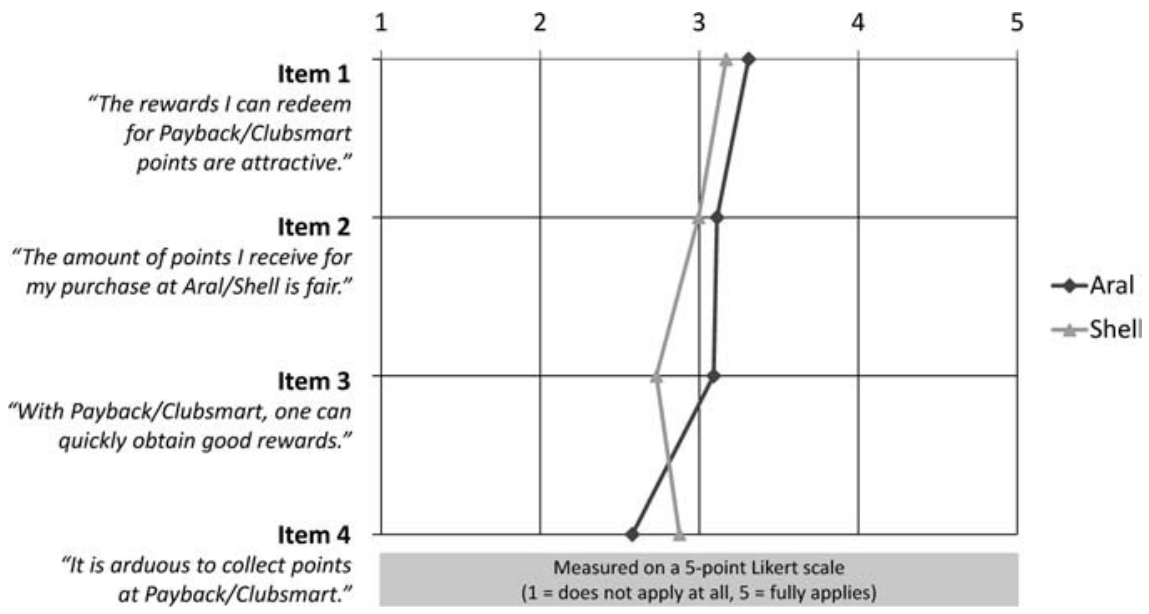

Figure 52: Descriptive Statistics - Assessment of Point and Reward Structure

\section{7) Regularity of Use}

With mean values between 4 and 4.5, this statement inquiring about the respondents' regularity of use of the loyalty card received some of the highest approval ratings in the study. In other words, both Payback and Clubsmart members used their loyalty card very regularly (albeit not always), although this time Shell turned out to have the lead over Aral. According to the t-test, which computed a $\mathrm{p}$-value of 0.030 , the difference is also significant. 


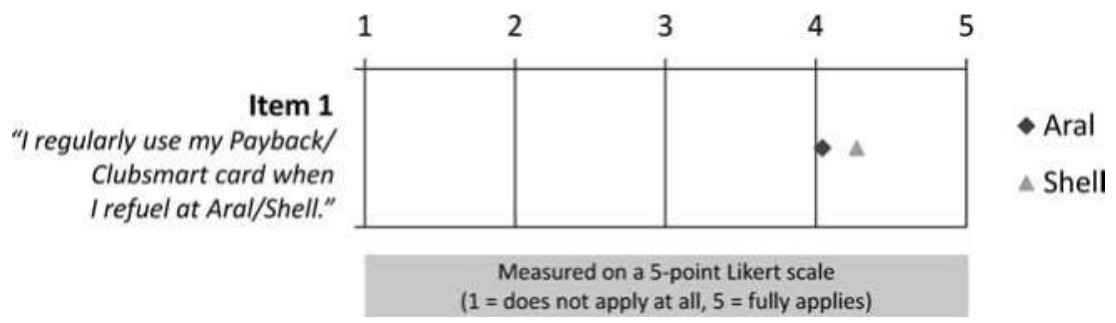

Figure 53: Descriptive Statistics - Regularity of Use

\section{8) Alteration of Purchase Behavior Through Membership}

Interestingly, no other Likert-scale question in the survey form revealed such big differences between the two main groups as these statements asking whether customers actively favored the fuel station since they became a member of that chain's program or whether they were willing to make a detour or at least postpone their next fuel stop to reach another station of that chain. With these questions of high practical relevance, the stand-alone program comes out as the clear winner over the coalition. In fact, Shell even achieved slightly higher agreement values for Item 3 than Aral did for Item 1, or in other words, compared to the coalition, the stand-alone solution seems to be significantly more successful at causing customers to prefer to refuel at their stations. The t-test produced highly significant $\mathrm{p}$-values for all three items $(\mathrm{p}<0.001)$.

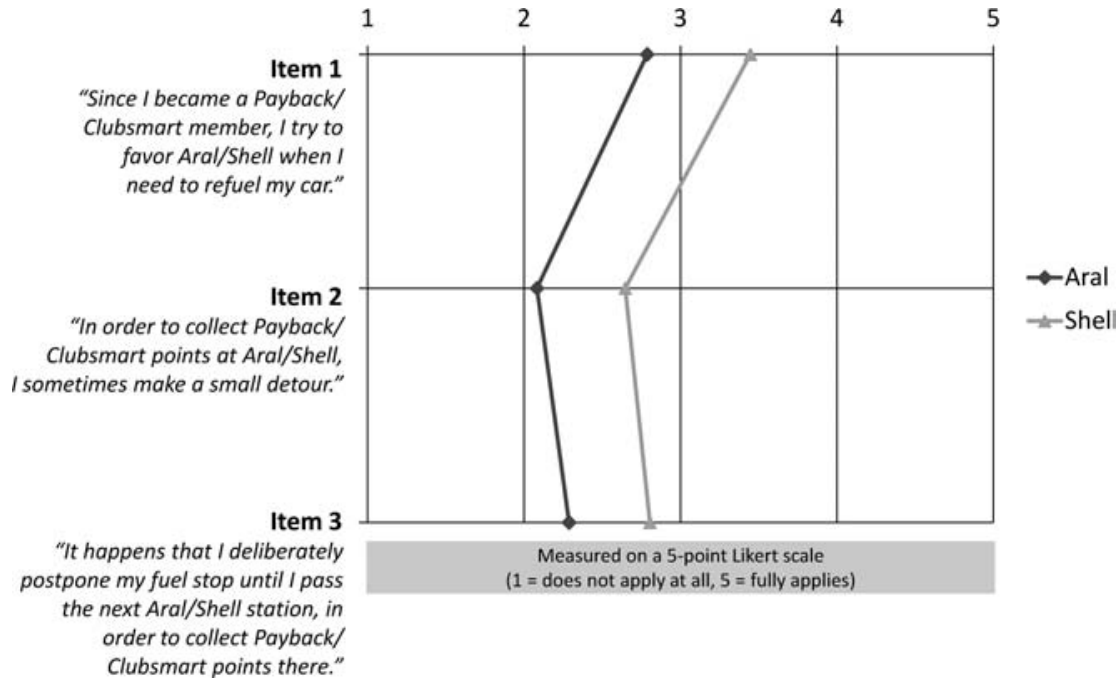

Figure 54: Descriptive Statistics - Alteration of Purchase Behavior Through Membership 


\subsubsection{Remaining Coalition Scheme-Specific Items}

\section{1) Coalition Partner Where Membership was Concluded \\ "Where did you become a Payback member?"}

With Payback founded in March 2000 and Aral having joined the loyalty coalition in May 2006, the quota of people having become a Payback member at Aral was expected to be comparatively low. Customers with membership concluded at a different company are not necessarily a bad thing. In fact, the high quota of around $78 \%$ of respondents holding a Payback card issued by another partner would theoretically speak for the ability of the multi-partner scheme to potentially stimulate cross-partner sales. Looking at section 3 in Chapter 6.2.5, however, it can be seen that no significant advantage of the coalition scheme over the stand-alone program was found to exist.

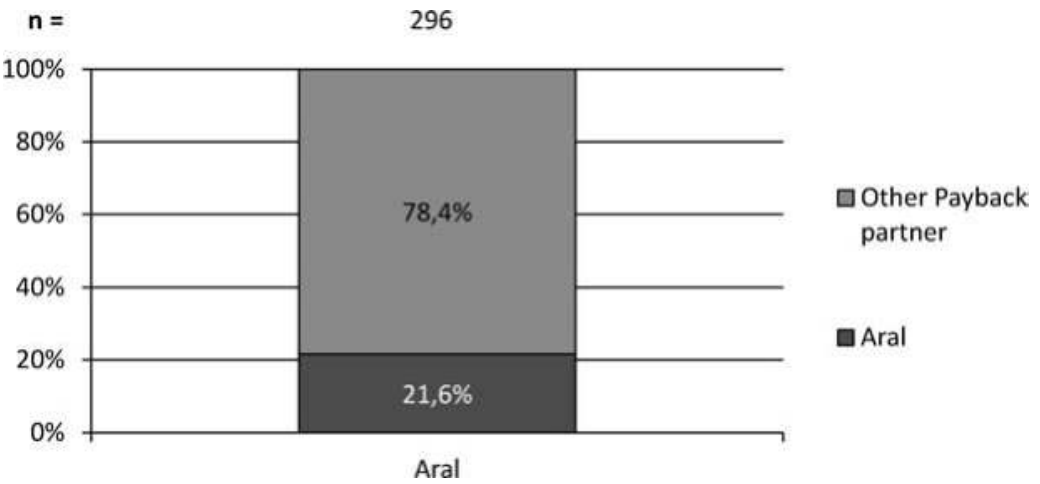

Figure 55: Descriptive Statistics - Coalition Partner Where Membership was Concluded

\section{2) Number of Coalition Partners Patronized}

"At how many partner companies of Payback have you shopped in the last year and used your Payback card during the purchase (including Aral; please estimate if necessary)."

The data resulting from this question confirms the impression given in the previous section on the company where the membership was concluded: for the most part, Payback members do patronize more than one partner company. Specifically, over $90 \%$ of Aral customers have collected points at at least one other coalition partner. With 38\%, the biggest group was that with respondents shopping at three coalition partners, followed by $23 \%$ of customers patronizing four and $19 \%$ purchasing goods at two partners. 


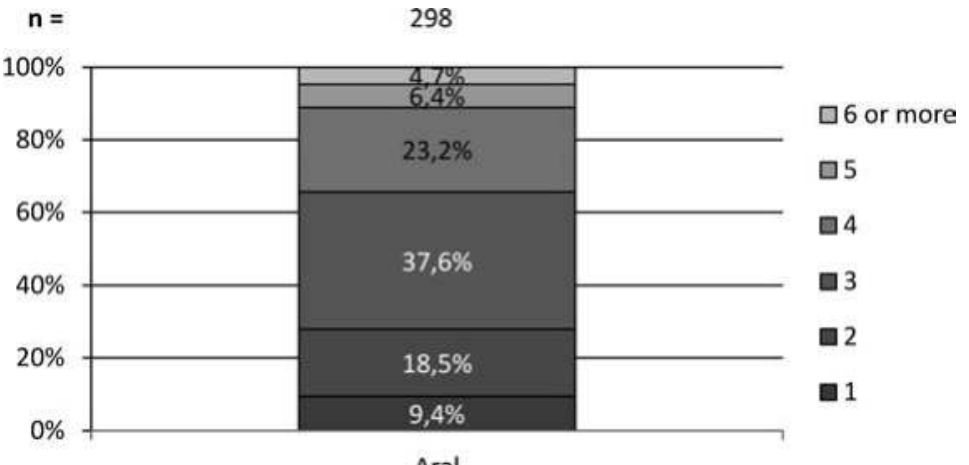

Aral

Figure 56: Descriptive Statistics - Number of Partner Companies Shopped at in the Past Year

\section{3) Collection of Sticker Points Prior to the Coalition Start}

"Have you ever collected sticker points at Aral prior to the introduction of Payback in May $2006 ? "$

Around $26 \%$ of respondents indicated that they had already collected sticker points prior to the introduction of Payback. This promotional tool, which could also be called the simplest form of a loyalty program, was used by Aral before becoming a partner in the Payback coalition scheme.

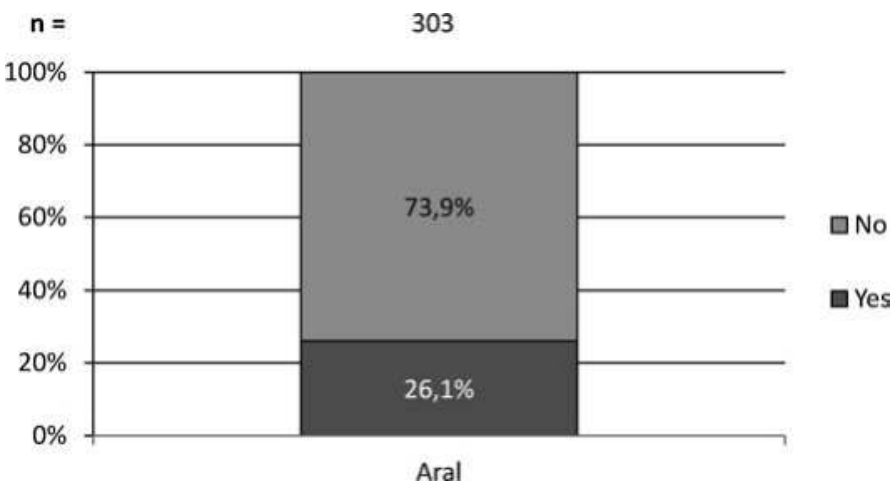

Figure 57: Descriptive Statistics - Collection of Sticker Points Prior to the Coalition Start

\section{4) Reaction to Cross-Selling Incentives}

"Have you ever been motivated by extra Payback points to wash your car or purchase something at the fuel station's store, even though you normally had not planned this?" 
Like the question asking whether the customers were motivated by points to purchase premium fuels, this question was aimed at finding out whether respondents were motivated to wash their car or buy something at the shop. Clubsmart members received a comparable question, but without the segment on the car wash, as no points can be collected for that at Shell stations. Consequently, no comparison was made between the answers of Aral and Shell. Altogether, almost 19\% of Aral customers stated that extra points had motivated them to wash their car or buy something at the shop without having normally planned to do so.

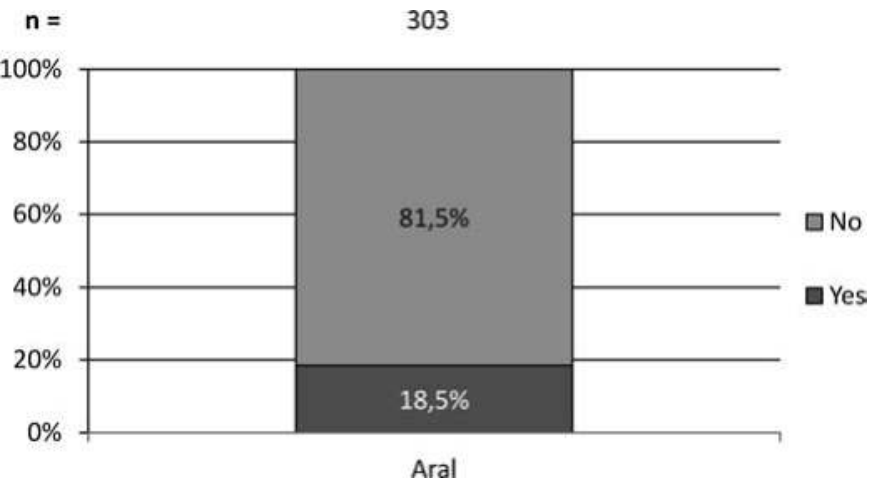

Figure 58: Descriptive Statistics - Reaction to Cross-Selling Incentives (Coalition Scheme)

Note: $\quad$ Incentives targeted at either store or car wash

\subsubsection{Remaining Stand-Alone Scheme-Specific Items}

\section{1) Membership in Special Program Tier}

"Are you, next to the regular Clubsmart program, also a member of the Shell V-Power Club?"

In addition to the regular Clubsmart program, Shell has introduced the so-called V-Power Club, which Clubsmart members are invited to join, once they have purchased 180 liters of V-Power premium fuels within 6 months. V-Power Club members then receive five points for every liter of V-Power fuel they purchase, as compared to one point per liter that normal Clubsmart members collect. Within the sample of 293 Clubsmart customers, $16 \%$ were members of the V-Power Club. The remaining $84 \%$ non-members were made up of $60 \%$ who at least knew of the $2^{\text {nd }}$ tier club and $24 \%$ who had not heard of it before. 


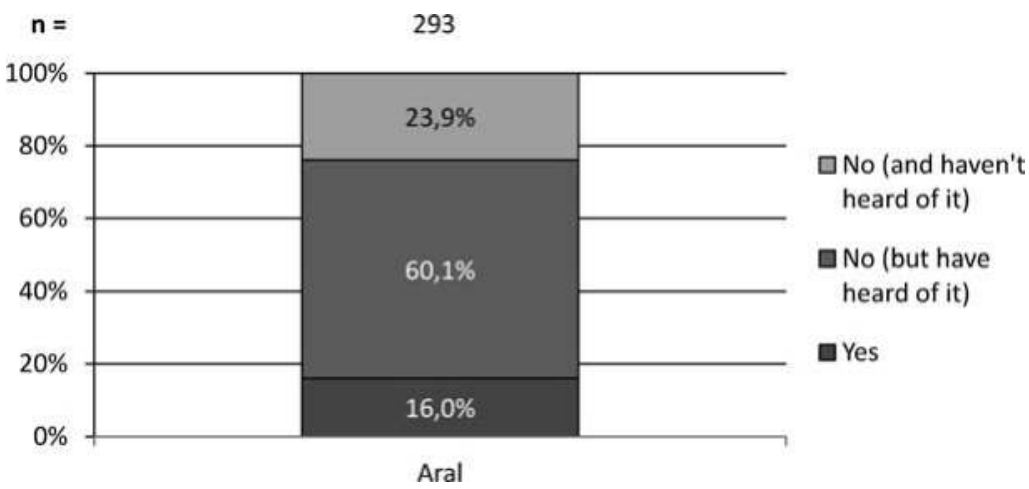

Figure 59: Descriptive Statistics - Membership in Special Program Tier

\section{2) Response to Specials From Stand-Alone Program Partner}

"Have you ever used the special offers for ADAC members at Shell?"

Shell offers two types of specials to all members of ADAC (Germany's main motoring club): (1) either a direct rebate of 1 cent per liter or (2) double Clubsmart points on the purchase. Given that the value of a point equals around 0.5 cents (see Table 10 in Chapter 5.1.3 for the exact calculation), regular Clubsmart customers would theoretically receive the same value with both options. V-Power Club members, on the other hand, could benefit more from the double point special when purchasing V-Power fuels. For every liter of premium fuel a V-Power Club member buys, he would receive a 1 cent discount plus 2.5 cents in points value if he makes use of the discount special ( $=3.5$ cents total value, as he still receives 5 points for that liter in addition to the discount), but 5 cent in points value if he capitalizes on the double points special (as he gets 10 points per liter). When interpreting Figure 60, it should be noted that multiple answers were possible only for the first two options (as a customer might have tried out both the rebate and the double points option), but not for the latter two. Altogether, $38 \%$ of all respondents were not a member of the ADAC, while $13 \%$ were members, but had no interest in the specials or had not heard of them. In other words, $49 \%$ of the respondents had already used either one or both of these specials, with the majority preferring the 1 cent rebate. As hypothesized before, this direction of preference turned out differently for V-Power Club members (who were also ADAC members). Out of 39 respondents falling into that category, 14 had used the rebate option, while 25 had used the double points option. 


$$
\mathbf{n}=
$$

$40 \%$

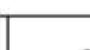

\section{$38,2 \%$}

$30 \%$

$20 \%$

$10 \%$

$0 \%$

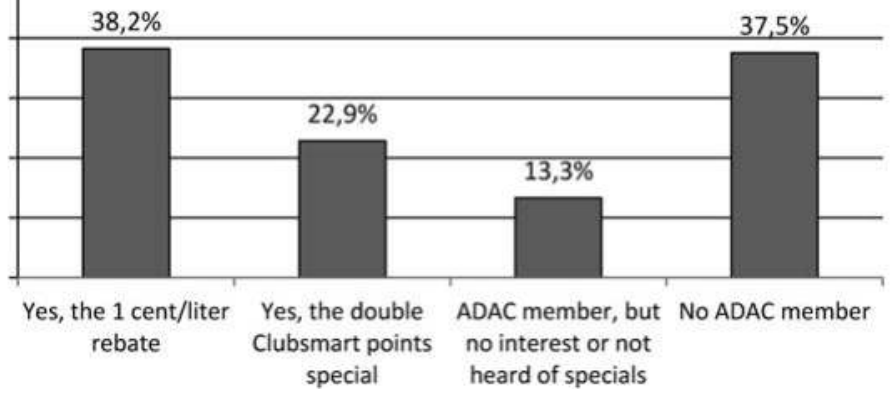

1 Including multiple answers (= number of answers given)

2 Excluding multiple answers (= number of respondents)

Figure 60: Descriptive Statistics - Response to Specials From Stand-Alone Program Partner

\section{3) Reaction to Cross-Selling Incentives}

"Have you ever been motivated by extra Clubsmart points to purchase something at the fuel station's store, even though you normally had not planned this?"

As mentioned before in the section on coalition scheme-specific questions, no comparison can be made with the similar question for Aral, as they differ with regard to the car wash element (Aral customers can receive points at the car wash, while Shell customers cannot). Focused purely on the motivation to trigger purchases at the shop, roughly $17 \%$ of respondents declared that they had previously responded to such an incentive.

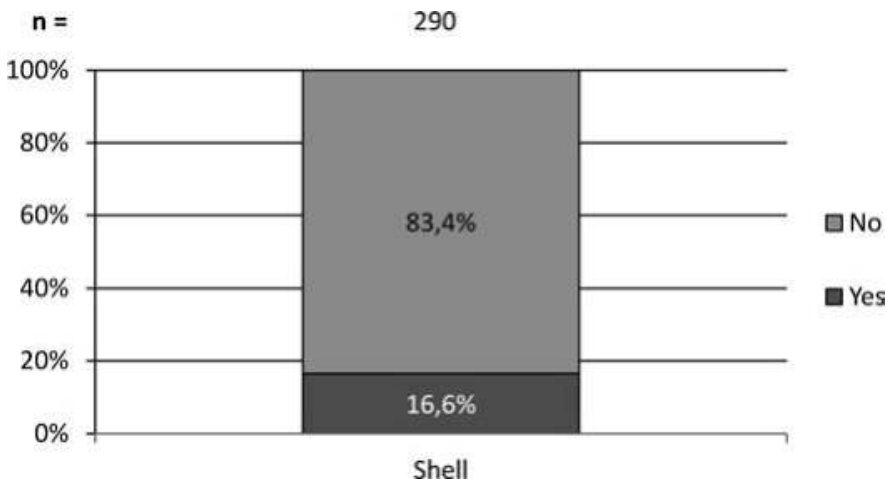

Figure 61: Descriptive Statistics - Reaction to Cross-Selling Incentives (Stand-Alone Scheme)

Note: $\quad$ Incentives targeted at store or only 


\subsection{Main Model Test}

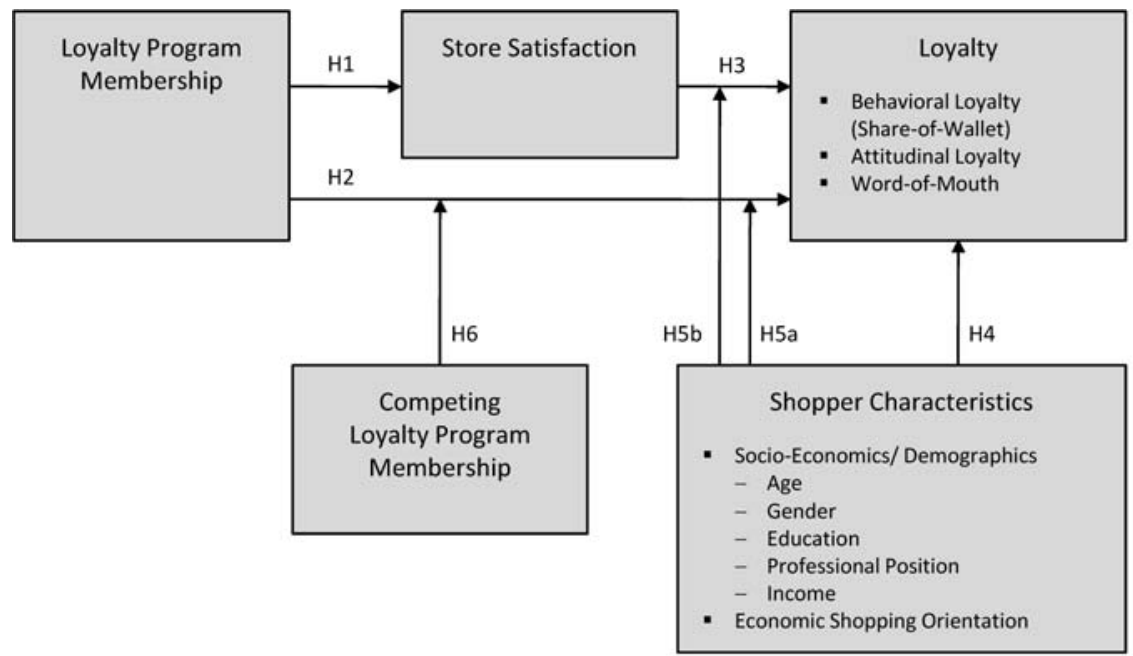

H1: Loyalty program membership has a positive effect on store satisfaction.

$\mathrm{H} 2$ : Loyalty program membership has a positive effect on loyalty.

H3: Store satisfaction has a positive effect on loyalty.

H4: Shopper characteristics influence the degree of developed loyalty.

H5a: Shopper characteristics moderate the effects of loyalty program membership on loyalty.

$\mathrm{H} 5 \mathrm{~b}$ : Shopper characteristics moderate the effects of store satisfaction on loyalty.

H6: Memberships in competing loyalty programs have a negative effect on the relationship between loyalty program membership and loyalty.

Figure 62: Study Framework and Hypotheses

To test the hypotheses illustrated in Figure 62, an analysis of covariance (ANCOVA) was selected as the statistical method to be used. Essentially, the ANCOVA is a combination of an analysis of variance and a regression, in that it allows both categorical and metric independent variables to be included in one single model test (Hatzinger \& Nagel 2009, Backhaus et al. 2011). Simply put, it was deemed the best statistical test to answer the questions discussed in this study and also, it is a method well proven and established in literature.

While taking a defensive position might be considered an uncommon or unnecessary thing to do, the option of using a structural equation model (SEM) shall nevertheless be commented on, as currently its use appears to be somewhat "trendy" in marketing research. In a range of cases, however, one might easily get the impression that, as the saying goes, a sledgehammer has been used to 
crack the nut. In the context of this study, the ANCOVA was found to feature several distinct advantages over an SEM:

- With 20 variables (prior to any aggregating measures), it is unlikely that a model fit would be given in an SEM.

- The multivariate normal distribution required for an SEM might not be achieved by a study using questionnaires.

- Furthermore, SEMs have rarely been used in the field of loyalty scheme success research. For example, in the 23 studies reviewed in Chapter 2.3, structural equation modeling found application in only a few rare cases where it was used in an exploratory manner prior to the actual analytical work. The only exception was one instance, where an SEM was used to test a single hypothesis out of many others in that particular study. Consequently, no reference values would have been available if the model did not fit.

Thus, with the exception of Hypothesis 1, where a separate linear regression was performed due to a different dependent variable, all hypotheses were tested using the ANCOVA within a single model. As far as the dependent variable loyalty is concerned, the options of using a principal component analysis or possibly an index were evaluated to deal with the three dimensions underlying this construct. Eventually, however, it was decided that three separate tests would be carried out to discover potential differences (i.e. one each for behavioral loyalty, attitudinal loyalty, and word-of-mouth). To further mark out the differences between the two loyalty scheme types, these tests were performed once with the Aral data set (main and control group) and once with Shell data (main and control group), resulting in six individual tests altogether. Consequently, six p-values will be presented in the detailed evaluation of Hypotheses 2 to 6 .

\subsubsection{Reliability and Validity}

Prior to the main model test, one last step needs to be taken and the reliability and validity of the employed constructs determined. Hereby, the measurement accuracy was captured by calculating the reliability coefficient Cronbach's using SPSS 18 (see e.g. Schermelleh-Engel \& Werner 2007 for further details). Whether or not the attribute that is supposed to be measured is actually measured (and not something else) is what a validity analysis generally seeks to find out (Hartig et al. 2007). The specific type of validity that was tested here is that of construct validity, which Moosbrugger \& Kelava (2007) characterized as dealing with the theoretical foundations of the trait that is being measured. In other words, the question is whether the scale actually measures the theorized construct which it is supposed to measure (see Cronbach \& Meehl 1955 for a look 
on the origins of this topic). To determine whether a common factor really underlies the different measures performed by the individual items, a confirmatory factor analysis was performed using AMOS 18 (Thompson 2008, Backhaus et al. 2011). As far as the outcome is concerned, standardized regression weights will be presented for each item, together with the Normed-Fit-Index (NFI) as a baseline comparison for model fit. Devised by Bentler \& Bonnet (1980), the NFI has been selected as one representative from a range of fit indicators due to its time-tested use in marketing research. While it can take on a value between 0 and 1, anything above 0.9 can be considered evidence of a good model fit (Backhaus et al. 2011).

Before continuing this chapter on reliability and validity tests, a brief excursion will be made on the subject of reflective and formative models. This distinction is of particular importance to structural equation modeling, which found application in the context of the confirmatory factor analysis to determine the validity of the constructs. As described in Chapter 5.5, three-item measures were used for construct operationalization, with the loyalty construct being special in that it appears to be a multidimensional, second-order model (see e.g. Albers \& Götz 2006 for further details on multidimensional models). In the latter case, however, the decision was taken to conduct separate tests with each component of the loyalty construct (i.e. behavioral and attitudinal loyalty, as well as wordof-mouth; see introduction to Chapter 6.3).

As far as operationalizing a construct is concerned, the basic question is always that regarding the direction of the relationship with its indicators (i.e. items) (Götz \& Liehr-Gobbers 2004). In reflective models, the observed variables (x) constitute a representation of the underlying construct ( ) and it is those variables that are afflicted with a measurement error ( ) (see Figure 63). Within these models, a change of the construct will automatically have a causal effect on the individual indicators (Hildebrandt \& Temme 2006). Consequently, the correlation (r) between these items will generally be high. By contrast, in formative models, the construct is explained by the indicators, or as Eberl (2006) put it, each indicator represents one material component of the construct. In other words, the construct is made up by the entirety of indicators, meaning also that these items are not necessarily correlated.

Jarvis et al. (2003) have provided a useful list of criteria which can be used to determine the reflective or formative nature of a construct. Similarly, Coltman et al. (2008) summarized both the theoretical and the empirical considerations necessary to establish the nature of the measurement model. Some controversy has sprouted meanwhile as to whether certain constructs can actually be conceptualized as both reflective and formative or not. For example, while discussing Gaski \& Nevin's (1985) measure of coercive power, Wilcox et al. (2008) noted that "the same list of items might, depending on the wording of the general instructions, be conceptualized as either formative or reflective" (p. 1220). Building on this 
and, among others, Diamantopoulos et al.'s (2008) contribution, Baxter (2009) concluded that "a construct is not intrinsically either formative or reflective: construct conceptualization determines the formative or reflective nature" (p. 1377). In response, Diamantopoulos (2010) agreed with this statement, but added that a controversy is often rooted in unclear conceptual definitions.
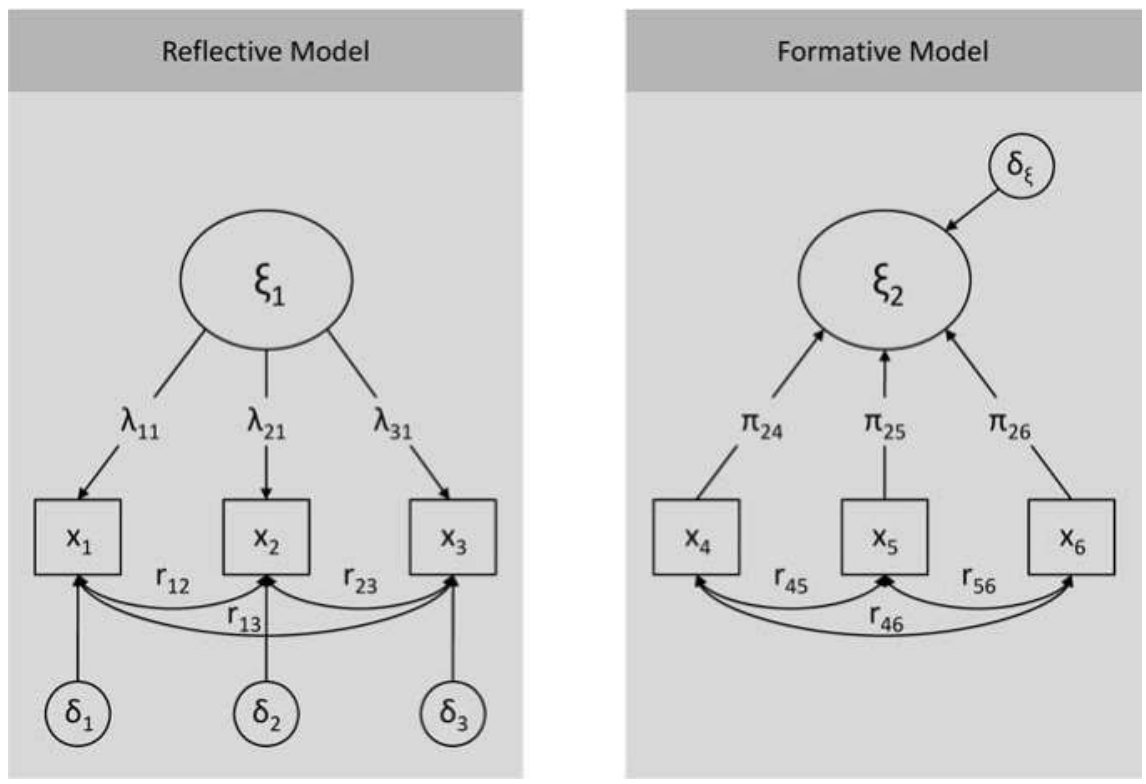

Figure 63: Reflective vs. Formative Models

Source: Götz \& Liehr-Gobbers 2004

As far as the constructs employed in this study are concerned, a reflective nature was presumed. Specifically, both a reliability and a validity test were conducted with the following four constructs:

- Store satisfaction

- Economic shopping orientation

- Attitudinal loyalty

- Word-of-mouth

\section{1) Store Satisfaction}

Item 1: I am satisfied with Aral/Shell fuel stations

Item 2: Aral/Shell fuel stations match my expectations

Item 3: Aral/Shell fuel stations come close to my image of a perfect fuel station 


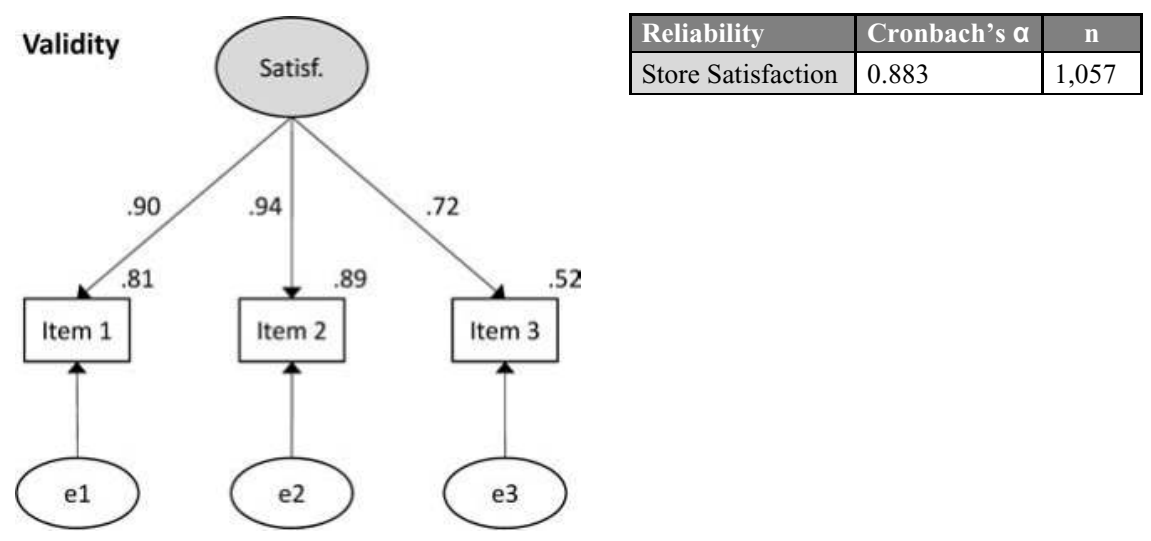

Figure 64: Validity/Reliability Test-Satisfaction Construct

Note: $\quad$ Validity figure shows standardized estimates

As seen in Figure 64, the validity test delivered standardized regression weights between 0.72 and 0.94 for the three items $(\mathrm{NFI}=1)$, while the reliability test turned out a Cronbach's of 0.88 . Statistical significance was determined for the three regression weights, while the Cronbach's can be considered more than acceptable (Schermelleh-Engel \& Werner 2007).

\section{2) Economic Shopping Orientation}

Item 1: I refuel at the fuel station which currently has the lowest prices Item 2: I compare what I get for my money at different fuel stations Item 3: You profit from comparing prices across different fuel stations

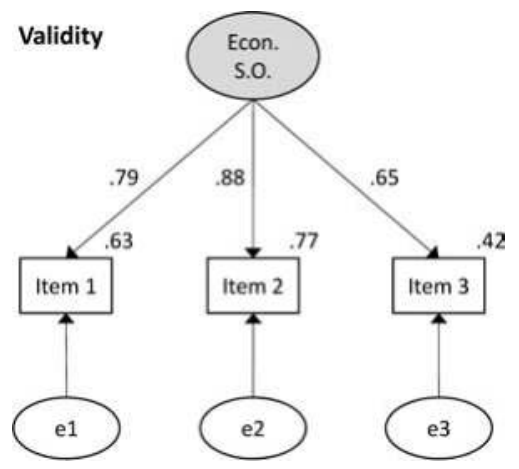

\begin{tabular}{|l|l|c|}
\hline Reliability & Cronbach's $\boldsymbol{\alpha}$ & $\mathbf{n}$ \\
\hline $\begin{array}{l}\text { Econ. Shopping } \\
\text { Orientation }\end{array}$ & 0.815 & 1,066 \\
\hline
\end{tabular}

Figure 65: Validity/Reliability Test-Economic Shopping Orientation Construct

Note: $\quad$ Validity figure shows standardized estimates 
In case of the economic shopping orientation construct, standardized regression weights between 0.65 and 0.88 were calculated for the three items in the confirmatory factor analysis (NFI =1). As far as the reliability test is concerned, a Cronbach's of 0.82 was observed. Similar to the previous construct, statistical significance could be established for the three regression weights, while a Cronbach's above 0.8 can be deemed satisfactory.

\section{3) Attitudinal Loyalty}

Item 1: I feel I am a loyal customer of Aral/Shell

Item 2: Because I feel a strong attachment to Aral/Shell, I remain a customer of Aral/Shell

Item 3: Because I feel a strong sense of belonging with Aral/Shell, I want to remain a customer of Aral/Shell

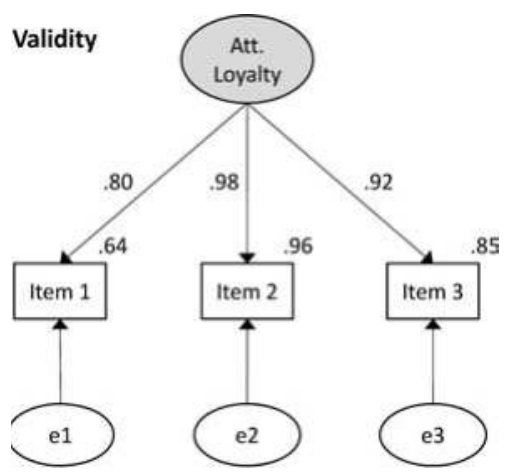

\begin{tabular}{|c|l|c|}
\hline \multicolumn{1}{|c|}{ Reliability } & Cronbach's $\mathbf{\alpha}$ & $\mathbf{n}$ \\
\hline Attitudinal Loyalty & 0.924 & 1,055 \\
\hline
\end{tabular}

Figure 66: Validity/Reliability Test-Attitudinal Loyalty Construct

Note: $\quad$ Validity figure shows standardized estimates

Evaluating the attitudinal loyalty construct, the confirmatory factor analysis found standardized regression weights between 0.80 and 0.98 for the three items $(\mathrm{NFI}=1)$, while a Cronbach's of 0.92 was determined in the reliability analysis. Given these high values, statistical significance was naturally given for the three regression weights and also a Cronbach's of 0.92 can be considered very satisfactory. 


\section{4) Word-of-Mouth}

Item 1: I often tell friends, family, or colleagues about the positive experiences with Aral/Shell

Item 2: I would recommend Aral/Shell to someone who seeks my advice

Item 3: Because of my experiences with Aral/Shell, I try to convince friends, family, or colleagues to switch to Aral/Shell

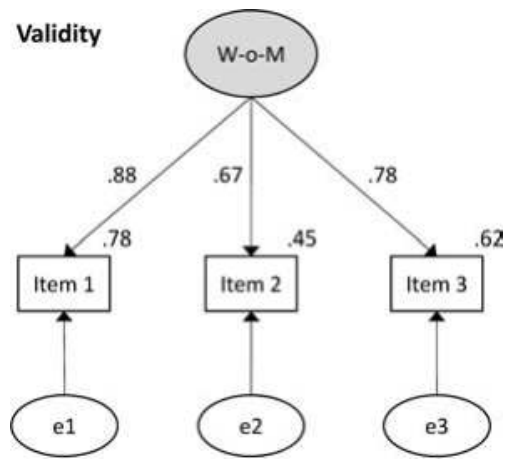

\begin{tabular}{|r|l|c|}
\hline Reliability & Cronbach's a & n \\
\hline Word-of-Mouth & 0.790 & 1,080 \\
\hline
\end{tabular}

Figure 67: Validity/Reliability Test-Word-of-Mouth Construct

Note: $\quad$ Validity figure shows standardized estimates

For the final construct of word-of-mouth, standardized regression weights between 0.67 and 0.88 were calculated for the three items (NFI =1), with the reliability analysis showing a Cronbach's of 0.79 . Though not as high as with the attitudinal loyalty construct, statistical significance was nevertheless given for the three regression weights, while a Cronbach's slightly below 0.8 can still be regarded as acceptable. 


\subsubsection{Hypothesis 1}

"Loyalty program membership has a positive effect on store satisfaction"

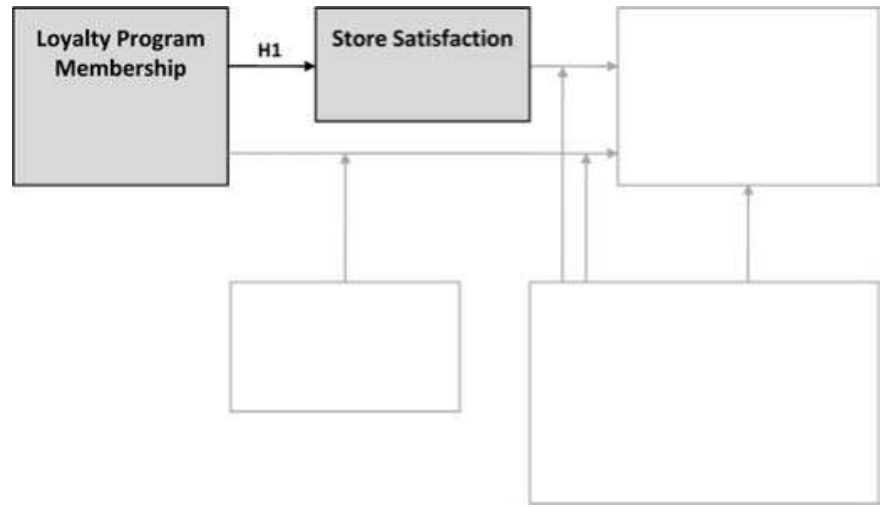

Coalition: Null hypothesis has been rejected

Stand-Alone: Null hypothesis has been rejected

\begin{tabular}{|l|l|l|}
\hline Membership & Test Group & p-value \\
\hline Satisfaction & - Coalition: & 0.009 \\
& - Stand-Alone: & 0.001 \\
\hline
\end{tabular}

Figure 68: Main Model Test - Hypothesis 1

Note: $\quad n=1,081$ (Coalition: 544, Stand-Alone: 537)

As mentioned before, Hypothesis 1 is the only hypothesis that has not been evaluated by performing the ANCOVA with the main model. Instead, a separate linear regression was carried out to determine the effect of loyalty program membership on store satisfaction. As seen in Figure 68, this effect turned out to be highly significant for both the loyalty coalition and the stand-alone program. Clearly, these findings give further reason to believe that loyalty programs as a marketing tool do indeed have an effect on satisfaction with the store (which in turn is known to be an important antecedent to customer loyalty). 


\subsubsection{Hypothesis 2}

"Loyalty program membership has a positive effect on loyalty"

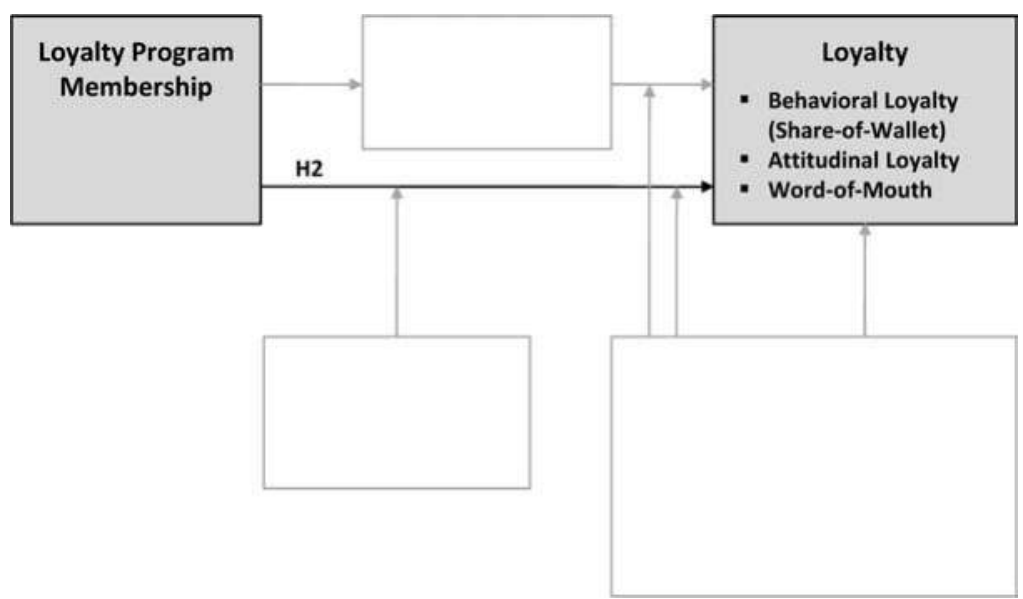

Coalition: Null hypothesis has been rejected with regard to two of the three dependent variables

Stand-Alone: Null hypothesis has been rejected

\begin{tabular}{|c|c|c|}
\hline Membership & Test Group & p-value \\
\hline $\begin{array}{l}\text { Behavioral } \\
\text { Loyalty }\end{array}$ & $\begin{array}{l}\text { - Coalition: } \\
\text { - Stand-Alone: }\end{array}$ & $\begin{array}{l}<0.001 \\
<0.001\end{array}$ \\
\hline $\begin{array}{l}\text { Attitudinal } \\
\text { Loyalty }\end{array}$ & $\begin{array}{l}\text { - Coalition: } \\
\text { - Stand-Alone: }\end{array}$ & $\begin{array}{l}0.004 \\
<0.001\end{array}$ \\
\hline $\begin{array}{l}\text { Word-of- } \\
\text { Mouth }\end{array}$ & $\begin{array}{l}\text { - Coalition: } \\
\text { - Stand-Alone: }\end{array}$ & $\begin{array}{l}0.468 \\
<0.001\end{array}$ \\
\hline
\end{tabular}

Figure 69: Main Model Test-Hypothesis 2

Note: $\quad n=742$ (Coalition: 377 , Stand-Alone: 365 )

Constituting the core of this work, Hypothesis 2 dealt with the question of whether loyalty program membership has an effect on customer loyalty or not. As mentioned in the literature review of Chapter 2.3, previous evidence on this matter is somewhat mixed. Summarizing that evidence, it was concluded that a positive effect can be expected for behavioral loyalty, while the opposite is true for attitudinal loyalty (depending on program and industry structure). 
Particularly in the case of the stand-alone scheme, evidence indicated a highly significant relationship between loyalty program membership and all three dependent variables (including attitudinal loyalty). Thus, contradictory to the general reasoning in Chapter 2.3, evidence points towards the ability of loyalty schemes to engender attitudinal loyalty in the fuel retailing industry. It has been said that a program's ability to do so is dependent on both its configuration and the industry and apparently, these conditions were both favorable for the subjects of study.

While all tests delivered positive results for the stand-alone solution, particularly with regard to word-of-mouth, things turned out differently for the coalition, where that test was clearly insignificant with a p-value of around 0.47. Positive word-of-mouth, a measure often named in connection with attitudinal loyalty, can arguably also be caused by non-attitudinal motivation (e.g. one might recommend a fuel station to a friend simply because the chain's loyalty program offers attractive rewards and not because of attitudinal loyalty to that chain). As seen in the results for word-of-mouth in the case of the coalition, there seems to be more to it, however. While the effect on both the behavioral and the attitudinal indicators was significant, this was not the case for word-of-mouth. It has already been demonstrated in the descriptive statistics section that within the three items making up the construct of word-of-mouth, only one of them showed a significant difference between the multi-partner main and control group. It is difficult to interpret why this is the case, but it is possible to ascertain one thing: the stand-alone program seems to be better able to stimulate its members to engage in positive word-of-mouth. 


\subsubsection{Hypothesis 3}

"Store satisfaction has a positive effect on loyalty"

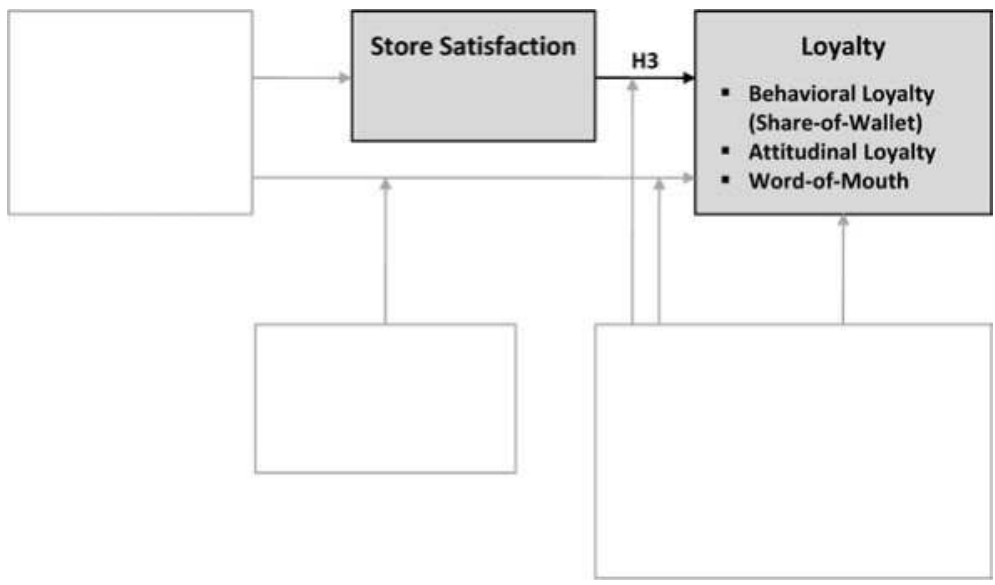

Coalition: Null hypothesis has been rejected

Stand-Alone: Null hypothesis has been rejected

\begin{tabular}{|l|l|l|}
\hline Satisfaction & \multicolumn{1}{|l}{ Test Group } & p-value \\
\hline Behavioral & - Coalition: & $<0.001$ \\
Loyalty & - Stand-Alone: & $<0.001$ \\
\hline Attitudinal & - Coalition: & $<0.001$ \\
Loyalty & - Stand-Alone: & $<0.001$ \\
\cline { 2 - 3 } Word-of- & - Coalition: & $<0.001$ \\
Mouth & - Stand-Alone: & $<0.001$ \\
\hline
\end{tabular}

Figure 70: Main Model Test-Hypothesis 3

Note: $\quad n=742$ (Coalition: 377 , Stand-Alone: 365 )

Whether or not satisfaction has an effect on loyalty has been the subject of many pieces of research (see e.g. Homburg et al. 2008). Even though this relationship might not always be present (Jones \& Sasser 1995), it certainly is more often than not. In any case, previous studies set in the context of loyalty schemes found differing magnitudes of this effect (e.g. Mägi 2003 for a grocery retailer or Bridson et al. 2008 for a health and beauty retailer). In this study covering the fuel retail industry, results were outright positive for all three elements making up the loyalty construct. With p-values of less than 0.001 for both the multipartner and the stand-alone program in every single test performed, it seems 
clear that store satisfaction indeed has a highly significant effect on customer loyalty in the fuel retailing industry.

\subsubsection{Hypothesis 4}

"Shopper characteristics influence the degree of developed loyalty"

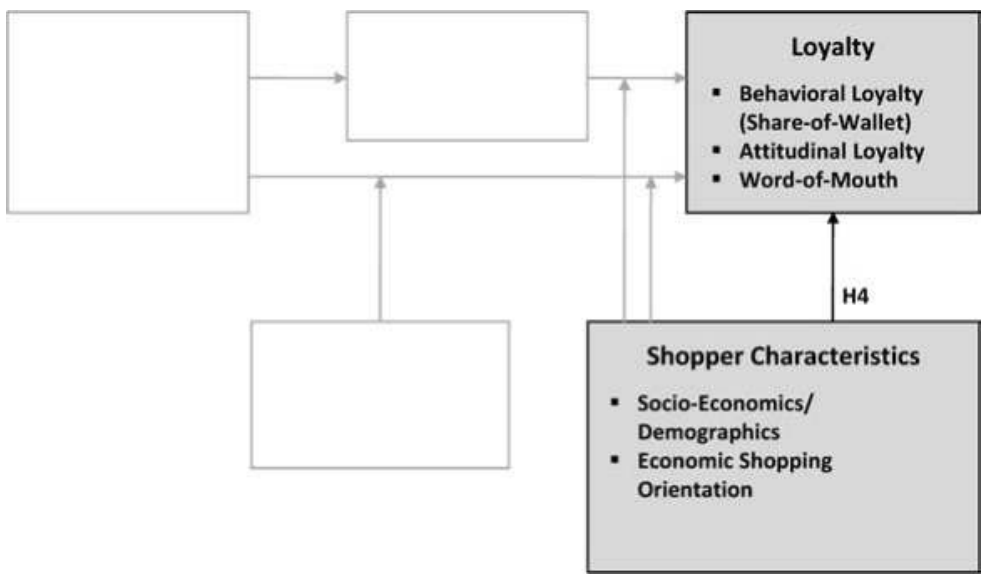

\begin{tabular}{|l|l|l|}
\hline Age & Test Group & p-value \\
\hline Behavioral & - Coalition: & 0.175 \\
Loyalty & - Stand-Alone: & 0.547 \\
\hline Attitudinal & - Coalition: & 0.384 \\
Loyalty & - Stand-Alone: & 0.393 \\
\hline Word-of- & - Coalition: & 0.397 \\
Mouth & - Stand-Alone: & 0.238 \\
\hline
\end{tabular}

\begin{tabular}{|l|l|l|}
\hline Gender & Test Group & p-value \\
\hline $\begin{array}{l}\text { Behavioral } \\
\text { Loyalty }\end{array}$ & - Coalition: & 0.223 \\
\hline Attitudinal & - Stand-Alone: & 0.801 \\
Loyalty & - Coalition: & 0.814 \\
Word-of- & - Ctand-Alone: & 0.292 \\
Mouth & - Stand-Alone: & 0.458 \\
\hline
\end{tabular}

\begin{tabular}{|l|l|l|}
\hline Education & Test Group & p-value \\
Behavioral & - Coalition: & 0.198 \\
Loyalty & - Stand-Alone: & 0.208 \\
\hline $\begin{array}{l}\text { Attitudinal } \\
\text { Loyalty }\end{array}$ & - Coalition: & 0.249 \\
Word-of- & - Stand-Alone: & $0.011 *$ \\
Mouth & - Coalition: & 0.052 \\
\end{tabular}

\begin{tabular}{|l|l|l|}
\hline Prof. Position & Test Group & p-value \\
Behavioral & - Coalition: & 0.911 \\
Loyalty & - Stand-Alone: & 0.213 \\
\hline Attitudinal & - Coalition: & 0.712 \\
Loyalty & - Stand-Alone: & 0.140 \\
Word-of- & - Coalition: & $0.011 *$ \\
Mouth & - Stand-Alone: & 0.073 \\
\hline
\end{tabular}




\begin{tabular}{|l|l|l|}
\hline Income & Test Group & p-value \\
\hline Behavioral & - Coalition: & 0.733 \\
Loyalty & - Stand-Alone: & 0.784 \\
\hline Attitudinal & - Coalition: & 0.427 \\
Loyalty & - Stand-Alone: & 0.772 \\
\hline Word-of- & - Coalition: & 0.980 \\
Mouth & - Stand-Alone: & 0.249 \\
\hline
\end{tabular}

\begin{tabular}{|l|l|l|}
\hline Economic S. O. & Test Group & p-value \\
\hline $\begin{array}{l}\text { Behavioral } \\
\text { Loyalty }\end{array}$ & - Coalition: & $<0.001 *$ \\
\hline Attitudinal & - Stand-Alone: & $<0.001 *$ \\
Loyalty & - Soalition: & $0.008^{*}$ \\
Word-of- & - Coalition: & 0.140 \\
Mouth & - Stand-Alone: & 0.135 \\
\hline
\end{tabular}

Figure 71: Main Model Test-Hypothesis 4

Note: $\quad n=742$ (Coalition: 377 , Stand-Alone: 365 )

All p-values significant at the $5 \%$ level have been marked with an asterisk (*)

Coalition: Null hypothesis has been rejected (Economic Shopping Orientation: with regard to two of the three dependent variables, Professional Position: with regard to one of the three dependent variables)

Stand-Alone: Null hypothesis has been rejected (Economic Shopping Orientation: with regard to two of the three dependent variables, Education: with regard to two of the three dependent variables)

Intentionally formulated in a very broad manner, Hypothesis 4 encompasses a range of five individual demographic and socio-economic variables as well as the construct termed economic shopping orientation (i.e. price consciousness). Thus, while the null hypothesis has been rejected, it is still necessary to review in detail which particular shopper characteristics have turned out to influence customer loyalty. When looking at the overview of all calculated p-values (Figure 71), it can be seen that age, gender, and income had no significant effect, while at least with regard to one of the three dependent variables and at least one of the two test groups, education, professional position, and economic shopping orientation did have such an effect.

In the case of the coalition, the type of professional position held significantly influenced the degree to which customers engaged in positive word-of-mouth. To be specific, employees and civil servants without leadership responsibilities showed the highest level of word-of-mouth behavior, followed by employees and civil servants with leadership responsibilities, and finally freelancers exhibiting the lowest level. Interestingly, this effect could not be observed for either behavioral or attitudinal loyalty indicators. The second variable where a significant effect on loyalty could be noticed was that of economic shopping orientation. This effect was observed for both behavioral and attitudinal loyalty, with loyalty naturally declining with an increase in economic shopping orientation (i.e. with higher price consciousness).

For the stand-alone program, the effect of economic shopping orientation corresponded to that of the multi-partner solution, but things looked somewhat different in relation to the other variables. At a 5\% level, professional position was insignificant, while education was significant for determining both attitudin- 
al loyalty and word-of-mouth behavior. For the purpose of the model test, educational background was compressed to the two levels of basic education (anything below university/college level) and higher education (university/college level) and results have shown that those respondents with a lower level of education exhibited a higher level of loyalty.

To determine whether any interaction effects between education and professional position exist, a ${ }^{2}$ test for independence was performed. With a Pearson's

${ }^{2}$ value of 0.020 , the null hypothesis that these two variables are unrelated had to be rejected. When interpreting the results of the model test with regard to Hypothesis 4, it should thus be kept in mind that the notion that educational background correlates with professional position has been confirmed.

\subsubsection{Hypotheses 5a $+b$}

5a: "Shopper characteristics moderate the effects of loyalty program membership on loyalty"

$5 b$ : "Shopper characteristics moderate the effects of store satisfaction on loyalty"

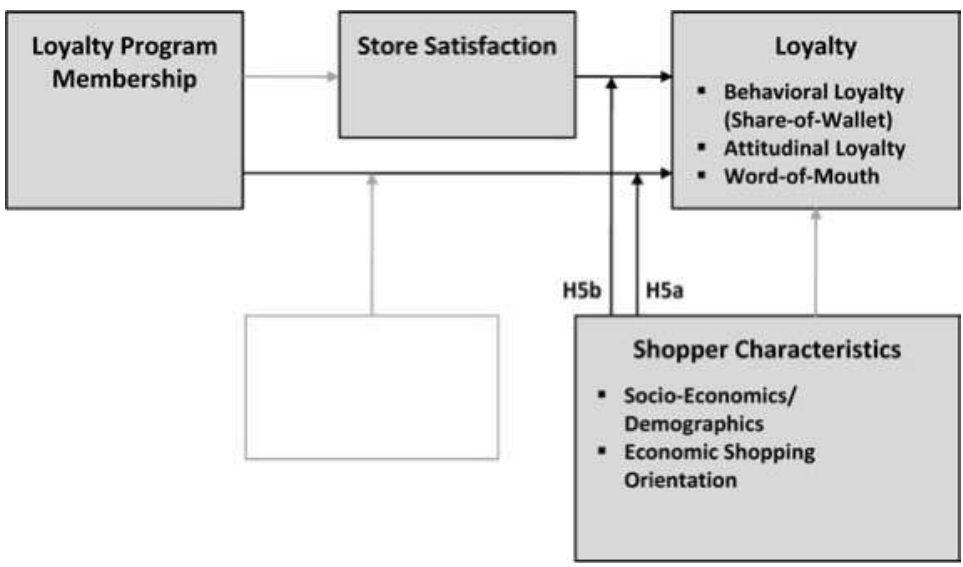

Figure 72: Main Model Test-Hypothesis $5 a+b$

Note: $\quad n=742$ (Coalition: 377 , Stand-Alone: 365 )

Coalition: H5a: Null hypothesis has been maintained H5b: Null hypothesis has been maintained

Stand-Alone: H5a: Null hypothesis has been maintained H5b: Null hypothesis has been maintained

Due to the issues associated with interpreting any significant effects with multiple interactions (i.e. anything more than 2-way), the decision has been made to focus on 2-way interactions only. As all of these effects, multiplied by three tests for the different dependent variables, multiplied by the two fuel station data sets 
equal a fairly high number of p-values, it has been decided to omit the overview tables for Hypotheses $5 \mathrm{a}$ and $5 \mathrm{~b}$. One further reason that contributed to this decision was the fact that none of the 2-way interaction effects between the six shopper characteristics variables and either loyalty program membership or store satisfaction turned out to be significant. This proved to be the case for all three dependent variables and both the multi-partner and the stand-alone scheme. In other words, no moderating effects could be observed.

\subsubsection{Hypothesis 6}

"Memberships in competing loyalty programs have a negative effect on the relationship between loyalty program membership and loyalty"

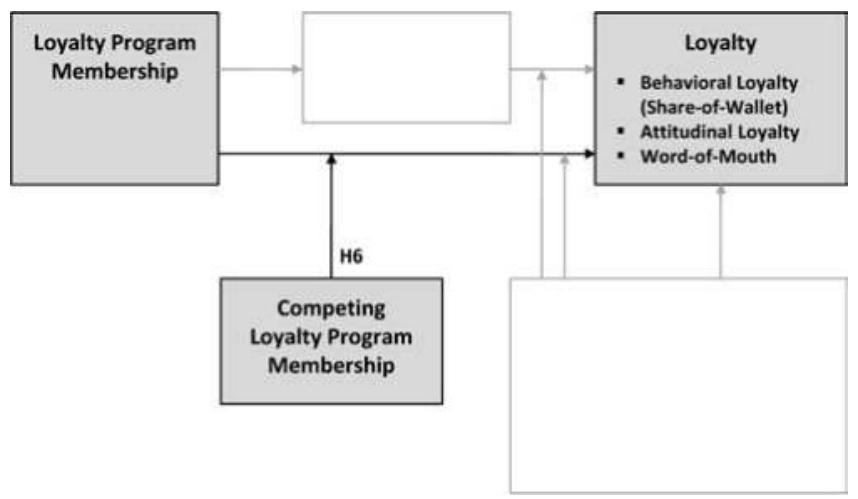

\begin{tabular}{|c|c|c|}
\hline $\begin{array}{l}\text { Competing } \\
\text { Membership }\end{array}$ & Test Group & p-value \\
\hline $\begin{array}{l}\text { Behavioral } \\
\text { Loyalty }\end{array}$ & $\begin{array}{l}\text { - Coalition: } \\
\text { - Stand-Alone: }\end{array}$ & $\begin{array}{l}0.488 \\
0.611\end{array}$ \\
\hline $\begin{array}{l}\text { Attitudinal } \\
\text { Loyalty }\end{array}$ & $\begin{array}{l}\text { - Coalition: } \\
\text { - Stand-Alone: }\end{array}$ & $\begin{array}{l}0.999 \\
0.020\end{array}$ \\
\hline $\begin{array}{l}\text { Word-of- } \\
\text { Mouth }\end{array}$ & $\begin{array}{l}\text { - Coalition: } \\
\text { - Stand-Alone: }\end{array}$ & $\begin{array}{l}0.696 \\
0.251\end{array}$ \\
\hline
\end{tabular}

Figure 73: Main Model Test-Hypothesis 6

Note: $\quad n=742$ (Coalition: 377 , Stand-Alone: 365 )

Coalition: Null hypothesis has been maintained

Stand-Alone: Null hypothesis has been rejected with regard to one of the three dependent variables

Contradictory to previous studies in the field (e.g. Mägi 2003 or Meyer-Waarden 2007, who discussed this issue in relation to lifetime duration), competing loyalty schemes were not found to have a moderating effect on the relationship be- 
tween loyalty program membership and loyalty in the case of the coalition. While it sounds perfectly logical in theory that the effects of multiple competing loyalty cards would cancel each other out (Dowling \& Uncles 1997), this need not necessarily be the case in practice. As far as Aral is concerned, possible reasons for this include the following: (1) weak competitive programs in the industry (with the exception of Shell Clubsmart), (2) a relatively low percentage of multiple card holders (among Payback members, only 19.5\% held at least one competitive card - and in most cases it was not more than one), (3) a strong program of its own with an attractive configuration.

Nevertheless, what may come as a surprise is the fact that a significant moderating effect of competitive programs on the relationship between membership in the own loyalty scheme and attitudinal loyalty could be observed during the evaluation of the stand-alone program data $(\mathrm{p}=0.020)$. This is even more curious, as it is this dependent variable where the smallest possible interaction effect was found for the coalition $(p=0.999)$. In any case, for the stand-alone solution, the moderating effect of memberships in competing loyalty schemes on the relationship between program membership and attitudinal loyalty turned out to be significantly negative. The reasons behind these discrepancies between the test groups are not fully known. However, what should be taken into account when interpreting these findings is the fact that the percentage of competitive card holders was lower among the coalition than among the stand-alone members. To be precise, $34.8 \%$ of Shell Clubsmart card holders were members in at least one other fuel station scheme (i.e. Aral Payback, in the majority of cases), while only $19.5 \%$ of Aral Payback members held at least one other competitive loyalty card (i.e. predominantly the Shell Clubsmart card). In other words, stand-alone scheme members had more opportunities to be disloyal due to temptation through a competitive scheme. Still, why this affected attitudinal loyalty in particular is not entirely clear. In any case, one thing is apparent: while the attitude of stand-alone program members might be negatively influenced by competitive card ownership, actual behavior is not!

\subsubsection{The Multi-Partner vs. Stand-Alone Comparison}

Up to now, the main model has been separately fed with two data sets consisting of a main and a control group each. In doing so, the question of whether multi-partner or stand-alone schemes really work better has not been addressed yet. In order to answer this question, a one-way ANOVA was performed for each of the three dependent loyalty-variables with the data of all four study groups. In addition to that, a post-hoc test (Duncan) was carried out to discover potential differences and determine homogeneous sub-groups. 


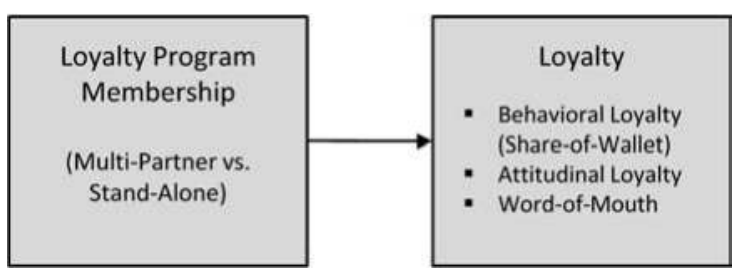

\begin{tabular}{|l|l|}
\hline Program Type Membership & p-value \\
\hline Behavioral Loyalty & $<0.001$ \\
\hline Attitudinal Loyalty & $<0.001$ \\
\hline Word-of-Mouth & $<0.001$ \\
\hline
\end{tabular}

Figure 74: The Multi-Partner vs. Stand-Alone Comparison-Concept and p-values Note: $\quad n=1,083$ (minus 4 in the case of attitudinal loyalty)

It can be seen in Figure 74, that the four sample groups differ significantly. Referring to the output of the Duncan test illustrated in Table 15, it can further be noted that no significant differences were found to exist between the control groups - no matter what dependent variable the test was performed with. When turning to the main groups, however, things look different. With regard to both behavioral and attitudinal loyalty as well as word-of-mouth, the multi-partner group differs significantly from the stand-alone group.

\begin{tabular}{|c|c|c|c|c|}
\hline & $\begin{array}{l}\text { Original Test } \\
\text { Group }\end{array}$ & $\begin{array}{l}\text { Group } 1 \\
\text { (Duncan) }\end{array}$ & $\begin{array}{l}\text { Group } 2 \\
\text { (Duncan) }\end{array}$ & $\begin{array}{l}\text { Group } 3 \\
\text { (Duncan) }\end{array}$ \\
\hline $\begin{array}{l}\text { Behavioral Loyalty } \\
\text { (Mean Share-of- } \\
\text { Wallet) }\end{array}$ & $\begin{array}{l}\text { - Aral Control: } \\
\text { - Shell Control: } \\
\text { - Aral: } \\
\text { - Shell }\end{array}$ & $\begin{array}{l}31.2 \% \\
30.4 \%\end{array}$ & $47.8 \%$ & $65.1 \%$ \\
\hline $\begin{array}{l}\text { Attitudinal Loyalty } \\
\text { (Mean Likert Scale } \\
\text { Declarations) }\end{array}$ & $\begin{array}{l}\text { - Aral Control: } \\
\text { - Shell Control: } \\
\text { - Aral: } \\
\text { - Shell }\end{array}$ & $\begin{array}{l}1.92 \\
2.03\end{array}$ & 2.48 & 2.87 \\
\hline $\begin{array}{l}\text { Word-of-Mouth } \\
\text { (Mean Likert Scale } \\
\text { Declarations) }\end{array}$ & $\begin{array}{l}\text { - Aral Control: } \\
\text { - Shell Control: } \\
\text { - Aral: } \\
\text { - Shell } \\
\end{array}$ & $\begin{array}{l}1.40 \\
1.49\end{array}$ & $\begin{array}{l}1.49 \\
1.59\end{array}$ & 2.00 \\
\hline
\end{tabular}

Table 15: Program Type Comparison - Determination of Homogeneous Sub-Groups

Note: $\quad$ Post-hoc test type conducted: Duncan; minor differences in mean values as compared to those reported in the descriptive statistics section are due to a slightly different sample size

So which program type performs better? As mentioned in Chapter 4 (and section 4.5 in particular), the majority of both practitioners and academics have praised multi-partner schemes as being superior to stand-alone programs. While it is certainly true that loyalty coalitions feature certain distinct advantages, light still 
needed to be shed on the question as to which type really offers the better performance in terms of influencing customer loyalty. The answer to this question is illustrated in Figure 75 (representing a graphic summary of the data presented in Table 15): the stand-alone scheme outperforms the multi-partner solution in all three areas! Figuratively speaking, the multi-partner program managed to take an effective step in the direction of manipulating customer loyalty. At the same time, however, the stand-alone solution was able to take two.
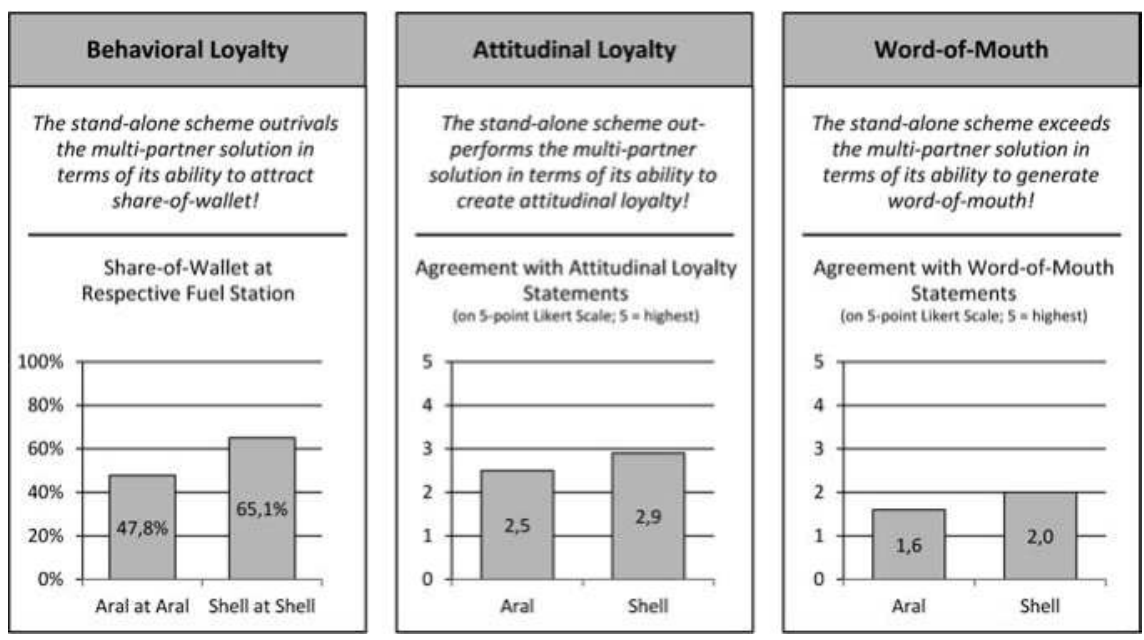

Figure 75: The Multi-Partner vs. Stand-Alone Comparison - Findings

Note: $\quad$ Minor differences in mean values as compared to those reported in the descriptive statistics section are due to a slightly different sample size

Naturally, the next question that comes to mind is that of the "why." At this point, no empirically validated answer can be given, but nevertheless, possible options can be discussed. It might very well be, for instance, that customers who participate in a multi-partner program simply are not that eager to earn the maximum number of points with every single partner they patronize from time to time, because either way they will be earning points somewhere else sooner or later. For example, a customer who became a Payback member at the German grocery chain "real,-" (which also results in him receiving a Payback card branded with that company's logo) might not be all that motivated to pool his fuel spend at Aral stations to earn points, because he will earn points during his next visit at real,- anyway. On the other hand, if a member of Shell's stand-alone program was driven to collect points, perhaps to receive a specific award, he inevitably has to make sure to refuel his car at that chain as often as possible. In that sense, the more focused nature of a stand-alone program might be paying off! 


\subsection{Qualitative Study Roundup}

As discussed in Chapter 5.1.1, the purpose of the qualitative component of this empirical study was twofold: (1) to serve as a source of input for the creation of the consumer survey, but also (2) to hear about the views and decisions of loyalty executives regarding a variety of subjects linked to the customer loyalty schemes they used. While the first point needs no further explanation, it is particularly the second one which shall not go completely unnoted in this paper.

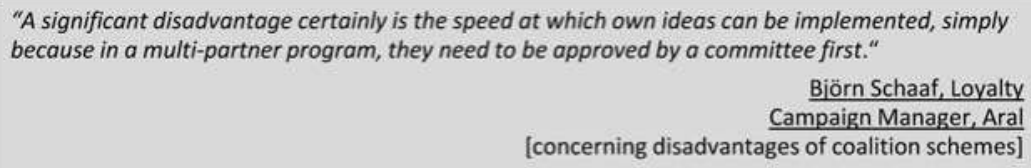

"A significant disadvantage certainly is the speed at which own ideas can be implemented, simply because in a multi-partner program, they need to be approved by a committee first."

Björn Schaaf, Loyalty Campaign Manager, Aral [concerning disadvantages of coalition schemes]

"...profit margins look different in every country. Consequently, one can afford things in some countries you can't in others, as far as forgoing profit margin is concerned."

Björn Schaaf

[concerning the fact that BP/Aral operates different loyalty scheme types in different countries]

"Well these numbers seem realistic, yes."

Jan-Christian Kempin, Loyalty Marketing Manager D-A-CH, Shell

[concerning the rise in Aral's market share from $22.5 \%$ to $23 \%$ after joining Payback in 2006]

"If we deduct existing customers that have previously patronized us and used Clubsmart, one can certainly speak of one million new customers. [...] We realize that partnerships are very, very important to us, because they bring new customers and we build on that. We will certainly further pursue that path."

Jan-Christian Kempin

[concerning Shell's partnership with the German Motoring Association ADAC]

'You're gonna have to go through that, yes. You gotta be creative, whether you can come up with something to protect yourself a little bit, but you're gonna have to go through that. I mean, that's just how it is."

Walter Lukner, Head of Partner Management,

Payback

[concerning the alleged disadvantage for coalition partners that customers develop loyalty towards the coalition program instead of the partner company]

"It won't be 10\% of turnover, but you will clearly notice it in the [development of] market share."

Walter Lukner

[concerning the effect that a multi-partner program can have]

Figure 76: Sample Expert Interview Quotes

Note: $\quad$ Translated from German to English 
Three personal interviews lasting between $1 \frac{1 / 2}{2}$ and 2 hours each resulted in a total transcript length of 84 single-spaced pages written in font size 11. As both space constraints as well as the focus on the main model do not permit presenting these in their entirety, the decision has been made to summarize the interview output and depict it selectively. To be specific, findings from the interviews found their way into this paper in one of two places: (1) in the program overview of the subjects of study in Chapter 5.1.3 and (2) in the elaborations presented within this section. As far as this chapter is concerned, a few sample quotes are illustrated in Figure 76 in order to get a feeling for how these dialogues went, while the more comprehensive Table 16 contrasts the interviewees' statements concerning a selected range of subjects in a succinct form. To prepare this table, 14 topics were chosen based on their degree of perceived interest, given that at least two of the three interview partners had commented on the issue.

\section{Aral \\ (partner in a coalition) \\ Shell (operator of a stand-alone scheme)}

\section{Loyalty Partner} (administrator of a coalition)

1) Advantages of Loyalty Coalitions Over Stand-Alone Programs

- Immediate market penetration upon joining the program

- Higher point value perceived by customer (due to the lack of transparency caused by the differing point values given out by each partner). "As opposed to a stand-alone program, I can probably save $30-40 \%$ of the costs per point handed out, simply because I suggest a higher value"

- Consequently lower variable cost

- Immediate access to knowhow concerning data mining, CRM and communication activities, etc.

- Regular access to a high number of customers via the account statement with costs being shared among partners (in case of Payback sent out four times a year)
- Higher customer interest in the case of a strong partner portfolio (as points can be collected at different partners through regular every-day shopping behavior)

- Theoretically, the ability to run cross-selling promotions
- Access to a higher number of customers and a bigger amount of data

- Higher attractiveness for the customer (more collection, but also redemption options)

- Ability to induce cross-selling

- Lower costs for the same output

- Competitive advantage if an exclusive partnership with each industry's market leader is formed in a coalition

- Advantages bigger when the partner company starts from scratch and has no standalone program in place already 


\begin{tabular}{c|c|c|}
\hline Aral & $\begin{array}{c}\text { Shell } \\
\text { (partner in a coalition) }\end{array}$ & $\begin{array}{c}\text { Loyalty Partner } \\
\text { (administrator of a coalition) }\end{array}$ \\
\hline
\end{tabular}

2) Disadvantages of Loyalty Coalitions in Comparison to Stand-Alone Programs

- Need for coordination in the steering committee when own ideas are to be implemented (delays might arise)

- In absolute terms, more expensive than a stand-alone scheme in the long run (although at the same time higher volume gains can be realized)
- Own experiences with Payback during a previous job with the former coalition partner DEA have shown that the partners' focus on their own goals often causes cross-selling efforts to miscarry

- Smaller amount of flexibility and consequently a longer time for implementation of innovation

- Marketing activities less effective

- Difficult for customer to focus on a single brand, due to a big clutter of program partners

- Expensive address list rental for big mailings
- Smaller amount of flexibility

- Customers could become loyal to the coalition instead of the partner brand

- IT systems need to be compatible to introduce a coalition scheme

\section{3) Ability of Loyalty Programs to Alter Customer Behavior}

- Increase of share-of-wallet

- Acquisition of new customers (whereby these need to overcompensate the negative effect on the profit margin caused by existing customers)

- Cross- and up-selling effects can be realized (customer development)

- Churn prevention possible

- The initial effect of an increase in market share from $22.5 \%$ to $23 \%$ as reported by Aral upon the start of its Payback partnership deemed realistic
- Increase of share-of-wallet

- Acquisition of new customers (e.g. around 1 million new customers through the partnership with the German Motoring Association ADAC)

- Cross- and up-selling effects can be realized (20-30\% uplift effect for premium fuels with customers who respond well)

- Aral's reported rise in market share from $22.5 \%$ to $23 \%$ and also the increase in purchase frequency observed with around $20 \%$ of Aral Payback members since the introduction of the program deemed realistic. "In the case of Shell, this latter figure is certainly more like $30 \%$ "
- A bump in sales can be realized with any program type, although it is more sustainable in a loyalty coalition, as compared with a stand-alone program that does not continue to invest. The bump "won't be $10 \%$ of turnover, but you will clearly notice it in the [development of] market share"

- Acquisition of new customers

- The initial effect of an increase in market share from $22.5 \%$ to $23 \%$ as reported by Aral upon the start of its Payback partnership deemed realistic 


\begin{tabular}{|c|c|c|}
\hline $\begin{array}{c}\text { Aral } \\
\text { (partner in a coalition) }\end{array}$ & $\begin{array}{c}\text { Shell } \\
\text { (operator of a stand-alone scheme) }\end{array}$ & $\begin{array}{c}\text { Loyalty Partner } \\
\text { (administrator of a coalition) }\end{array}$ \\
\hline
\end{tabular}

4) Ability of Loyalty Programs to Alter Customer Attitude

- Expected to be the case, but it is unclear whether customers really respond that way
- It is a clear goal of the program to cause a stronger identification with Shell and increase loyalty to the brand (e.g. in the case of the V-Power Club with strong emotional value)

- Not only simple incentives, but also emotions are part of the strategy

5) Measurement of Success

- There is no long-term control/measurement mechanism possible

- No control group exists (except for specific promotional activities)

- However, groups are sometimes formed from Payback members who appear to act like non-members (as indicated by their past purchase behavior)

- The only thing that can be measured: uplift effect upon introduction of the program (e.g. one day or 2 months after)

- Still, Aral has reports based on all Payback customers where customer life cycles are modeled, where one can see how many customers have stopped patronizing the company, etc.

- Also, one piece of market research was conducted monthly over a period of years (plus a conjoint analysis), where Aral could experiment with different scenarios, see what the drivers of value are, and how they influence market share

- In the end, however, "it is partly about gut feeling!"
- Market research is conducted

- Regular tracking in the form of cost effectiveness studies: standardized across all countries, conducted to capture the volume uplift in connection with the current margin per liter and, of course, the costs

- Calculations take place with a particular "experience value," a percentage derived from loyalty measures

- Control groups are used
- Payback aims to build up relationships
- Except for the beginning, the effect caused by the loyalty program is difficult to separate from other variables

- Effects derived from loyalty measures only measurable by stopping the program

- Possibly, small geographic areas could be excluded from the program, although this would be problematic

- Test groups are used for promotional activities

- Groups are formed from Payback members who are expected to act like nonmembers (i.e. who behave as if they were in a stand-alone program and patronize only one partner company) and compared against the other customers: how many new customers could be won for the other partners, how many reacted to promotions, has the average spend increased, etc. 


\begin{tabular}{|c|c|c|}
\hline $\begin{array}{c}\text { Aral } \\
\text { (partner in a coalition) }\end{array}$ & $\begin{array}{c}\text { Shell } \\
\text { (operator of a stand-alone scheme) }\end{array}$ & $\begin{array}{c}\text { Loyalty Partner } \\
\text { (administrator of a coalition) }\end{array}$ \\
\hline \multicolumn{3}{|l|}{ 6) Data } \\
\hline $\begin{array}{l}\text { - The level of detail at which } \\
\text { Payback or emnos (the Pay- } \\
\text { back subsidiary dealing with } \\
\text { data mining requests) cap- } \\
\text { ture and store data varies } \\
\text { between partner companies } \\
\text { - Emnos is heavily used by } \\
\text { Aral due to the small size of } \\
\text { the loyalty department } \\
\text { - Aral possesses all data at } \\
\text { article-level for both shop } \\
\text { items and fuel sales } \\
\text { - To conduct analyses, Pay- } \\
\text { back receives data only at a } \\
\text { higher level of aggregation } \\
\text { - Each partner only has direct } \\
\text { access to his own data, but } \\
\text { via Payback, the data of dif- } \\
\text { ferent members can be ana- } \\
\text { lyzed together upon request } \\
\text { - According to the general } \\
\text { terms and conditions, Pay- } \\
\text { back is the owner of the } \\
\text { complete set of data }\end{array}$ & $\begin{array}{l}\text { - Shell captures data at article- } \\
\text { level for both shop items and } \\
\text { fuel sales } \\
\text { - Data analysis is conducted } \\
\text { by a Shell business unit in } \\
\text { Hungary, but at the same } \\
\text { time, all data can be ac- } \\
\text { cessed and viewed online by } \\
\text { Shell Germany (e.g. by the } \\
\text { call center staff, etc.) }\end{array}$ & $\begin{array}{l}\text { - Four of the Payback partner } \\
\text { companies can also issue } \\
\text { cards branded with their } \\
\text { name: in these cases the cus- } \\
\text { tomer is more or less } \\
\text { "shared" between Payback } \\
\text { and the respective company } \\
\text { - Payback possesses the } \\
\text { registration data, transaction } \\
\text { data is owned both by Pay- } \\
\text { back and the partner } \\
\text { - All partners can store trans- } \\
\text { action data at article-level, } \\
\text { but for analysis, data is pret- } \\
\text { ty much always dealt with at } \\
\text { a lower level of detail } \\
\text { (which level that is, is de- } \\
\text { cided individually by each } \\
\text { partner) } \\
\text { - Data analysis generally } \\
\text { happens at Payback, with the } \\
\text { subsidiary emnos only active } \\
\text { upon request } \\
\text { - Payback partners do not } \\
\text { have direct access to each } \\
\text { others' data }\end{array}$ \\
\hline \multicolumn{3}{|l|}{ 7) Tiering } \\
\hline $\begin{array}{l}\text { - Unknown whether this has } \\
\text { ever been discussed }\end{array}$ & $\begin{array}{l}\text { - Shell V-Power Club for } \\
\text { customers of "differentiated } \\
\text { fuels:" membership upon } \\
\text { invitation after } 180 \text { liters of } \\
\text { V-Power fuel have been } \\
\text { purchased within } 6 \text { months } \\
\text { - No additional measures } \\
\text { planned }\end{array}$ & $\begin{array}{l}\text { - Status is an important ele- } \\
\text { ment of loyalty, but difficult } \\
\text { to implement in a multi- } \\
\text { partner program due to its } \\
\text { heterogeneous nature } \\
\text { - Marketing research shows } \\
\text { that being a member of a } \\
\text { loyalty scheme and showing } \\
\text { your card during a regular } \\
\text { act of purchase has a status } \\
\text { element to it }\end{array}$ \\
\hline
\end{tabular}




\begin{tabular}{|c|c|c|}
\hline $\begin{array}{c}\text { Aral } \\
\text { (partner in a coalition) }\end{array}$ & $\begin{array}{c}\text { Shell } \\
\text { (operator of a stand-alone scheme) }\end{array}$ & $\begin{array}{c}\text { Loyalty Partner } \\
\text { (administrator of a coalition) }\end{array}$ \\
\hline
\end{tabular}

8) Industry-Specific Success

- Particular industries can certainly benefit more from a loyalty scheme, because they follow a different business model (e.g. retailers with many articles from different manufacturers can sell data to these companies and thus probably recuperate most of the costs of the program)

9) Costs and Other Financial Aspects

- In the long run, looking at fixed costs only (and disregarding effectiveness, efficiency, etc.):

- Stand-alone version (with an existing system that can be adapted - e.g. the scheme is already in place in a different country): cheapest

- Stand-alone version (from scratch): second-cheapest

- Multi-partner version: most expensive
- Information about other industries unknown
- Unsure, but what is important for becoming a partner in a coalition scheme is a certain industry-specific purchase frequency (e.g. for a manufacturer of windows to become a partner would not make a lot of sense)
- Looking at fixed costs:

- Stand-alone version (adapted): cheapest

- Stand-alone version (from scratch): second-cheapest

- Multi-partner solution: most expensive

- For Shell, the break-even point was reached after around 3 years (adaption of existing stand-alone version vs. multi-partner program)

- Costs of 20-40 million GBP for the conception from scratch in the case of Shell's program in the United Kingdom sound plausible (this figure was reported by Berman 2006)

- The biggest cost-component are the points (= variable cost)
- It is "probably not wrong" that multi-partner programs are more expensive than standalone solutions when only looking at the bottom-line

- Given a particular output, however, the multi-partner solution will be cheaper, as point costs, redemption channel management costs, communication costs, etc. can all be shared by the program partners

- Variable (i.e. point) costs will be lower in a coalition, as each partner can afford to hand out fewer points to achieve the same effect as a stand-alone program would have achieved (due to the fact that either way, customers collect a high number of points by patronizing different partners; i.e. the perceived value per point is higher for the customer)

- In any case, it is important to employ a holistic perspective when looking at costs (loyalty programs have a lot of hidden costs as well, such as left over rewards, etc.) 


\section{\begin{tabular}{c|c|c|}
\hline $\begin{array}{c}\text { Aral } \\
\text { (partner in a coalition) }\end{array}$ & $\begin{array}{c}\text { Shell } \\
\text { (operator of a stand-alone scheme) }\end{array}$ & $\begin{array}{c}\text { Loyalty Partner } \\
\text { (administrator of a coalition) }\end{array}$
\end{tabular}}

10) Are Loyalty Coalitions the Next Evolutionary Step?

- When talking about technical complexity and possibly also scientific relevance: yes

- Developing the transparent customer, engaging in crossand up-selling, etc. is highly interesting in theory, but often limited by privacy regulations in practice

- Strong partners are important for growth, as you get access to unused customer potential

- Shell has realized this, begun to develop in this direction, and will increasingly build on partnerships in the future (though not in the form of a coalition scheme, where brand awareness might be lost among a whole range of partners)

\section{1) Success Factors for a Loyalty Scheme}

- Strong partner network (if possible with market leaders, characterized by high purchase frequency), good communication measures, high perceived value

12) Program Types Used in Other Countries

- BP/Aral with coalition schemes in Germany and UK, simple promotions in Austria, Switzerland, and Turkey, and stand-alone schemes in a range of other countries: based on the belief that customers in each country are different in terms of their loyalty behavior (e.g. the convenience retail business is different: in Germany, car wash and shops are very strong, but there are other countries where that is not the case)

- Furthermore, profit margins are different in every country, which in turn determines what program $\mathrm{BP} /$ Aral can afford (e.g. as the output volume of refineries cannot be
- Fairly standardized approach across countries with standalone scheme (possibly coupled with promotions; coalition scheme membership in the S'Miles program in France was terminated at the end of 2009)

- Unknown why the Shell Smart Program (today called Driver's Club) failed to set up a form of multi-partner solution (see e.g. Tapp \& Stone 2004)
- Continuous good brand position and brand building, strong partners 


\begin{tabular}{|c|c|c|}
\hline $\begin{array}{l}\text { Aral } \\
\text { (partner in a coalition) }\end{array}$ & $\begin{array}{l}\text { Shell } \\
\text { (operator of a stand-alone scheme) }\end{array}$ & $\begin{array}{l}\text { Loyalty Partner } \\
\text { (administrator of a coalition) }\end{array}$ \\
\hline $\begin{array}{l}\text { easily reduced or increased, } \\
\text { it might make more business } \\
\text { sense to sell excess volume } \\
\text { on the German market with } \\
\text { a rebate in the form of loyal- } \\
\text { ty points as opposed to ship- } \\
\text { ping it to the USA, for ex- } \\
\text { ample) }\end{array}$ & & \\
\hline \multicolumn{3}{|l|}{ 13) Threat of Cannibalization } \\
\hline $\begin{array}{l}\text { "We believe that we have a } \\
\text { positive effect, that new cus- } \\
\text { tomers have overcompen- } \\
\text { sated the cannibalization } \\
\text { effect with existing custom- } \\
\text { ers" (data concerning this } \\
\text { issue cannot be made public, } \\
\text { however) }\end{array}$ & $\begin{array}{l}\text { - "Shell has analysts dealing } \\
\text { with this" }\end{array}$ & \\
\hline \multicolumn{3}{|c|}{$\begin{array}{l}\text { 14) The Fuel Chain DEA's Decision to Leave Payback (Thereby Making Aral's Membership } \\
\text { Possible) }\end{array}$} \\
\hline $\begin{array}{l}\text { DEA's termination of its } \\
\text { Payback membership fol- } \\
\text { lowing its acquisition by } \\
\text { Shell probably caused by a } \\
\text { different strategy, where a } \\
\text { uniform European strategy } \\
\text { has trumped a localized ap- } \\
\text { proach }\end{array}$ & $\begin{array}{l}\text { - Limited flexibility, access to } \\
\text { customer data from other } \\
\text { program partners only tem- } \\
\text { porary and costly }\end{array}$ & $\begin{array}{l}\text { - That was a simple strategic } \\
\text { decision. For Shell, "control } \\
\text { comes first. He [the Shell } \\
\text { CEO] probably wouldn't say } \\
\text { it like that, but control } \\
\text { comes before customer of- } \\
\text { fer" }\end{array}$ \\
\hline
\end{tabular}

Table 16: Comparison of Statements from Expert Interviews

Note: $\quad$ Quotes were translated from German to English; statements included in this table were not subjected to criticism by the author 


\section{Conclusion}

Based on an extensive literature review, an overview of the loyalty concept (Chapter 2), customer loyalty schemes in general (Chapter 3), and coalition schemes as a particular type of these programs (Chapter 4) has been given in the course of this paper. While this review has revealed a whole range of topics that would require further research, the focus of this study has always been the success impact of loyalty programs. In addition, a range of more general questions was included in the empirical part of this study, which addressed both loyalty managers and consumers. An overview of this empirical part, including the subjects of study, the development of its theoretical base and underlying study framework and hypotheses can be found in Chapter 5, while the detailed documentation of this study's findings forms part of Chapter 6.

Chapter 7 will be structured as follows: first, a summary of the findings from the empirical study will be presented (Chapter 7.1), followed by a discussion on emanating managerial implications (Chapter 7.2). Subsequently, the limitations of the applied empirical approach will be pointed out, suggestions for future research endeavors given (Chapter 7.3), and finally, a critical reflection on the research area in general provided (Chapter 7.4).

\subsection{Summary}

In the following section, a brief summary of each of the four research questions illustrated in Figure 77 will be presented. 


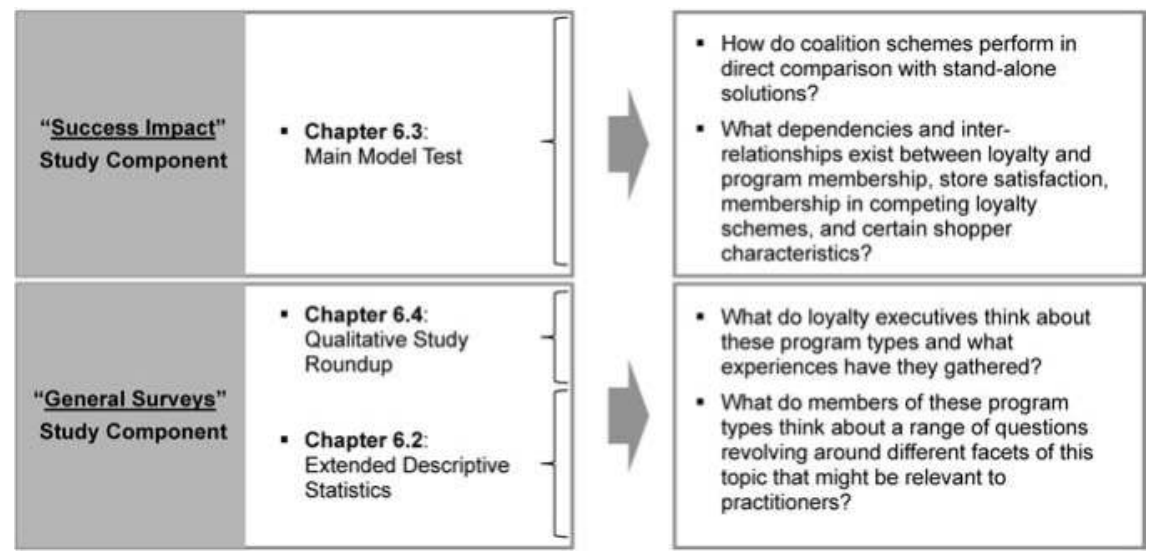

Figure 77: Research Questions and Where They are Evaluated Within This Paper

\section{1) How do coalition schemes perform in direct comparison with stand-alone solutions?}

Stand-alone programs were found to outperform multi-partner schemes in their ability to engender behavioral loyalty, attitudinal loyalty, and word-of-mouth behavior. In other words, stand-alone scheme members distributed a higher share-ofwallet to the company, were characterized by a more positive attitude towards the organization, and were more likely to talk positively about the firm and recommend it to friends, family, or coworkers. While generally, members of loyalty programs showed significantly higher levels of loyalty than non-members, those of the standalone solution did so to an even greater extent than those of the coalition scheme.

What is particularly interesting is that falling in line with theory, coalition members found their program more appealing than stand-alone members. For instance, they found the program better as compared with competitors, the advantages it had to offer more appealing, and also, they found it less arduous to collect points and felt they could obtain good rewards more quickly. In addition, members of the multi-partner scheme were also more likely to have redeemed their points for a reward at least once. For some reason, however, the coalition seemed to have problems translating this edge into actual results. To be specific, multi-partner program members were characterized by a (slightly) lower regularity of use, they were less easily persuaded by a program-related up-selling incentive, and fewer respondents indicated that they had increased their frequency of purchase since becoming a member of the scheme. 
A good indicator for the ability to affect the bottom-line in the study's context of fuel retailing is probably the program members' answers to the following three questions asked in the survey: whether they try to favor the company when having to refuel, whether they sometimes make a little detour to reach the respective chain, or whether they even purposely postpone their next fuel stop to be able to collect points. With regard to all these questions, the stand-alone scheme clearly outrivaled the multi-partner program, and it is probably the combination of all these factors that has led to the significantly better performance of the company-owned stand-alone solution in terms of affecting customer loyalty. While loyalty is a multifaceted construct, behavioral loyalty is sometimes considered the real bottom-line of business. Leaving any judgment on this matter aside, it is this factor that most clearly differentiates the program types: the average share-of-wallet of both control groups hovered around 31-32\%, while that of the coalition members turned out to be roughly $49 \%$ and that of stand-alone members an astonishing 66\% (see Table 14 in Chapter 6.2.4).

2) What dependencies and interrelationships exist between loyalty, program membership and store satisfaction, membership in competing loyalty schemes, and certain shopper characteristics?

Loyalty program membership was found to have a significant positive effect on satisfaction, with satisfaction in turn having a significant positive effect on loyalty. As far as memberships in competing schemes are concerned, the negative effects on the relationship between membership in the original program and loyalty were not as strong as expected. Most importantly, a moderating effect of competitive schemes on this relationship was non-existent in relation to behavioral loyalty as the dependent variable for both the stand-alone and the coalition program. A similar situation persisted in case of word-of-mouth, with the single exception being attitudinal loyalty. Under these circumstances, it was only the stand-alone program that experienced a negative effect. Why this was the case is not entirely clear. It should be noted, however, that the percentage of multiple card holders was generally very low (the average number of cards within the industry under review was 1.2 per customer for coalition scheme and 1.4 for stand-alone scheme members) and in most cases, the second card held was that of the competitive scheme also evaluated in this study. This can easily be explained by the fact that the two evaluated programs are also the two strongest in the industry, with the difference in card ownership attributed to the coalition's higher overall penetration rate. Therefore, it may have been due to the greater likelihood of being tempted by membership in a competitive scheme to become disloyal that led to the slightly more negative outcome in case of the stand-alone program. 
The last set of variables included in the study's main model was that of shopper characteristics. Together with a construct termed economic shopping orientation (i.e. price-consciousness), five demographic and socio-economic variables were tested for their direct or moderating effect on loyalty. Among these six variables, none were found to have a significant moderating effect on either the relationship between satisfaction and loyalty or that between loyalty program membership and loyalty. Effects were only observed with regard to the direct impact on the loyalty construct. Specifically, price consciousness had a significant negative effect on behavioral and attitudinal loyalty for both program types, while a significant effect of educational background on at least one loyalty component could only be witnessed in case of the stand-alone program (here, a lower level of education was found to be associated with higher levels of attitudinal loyalty and word-ofmouth). As for the coalition scheme, the only other shopper characteristic, aside from price consciousness, where an effect could be noted was professional position (employees and civil servants without leadership responsibilities showed the highest level of word-of-mouth behavior, followed by employees and civil servants with leadership responsibilities, and finally freelancers exhibiting the lowest level). All other tested variables - namely gender, age, and income - had neither a direct, nor a moderating effect.

3) What do loyalty executives think about these program types and what experiences have they gathered?

A summary of the three $1 \frac{1 / 2-2}{2}$ hour long personal interviews with the loyalty managers of the two subjects of study, as well as an executive of the third party administrating the multi-party program, has been presented in Chapter 6.4. In an attempt to provide nothing but the distillate of what was discussed, a single bullet point will now be listed for each of the 14 topics that were covered without distinguishing between the three interviewed parties (and without passing judgment on the interviewees' statements):

- Advantages of coalitions over stand-alone programs: immediate high market penetration, access to know-how, and access to high data volume; higher perceived point value; lower variable cost; higher customer interest in the case of a strong partner portfolio; cross-/up-selling potential, competitive advantage when the partner portfolio is made up of market leaders

- Disadvantages of coalitions in comparison to stand-alone programs: smaller amount of flexibility; higher cost in absolute terms; potentially egoistic behavior of other partners; less effective marketing activities; no brand focus of consumer due to big clutter of partners; loyalty of the consumer towards 
the program instead of the partners; expensive address list rental; potential complications with IT

- Ability of loyalty programs to alter customer behavior: share-of-wallet can be increased; new customers can be acquired; churn can be prevented and cross-/up-selling measures implemented

- Ability of loyalty programs to alter customer attitude: this is the goal of the program; it is unclear whether customers really respond with increased attitudinal loyalty (note: differing opinions given by interviewees)

- Measurement of success: uplift effect upon introduction of the program is measurable; no long-term control mechanism is possible; pseudo-control groups are formed with program members who behave like non-members; calculations are conducted with experience values; market research is commissioned; cost-effectiveness studies are carried out; the only long-term option of measurement would be to terminate the program; "in the end, it's partly about gut feeling!"

- Data: available at article level per transaction; usually processed at a higher level of aggregation (particularly by the coalition scheme administrator); analysis of data by the administrator possible upon request from other coalition members; administrator possesses registration data while transaction data is owned by both administrator and partner

- Tiering: difficult to implement tiers in a heterogeneous program like a loyalty coalition; showing the card during a regular act of purchase was shown to have a status element to it; implemented in the stand-alone scheme in a mild form, but no further measures are planned

- Industry-specific success: companies in other industries certainly benefit more from a loyalty program due to a different business model (e.g. some retailers are better able to recuperate costs from manufacturers than others)

- Costs and other financial aspects: looking at fixed costs, a coalition is the most expensive in the long run, followed by a stand-alone program developed from scratch and finally, a stand-alone program adapted from another country; in terms of efficiency, however, the coalition scheme is the least expensive (costsharing among partners); variable costs (i.e. the points) are the biggest cost component; value per point is perceived to be higher in a coalition and thus the variable costs will be lower as fewer points need to be handed out; compared to a coalition, a break-even time of three years was experienced for the stand-alone scheme with adaptation from a program active in another country; 20-40 million GBP to develop a big fuel retailing scheme from scratch sound plausible

- Are loyalty coalitions the next evolutionary step?: in terms of technical complexity and possibly also scientific relevance, yes; limitations are mostly due to privacy regulations; access to new customers through strong program 
partners is very important; partnerships are important, but can also be established with a stand-alone program

- Success factors for a loyalty scheme: good communication measures; offer of a high perceived value; in case of coalitions, a strong partner network, strong brand positioning, and brand building

- Program types used in other countries: standardized approach works well; each country is different in terms of customers' loyalty behavior, thus requiring a different approach (note: differing opinions given by interviewees); also profit margins are different in every country and determine what one can afford to forfeit in terms of margin; program is used to facilitate selling of excess capacities (e.g. as the output volume of refineries cannot easily be reduced or increased it might make more business sense to sell excess volume on the German market with a rebate in the form of loyalty points as opposed to shipping it to the USA, for example)

- Cannibalization effect: it is believed that other benefits have overcompensated for this problem

- The fuel chain DEA's decision to leave Payback (thereby making Aral's membership in 2006 possible): this was due to a different strategy of Shell (DEA's acquirer), whereby a uniform European strategy has trumped a localized approach; this was a case where "control came before customer offer;" the decision was taken due to limited flexibility and only temporary and costly access to customer data from other coalition partners (note: differing opinions given by interviewees)

4) What do members of these program types think about a whole range of questions revolving around different facets of this topic that might be relevant to practitioners?

Figure 78 gives an overview of all the topics that were covered in the questionnaires filled out by respondents to the survey. While all these have been processed in detail in Chapter 6.2 as part of the descriptive statistics section, only three of the five groups of topics featured in Figure 78 will now be summarized (as one of these groups does not permit an intra-group comparison and the other one contains only demographic and other characteristics of the respondents). Similar to the previous paragraph outlining the qualitative study component, this will be done by condensing the findings into roughly one bullet point per topic. In this respect, a distinction will be made between the stand-alone program, the coalition, and the control groups (where applicable), whereby in the latter case, a single weighted average value will be presented for the two control groups. 


\begin{tabular}{|l|}
\hline \multicolumn{1}{|c|}{$\begin{array}{c}\text { Loyalty Cards - Part } 1 \\
\text { General Section } \\
\text { (including comparison with control groups) }\end{array}$} \\
\hline - Memberships with loyalty schemes in the \\
industry \\
- Memberships with other coalition schemes \\
- Number of loyalty cards carried \\
- Preferred type of loyalty scheme \\
- Garriers of exit
\end{tabular}

\begin{tabular}{|l|}
\hline \multicolumn{1}{|c|}{$\begin{array}{c}\text { Loyalty Cards - Part } 2 \\
\text { Membership-Specific Section } \\
\text { (coalition vs, stand-alone comparison) }\end{array}$} \\
\hline - Place where loyalty card is kept \\
- Reward redemption behavior \\
- Patronization prior to program \\
- membership \\
- Reaction to up-selling incentives \\
- Rating of own program \\
- Assessment of point and reward structure \\
- Regularity of use \\
- mereration of purchase behavior through \\
- Lovalty scheme-related loyalty \\
- Penetration rate?
\end{tabular}

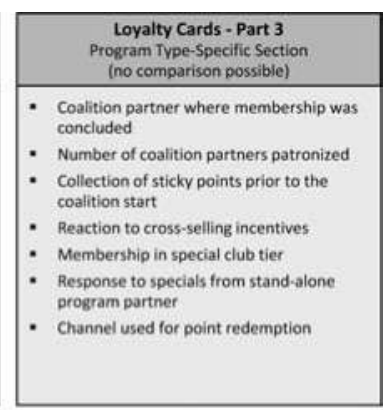

\begin{tabular}{|c|}
\hline $\begin{array}{l}\text { Satisfaction, Loyalty. } \\
\text { and Other Purchase Behavior }\end{array}$ \\
\hline $\begin{array}{l}\text { - Store satisfaction } \\
\text { - Attitudinal loyalty } \\
\text { - Word-of-mouth } \\
\text { - Share-of-wallet } \\
\text { - Purchase frequency } \\
\text { - Monthly category spend } \\
\text { - Cost per tank }\end{array}$ \\
\hline
\end{tabular}

1 Not covered in Chapter 6.2, but in the sample description of Chapter 6.1

2 Not used for main model test

Figure 78: Topics Addressed by the Consumer Survey

Note: $\quad$ Boxes shaded in gray will not be part of this chapter's summary

Tables 17, 18, and 19 each cover one of the three highlighted groups in Figure 78. The key findings from the general section on loyalty programs will be presented in Table 17 (questions which members of the control groups have also answered), those from the membership-specific comparison condensed in Table 18 (contrasting multi-partner and stand-alone schemes), and findings regarding satisfaction, loyalty, and other purchase behavior illustrated in Table 19. To verbalize answers that were captured on a 5-point Likert scale ( 5 being highest), the following mechanism was applied: average values from 1-1.9 were termed "very low," from 2.0-2.9 "rather low," from 3.0-3.9 "rather high," and from 4.05.0 "very high." Any values around the midpoint of the scale (3.0) were further referred to as "average" in some instances.

\begin{tabular}{|c|c|c|c|}
\hline & Test Group & Key Findings & $\begin{array}{l}\text { Inter-Group } \\
\text { Differences }\end{array}$ \\
\hline \multirow{3}{*}{$\begin{array}{l}\text { Memberships in } \\
\text { loyalty schemes } \\
\text { in the industry }\end{array}$} & - Coalition: & 1.2 memberships on average & yes \\
\hline & - Stand-Alone: & 1.4 memberships on average & \\
\hline & - Control Groups: & 0.2 memberships on average & \\
\hline $\begin{array}{l}\text { Memberships in } \\
\text { other coalition } \\
\text { schemes }\end{array}$ & - Coalition: & $\begin{array}{l}25 \% \text { were also members in Germany's } \\
\text { second-biggest, } 9 \% \text { in the third-biggest } \\
\text { coalition }{ }^{1}\end{array}$ & yes \\
\hline
\end{tabular}




\begin{tabular}{|c|c|c|c|}
\hline & Test Group & Key Findings & $\begin{array}{l}\text { Inter-Group } \\
\text { Differences }\end{array}$ \\
\hline & - Stand-Alone: & $\begin{array}{l}33 \% \text { were members in the nation's } \\
\text { biggest, } 18 \% \text { in second-biggest, } 8 \% \text { in } \\
\text { third-biggest }\end{array}$ & \\
\hline & - Control Groups: & $\begin{array}{l}19 \% \text { were members in the nation's } \\
\text { biggest, } 8 \% \text { in second-biggest, } 2 \% \text { in } \\
\text { third-biggest }\end{array}$ & \\
\hline \multirow{3}{*}{$\begin{array}{l}\text { Number of loyal- } \\
\text { ty cards carried } \\
\text { (from all indus- } \\
\text { tries) }\end{array}$} & - Coalition: & $\begin{array}{l}3.2 \text { on average; } 3 \% \text { carried no loyalty } \\
\text { card, most two or three cards ( } 22 \% \text { and } \\
19 \% \text { respectively) }\end{array}$ & yes \\
\hline & - Stand-Alone: & $\begin{array}{l}3.0 \text { on average; } 9 \% \text { carried no loyalty } \\
\text { card, most two or three cards ( } 23 \% \text { and } \\
20 \% \text { respectively) }\end{array}$ & \\
\hline & - Control Groups: & $\begin{array}{l}1.7 \text { on average; } 36 \% \text { carried no loyalty } \\
\text { card, the next biggest group is that } \\
\text { carrying one card }(20 \%)\end{array}$ & \\
\hline \multirow[t]{3}{*}{$\begin{array}{l}\text { Preferred type of } \\
\text { loyalty scheme }\end{array}$} & - Coalition: & $\begin{array}{l}46 \% \text { : immediate discount } \\
39 \% \text { : point collection } \\
3 \% \text { : sticker or stamp collection } \\
12 \% \text { : other or no difference perceived }\end{array}$ & yes \\
\hline & - Stand-Alone: & $\begin{array}{l}50 \% \text { : point collection } \\
41 \% \text { : immediate discount } \\
3 \%: \text { sticker or stamp collection } \\
6 \%: \text { other or no difference perceived }\end{array}$ & \\
\hline & - Control Groups: & $\begin{array}{l}50 \% \text { : immediate discount } \\
18 \% \text { : point collection } \\
8 \% \text { : sticker or stamp collection } \\
24 \% \text { : other or no difference perceived }\end{array}$ & \\
\hline Barriers of exit & - All Groups: & $\begin{array}{l}\text { Agreement is rather low that it is cum- } \\
\text { bersome to change program or that the } \\
\text { number of lost points would be high } \\
\text { (ratings between } 2 \text { and } 2.5 \text { ) }\end{array}$ & no \\
\hline \multirow[t]{3}{*}{$\begin{array}{l}\text { General attitude } \\
\text { towards loyalty } \\
\text { programs }\end{array}$} & - Coalition: & $\begin{array}{l}\text { Rather high positive attitude towards } \\
\text { loyalty cards along all statements, ex- } \\
\text { cept: rather high level of annoyance at } \\
\text { carrying many loyalty cards (ratings } \\
\text { between } 3.5 \text { and } 4 \text { ) }\end{array}$ & yes \\
\hline & - Stand-Alone: & $\begin{array}{l}\text { Likewise, rather high positive attitude } \\
\text { towards loyalty cards along all state- } \\
\text { ments, except: rather high level of } \\
\text { annoyance at carrying many loyalty } \\
\text { cards (ratings between } 3.5 \text { and } 4 \text { ) }\end{array}$ & \\
\hline & - Control Groups: & $\begin{array}{l}\text { Not characterized by a generally bad at- } \\
\text { titude, but also most annoyed at carrying } \\
\text { many loyalty cards of different companies } \\
\text { (ratings between } 4 \text { and } 4.5 \text { ) }\end{array}$ & \\
\hline
\end{tabular}




\begin{tabular}{|l|l|l|l|}
\hline Privacy concerns & Test Group & Key Findings & $\begin{array}{l}\text { Inter-Group } \\
\text { Differences }\end{array}$ \\
\cline { 2 - 4 } & - Coalition: & $\begin{array}{l}\text { Similar to stand-alone program, around } \\
\text { average privacy concerns (2.9) }\end{array}$ & yes \\
\cline { 2 - 5 } & - Control Groups: & $\begin{array}{l}\text { Similar to multi-partner program, } \\
\text { around average privacy concerns (3.0) }\end{array}$ & $\begin{array}{l}\text { Rather high levels of concern about } \\
\text { privacy (3.6) }\end{array}$ \\
\hline
\end{tabular}

1 All respondents in this group were member in the nation's largest coalition scheme

2 Averages are slightly understated, as the "more than 7" category was set to 7 for this calculation

Table 17: Summary - General Findings Regarding Loyalty Cards

Note: $\quad$ Ratings were indicated on a 5-point Likert scale (5 being highest)

\begin{tabular}{|c|c|c|c|}
\hline & Test Group & Key Findings & $\begin{array}{l}\text { Inter-Group } \\
\text { Differences }\end{array}$ \\
\hline \multirow{2}{*}{$\begin{array}{l}\text { Place where loyal- } \\
\text { ty card is kept }\end{array}$} & - Coalition: & $92 \%$ : wallet, $3 \%$ : car, $5 \%$ : other & yes \\
\hline & - Stand-Alone: & $69 \%$ : wallet, $26 \%$ : car, $5 \%$ : other & \\
\hline \multirow{2}{*}{$\begin{array}{l}\text { Reward redemp- } \\
\text { tion behavior }\end{array}$} & - Coalition: & $76 \%$ have redeemed at least once & yes \\
\hline & - Stand-Alone: & $69 \%$ have redeemed at least once & \\
\hline \multirow[t]{2}{*}{$\begin{array}{l}\text { Patronization prior } \\
\text { to program mem- } \\
\text { bership }\end{array}$} & - Coalition: & $\begin{array}{l}94 \% \text { patronization rate prior to member- } \\
\text { ship; past purchase frequency: } 27 \% \\
\text { rather less frequent }\end{array}$ & $\begin{array}{l}\text { yes (for } 1 \text { of } 2 \\
\text { components) }\end{array}$ \\
\hline & - Stand-Alone: & $\begin{array}{l}\text { 94\% patronization rate prior to member- } \\
\text { ship; past purchase frequency: } 38 \% \\
\text { rather less frequent }\end{array}$ & \\
\hline \multirow[t]{2}{*}{$\begin{array}{l}\text { Reaction to up- } \\
\text { selling incentives }\end{array}$} & - Coalition: & $\begin{array}{l}7 \% \text { persuaded by point incentive to try } \\
\text { out premium fuels; out of the } 100 \% \text { who } \\
\text { tried, } 5 \% \text { continued to purchase them } \\
\text { permanently }\end{array}$ & yes \\
\hline & - Stand-Alone: & $\begin{array}{l}26 \% \text { persuaded by point incentive to try } \\
\text { out premium fuels; out of the } 100 \% \text { who } \\
\text { tried, } 31 \% \text { continued to purchase them } \\
\text { permanently }\end{array}$ & \\
\hline \multirow[t]{2}{*}{$\begin{array}{l}\text { Rating of own } \\
\text { program }\end{array}$} & - Coalition: & $\begin{array}{l}\text { Rather high appeal of own program } \\
(3.7)\end{array}$ & yes \\
\hline & - Stand-Alone: & $\begin{array}{l}\text { Also rather high, but compared to multi- } \\
\text { partner program, still somewhat smaller } \\
\text { appeal of own program (3.3) }\end{array}$ & \\
\hline $\begin{array}{l}\text { Assessment of } \\
\text { point and reward } \\
\text { structure }\end{array}$ & - Coalition: & $\begin{array}{l}\text { Rather high rating of attractiveness of } \\
\text { rewards (3.3) and fairness of points } \\
\text { (3.1); slightly above average agreement } \\
\text { that good rewards can be obtained } \\
\text { quickly (3.1) and rather low agreement } \\
\text { that it is arduous to collect points (2.6) }\end{array}$ & $\begin{array}{l}\text { yes (for } 2 \text { of } 4 \\
\text { components) }\end{array}$ \\
\hline
\end{tabular}




\begin{tabular}{|c|c|c|c|}
\hline & Test Group & Key Findings & \begin{tabular}{|l} 
Inter-Group \\
Differences
\end{tabular} \\
\hline & - Stand-Alone: & $\begin{array}{l}\text { Rather high rating of attractiveness of } \\
\text { rewards (3.2) and fairness of points ( } 3.2) \\
\text { (= no significant difference to coalition); } \\
\text { rather low agreement that good rewards } \\
\text { can be obtained quickly (2.7) and that it } \\
\text { is arduous to collect points (2.9) } \\
\text { (= significant difference to coalition) }\end{array}$ & \\
\hline \multirow[t]{2}{*}{ Regularity of use } & - Coalition: & $\begin{array}{l}\text { Very high usage rates, though below } \\
\text { stand-alone program (4.0) }\end{array}$ & yes \\
\hline & - Stand-Alone: & Very high usage rates (4.3) & \\
\hline \multirow{2}{*}{$\begin{array}{l}\text { Alteration of } \\
\text { purchase behavior } \\
\text { through member- } \\
\text { ship }\end{array}$} & - Coalition: & $\begin{array}{l}\text { Rather low tendency to favor own fuel } \\
\text { chain, make a small detour, or postpone } \\
\text { the fuel stop to collect points }(2.4)\end{array}$ & yes \\
\hline & - Stand-Alone: & $\begin{array}{l}\text { Average tendency to favor own fuel } \\
\text { chain, make a small detour, or postpone } \\
\text { the fuel stop to collect points ( } 3.0) \\
\text { (= biggest difference to coalition among } \\
\text { all Likert scale questions) }\end{array}$ & \\
\hline \multirow[t]{2}{*}{$\begin{array}{l}\text { Loyalty scheme- } \\
\text { related loyalty }\end{array}$} & - Coalition: & $\begin{array}{l}\text { Rather low likelihood to refuel at chain } \\
\text { even if program did not exist }(2.4)\end{array}$ & yes \\
\hline & - Stand-Alone: & $\begin{array}{l}\text { Rather low likelihood to refuel at chain } \\
\text { even if program did not exist ( } 2.6 \text { ) } \\
\text { (meaning more loyalty to the chain and } \\
\text { less to the program itself) }\end{array}$ & \\
\hline \multirow[t]{2}{*}{ Penetration rate } & - Coalition: & $43 \%$ program membership quota & yes \\
\hline & - Stand-Alone: & $32 \%$ program membership quota & \\
\hline
\end{tabular}

Table 18: Summary - Membership-Specific Findings Regarding Loyalty Cards

Note: $\quad$ Ratings were indicated on a 5-point Likert scale (5 being highest)

\begin{tabular}{|l|l|l|l|}
\hline Store satisfaction & - Coalition: & $\begin{array}{l}\text { Key Findings } \\
\text { Rather high level of store satisfaction } \\
\text { with differences only to control groups } \\
(3.8)\end{array}$ & $\begin{array}{l}\text { Inter-Group } \\
\text { Differences }\end{array}$ \\
\cline { 2 - 5 } & - Stand-Alone: & $\begin{array}{l}\text { Rather high level of store satisfaction } \\
\text { with differences only to control groups } \\
(3.8)\end{array}$ & \\
\cline { 2 - 5 } & - Control Groups: & $\begin{array}{l}\text { Also rather high, but still significantly } \\
\text { smaller level of satisfaction than among } \\
\text { program members (3.6) }\end{array}$ & \\
\hline Attitudinal loyalty & - Coalition: & $\begin{array}{l}\text { Rather low levels of attitudinal loyalty } \\
(2.5)\end{array}$ & yes \\
\hline
\end{tabular}




\begin{tabular}{|c|c|c|c|}
\hline & Test Group & Key Findings & $\begin{array}{l}\text { Inter-Group } \\
\text { Differences }\end{array}$ \\
\hline & - Stand-Alone: & $\begin{array}{l}\text { Slightly below average levels of attitu- } \\
\text { dinal loyalty (2.9) }\end{array}$ & \\
\hline & - Control Groups: & $\begin{array}{l}\text { Rather low levels of attitudinal loyalty } \\
(2.0)\end{array}$ & \\
\hline \multirow[t]{3}{*}{ Word-of-mouth } & - Coalition: & $\begin{array}{l}\text { Very low levels of word-of-mouth beha- } \\
\text { vior (1.6) }\end{array}$ & yes \\
\hline & - Stand-Alone: & $\begin{array}{l}\text { Rather low levels of word-of-mouth } \\
\text { behavior (2.0) }\end{array}$ & \\
\hline & - Control Groups: & $\begin{array}{l}\text { Very low levels of word-of-mouth beha- } \\
\text { vior (1.4); difference to multi-partner } \\
\text { program small, albeit significant }\end{array}$ & \\
\hline \multirow[t]{3}{*}{ Share-of-wallet } & - Coalition: & Average share-of-wallet of $49 \%$ & yes \\
\hline & - Stand-Alone: & Average share-of-wallet of $66 \%$ & \\
\hline & - Control Groups: & Average share-of-wallet of $31 \%$ & \\
\hline \multirow[t]{3}{*}{$\begin{array}{l}\text { Purchase } \\
\text { frequency }\end{array}$} & - Coalition: & $\begin{array}{l}3.5 \text { purchases per month (= lower value } \\
\text { than for control groups) }\end{array}$ & yes \\
\hline & - Stand-Alone: & $\begin{array}{l}4.5 \text { purchases per month }(=\mathrm{a} \text { lot higher } \\
\text { value than for control groups) }\end{array}$ & \\
\hline & - Control Groups: & $\begin{array}{l}\text { Significant differences among control } \\
\text { groups: } 4.0 \text { for multi-partner and } 3.3 \text { for } \\
\text { stand-alone control group }\end{array}$ & \\
\hline \multirow[t]{3}{*}{$\begin{array}{l}\text { Monthly category } \\
\text { spend }\end{array}$} & - Coalition: & $\begin{array}{l}194 \text { EUR of category expenditure per } \\
\text { month (= lower value than for control } \\
\text { groups) }\end{array}$ & yes \\
\hline & - Stand-Alone: & $\begin{array}{l}283 \text { EUR of category expenditure per } \\
\text { month (= a lot higher value than for } \\
\text { control groups) }\end{array}$ & \\
\hline & - Control Groups: & $\begin{array}{l}\text { Significant differences among control } \\
\text { groups: } 210 \text { EUR for multi-partner and } \\
184 \text { EUR for stand-alone control group }\end{array}$ & \\
\hline \multirow[t]{3}{*}{ Cost per tank } & - Coalition: & $\begin{array}{l}\text { Average cost per tank of } 59 \text { EUR (no } \\
\text { significant difference to control groups) }\end{array}$ & yes \\
\hline & - Stand-Alone: & Average cost per tank of 66 EUR & \\
\hline & - Control Groups: & Average cost per tank of 61 EUR & \\
\hline
\end{tabular}

Table 19: Summary - Satisfaction, Loyalty, and Other Purchase Behavior

Note: $\quad$ Ratings were indicated on a 5-point Likert scale (5 being highest) 


\subsection{Managerial Implications}

The fundamental goal of this paper was two-fold in that it was written to advance academic research on loyalty programs while at the same time being practically relevant. To fulfill these demands, care was taken to ensure that neither the literature review nor the empirical study developed in only one of these directions. After all, academic rigor and practical relevance certainly do not have to be mutually exclusive. As far as managerial relevance is concerned, the literature review can be considered a baseline overview. Particularly the outline of issues surrounding loyalty schemes, such as data mining, ways to structure a program, its positive and negative effects (Chapter 3), or the idiosyncrasies of loyalty coalitions (Chapter 4) form a frame of reference for managerial decisions on the subject. The primary contribution of the empirical study to academic literature was to provide a comparison between multi-partner programs and stand-alone solutions in terms of their effect on customer loyalty. In addition to that, however, various other findings of this study are expected to have further enhanced the managerial decision base on which to draw from when dealing with a range of subjects related to loyalty schemes. Furthermore, several independent issues surrounding that topic have also been evaluated in this study.

Within this chapter on managerial implications, a general overview of considerations necessary for deciding between the implementation of either a multipartner or a stand-alone program will be given first. Subsequently, a range of further implications will be formulated based upon the various remaining individual findings of this study.

\section{1) Multi-Partner or Stand-Alone Program?}

A high-level comparison of the two program types under review can be found in Figure 79. In essence, these are the primary criteria that would need to be evaluated when deciding between these two program formats. On the one hand, the cost-side will be taken into account, including both fixed costs (i.e. especially the program infrastructure) and variable costs (i.e. particularly points and communication costs). A stand-alone program would require a larger up-front investment, while annual management fees will need to be paid to become a partner in a coalition. On the other hand, potential benefits of the two types need be considered. It was discovered in this study that as far as the bottom-line is concerned (namely the effect of program membership on customer loyalty), it is the wellmanaged stand-alone scheme that can generate a higher impact due to its more focused nature. It needs to be kept in mind, however, that there are many other factors that cannot be neglected when taking such a decision (see Figure 79). 


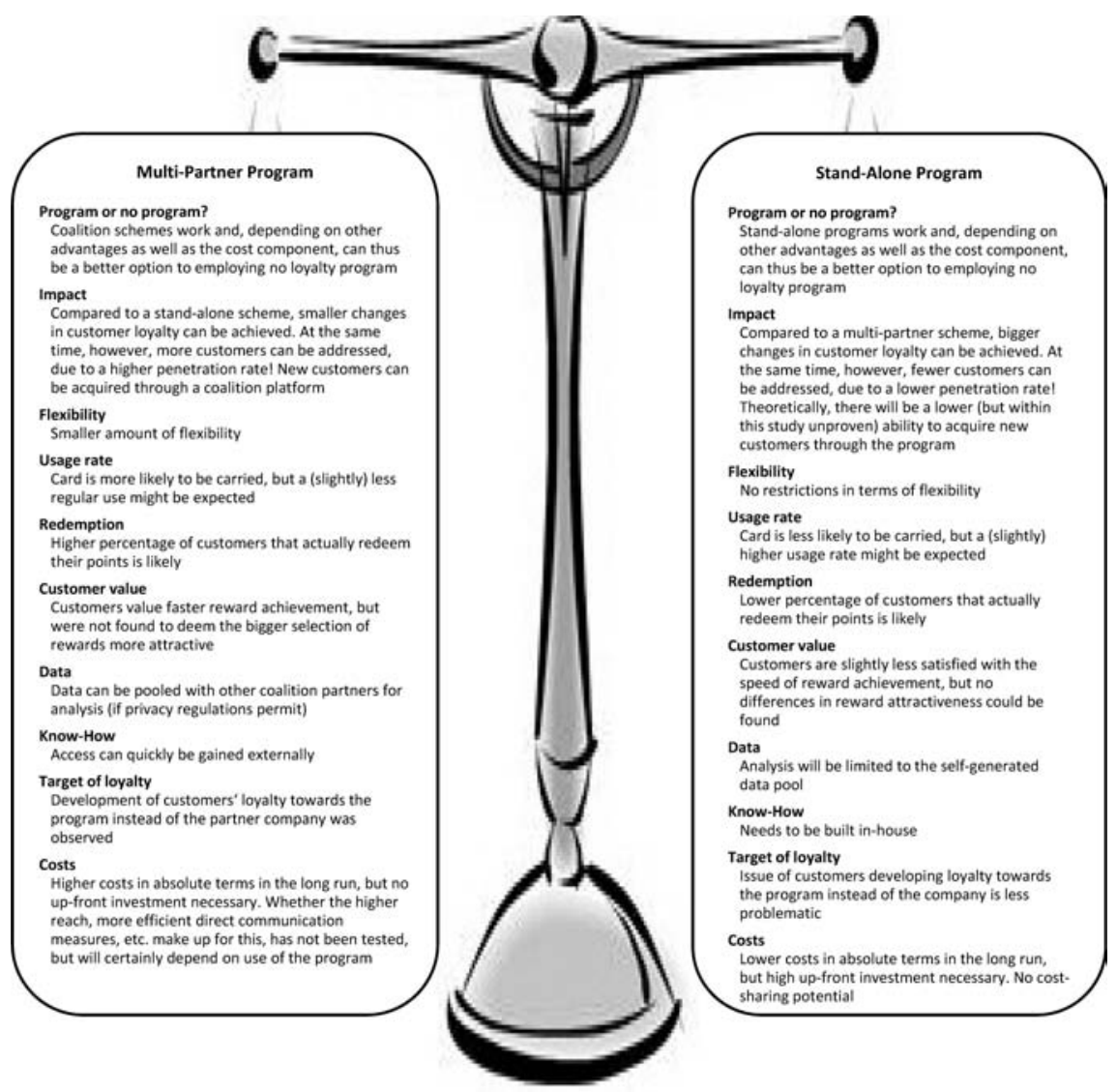

Figure 79: Cost/Benefit Comparison for Multi-Partner and Stand-Alone Programs

When joining a coalition scheme, certain things will be handed to you on a plate (albeit for a price). For example, a larger number of customers can be reached with a multi-partner program, and necessary know-how for program administration and data analysis does not have to be built in-house. At the same time, to name just one other example, flexibility will be lost in a loyalty coalition because changes to the program structure cannot be made without the prior consent of the steering committee, and furthermore, partnerships are also established for a minimum amount of time. Thus, it is a strategic decision that needs to be based on the specific situation of the company and its goals. 
Aside from the comparison of multi-partner and stand-alone programs, a couple of other general topics concerning loyalty schemes yielded noteworthy results. Having been summarized in a very descriptive and data-oriented manner in Table 17, they shall now be translated into actionable managerial implications (see Table 20).

\begin{tabular}{|c|c|c|}
\hline & Key Finding & Implication \\
\hline $\begin{array}{l}\text { Memberships in } \\
\text { loyalty schemes } \\
\text { in the industry }\end{array}$ & $\begin{array}{l}\text { Low percentage of multiple } \\
\text { card holders among members } \\
\text { of the leading schemes of the } \\
\text { industry }\end{array}$ & $\begin{array}{l}\text { Strive to establish the industry's strongest } \\
\text { scheme to create insulation from competitors }\end{array}$ \\
\hline $\begin{array}{l}\text { Memberships in } \\
\text { other coalition } \\
\text { schemes }\end{array}$ & $\begin{array}{l}\text { Low membership rates in } \\
\text { me-too coalitions }\end{array}$ & $\begin{array}{l}\text { Consider a partnership with a coalition } \\
\text { scheme primarily with the country's strongest } \\
\text { program. If the circle of partner companies is } \\
\text { made up of each retail sector's market leader, } \\
\text { an additional source of competitive advantage } \\
\text { might be attained }\end{array}$ \\
\hline $\begin{array}{l}\text { Number of loyalty } \\
\text { cards carried } \\
\text { (from all } \\
\text { industries) }\end{array}$ & $\begin{array}{l}\text { Most consumers carry a range } \\
\text { of loyalty cards in their } \\
\text { wallet. At the same time, } \\
\text { most customers are bothered } \\
\text { by carrying many cards with } \\
\text { them }\end{array}$ & $\begin{array}{l}\text { Refrain from putting another card in custom- } \\
\text { ers' wallets by using innovative measures } \\
\text { tailored to the needs of different customer } \\
\text { segments (e.g. provide options to register the } \\
\text { customer with his debit card's chip, use bar } \\
\text { code stickers for the customer to put on the } \\
\text { back of other cards or items he carries, use a } \\
\text { key fob, or possibly allow for the cashier to } \\
\text { quickly look up the customer's name in the } \\
\text { membership database at check-out) }\end{array}$ \\
\hline $\begin{array}{l}\text { Preferred type } \\
\text { of loyalty } \\
\text { scheme }\end{array}$ & $\begin{array}{l}\text { Programs providing a direct } \\
\text { discount are generally favored } \\
\text { by customers, even though } \\
\text { members of a strong point } \\
\text { collection program might be } \\
\text { convinced otherwise. Sticker } \\
\text { or stamp collection schemes } \\
\text { are the least preferred type }\end{array}$ & $\begin{array}{l}\text { Despite the fact that direct discount schemes } \\
\text { are generally favored, put the focus on point } \\
\text { collection schemes, as only they can provide } \\
\text { the psychological stimuli that cause the cus- } \\
\text { tomer to keep returning for a reason other } \\
\text { than having been offered an outright bribe. } \\
\text { Furthermore, these programs will be harder to } \\
\text { copy, better able to engender attitudinal loyal- } \\
\text { ty (depending on the rewards issued), and in } \\
\text { some cases, barriers of exit might be built up. } \\
\text { Sticker or stamp collection solutions are } \\
\text { generally not recommended, but depending on } \\
\text { size and financial means of the company, } \\
\text { might be an option upon careful examination } \\
\text { of the competitive situation }\end{array}$ \\
\hline
\end{tabular}




\begin{tabular}{|l|l|l|}
\hline \multicolumn{2}{|l}{ Key Finding } \\
\hline Barriers of exit & $\begin{array}{l}\text { Rather low agreement of } \\
\text { customers that it is cumber- } \\
\text { some to change program or } \\
\text { that the number of lost points } \\
\text { would be high upon a change } \\
\text { to a competitive program }\end{array}$ & $\begin{array}{l}\text { Make sure that the program remains attrac- } \\
\text { tive, as barriers of exit are not considered } \\
\text { particularly high by the average customer }\end{array}$ \\
\hline $\begin{array}{l}\text { General attitude } \\
\text { towards loyalty } \\
\text { programs }\end{array}$ & $\begin{array}{l}\text { Even non-members of loyalty } \\
\text { schemes do not have a gener- } \\
\text { ally bad attitude towards } \\
\text { loyalty programs, but they are } \\
\text { highly concerned about cer- } \\
\text { tain aspects, such as threats to } \\
\text { their privacy or having to } \\
\text { carry many cards }\end{array}$ & $\begin{array}{l}\text { Make sure to address these issues that cus- } \\
\text { tomers might be concerned or annoyed about } \\
\text { to provide the best package possible and to } \\
\text { attain the maximum membership rate (see e.g. } \\
\text { row “number of loyalty cards carried" or } \\
\text { "privacy concerns" in this table) }\end{array}$ \\
\hline Privacy concerns & $\begin{array}{l}\text { Particularly non-members } \\
\text { show a rather high level of } \\
\text { concern about an infringe- } \\
\text { ment of privacy, but even the } \\
\text { program members' level of } \\
\text { concern was found to be } \\
\text { around average }\end{array}$ & $\begin{array}{l}\text { Openly communicate the company's data } \\
\text { protection policy, emphasizing what will be } \\
\text { done with the data and that no address lists } \\
\text { will be sold, etc. (plus, possibly come up with } \\
\text { a measure to guarantee this to the consumer) }\end{array}$ \\
\hline
\end{tabular}

Table 20: General Managerial Implications

It should be noted that the implications presented in this chapter are naturally not allencompassing as far as information that can be derived from this paper is concerned. A look into the literature review could, for example, give valuable inputs to a loyalty manager who needs to decide upon his program's reward configuration (Chapter 3.3.8). Alternatively, a manager of a fuel station scheme might draw conclusions for his program when learning that a quarter of the members in the stand-alone program under review kept their card in their car (e.g. in relation to the issue of consumers' wallets overflowing with loyalty cards).

The focus of this section has been directed towards findings from this paper's empirical component, and specifically to those findings that can be generalized to loyalty schemes of all retail sectors. An interested reader can find further details on all reviewed as well as empirically tested subjects in Chapters 2 to 6.

\subsection{Limitations and Further Research}

Like every empirical investigation, this study suffers from various limitations. These will be discussed in the course of this section and furthermore, links to potential future research endeavors established. 
Limitations of the consumer survey revolve around the following issues:

- First, Munich was selected as the single place to conduct the study. Possible nation-wide differences have thus not been taken into account and despite the fact that multiple locations within Munich were carefully selected to minimize bias, neither can it be ensured that the sample is perfectly representative of the city itself. While the usable sample size of 1,084 appeared satisfactory, a possible step to remedy this situation might be to extend the focus of a future survey into rural areas to include the effect of a lack of competitive options. In any case, the sampling process pursued was not necessarily designed to guarantee for external validity.

- Second, perfect comparability of the two programs under review can naturally not be warranted either. Again, care has been taken to minimize potential interferences by choosing programs of two competitors with similar size and regional strength, comparable differentiated strategic positioning, similar program configurations (e.g. value per point, redemption options, etc.), and which had no particular loyalty campaign in progress during the study. Nevertheless, certainly not all covariates could be accounted for. For example, gender and income were found to differ between the two main sample groups. It should be noted, however, that these two demographic/socio-economic characteristics had no direct or moderating effect on the model. Still, control groups are expected to have held off potential negative interferences.

- Third, the general success research bias of customers having joined the program because they already were loyal customers of the company and hence got the biggest benefit out of becoming a member is also a limiting factor of this study. What came first, the chicken or the egg? Or in other words, was the difference in observed loyalty really caused by the program membership or rather by the higher likelihood that already loyal customers join the program? One of the few attempts to account for these self-selecting members was made by Leenheer et al. (2007), who compared their observations with a model that tries to predict attraction of customers. Leenheer et al.'s approach is somewhat similar to the work of Lewis (2004), who tried to model the optimizing behavior of the consumer. It is important to note that these approaches naturally also suffer from a range of limitations in that they simply model the expected customer behavior or attraction, as it is highly difficult to measure the actual impact of self-selecting members (plus, any model is incomplete in the first place). Despite these measures to account for this issue, however, these authors come to the conclusion that program membership has a significant effect on behavioral loyalty. This survey's conclusion is thus perfectly in line with their findings on the positive nature of this relationship 
- an outcome that has further been backed by the answers to two questions included in the survey: (1) while around $94 \%$ of respondents declared that they had patronized the company prior to becoming a program member, between $27 \%$ and $38 \%$ (depending on program type) of these also stated that their frequency of purchase had been "rather less frequent" before. (2) Furthermore, program members only indicated an agreement of between 2.4 and 2.6 on the 5-point Likert scale ( 5 being highest; value depending on program type) with the statement that they would continue to prefer patronizing the company if the respective loyalty scheme no longer existed.

- Fourth, this study was conducted with members of two strong German fuel retailing schemes. Further studies could contribute to the generalizability of these findings on the differences between loyalty coalitions and stand-alone programs by evaluating these in the context of other retail sectors and possibly also multiple geographical regions.

- Fifth, limitations regarding the methodological approach include the following: (1) reliability issues inherent to a survey design relying on self-reported data were certainly a problem associated with this study, but had to be accepted due to a lack of better alternatives. (2) A common method bias might be present due to the focus on questionnaires as the primary instrument of data collection (Homburg et al. 2009, Homburg \& Klarmann 2009). While adding a qualitative component to the study could be interpreted as an attempt to counteract this issue, this really is the case only to a very limited extent. However, common method variance (i.e. variance caused by the measurement method instead of the construct that is supposed to be measured) has been minimized by following Temme et al.'s (2009) recommendations. (3) A key informant bias might be present in relation to the qualitative study component (Homburg \& Klarmann 2009). However, the threat of a biased view or incomplete information due to interviewing only one representative of each company is deemed to be rather small at least with Aral and Shell, because their loyalty departments consist of only 3 to 10 people. Furthermore, in each case the most suitable employee was selected for the interview (which was of particular importance in the case of Payback, which employs around $130-180$ people).

The field of loyalty schemes still offers a lot of potential for further research into a wide range of topics. As it would go a little too far to elaborate on all these topics, this paper's discussion on future research opportunities will focus on success research, the study's primary objective. In addition to the suggestions that have been formulated in the previous paragraphs on this study's limitations, the following research endeavors would be worthwhile: (1) what just might be 
the holy grail of loyalty scheme success research is a longitudinal study with customers both before and after their membership in a loyalty program and/or during their membership and after the termination of that scheme. If a practicable way of capturing the purchase data of a range of customers prior to a program membership could be found and it could be compared with data from a later (uninfluenced) scheme participation, precise conclusions could then be drawn about the actual magnitude of the program's effects as well as that of selfselecting members (e.g. Meyer-Waarden \& Benavent 2009 made a noteworthy step in that direction using panel data). (2) It would be interesting to find out what really determines the strength or weakness of a loyalty program and to consequently compare strong and weak schemes in terms of their effect on loyalty, ability to insulate from competitive programs, effect on satisfaction, etc. (3) In addition to that, it might be fascinating to contrast the effectiveness of different coalition schemes based on the strength of their partner portfolio. (4) Apart from extending the comparison of multi-partner and stand-alone programs into other industries or geographical regions, further research projects could focus on advantages and disadvantages of these scheme types, aside from just their effect on customer loyalty. From a practical point of view, it appears particularly necessary to shed more light on the cost component of these options in order to be able to conduct a meaningful cost-benefit analysis. Furthermore, the relative ability of different program types to acquire new customers is a severely understudied subject. It remains untested whether coalition partners can really afford to hand out fewer points due to the purported fact that customers perceive these points as more valuable (as suggested by the interviewed coalition scheme manager). (5) Still loosely connected to the topic of success research is the question of how other factors that even program members rated negatively influence their behavior (e.g. privacy concerns, having to carry many cards in the wallet, etc.). Likewise, what are the most important considerations for non-members? (6) Moreover, further insight is required in order to determine what reward configurations are most effective at positively influencing customer loyalty (see Chapter 3.3.8 for a review of the available body of knowledge).

\subsection{Concluding Reflection}

"Are coalition schemes the next evolutionary step?" is the question that was asked in the introduction and repeated throughout this paper. To answer this question, one should keep in mind that natural selection is a key mechanism of evolution. It is, in essence, a process during which the specific traits of individuals become more or less common in the general population, depending on the 
fitness of these individuals (Darwin 1859, Futuyma 2009). Applied to the context of this paper, this would mean that to be the next evolutionary step, the net positive characteristics inherent in multi-partner schemes would have to be superior to those of stand-alone programs. Thinking this logic through, this would also mean that coalitions would eventually become the dominant loyalty solution.

This is not believed to be the case, however, for the simple reason that both multi-partner and stand-alone programs offer distinct advantages. These two program types complement one another and neither one should be seen as the logical replacement for the other. Which type is chosen by the company will depend on the specific situation, with factors such as the willingness to commit to a high up-front investment in program infrastructure, marketing, and human resources or the amount of desired flexibility in relation to the scheme's configuration influencing this decision. Each program type offers a unique combination of costs and benefits and it will be up to the loyalty manager to decide which profile best fits the requirements of his company.

What is important for every organization to understand is that loyalty programs will not work wonders in terms of influencing customer loyalty and increasing turnover. This, in fact, is the task of the core activities of the company, such as offering a desirable product at a good price, coupled with sound customer service (Volk 2010). These activities are the actual, fundamental drivers of satisfaction and customer loyalty, and only once these are taken care of, should the company consider boosting loyalty further with the help of a loyalty program. With a well-managed solution, the resulting effect on turnover and consequently profits will certainly be noticeable, but should not be overestimated. Furthermore, one needs to remember that this impact will not be the sole benefit of such a scheme. The ability to generate customer data probably constitutes the single most important source of additional value.

Moreover, the administration of a loyalty program will require a continuous and not a one-off effort. Customer loyalty schemes rely on the idea of developing the customer over time and whenever an effect is to be measured, companies need to take several time periods into account. As far as multiple time intervals are concerned, these programs follow the basic idea of Gutenberg (1955), sometimes referred to as the father of modern business studies in the German-speaking area (Pierenkemper 2000). Among other things, he criticized the previously very constricted view on specific elements of business, while the consideration of different time periods was neglected (Homburg \& Fürst 2008). For loyalty schemes, this not only includes providing novelty to the customer to maintain interest over time, but also primarily focusing on optimizing customer lifetime value in the long run. 
In any case, loyalty programs have generally been shown to work, but how well they perform will depend on the specific industry conditions and the particular program configuration. This study has focused on one specific industry only and the applied sampling approach needs to be kept in mind when making judgments about external validity. Stories of both success and failure exist within the very same sector and geographical market, illustrating that the outcome is above all influenced by the administrator of the loyalty solution. In the end, what loyalty schemes need to do is to deliver value to the customer. Hopefully, this paper has helped to strengthen the decision base for loyalty managers, while at the same time contributing a further piece of the puzzle to academic research. 


\section{Appendix}

\section{Appendix A: Survey Form Cover Page}

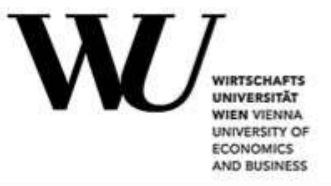

Institut für Handel und Marketing

\section{Studie}

Tankverhalten und Kundenkarten

Liebe Damen und Herren,

ich möchte mich herzlich bedanken, dass Sie sich ein paar Minuten Zeit nehmen, um bei dieser Studie mitzumachen!

Dieser Fragebogen umfasst allgemeine Fragen zu Besitz, Nutzung und Einstellungen zu Kundenkarten, sowie zum Tankverhalten. Die Ergebnisse werden für meine Doktorarbeit am Institut für Handel \& Marketing der Wirtschaftsuniversität Wien verwendet.

Bitte beantworten Sie die Fragen vollständig - Ihre Angaben bleiben dabei absolut anonym! Geben Sie danach den Fragebogen im beiliegenden, schon frankierten Umschlag einfach bei der Post ab oder werfen Sie ihn in den năchsten Briefkasten. Insgesamt sollte das Ausfüllen maximal 10-15 Minuten in Anspruch nehmen.

Bei Rückfragen, sowie bei Interesse an den Ergebnissen der Studie, bin ich für Sie jederzeit via Email unter nicolas.hoffmann@wu.ac.at erreichbar.

Mit freundlichen Grüßen

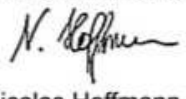

Nicolas Hoffmann 


\title{
Appendix B: Survey Form 1 - Aral Main Group
}

\section{Tankverhalten und Kundenkarten}

\section{Kundenkarten allgemein:}

(Bitte kreuzen Sie das jeweils zutreffende Kästchen an!)

- Welche dieser Kundenkarten von Tankstellen besitzen Sie bzw. bei welchen dieser Punktesammelaktionen sammeln Sie Punkte (mehrere Antworten möglich)?

ㅁ Aral: Payback

$\square$ Shell: Clubsmart

ㅁ Esso: Extras

ㅁ Total: stop\&win

\author{
ㅁ OMV: Wellness-Punkte \\ Andere: \\ ․ Keine/ Ich sammle bei keiner Aktion
}

- Welche dieser beiden Kundenkarten besitzen Sie noch?

(mehrere Antworten möglich; falls Sie keine der beiden besitzen, bitte Frage überspringen)

$\square$ Deutschland Card $\square$ HappyPoints (= HappyDigits)

- Wieviele Kundenkarten tragen Sie insgesamt (also nicht nur Karten von Tankstellen) normalerweise bei sich (z.B. in Ihrer Geldbörse)?
ㅁ Keine
ㅁ 1
ㅁ 2
ㅁ 4
ㅁ 5
ㅁ 6
ㅁ 3 7 oder mehr

- Welche Art von Kundenbindungsprogramm finden Sie am besten?

ㅁ Sammeln von Klebemarken oder Stempeln

․ Kundenkarten mit Sofortrabatt

․ Kundenkarten zum Punktesammeln und Eintausch gegen Prämien

ㅁ Empfinde keinen Unterschied

- Andere:

(Wie sehr treffen die folgenden Aussagen zu? Bitte kreuzen Sie in jeder Zeile das zutreffende Kästchen an!)

$$
\begin{aligned}
& \text { trift gar triff eher teils, trift } \\
& \text { nicht zu nicht zu trift } \\
& \text { teils }
\end{aligned}
$$

- Es wäre beschwerlich, zur Kundenkarte einer anderen Tankstellenkette zu wechseln.

- Die Kosten in Bezug auf verlorene Punkte/Prämien wăren groß beim Wechsel zur Kundenkarte einer anderen Tankstellenkette.

- Kundenkarten sind für ein Unternehmen eine gute Möglichkeit, Kunden Wertschătzung entgegen zu bringen.

- Ich finde Kundenkarten gut.

- Kundenkarten helfen dem Unternehmen, Kunden an sich zu binden.

- Kundenkarten finde ich lästig.

- Mich stört es, viele Kundenkarten von verschiedenen Unternehmen bei mir zu tragen.

- Bei Kundenkarten habe ich Angst um meine Privatsphäre.

- Besitzer von Kundenkarten sollten sich Sorgen um die Vertraulichkeit ihrer Daten machen. 


\section{Payback:}

- Bei welchem Unternehmen sind Sie Payback-Mitglied geworden?
- Bei Ara
$\square$ Bei einem anderen Payback-Partnerunternehmen

- Wo bewahren Sie Ihre Payback-Karte normalerweise auf?
Im Auto
$\square$ In der Handtasche
ㄴ In der Geldbörse
- An einem anderen Platz

- Haben Sie schon einmal Payback-Punkte gegen Prămien eingelöst (mehrere Antworten möglich)?
․ Ja, bei Aral
ㄱa, direkt über Payback
$\square \quad \mathrm{Ja}$, bei einem anderen Partnerunternehmen Nein

- Bei wievielen Partnerunternehmen von Payback haben Sie im letzten Jahr eingekauft und dabei Ihre Payback-Karte verwendet (Aral mitgezähit; bitte schaltzen Sie, falls notwendig)?
ㅁ 1
口 3
口 5
ㄴ 2
4
․ 6 oder mehr

- Haben Sie schon bei Aral getankt, bevor Sie Payback-Mitglied wurden?
Ja
Nein

Falls ja (sonst bitte Frage überspringen): Haben Sie damals im Vergleich zu heute

$\square$ eher seltener $\square$ etwa gleich hâufig $\square$ eher hăufiger

bei Aral getankt?

- Haben Sie bei Aral vor Einfuhrung von Payback im Mai 2006 jemals Klebemarken gesammelt?

- Haben Sie sich schon einmal durch Payback-Zusatzpunkte motivieren lassen, Ultimate 100 bzw. Ultimate Diesel zu tanken, auch wenn Sie normalerweise reguläres Benzin/ Super bzw. Diesel gekauft hatten?

Falls ja (sonst bitte Frage oberspringen):

Sind Sie danach dauerhaft bei Ultimate Treibstoffen geblieben?

- Haben Sie sich schon einmal durch Payback-Zusatzpunkte motivieren lassen, ihr Auto zu waschen oder im Tankstellen-Shop einzukaufen, auch wenn Sie dies normalerweise nicht geplant hatten?

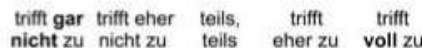

- Verglichen mit anderen Kundenkarten finde ich Payback gut. — $\square$

- Ich finde die Vorteile, die Payback bietet, ansprechend.

- Die Prämien, die ich gegen Payback-Punkte eintauschen kann, sind attraktiv.

- Ich finde die Anzahl der Punkte, die ich bei Aral für meinen Einkauf bekomme, fair.

- Man kann bei Payback schnell zu guten Prämien kommen-— $\square$

- Es ist mühsam, bei Payback Punkte zu sammeln.

- Ich verwende die Payback-Karte regeimaßig, wenn ich bei Aral tanke.

- Seit ich Mitglied bei Payback bin und dort Punkte sammle, versuche ich bevorzugt bei Aral zu tanken.

- Um Payback-Punkte bei Aral zu sammeln, nehme ich manchmal auch einen kleinen Umweg in Kauf.

- Es kommt vor, dass ich meinen Tankstopp extra bis zur năchsten Aral Tankstelle hinauszögere, um dort PaybackPunkte sammeln zu können. 
3. Aral:

trifft gar trifft eher teils, trifft trifft nicht zu nicht zu teils eher zu voll zu

- Ich bin mit Aral Tankstellen zufrieden.

- Aral Tankstellen entsprechen meinen Erwartungen.

- Aral Tankstellen sind nah dran an meiner Vorstellung einer perfekten Tankstelle.

$-\square$

ㅁ $\square$ ㅁ

Ich fühle mich als loyale/r Aral-Kunde/in.

- Weil ich eine starke Verbundenheit zu Aral empfinde, bleibe ich Kunde/in von Aral.

- Weil ich ein starkes Zugehörigkeitsgefühl zu Aral empfinde, möchte ich ein/e Kunde/in von Aral bleiben.

- Auch wenn es Payback nicht gäbe, würde ich bevorzugt bei Aral tanken.

- Ich erzähle häufig Freunden, Familienangehörigen oder Kollegen über die positiven Erfahrungen mit Aral.

- Wegen meiner Erfahrungen mit Aral versuche ich Freunde, Familienangehörige oder Kollegen davon zu uberzeugen, zu Aral zu wechseln.

\section{Tankverhalten:}

Die folgenden vier Fragen lassen sich naturlich nicht ganz genau beantworten Bitte überlegen Sie einfach kurz und versuchen Sie die Antworten bestmöglich zu schätzen.

- Bitte schätzen Sie, wie sich aktuell Ihre gesamten Ausgaben für Treibstoff auf die folgenden Tankstellenketten aufteilen. Teilen Sie hierzu bitte $100 \%$ auf (nicht besuchte Tankstellen frei lassen).

$\begin{array}{rr}\% \text { bei Aral } & \% \text { bei Avia } \\ \% \text { bei Shell } & \% \text { bei Total } \\ \% \text { bei Esso } & \% \text { bei Agip } \\ \% \text { bei Jet } & \% \text { bei OMV }\end{array}$

$\%$ bei (anderer:)

$\%$ bei (anderer:

$\%$ bei (anderer:)

- Bitte schätzen Sie, wieviel Geld Sie aktuell im Monat für Treibstoff ausgeben. EUR

- Bitte schätzen Sie, wie oft Sie im Monat tanken.

$\mathrm{Mal}$

- Bitte schätzen Sie, wieviel Sie aktuell eine durchschnittliche Tankfüllung kostet. EUR 


\section{Einstellung zum Tanken :}

triff gar trifft eher teils, trifft trifft nicht zu nicht zu teils eher zu voll zu

- Ich tanke an der Tankstelle mit den aktuell niedrigsten Preisen.

- Ich tanke an der Tankstelle, die für mich am besten gelegen ist.

- Ich vergleiche an verschiedenen Tankstellen, was ich für mein Geld bekomme.

- Man profitiert vom Preisvergleich bei unterschiedlichen Tankstellen.

\section{Informationen über den/die Umfrageteilnehmer/in}

Wie eingangs erwähnt, bleiben sämtliche Antworten dieser Studie anonym und können nicht auf den/die Umfrageteilnehmer/in zurückverfolgt werden. Dies gilt natürlich auch für diesen Abschnitt, welcher lediglich zur Einordnung der Ergebnisse verwendet wird.

- Bitte geben Sie Ihr Geschlecht an.

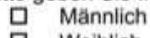

․ Weiblich

- Bitte geben Sie Ihr Alter an.

Jahre

- Bitte geben Sie Ihren höchsten, bereits erreichten schulischen Abschluss an.
口 Pflichtschulabschluss
ㅁ Berufsschulabschluss
$\square$ Diplomstudium
A Abitur
Master
口 Promotion

ㅁ Bakkalaureat

Anderer:

- Bitte geben Sie an, welche berufliche Position auf Sie zutriftt.
$\square$ Schüler(in)
ㅁ Angestellte(r)/ Beamte(r) ohne Führungsverantwortung
Student(in)
$\square$ Angestellte(r)/ Beamte(r) mit Fürungsverantwortung
ㅁ Auszubildende $(r)$ im Lehrberuf
口 Hausfrau/ Hausmann
․ Selbständig
Renter(in)/ Pensionär(in)
Z Zur Zeit ohne Erwerbstätigkeit
․ Sonstiges

- Bitte geben Sie zuletzt lhr ungefähres monatliches Nettoeinkommen an.

(= das Einkommen, das Ihnen nach Abzug von Steuern und Sozialabgaben zur Verfügung steht)

EUR

\section{Vielen herzlichen Dank für Ihre Teilnahme und die Zeit, die Sie dafür investiert haben! Bitte überprüfen Sie noch einmal, ob alle Fragen vollständig beantwortet wurden.}

Geben Sie danach den Fragebogen im beiliegenden, schon frankierten Umschlag einfach bei der Post ab oder werfen Sie ihn in den nächsten Briefkasten. 


\section{Appendix C: Survey Form 2 - Shell Main Group}

$\mathbf{W}$

\section{Tankverhalten und Kundenkarten}

\section{Kundenkarten allgemein:}

(Bitte kreuzen Sie das jeweils zutreffende Kästchen an!)

- Welche dieser Kundenkarten von Tankstellen besitzen Sie bzw. bei welchen dieser Punktesammelaktionen sammeln Sie Punkte (mehrere Antworten möglich)?

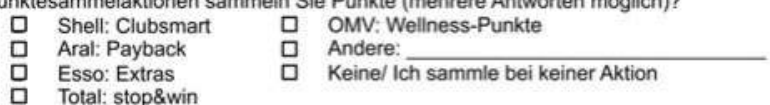

- Welche dieser beiden Kundenkarten besitzen Sie noch?

(mehrere Antworten möglich; falls Sie keine der beiden besitzen, bitte Frage uberspringen)

$\square$ Deutschland Card $\square$ HappyPoints (= HappyDigits)

- Wieviele Kundenkarten tragen Sie insgesamt (also nicht nur Karten von Tankstellen) normalerweise bei sich (z.B. in Ihrer Geldbörse)?
Keine
ㄴ 4
ㅁ 1
마 2
ㅁ 5
ㅁ 3 o 7 oder mehr

- Welche Art von Kundenbindungsprogramm finden Sie am besten?
․ Sammeln von Klebemarken oder Stempeln
ㅁ Kundenkarten mit Sofortrabatt
Kundenkarten zum Punktesammeln und Eintausch gegen Prämien
ㅁ Empfinde keinen Unterschied

ㅁ Andere:

(Wie sehr treffen die folgenden Aussagen zu? Bitte kreuzen Sie in jeder Zeile das zutreffende Kästchen an!)

trift gar triff eher teils, triff
nicht zu nicht zu
teils

- Es wäre beschwerlich, zur Kundenkarte einer anderen Tankstellenkette zu wechseln.

- Die Kosten in Bezug auf verlorene Punkte/Prämien wăren groß beim Wechsel zur Kundenkarte einer anderen Tankstellenkette.

- Kundenkarten sind für ein Unternehmen eine gute Möglichkeit, Kunden Wertschatzung entgegen zu bringen. - $\square$

- Ich finde Kundenkarten gut.

- Kundenkarten helfen dem Untemehmen, Kunden an sich zu binden.

- Kundenkarten finde ich lästig

- Mich stört es, viele Kundenkarten von verschiedenen

- $\quad$ Unternehmen bei mir zu tragen.

- Besitzer von Kundenkarten sollten sich Sorgen um die Vertraulichkeit ihrer Daten machen. 


\section{Kundenkarten und der Erwerb von Treibstoffen}

\section{Clubsmart:}

- Sind Sie neben dem regulären Clubsmart-Programm auch Mitglied im Shell V-Power Club?
$\square$ Ja
ㅁ. Nein
Kenne ich nicht

- Haben Sie bei Shell schon einmal die Aktionen für ADAC Mitglieder genutzt?

․ Ja, den Rabatt von 1 Cent je Liter

口 Ja, die Aktion für doppelte Clubsmart-Punkte

Ich bin zwar ADAC Mitglied, habe aber kein Interesse an den Aktionen bzw. kenne diese nicht

$\square \quad$ Ich bin kein ADAC Mitglied

- Wo bewahren Sie Ihre Clubsmart-Karte normalerweise auf?
口 Im Auto
I In der Handtasche
․ In der Geldbörse
口 An einem anderen Platz

- Haben Sie schon einmal Clubsmart-Punkte gegen Prämien eingelöst (mehrere Antworten möglich)?

ㅁ Ja, bei einer Tankstelle $\square$ Nein

․ Ja, über das Internet

- Haben Sie schon bei Shell getankt, bevor Sie Clubsmart-Mitglied wurden?
ㄱa
․ Nein
Falls ja (sonst bitte Frage überspringen): Haben Sie damals im Vergleich zu heute
ㅁ eher seltener

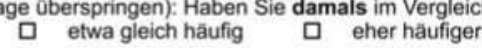

bei Shell getankt?

Haben Sie sich schon einmal durch Clubsmart-Zusatzpunkte motivieren lassen, V-Power
Treibstoffe zu tanken, auch wenn Sie normalerweise reguläres Benzin/Super bzw. Diesel

gekauft hătten?

- V-Power 95

- V-Power Racing 100

- V-Power Diesel

Falls ja (sonst bitte Frage überspringen):

Sind Sie danach dauerhaft bei V-Power Treibstoffen geblieben?

- Haben Sie sich schon einmal durch Clubsmart-Zusatzpunkte motivieren lassen im

Tankstellen-Shop einzukaufen, auch wenn Sie dies normalerweise nicht geplant hatten?-

$$
\begin{array}{cccc}
\text { triff gar trift eher } & \text { teils, } & \text { trifft } & \text { triff } \\
\text { nicht zu nicht zu } & \text { teils } & \text { eher zu } & \text { voll zu }
\end{array}
$$

- Verglichen mit anderen Kundenkarten finde ich Clubsmart gut. - $-\square$

- Ich finde die Vorteile, die Clubsmart bietet, ansprechend.

- Die Prämien, die ich gegen Clubsmart-Punkte eintauschen kann, sind attraktiv.

- Ich finde die Anzahl der Punkte, die ich bei Shell für meinen Einkauf bekomme, fair.

- Man kann bei Clubsmart schnell zu guten Prămien kommen

- Es ist mühsam, bei Clubsmart Punkte zu sammeln.

- Ich verwende die Clubsmart-Karte regelmäßig, wenn ich bei Shell tanke.

- Seit ich Mitglied bei Clubsmart bin und dort Punkte sammle, versuche ich bevorzugt bei Shell zu tanken.

- Um Clubsmart-Punkte bei Shell zu sammeln, nehme ich manchmal auch einen kleinen Umweg in Kauf.

- Es kommt vor, dass ich meinen Tankstopp extra bis zur nächsten Shell Tankstelle hinauszögere, um dort ClubsmartPunkte sammeln zu können. 


\section{Shell:}

trifft gar trifft eher teils, trifft trifft nicht zu nicht zu teils eherzu voll zu

- Ich bin mit Shell Tankstellen zufrieden.

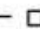

- Shell Tankstellen entsprechen meinen Erwartungen.

- Shell Tankstellen sind nah dran an meiner Vorstellung einer perfekten Tankstelle.

- Ich fühle mich als loyale/r Shell-Kunde/in.

- Weil ich eine starke Verbundenheit zu Shell empfinde, bleibe ich Kunde/in von Shell.

- Weil ich ein starkes Zugehörigkeitsgefühl zu Shell empfinde, möchte ich ein/e Kunde/in von Shell bleiben.

- Auch wenn es Clubsmart nicht gäbe, würde ich bevorzugt bei Shell tanken.

- Ich erzähle hảufig Freunden, Familienangehörigen oder Kollegen über die positiven Erfahrungen mit Shell.

\section{$\square$}

$\square \quad \square \quad \square \quad \square$

Ich würde Shell jemandem empfehlen, der meinen Rat such

- Wegen meiner Erfahrungen mit Shell versuche ich Freunde,

Familienangehörige oder Kollegen davon zu oberzeugen, zu

Shell zu wechseln.

\section{Tankverhalten:}

Die folgenden vier Fragen lassen sich naturlich nicht ganz genau beantworten.

Bitte uberlegen Sie einfach kurz und versuchen Sie die Antworten bestmöglich zu schätzen.

- Bitte schätzen Sie, wie sich aktuell Ihre gesamten Ausgaben für Treibstoff auf die folgenden Tankstellenketten aufteilen. Teilen Sie hierzu bitte $100 \%$ auf (nicht besuchte Tankstellen frei lassen).

$\begin{array}{cr}\% \text { bei Shell } & \% \text { bei Avia } \\ \% \text { bei Aral } & \% \text { bei Total } \\ \% \text { bei Esso } & \% \text { bei Agip } \\ \% \text { bei Jet } & \% \text { bei OMV }\end{array}$

$\%$ bei (anderer:)

$\%$ bei (anderer:

$\%$ bei (anderer:)

- Bitte schätzen Sie, wieviel Geld Sie aktuell im Monat für Treibstoff ausgeben.

EUR

- Bitte schätzen Sie, wie oft Sie im Monat tanken.

Mal

- Bitte schätzen Sie, wieviel Sie aktuell eine durchschnittliche Tankfüllung kostet. EUR 


\section{Einstellung zum Tanken :}

trifft gar trifft eher teils, trifft trifft nicht zu nicht zu teils eher zu voll zu

- Ich tanke an der Tankstelle mit den aktuell niedrigsten Preisen.

- Ich tanke an der Tankstelle, die für mich am besten gelegen ist.

- Ich vergleiche an verschiedenen Tankstellen, was ich für mein Geld bekomme.

- Man profitiert vom Preisvergleich bei unterschiedlichen Tankstellen.

\section{Informationen über den/die Umfrageteilnehmer/in}

Wie eingangs enwähnt, bleiben sämtliche Antworten dieser Studie anonym und können nicht auf den/die Umfrageteilnehmer/in zurückverfolgt werden. Dies gilt natürlich auch für diesen Abschnitt, welcher lediglich zur Einordnung der Ergebnisse verwendet wird.

- Bitte geben Sie Ihr Geschlecht an.

$$
\text { ㅁ Männlich }
$$

- Bitte geben Sie Ihr Alter an.

$$
\text { Jahre }
$$

- Bitte geben Sie Ihren höchsten, bereits erreichten schulischen Abschluss an.
$\square$ Pflichtschulabschluss
ㅁiplomstudium
ㅁ Berufsschulabschluss
M Master
A Abitur
ㅁ Bakkalaureat
Promotion
A Anderer:

- Bitte geben Sie an, welche berufliche Position auf Sie zutriftt.
口 Schüler(in)
ㅁ Angestellte(r)/ Beamte(r) ohne Führungsverantwortung
$\square \quad$ Student(in)
$\square$ Angestellte(r)/ Beamte(r) mit Fuhrungsverantwortung
ㅁ Auszubildende $(r)$ im Lehrberuf
口 Hausfrau/ Hausmann
Selbständig
Z Zur Zeit ohne Erwerbstatigkeit
․ Sonstiges

- Bitte geben Sie zuletzt lhr ungefähres monatliches Nettoeinkommen an.

(= das Einkommen, das Ihnen nach Abzug von Steuern und Sozialabgaben zur Verfügung steht) EUR

\section{Vielen herzlichen Dank für Ihre Teilnahme und die Zeit, die Sie dafür investiert haben! Bitte überprüfen Sie noch einmal, ob alle Fragen vollständig beantwortet wurden.}

Geben Sie danach den Fragebogen im beiliegenden, schon frankierten Umschlag einfach bei der Post ab oder werfen Sie ihn in den nächsten Briefkasten. 


\section{Appendix D: Survey Form 3 - Aral Control Group}

$\mathbf{W}$

\section{Tankverhalten und \\ Kundenkarten}

\section{Kundenkarten allgemein:}

(Bitte kreuzen Sie das jeweils zutreffende Kästchen an!)

- Welche dieser Kundenkarten von Tankstellen besitzen Sie bzw. bei welchen dieser Punktesammelaktionen sammeln Sie Punkte (mehrere Antworten möglich)?

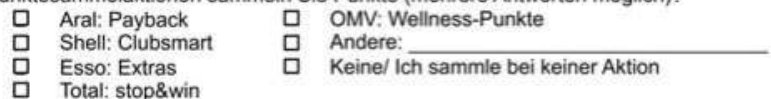

- Welche dieser beiden Kundenkarten besitzen Sie noch?

(mehrere Antworten möglich; falls Sie keine der beiden besitzen, bitte Frage uberspringen)

$\square$ Deutschland Card $\square$ HappyPoints (= HappyDigits)

- Wieviele Kundenkarten tragen Sie insgesamt (also nicht nur Karten von Tankstellen) normalerweise bei sich (z.B. in Ihrer Geldbörse)?
ㅁeine
4
ㅁ 1
ㄴ 2
ㅁ 5
ㅁ 3
ㅁ 6
ㅁ 7 oder mehr

- Welche Art von Kundenbindungsprogramm finden Sie am besten?

ㅁ Sammeln von Klebemarken oder Stempeln

․ Kundenkarten mit Sofortrabatt

Kundenkarten zum Punktesammeln und Eintausch gegen Prämien

ㅁ Empfinde keinen Unterschied

ㅁ Andere:

(Wie sehr treffen die folgenden Aussagen zu? Bitte kreuzen Sie in jeder Zeile das zutreffende Kästchen an!)

$$
\begin{array}{lll}
\text { trift gar trift eher teils, triff } & \text { trifft } \\
\text { nicht zu nicht zu } & \text { teils eher zu voll zu }
\end{array}
$$

- Es wäre beschwerlich, zur Kundenkarte einer anderen Tankstellenkette zu wechseln.

- Die Kosten in Bezug auf verlorene Punkte/Prämien wăren groß beim Wechsel zur Kundenkarte einer anderen Tankstellenkette.

- Kundenkarten sind für ein Unternehmen eine gute Móglichkeit. Kunden Wertschatzung entgegen zu bringen.

- Ich finde Kundenkarten gut.

- Kundenkarten helfen dem Unternehmen, Kunden an sich zu binden.

- Kundenkarten finde ich lästig.

- Mich stört es, viele Kundenkarten von verschiedenen Unternehmen bei mir zu tragen.

- Bei Kundenkarten habe ich Angst um meine Privatsphäre.

- Besitzer von Kundenkarten sollten sich Sorgen um die Vertraulichkeit ihrer Daten machen. 
2. Aral:

$$
\begin{array}{cccc}
\text { trifft gar trifft eher } & \text { teils, } & \text { trifft } & \text { trifft } \\
\text { nicht zu nicht zu } & \text { teils } & \text { eher zu voll zu }
\end{array}
$$

- Ich bin mit Aral Tankstellen zufrieden.

- Aral Tankstellen entsprechen meinen Erwartungen.

- Aral Tankstellen sind nah dran an meiner Vorstellung einer perfekten Tankstelle.

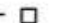

$\square \square \square$

- Ich fühle mich als loyale/r Aral-Kunde/in.

- Weil ich eine starke Verbundenheit zu Aral empfinde, bleibe ich Kunde/in von Aral.

- Weil ich ein starkes Zugehörigkeitsgefühl zu Aral empfinde, möchte ich ein/e Kunde/in von Aral bleiben.

- Auch wenn es Payback nicht gäbe, würde ich bevorzugt bei Aral tanken.

- Ich erzăhle hăufig Freunden, Familienangehörigen oder Kollegen über die positiven Erfahrungen mit Aral.

- Ich würde Aral jemandem empfehlen, der meinen Rat sucht.

- Wegen meiner Erfahrungen mit Aral versuche ich Freunde,

Familienangehörige oder Kollegen davon zu uberzeugen, zu Aral zu wechseln.

\section{Tankverhalten:}

Die folgenden vier Fragen lassen sich naturlich nicht ganz genau beantworten.

Bitte überlegen Sie einfach kurz und versuchen Sie die Antworten bestmöglich zu schätzen.

- Bitte schătzen Sie, wie sich aktuell Ihre gesamten Ausgaben für Treibstoff auf die folgenden Tankstellenketten aufteilen. Teilen Sie hierzu bitte $100 \%$ auf (nicht besuchte Tankstellen frei lassen).

$\%$ bei Aral
$\%$ bei Shell
$\%$ bei Esso
$\%$ bei Jet

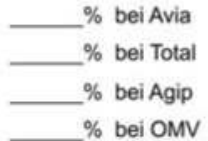
$\%$ bei (anderer:)
$\%$ bei (anderer:)
$\%$ bei (anderer:

- Bitte schätzen Sie, wieviel Geld Sie aktuell im Monat für Treibstoff ausgeben.

EUR

- Bitte schätzen Sie, wie oft Sie im Monat tanken.

Mal

- Bitte schätzen Sie, wieviel Sie aktuell eine durchschnittliche Tankfüllung kostet.

EUR 


\section{Einstellung zum Tanken :}

$$
\text { trifft gar trifft eher teils, trifft trifft }
$$

- Ich tanke an der Tankstelle mit den aktuell niedrigsten Preisen.

- Ich tanke an der Tankstelle, die für mich am besten gelegen ist.

- Ich vergleiche an verschiedenen Tankstellen, was ich für mein Geld bekomme.

- Man profitiert vom Preisvergleich bei unterschiedlichen Tankstellen.

\section{Informationen über den/die Umfrageteilnehmer/in}

Wie eingangs erwähnt, bleiben sämtliche Antworten dieser Studie anonym und können nicht auf den/die Umfrageteilnehmer/in zurückverfolgt werden. Dies gilt natürlich auch für diesen Abschnitt, welcher lediglich zur Einordnung der Ergebnisse verwendet wird.

- Bitte geben Sie Ihr Geschlecht an.

ㅁ Mănnlich

ㅁ Weiblich

- Bitte geben Sie Ihr Alter an.

Jahre

- Bitte geben Sie Ihren höchsten, bereits erreichten schulischen Abschluss an.

$\square$ Pflichtschulabschluss

B Berufsschulabschluss

․ Abitur

ㅁ Bakkalaureat

ㅁ Diplomstudium

Master

ㅁ Promotion

A Anderer:

- Bitte geben Sie an, welche berufliche Position auf Sie zutriftt.
S Schüler(in)
S Student(in)
ㅁ Angestellte(r)/ Beamte(r) ohne Fuhrungsverantwortung
Auszubildende( $r$ ) im Lehrberuf
口 Hausfrau/ Hausmann
․ Selbständig
․ Angestellte(r)/ Beamte(r) mit Fürungsverantwortung
R Renter(in)/ Pensionär(in)
Z Zur Zeit ohne Erwerbstatigkeit
口 Sonstiges

- Bitte geben Sie zuletzt lhr ungefahres monatliches Nettoeinkommen an.

(= das Einkommen, das Ihnen nach Abzug von Steuern und Sozialabgaben zur Verfügung steht)

EUR

\section{Vielen herzlichen Dank für Ihre Teilnahme und die Zeit, die Sie dafür investiert haben! \\ Bitte überprüfen Sie noch einmal, ob alle Fragen vollständig beantwortet wurden.}

Geben Sie danach den Fragebogen im beiliegenden, schon frankierten Umschlag einfach bei der Post ab oder werfen Sie ihn in den nächsten Briefkasten. 


\section{Appendix E: Survey Form 4 - Shell Control Group}

\section{Tankverhalten und Kundenkarten}

\section{Kundenkarten allgemein:}

(Bitte kreuzen Sie das jeweils zutreffende Kăstchen an!)

- Welche dieser Kundenkarten von Tankstellen besitzen Sie bzw. bei welchen dieser Punktesammelaktionen sammeln Sie Punkte (mehrere Antworten möglich)?
口 Shell: Clubsmart
ㅁ Aral: Payback
Esso: Extras
Total: stop\&win

\author{
ㅁ OMV: Wellness-Punkte \\ $\square$ Andere: \\ ․ Keine/ Ich sammle bei keiner Aktion
}

- Welche dieser beiden Kundenkarten besitzen Sie noch?

(mehrere Antworten möglich; falls Sie keine der beiden besitzen, bitte Frage úberspringen)
ㅁ Deutschland Card
․ HappyPoints (= HappyDigits)

- Wieviele Kundenkarten tragen Sie insgesamt (also nicht nur Karten von Tankstellen) normalerweise bei sich ( $z$.B. in Ihrer Geldbörse)?
ㅁ Keine
4
ㅁ 1
ㅁ 2
ㄷ 5
ㅁ 3
ㅁ 6
ㅁ 7 oder mehr

- Welche Art von Kundenbindungsprogramm finden Sie am besten?
․ Sammeln von Klebemarken oder Stempeln
․ Kundenkarten mit Sofortrabatt
uㅔenkarten zum Punktesammeln und Eintausch gegen Pramien
Empfinde keinen Unterschied
andere:

(Wie sehr treffen die folgenden Aussagen zu? Bitte kreuzen Sle in jeder Zeile das zutreffende Kästchen anl)

$$
\begin{array}{lll}
\text { trift gar trift eher teils, } & \text { triff } & \text { trift } \\
\text { nicht zu nicht zu } & \text { teils eher zu voll zu }
\end{array}
$$

- Es wäre beschwerlich, zur Kundenkarte einer anderen Tankstellenkette zu wechsein.

- Die Kosten in Bezug auf verlorene Punkte/Prămien wăren groß beim Wechsel zur Kundenkarte einer anderen Tankstellenkette.

- Kundenkarten sind für ein Unternehmen eine gute Möglichkeit, Kunden Wertschătzung entgegen zu bringen.

- Ich finde Kundenkarten gut.

- Kundenkarten helfen dem Unternehmen, Kunden an sich zu binden.

- Kundenkarten finde ich lästig.

- Mich stört es, viele Kundenkarten von verschiedenen Unternehmen bei mir zu tragen.

- Bei Kundenkarten habe ich Angst um meine Privatsphâre.

- Besitzer von Kundenkarten sollten sich Sorgen um die Vertraulichkeit ihrer Daten machen. 


\section{Shell:}

trifft gar trifft eher teils, trifft trifft nicht zu nicht zu teils eher zu voll zu

- Ich bin mit Shell Tankstellen zufrieden.

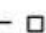

- Shell Tankstellen entsprechen meinen Erwartungen

- Shell Tankstellen sind nah dran an meiner Vorstellung einer perfekten Tankstelle.

Ich fühle mich als loyale/r Shell-Kunde/in.

- Weil ich eine starke Verbundenheit zu Shell empfinde, bleibe ich Kunde/in von Shell.

- Weil ich ein starkes Zugehörigkeitsgefühl zu Shell empfinde, möchte ich ein/e Kunde/in von Shell bleiben.

- Auch wenn es Clubsmart nicht gäbe, würde ich bevorzugt bei Shell tanken.

- Ich erzăhle haufig Freunden, Familienangehörigen oder Kollegen uber die positiven Erfahrungen mit Shell.

- Ich würde Shell jemandem empfehlen, der meinen Rat sucht.

- Wegen meiner Erfahrungen mit Shell versuche ich Freunde, Familienangehörige oder Kollegen davon zu uberzeugen, zu Shell zu wechseln

\section{Tankverhalten:}

Die folgenden vier Fragen lassen sich naturlich nicht ganz genau beantworten. Bitte uberlegen Sie einfach kurz und versuchen Sie die Antworten bestmöglich zu schätzen.

- Bitte schätzen Sie, wie sich aktuell Ihre gesamten Ausgaben für Treibstoff auf die folgenden Tankstellenketten aufteilen. Teilen Sie hierzu bitte $100 \%$ auf (nicht besuchte Tankstellen frei lassen).

$\begin{array}{cr}\% \text { bei Shell } & \% \text { bei Avia } \\ \% \text { bei Aral } & \% \text { bei Total } \\ \% \text { bei Esso } & \% \text { bei Agip } \\ \% \text { bei Jet } & \% \text { bei OMV }\end{array}$
$\%$ bei (anderer:) $\%$ bei (anderer: $\%$ bei (anderer:)

- Bitte schätzen Sie, wieviel Geld Sie aktuell im Monat für Treibstoff ausgeben. EUR

- Bitte schătzen Sie, wie oft Sie im Monat tanken.

Mal

- Bitte schätzen Sie, wieviel Sie aktuell eine durchschnittliche Tankfüllung kostet. EUR 


\section{Einstellung zum Tanken :}

trifft gar trifft eher teils, trifft trifft nicht zu nicht zu teils eher zu voll zu

- Ich tanke an der Tankstelle mit den aktuell niedrigsten Preisen.

- Ich tanke an der Tankstelle, die für mich am besten gelegen ist.

- Ich vergleiche an verschiedenen Tankstellen, was ich für mein Geld bekomme.

- Man profitiert vom Preisvergleich bei unterschiedlichen Tankstellen.

\section{Informationen über den/die Umfrageteilnehmer/in}

Wie eingangs erwähnt, bleiben sämtliche Antworten dieser Studie anonym und können nicht auf den/die Umfrageteilnehmer/in zurückverfolgt werden. Dies gilt natürlich auch für diesen Abschnitt, welcher lediglich zur Einordnung der Ergebnisse verwendet wird.

- Bitte geben Sie Ihr Geschlecht an.

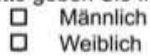

- Bitte geben Sie Ihr Alter an. Jahre

- Bitte geben Sie Ihren höchsten, bereits erreichten schulischen Abschluss an.
口 Pflichtschulabschluss
ㅁiplomstudium
ㅁ Berufsschulabschluss
Master
A Abitur
Promotion

ㅁ Bakkalaureat

Anderer:

- Bitte geben Sie an, welche berufliche Position auf Sie zutrift.
$\square$ Schüler(in)
- Angestellte(r)/ Beamte(r) ohne Führungsverantwortung
Student(in)
$\square$ Angestellte(r)/ Beamte(r) mit Führungsverantwortung
ㅁ. Auszubildende( $r$ ) im Lehrberuf
口 Hausfrau/ Hausmann
․ Selbständig
Renter(in)/ Pensionär(in)
Z Zur Zeit ohne Erwerbstätigkeit
․ Sonstiges

- Bitte geben Sie zuletzt lhr ungefähres monatliches Nettoeinkommen an.

(= das Einkommen, das Ihnen nach Abzug von Steuern und Sozialabgaben zur Verfügung steht) EUR

Vielen herzlichen Dank für Ihre Teilnahme und die Zeit, die Sie dafür investiert haben! Bitte überprüfen Sie noch einmal, ob alle Fragen vollständig beantwortet wurden.

Geben Sie danach den Fragebogen im beiliegenden, schon frankierten Umschlag einfach bei der Post ab oder werfen Sie ihn in den nächsten Briefkasten. 



\section{References}

\section{A}

Agrawal, R., Imielinski, T. \& Swami, A. (1993). Mining Association Rules Between Sets of Items in Large Databases, Proceedings of the ACM SIGMOD International Conference on Management of Data, Washington, USA.

Agrawal, R. \& Srikant, R. (1994). Fast Algorithms for Mining Association Rules. Proceedings of the $20^{\text {th }}$ VLDB Conference, Santiago, Chile.

Ainslie, A. \& Rossi, P.E. (1998). Similarities in Choice Behavior Across Product Categories. Marketing Science, 17(2), 91-106.

Air Miles (2009). Media Information. Retrieved on March 31, 2009, from http://www.airmiles.co.uk/tertiary/pressreleases.do.

Ajzen, I. \& Fishbein, M. (1980). Understanding Attitudes and Predicting Social Behavior. Englewood Cliffs: Prentice Hall.

Albers, S. \& Götz, O. (2006). Messmodelle mit Konstrukten zweiter Ordnung in der betriebswirtschaftlichen Forschung. Die Betriebswirtschaft, 66(6), 669-677.

Alderfer, C.P. (1969). An Empirical Test of a New Theory of Human Needs. Organizational Behavior and Human Performance, 4(2), 142-175.

Anderson, E.W. (1998). Customer Satisfaction and Word of Mouth. Journal of Service Research, 1(1), 5-17.

Anderson, E.W., Fornell, C. \& Lehmann, D.R. (1994). Customer Satisfaction, Market Share, and Profitability. Journal of Marketing, 58(3), 53-66.

Anderson, E.W. \& Mittal, V. (2000). Strengthening the Satisfaction-Profit Chain. Journal of Service Research, 3(2), 107-120.

Anderson, J.L., Jolly, L.D. \& Fairhurst, A.E. (2007). Customer Relationship Management in Retailing: A Content Analysis of Retail Trade Journals. Journal of Retailing and Consumer Services, 14(6), 394-399.

Arnold, S.J., Oum, T.H. \& Tigert, D.J. (1983). Determinant Attributes in Retail Patronage: Seasonal, Temporal, Regional, and International Comparisons. Journal of Marketing Research, 20(2), 149-157.

Auh, S. \& Johnson, M.D. (1997). The Complex Relationship Between Customer Satisfaction and Loyalty for Automobiles. In: Johnson, M.D., Herrmann, A., Huber, F. \& Gustafsson, A. (eds.). Customer Retention in the Automotive Industry. Wiesbaden: Gabler, 141-166. 
Backhaus, K. \& Blechschmidt, B. (2009). Fehlende Werte und Datenqualität. Eine Simulationsstudie am Beispiel der Kausalanalyse. Die Betriebswirtschaft, 69(2), 265-287.

Backhaus, K., Erichson, B., Plinke, W. \& Weiber, R. (2011). Multivariate Analysemethoden. Eine anwendungsorientierte Einführung. Berlin: Springer.

Barlow, R. (1999). Marketing Trends That'll Change Your Business. Card News, 14(12), 1.

Barnard, C.I. (1938). The Functions of the Executive. Cambridge: Harvard University Press.

Bauer, R. (1967). Consumer Behavior as Risk Taking. In: Cox, D.F. (ed.). Risk Taking and Information Handling in Consumer Behavior. Boston: Harvard University Press, 23-33.

Baxter, R. (2009): Reflective and Formative Metrics of Relationship Value: A Commentary Essay. Journal of Business Research, 62(12), 1370-1377.

Bayus, B.L. (1992). Brand Loyalty and Marketing Strategy: An Application to Home Appliances. Marketing Science, 11(1), 21-38.

Bea, F.X., Dichtl, E. \& Schweitzer, M. (eds.). (2000). Allgemeine Betriebswirtschaftslehre. Bd. 1: Grundfragen. Stuttgart: Lucius \& Lucius.

Bearden, W.O. \& Teel, J.E. (1983). Selected Determinants of Customer Satisfaction and Complaint Reports. Journal of Marketing Research, 20(1), 21-28.

Beatty, S., Kahle, L. \& Homer, P. (1988). The Involvement-Commitment Model. Journal of Business Research, 16(2), 146-167.

Becker, G.S. \& Mulligan, C.B. (1997). The Endogenous Determination of Time Preference. Quarterly Journal of Economics, 112(3), 729-758.

Bellenger, D.N., Robertson, D.H. \& Greenberg, B.A. (1977). Shopping Center Patronage Motives. Journal of Retailing, 53(2), 29-38.

Bellizzi, J.A. \& Bristol, T. (2004). An Assessment of Supermarket Loyalty Cards in one Major US Market. Journal of Consumer Marketing, 21(2), 144-154.

Bentler, P.M. \& Bonett, D.G. (1980). Significance Tests and Goodness of Fit in the Analysis of Covariance Structures. Psychological Bulletin, 88, 588-606.

Berman, B. (2006). Developing an Effective Customer Loyalty Program. California Management Review, 49(1), 123-148.

Berry, C. J. (1994). The Idea of Luxury. Cambridge: Cambridge University Press.

Berry, L.L. (1983). Relationship Marketing. In: Berry, L.L., Shostack, G. \& Upah, G. (eds.). Emerging Perspectives on Services Marketing. Chicago: American Marketing Association, 25-28.

Berry, M.J.A. \& Linoff, G.S. (2004). Data Mining Techniques. For Marketing, Sales, and Customer Relationship Management. Indianapolis: Wiley. 
Bhattacharya, C.B., Rao, H. \& Glynn, M.A. (1995). Understanding the Bond of Identification: An Investigation of its Correlates Among Art Museum Members. Journal of Marketing, 59(4), 46-57.

Bitner, M.J. (1990). Evaluating Service Encounters: The Effects of Physical Surroundings and Employee Responses. Journal of Marketing, 54(2), 69-82.

Black, T.R. (2005). Doing Quantitative Research in the Social Sciences. An Integrated Approach to Research Design, Measurement and Statistics. London: Sage.

Blattberg, R.C., Glazer, R. \& Little, J.D.C. (1994). The Marketing Information Revolution. Boston: Harvard Business School Press.

Blau, P.M. (1992). Exchange and Power in Social Life. New Brunswick: Transaction Publishers.

Bloemer, J. \& De Ruyter, K. (1998). On the Relationship Between Store Image, Store Satisfaction and Store Loyalty. European Journal of Marketing, 32(5/6), 499-513.

Bolton, R.N., Kannan, P.K. \& Bramlett, M.D. (2000). Implications of Loyalty Program Membership and Service Experiences for Customer Retention and Value. Journal of the Academy of Marketing Science, 28(1), 95-108.

Bower, G.H. \& Hilgard, E.R. (1981). Theories of Learning. Englewood Cliffs: Prentice-Hall.

Bowman, D. \& Narayandas, D. (2001). Managing Customer-Initiated Contacts With Manufacturers: The Impact on Share of Category Requirements and Word-of-Mouth Behavior. Journal of Marketing Research, 38(3), 281-297.

Boztu , Y. \& Silberhorn, N. (2006). Modellierungsansätze in der Warenkorbanalyse im Überblick. Journal für Betriebswirtschaft, 56(2), 105-128.

Böcker, F. (1978). Die Bestimmung der Kaufverbundenheit von Produkten. Berlin: Duncker \& Humblot.

Breese, J., Heckerman, D. \& Kadie, C. (1998). Empirical Analysis of Predictive Algorithms for Collaborative Filtering. Proceedings of the 14th Conference on Uncertainty in Artificial Intelligence, Madison, USA.

Brehm, J.W. (1966). A Theory of Psychological Reactance. New York: Academic Press.

Bridson, K., Evans, J. \& Hickman, M. (2008). Assessing the Relationship Between Loyalty Program Attributes, Store Satisfaction and Store Loyalty. Journal of Retailing and Consumer Services, 15(5), 364-374.

British Airways (2008). Annual Report 2007/08. Retrieved on April 8, 2009, from http://www.britishairways.com/cms/global/microsites/ba_reports/pdfs/ BA_Report_2007_08.pdf. 
Bryant, B.E. \& Cha, J. (1996). Crossing the Threshold. Some Customers are Harder to Please Than Others, so Analyze Satisfaction Scores Carefully. Marketing Research, 8(4), 20-28.

Bucklin, R.E., Lehmann, D.R. \& Little, J.D.C. (1998). From Decision Support to Decision Automation: A 2020 Vision. Marketing Letters, 9(3), 235-246.

Butscher, S.A. (2002). Customer Loyalty Programmes and Clubs. Burlington: Gower.

Byrom, J. (2001). The Role of Loyalty Card Data Within Local Marketing Initiatives. International Journal of Retail \& Distribution Management, 29(7), 333-341.

Byrom, J., Hernández, T., Bennison, D. \& Hooper, P. (2001). Exploring the Geographical Dimension in Loyalty Card Data. Marketing Intelligence and Planning, 19(3), 162-170.

C

Caminal, R. \& Claici, A. (2007). Are Loyalty-Rewarding Pricing Schemes AntiCompetitive? International Journal of Industrial Organization, 25(4), 657674.

Cannon, J. (ed.) (2004). A Dictionary of British History. New York: Oxford University Press.

Capizzi, M.T. \& Ferguson, R. (2005). Loyalty Trends for the Twenty-First Century. Journal of Consumer Marketing, 22(2), 72-80.

Cedrola, E. \& Memmo, S. (2010). Loyalty Marketing and Loyalty Cards: A Study of the Italian Market. International Journal of Retail \& Distribution Management, 38(3), 205-225.

Chalmers, A.F. (2007). Wege der Wissenschaft. Einführung in die Wissenschaftstheorie. Berlin: Springer.

Chen, Y.-L., Tang, K., Shen, R-J. \& Hu, Y.-H. (2005). Market Basket Analysis in a Multiple Store Environment. Decision Support Systems, 40(2), 339-354.

Chiu, S. \& Tavella, D. (2008). Data Mining and Market Intelligence for Optimal Marketing Returns. Oxford: Butterworth-Heinemann.

Churchill, G.A.Jr. (1979). A Paradigm for Developing Better Measures of Marketing Constructs. Journal of Marketing Research, 16(1), 64-73.

Churchill, G.A.Jr. \& Surprenant, C. (1982). An Investigation into the Determinants of Customer Satisfaction. Journal of Marketing Research, 19(4), 491-504.

Cigliano, J., Georgiadis, M., Pleasance, D. \& Whalley, S. (2000a). The Price of Loyalty. The McKinsey Quarterly, 2000(4), 68-77.

Cigliano, J., Georgiadis, M., Pleasance, D. \& Whalley, S. (2000b). The Power of Loyalty. Creating Winning Retail Loyalty Programs. Retrieved on February 
11, 2009, from http://www.mckinsey.com/practices/marketing/ourknowledge/ pdf/WhitePaper_PowerofLoyalty.pdf.

Clark, P. (2006). The 22 Major Factors That Will Shape the Future of Customer Loyalty. Retrieved on March 30, 2009, from http://www.customer lifecycle.us/pdfs\%5Cwhitepapers $\% 5$ CThe $\% 2022 \% 20$ Major\%20Factors $\% 20$ that $\% 20$ will $\% 20$ Shape $\% 20$ the $\% 20$ Future $\% 20$ of $\% 20$ Customer\%20Loyalty.pdf.

Clark, R. \& Clark, P. (2009). The Loyalty Guide III. Retrieved on April 2, 2009, from http://www.theloyaltyguide.com/order.asp.

Clayton-Smith, D. (1996). Do It All's Loyalty Programme - And its Impact on Customer Retention. Managing Service Quality, 6(5), 33-37.

Coase, R.H. (1937). The Nature of the Firm. Economica, 4(16), 386-405.

Coltman, T., Devinney, T.M., Midgley, D.F. \& Venaik, S. (2008). Formative Versus Reflective Measurement Models: Two Applications of Formative Measurement. Journal of Business Research, 61(12), 1250-1262.

Copeland, M. (1923). Relation of Consumer's Buying Habit to Marketing Methods. Harvard Business Review, 1(3), 282-289.

Cronbach, L.J. \& Meehl, P.E. (1955). Construct Validity in Psychological Tests. Psychological Bulletin, 52, 281-302.

D

Dagger, T.S. \& O'Brien, T.K. (2010). Does Experience Matter? Differences in Relationship Benefits, Satisfaction, Trust, Commitment and Loyalty for Novice and Experienced Service Users. European Journal of Marketing, 44(9/10), $1528-1552$.

Darwin, C. (1859). On the Origin of Species by Means of Natural Selection, or the Preservation of Favoured Races in the Struggle for Life. London: John Murray.

Daryanto, A., de Ruyter, K., Wetzels, M. \& Patterson, P.G. (2010). Service Firms and Customer Loyalty Programs: A Regulatory Fit Perspective of Reward Preferences in a Health Club Setting. Journal of the Academy of Marketing Science, 38(5), 604-616.

Day, G.S. (1969). A Two-Dimensional Concept of Brand Loyalty. Journal of Advertising Research, 9(3), 29-35.

Decker, R. (2005). Market Basket Analysis by Means of a Growing Neural Network. International Review of Retail, Distribution and Consumer Research, 15(2), 151-169.

Demoulin, N.T.M. \& Zidda, P. (2008). On the Impact of Loyalty Cards on Store Loyalty: Does the Customers' Satisfaction With the Reward Scheme Matter? Journal of Retailing and Consumer Services, 15(5), 386-398. 
Demoulin, N.T.M. \& Zidda, P. (2009). Drivers of Customers' Adoption and Adoption Timing of a New Loyalty Card in the Grocery Retail Market. Journal of Retailing, 85(3), 391-405.

De Wulf, K. \& Odekerken-Schröder, G. (2003). Assessing the Impact of a Retailer's Relationship Efforts on Consumers' Attitudes and Behavior. Journal of Retailing and Consumer Services, 10(2), 95-108.

De Wulf, K., Odekerken-Schröder, G., De Cannière, M.H. \& Van Oppen, C. (2003). What Drives Consumer Participation to Loyalty Programs? A Conjoint Analytical Approach. Journal of Relationship Marketing, 2(1/2), 69-85.

De Wulf, K., Odekerken-Schröder, G. \& Iacobucci, D. (2001). Investments in Consumer Relationships: A Cross-Country and Cross-Industry Exploration. Journal of Marketing, 65(4), 33-50.

Dhar, R. \& Wertenbroch, K. (2000). Consumer Choice Between Hedonic and Utilitarian Goods. Journal of Marketing Research, 37(1), 29-44.

Diamantopoulos, A. (2010). Reflective and Formative Metrics of Relationship Value: Response to Baxter's Commentary Essay. Journal of Business Research, 63(1), 91-93.

Diamantopoulos, A., Riefler, P. \& Roth, K.P. (2008). Advancing Formative Measurement Models. Journal of Business Research, 61(12), 1203-1218.

Dick, A.S. \& Basu, K. (1994). Customer Loyalty: Toward an Integrated Conceptual Framework. Journal of the Academy of Marketing Sciences, 22(2), 99-113.

Dickinson, R., Harris, F. \& Sircar, S. (1992). Merchandise Compatibility: An Exploratory Study of its Measurement and Effect on Department Store Performance. International Review of Retail, Distribution and Consumer Research, 2(4), 351-379.

Diller, H. (1996). Kundenbindung als Marketingziel. Marketing - Zeitschrift für Forschung und Praxis, 18(2), 81-94.

Diller, H. (1997). Was leisten Kundenclubs? Ein Testbeispiel. Marketing - Zeitschrift für Forschung und Praxis, 19(1), 33-41.

Diller, H., Bauer, T. \& Bonakdar, A. (2008). Customer Lifetime Value (CLV)Modelle für den Einzelhandel - Ein empirischer Vergleich konkurrierender Modelle. Working Paper No. 162, Institute for Marketing, FriedrichAlexander-Universität Erlangen-Nürnberg, Erlangen, Germany.

Dowling, G.R. (2002). Customer Relationship Management: In B2C Markets, Often Less is More. California Management Review, 44(3), 87-104.

Dowling, G.R. \& Uncles, M.D. (1997). Do Customer Loyalty Schemes Really Work? Sloan Management Review, 38(4), 71-82.

Drèze, X. \& Hoch, S.J. (1998). Exploiting the Installed Base Using CrossMerchandising and Category Destination Programs. International Journal of Research in Marketing, 15(5), 459-471. 
Drèze, X. \& Nunes, J.C. (2009). The Impact of Loyalty Program Structure on Customers' Perceptions of Status. Journal of Consumer Research, 35(6), 890-905.

Duffy, D.L. (2003). Internal and External Factors Which Affect Customer Loyalty. Journal of Consumer Marketing, 20(5), 480-485.

Dwyer, F.R. (1997). Customer Lifetime Valuation to Support Marketing Decision Making. Journal of Direct Marketing, 11(4), 6-13.

Dwyer, F.R., Schurr, P.H. \& Oh, S. (1987). Developing Buyer-Seller Relationships. Journal of Marketing, 51(2), 11-27.

$\mathbf{E}$

Eagly, A.H. \& Chaiken, S. (1993). The Psychology of Attitudes. Fort Worth: Harcourt Brace Jovanovich.

East, R., Hammond, K., Harris, P. \& Lomax, W. (2000). First-Store Loyalty and Retention. Journal of Marketing Management, 16(4), 307-325.

East, R., Harris, P., Willson, G. \& Lomax, W. (1995). Loyalty to Supermarkets. The International Review of Retail, Distribution and Consumer Research, 5(1), 99-109.

Eberl, M. (2006). Formative und reflektive Konstukte und die Wahl des Strukturgleichungsverfahrens. Eine statistische Entscheidungshilfe. Die Betriebswirtschaft, 66(6), 651-668.

Ebert, J. \& Prelec, D. (2003). Valuation of Future Rewards: Considering Cognitive Effort, Lay Beliefs, and Salience of Delay. In: Ebert, J. (ed.). Psychological Approaches to Future Rewards: Sequences, Valuation, Effort, and Frequency Programs. Advances in Consumer Research, 30(1), 69-70.

Egan, J. (2004). Relationship Marketing. Exploring Relational Strategies in Marketing. Harlow: FT Prentice Hall.

Emerson, R.M. (1976). Social Exchange Theory. Annual Review of Sociology, 2, 335-362.

Engel, J., Blackwell, R. \& Miniard, P. (1995). Consumer Behavior. Fort Worth: Dryden Press.

Engel, J.F., Kegerreis, R.J. \& Blackwell, R.D. (1969). Word-of-Mouth Communication by the Innovator. Journal of Marketing, 33(3), 15-19.

Enis, B.M. \& Paul, G.W. (1970). Store Loyalty as a Basis for Market Segmentation. Journal of Retailing, 46(3), 42-56.

Evans, M. (1999). Food Retailing Loyalty Schemes - and the Orwellian Millennium. British Food Journal, 101(2), 132-147. 
Fayyad, U.M., Piatetsky-Shapiro, G., Smyth, P. \& Uthurusamy, R. (eds.). (1996). Advances in Knowledge Discovery and Data Mining. Menlo Park: AAAI Press.

Felser, G. (2007). Werbe- und Konsumentenpsychologie. Heidelberg: Spektrum.

Ferguson, R. \& Hlavinka, K. (2006). Loyalty Trends 2006: Three Evolutionary Trends to Transform Your Loyalty Strategy. Journal of Consumer Marketing, 23(5), 292-299.

Ferguson, R. \& Hlavinka, K. (2007). Quo Vadis. Sizing up the U.S. Loyalty Marketing Industry. Retrieved on March 17, 2009, from http://www.colloquy.com/ files/2007-COLLOQUY-Loyalty-Census.pdf.

Ferguson, R. \& Hlavinka, K. (2009). The New Champion Customers. Measuring Word-of-Mouth Activity Among Reward Program Members. Retrieved on March 17, 2009, from http://www.colloquy.com/files/2009-COLLOQUYTalk-Talk-White-Paper.pdf.

Festinger, L. (1970). A Theory of Cognitive Dissonance. Stanford: Stanford University Press.

Financial Times. (2002). Inside Track - What it Really Means to be Loyal. Retrieved on January 17, 2008, from http://search.ft.com/nonFtArticle?id= 020614000335.

Finnie, W. \& Randall, R.L. (2002). Loyalty as a Philosophy and Strategy: An Interview With Frederick F. Reichheld. Strategy \& Leadership, 30(2), 25-31.

Fischer, L. \& Wiswede, G. (2009). Grundlagen der Sozialpsychologie. München: Oldenbourg.

FMI (n.d.). Loyalty-Marketing Programs in the Retail Food Industry. Retrieved on January 17, 2008, from http://www.fmi.org/docs/media/bg/loyaltymarketing. pdf.

Fornell, C. (1992). A National Customer Satisfaction Barometer: The Swedish Experience. Journal of Marketing, 56(1), 6-21.

Fornell, C., Johnson, M.D., Anderson, E.W., Cha, J. \& Bryant, B.E. (1996). The American Customer Satisfaction Index: Nature, Purpose, and Findings. Journal of Marketing, 60(4), 7-18.

Fornell, C. \& Wernerfelt, B. (1987). Defensive Marketing Strategy by Customer Complaint Management: A Theoretical Analysis. Journal of Marketing Research, 24(4), 337-346.

Freedman, D., Pisani, R. \& Purves, R. (2007). Statistics. New York: Norton.

Frisou, J. \& Hildiz, H. (2011). Consumer Learning as a Determinant of a MultiPartner Loyalty Program's Effectiveness: A Behaviorist and Long-Term Perspective. Journal of Retailing and Consumer Services, 18(1), 81-91. 
Fuchs, C. \& Diamantopoulos, A. (2009). Using Single-Item Measures for Construct Measurement in Management Research. Die Betriebswirtschaft, 69(2), 195-210.

Funk, T. (2005). Die Wirkungen von Bonusprogrammnetzwerken auf das CrossBuying-Verhalten. Wiesbaden: Deutscher Universitäts-Verlag.

Furinto, A., Pawitra, D. \& Balqiah, T.E. (2009). Designing Competitive Loyalty Programs: How Types of Program Affect Customer Equity. Journal of Targeting, Measurement and Analysis for Marketing, 17(4), 307-319.

Futuyma, D.J. (2009). Evolution. Sunderland: Sinauer Associates.

\section{G}

Garbarino, E. \& Johnson, M.S. (1999). The Different Roles of Satisfaction, Trust, and Commitment in Customer Relationships. Journal of Marketing, 63(2), 70-87.

Gaski, J.F. \& Nevin, J.R. (1985). The Differential Effects of Exercised and Unexercised Power Sources in a Marketing Channel. Journal of Marketing Research, 22(2), 130-142.

GfK (2007). Besitz und Nutzung von Kundenkarten. Retrieved on November 3, 2008, from http://www.loyaltypartner.com/fileadmin/upload/Presse/Studien/ BesitzNutzung_Kundenkarten_Sept07.pdf.

Gilbert, D. (1996). Airlines. In: Buttle, F. (ed.). Relationship Marketing. Theory and Practice. London: Chapman, 131-144.

Gómez, B.G., Arranz, A.G. \& Cillán, J.G. (2006). The Role of Loyalty Programs in Behavioral and Affective Loyalty. Journal of Consumer Marketing, 23(7), 387-396.

Götz, O. \& Liehr-Gobbers, K. (2004). Analyse von Strukturgleichungsmodellen mit Hilfe der Partial-Least-Squares(PLS)-Methode. Die Betriebswirtschaft, 64(6), 714-738.

Grönroos, C. (1994). From Marketing Mix to Relationship Marketing: Towards a Paradigm Shift in Marketing. Management Decision, 32(2), 4-20.

Gudmundsson, S.V., De Boer, E.R. \& Lechner, C. (2002). Integrating Frequent Flyer Programs in Multilateral Airline Alliances. Journal of Air Transport Management, 8(6), 409-417.

Gundlach, G.T., Achrol, R.S. \& Mentzer, J.T. (1995). The Structure of Commitment in Exchange. Journal of Marketing, 59(1), 78-92.

Gupta, S., Hanssens, D., Hardie, B., Kahn, W., Kumar, V., Lin, N., Ravishanker, N. \& Sriram, S. (2006). Modeling Customer Lifetime Value. Journal of Service Research, 9(2), 139-155.

Gutenberg, E. (1955). Grundlagen der Betriebswirtschaftslehre. Berlin: Springer. 
Haeberle, M. (2004). Loyalty is Dead. Great Experiences, not Price, Will Create Loyal Customers. Chain Store Age, Retail Technology Quarterly (January), $17 \mathrm{~A}$.

Hallberg, G. (2004). Is Your Loyalty Programme Really Building Loyalty? Why Increasing Emotional Attachment, not Just Repeat Buying, is Key to Maximising Programme Success. Journal of Targeting, Measurement and Analysis for Marketing, 12(3), 231-241.

Hallowell, R. (1996). The Relationships of Customer Satisfaction, Customer Loyalty, and Profitability: An Empirical Study. Journal of Service Industry Management, 7(4), 27-42.

Hanna, J.G. (1980). A Typology of Consumer Needs. In: Sheth, J.N. (ed.). Research in Marketing. Vol. 3. Greenwich: JAI Press, 83-104.

Harker, M.J. (1999). Relationship Marketing Defined? An Examination of Current Relationship Marketing Definitions. Marketing Intelligence and Planning, 17(1), 13-20.

Hart, S., Smith, A., Sparks, L. \& Tzokas, N. (1999). Are Loyalty Schemes a Manifestation of Relationship Marketing? Journal of Marketing Management, 15(6), 541-562.

Hartig, J., Frey, A. \& Jude, N. (2007). Validität. In: Moosbrugger, H. \& Kelava, A. (eds.). Testtheorie und Fragebogenkonstruktion. Heidelberg: Springer, 135163.

Hastie, T., Tibshirani, R. \& Friedman, J. (2008). The Elements of Statistical Learning. Data Mining, Inference, and Prediction. New York: Springer.

Hatzinger, R. \& Nagel, H. (2009). PASW Statistics. München: Pearson Studium.

Hausknecht, D.R. (1990). Measurement Scales in Consumer Satisfaction/Dissatisfaction. Journal of Consumer Satisfaction, Dissatisfaction and Complaining Behavior, 3, 1-11.

Heider, F. (1958). The Psychology of Interpersonal Relations. New York: Wiley. Hennig-Thurau, T., Gwinner, K.P. \& Gremler, D.D. (2000). Why Customers Build Relationships With Companies - and why not. In: Hennig-Thurau, T. \& Hansen, U. (eds.). Relationship Marketing: Gaining Competitive Advantage Through Customer Satisfaction and Customer Retention. Berlin: Springer, 369-391.

Herkner, W. (2001). Lehrbuch Sozialpsychologie. Bern: Huber.

Herzberg, F., Mausner, B. \& Snyderman, B.B. (1959). The Motivation to Work.

New York: Wiley. 
Heskett, J.L., Jones, T.O., Loveman, G.W., Sasser, W.E.Jr. \& Schlesinger, L.A. (1994). Putting the Service-Profit Chain to Work. Harvard Business Review, 72(2), 164-170.

Hildebrandt, L. \& Temme, D. (2006). Probleme der Validierung mit Strukturgleichungsmodellen. Die Betriebswirtschaft, 66(6), 618-639.

Hill, N. \& Alexander, J. (2006). Handbook of Customer Satisfaction and Loyalty Measurement. Aldershot: Gower.

Hippner, H., Küsters, U., Meyer, M. \& Wilde, K. (eds.). (2001). Handbuch Data Mining im Marketing. Knowledge Discovery in Marketing Databases. Wiesbaden: Vieweg.

Hirschman, E.C. \& Holbrook, M.B. (1982). Hedonic Consumption: Emerging Concepts, Methods, and Propositions. Journal of Marketing, 46(3), 92-101.

Hoffmann, A. (2008). Die Akzeptanz kartenbasierter Kundenbindungsprogramme aus Konsumentensicht. Determinanten und Erfolgswirkungen. Wiesbaden: Gabler.

Holz, S. (1997). Kundenclubs als Kundenbindungsinstrument. Generelle und situationsbezogene Gestaltungsempfehlungen für ein erfolgreiches Kundenclub-Marketing. Bamberg: Difo-Druck.

Homans, G.C. (1958). Social Behavior as Exchange. American Journal of Socio$\log y, 63(6), 597-606$.

Homburg, C. (ed.). (2006). Kundenzufriedenheit. Konzepte - Methoden - Erfahrungen. Wiesbaden: Gabler.

Homburg, C., Becker, A. \& Hentschel, F. (2008). Der Zusammenhang zwischen Kundenzufriedenheit und Kundenbindung. In: Bruhn, B. \& Homburg, C. (eds.). Handbuch Kundenbindungsmanagement. Wiesbaden: Gabler, 103-134.

Homburg, C. \& Bruhn, M. (2008). Kundenbindungsmanagement - Eine Einführung in die theoretischen und praktischen Problemstellungen. In: Bruhn, B. \& Homburg, C. (eds.). Handbuch Kundenbindungsmanagement. Wiesbaden: Gabler, 3-37.

Homburg, C. \& Fürst, A. (2008). Gutenbergs Werk aus Sicht der heutigen Marketing-Forschung. In: Reese, J. \& Steven, M. (eds.). ZfB Special Issue 5/2008. Erich Gutenbergs Theorie der Unternehmung - Wirkungen auf die heutige Betriebswirschaftslehre. Wiesbaden: Gabler, 17-50.

Homburg, C. \& Giering, A. (2001). Personal Characteristics as Moderators of the Relationship Between Customer Satisfaction and Loyalty - An Empirical Analysis. Psychology \& Marketing, 18(1), 43-66.

Homburg, C. \& Klarmann, M. (2009). Multi Informant-Designs in der empirischen betriebswirtschaftlichen Forschung. Problemfelder und Anwendungsempfehlungen. Die Betriebswirtschaft, 69(2), 147-171. 
Homburg, C., Schilke, O. \& Reimann, M. (2009). Triangulation von Umfragedaten in der Marketing- und Managementforschung. Die Betriebswirtschaft, 69(2), 173-193.

Houston, M.J. \& Rothschild, M.L. (1977). A Paradigm for Research on Consumer Involvement. Working Paper 17-11-46, University of Wisconsin, Madison, USA.

Howard, J.A. \& Osterlund, L.E. (1973). The Model: Current Status of Buyer Behavior Theory. In: Howard, J.A. \& Osterlund, L.E. (eds.). Buyer Behavior. New York: Alfred A. Knopf, 3-32.

Hoyer, W.D. \& MacInnis, D.J. (2007). Consumer Behavior. Boston: Houghton Mifflin.

Hruschka, H., Lukanowicz, M. \& Buchta, C. (1999). Cross-Category Sales Promotion Effects. Journal of Retailing and Consumer Services, 6(2), 99-105.

Hull, C.L. (1966). Principles of Behavior. An Introduction to Behavior Theory. New York: Appleton-Century-Crofts.

Humby, C., Hunt, T. \& Phillips, T. (2008). Scoring Points: How Tesco Continues to Win Customer Loyalty. London: Kogan Page.

\section{I}

In-Store (2008). Loyalty Card Fatigue has set in Among Consumers. In-Store, May, 5.

$\mathbf{J}$

Jacoby, J. (1978). Consumer Research: How Valid and Useful are all our Consumer Behavior Research Findings? A State of the Art Review. Journal of Marketing, 42(2), 87-96.

Jacoby, J. (2002). Stimulus-Organism-Response Reconsidered: An Evolutionary Step in Modeling (Consumer) Behavior. Journal of Consumer Psychology, 12(1), 51-57.

Jacoby, J. \& Chestnut R.W. (1978). Brand Loyalty Measurement and Management. New York: Wiley.

Jacoby, J. \& Kyner, D.B. (1973). Brand Loyalty vs. Repeat Purchase Behavior. Journal of Marketing Research, 10(1), 1-9.

Jacoby, J. \& Olsen, J.C. (1970). An Attitudinal Model of Brand Loyalty: Conceptual Underpinnings and Instrumentation Research. Purdue Papers in Consumer Psychology, 159, Purdue University, West Lafayette, USA.

Jarvis, C.B., MacKenzie, S.B. \& Podsakoff, P.M. (2003). A Critical Review of Construct Indicators and Measurement Model Misspecification in Marketing and Consumer Research. Journal of Consumer Research, 30(2), 199-218. 
Johnson, B. (2002). A Looming Conflict of Loyalty Schemes. Marketing Week, 25(36), 19-20.

Jones, E.E. (1972). Attribution. Perceiving the Causes of Behavior. Morristown: General Learning Press.

Jones, M.A., Mothersbaugh, D.L. \& Beatty, S.E. (2000). Switching Barriers and Repurchase Intentions in Services. Journal of Retailing, 76(2), 259-274.

Jones, T.O. \& Sasser, W.E. (1995). Why Satisfied Customers Defect. Harvard Business Review, 73(6), 88-99.

Julander, C.-R. (1992). Basket Analysis: A New Way of Analysing Scanner Data. International Journal of Retail and Distribution Management, 20(7), 10-18.

\section{$\mathbf{K}$}

Kaas, K.-P. (2000). Alternative Konzepte der Theorieverankerung. In: Backhaus, K. (ed.). Deutschsprachige Marketingforschung. Bestandsaufnahme und Perspektiven. Stuttgart: Schäffer-Poeschel, 55-78.

Keh, H.T. \& Lee, Y.H. (2006). Do Reward Programs Build Loyalty for Services? The Moderating Effect of Satisfaction on Type and Timing of Rewards. Journal of Retailing, 82(2), 127-136.

Kelley, H. (1973). The Process of Causal Attribution. American Psychologist, 28(2), 107-128.

Khatibi, A.A., Ismail, H. \& Thyagarajan, V. (2002). What Drives Customer Loyalty: An Analysis From the Telecommunications Industry. Journal of Targeting, Measurement and Analysis for Marketing, 11(1), 34-44.

Kim, B.-D., Shi, M. \& Srinivasan, K. (2001). Reward Programs and Tacit Collusion. Marketing Science, 20(2), 99-120.

Kim, B.-D., Srinivasan, K. \& Wilcox, R.T. (1999). Identifying Price-Sensitive Consumers: The Relative Merits of Demographic vs. Purchase Pattern Information. Journal of Retailing, 75(2), 173-193.

Kivetz, R. \& Simonson, I. (2002). Earning the Right to Indulge: Effort as a Determinant of Customer Preferences Toward Frequency Program Rewards. Journal of Marketing Research, 39(2), 155-170.

Kivetz, R., Urminsky, O. \& Zheng, Y. (2006). The Goal-Gradient Hypothesis Resurrected: Purchase Acceleration, Illusionary Goal Progress, and Customer Retention. Journal of Marketing Research, 43(1), 39-58.

Knox, S.D. \& Denison, T.J. (2000). Store Loyalty: Its Impact on Retail Revenue. An Empirical Study of Purchasing Behaviour in the UK. Journal of Retailing and Consumer Services, 7(1), 33-45. 
Kohn, A. (1999). Punished by Rewards. The Trouble With Gold Stars, Incentive Plans, A's, Praise, and Other Bribes. Boston: Houghton Mifflin.

Kopalle, P.K. \& Neslin, S.A. (2003). The Economic Viability of Frequency Reward Programs in a Strategic Competitive Environment. Review of Marketing Science, 1(1), 1-39.

Kraftfahrt-Bundesamt (2010). Emissionen, Kraftstoffe - Deutschland und seine Länder am 1. Januar 2010. Retrieved on September 6, 2010, from http://www.kba.de/cln_015/nn_269000/DE/Statistik/Fahrzeuge/Bestand/Emis sionenKraftstoffe/2010_b_emi_eckdaten_absolut.html.

Kralev, N. (2009). Frequent Flyers Question Loyalty Schemes. Retrieved on March 16, 2009, from http://www.washingtontimes.com/news/2009/jan/26/ frequent-fliers-question-loyalty-schemes.

Kroeber-Riel, W. (1975). Konsumentenverhalten. München: Vahlen.

Kroeber-Riel, W., Weinberg, P. \& Gröppel-Klein, A. (2009). Konsumentenverhalten. München: Vahlen.

Kuhl, J. \& Beckmann, J. (eds.). (1985). Action Control: From Cognition to Behavior, Berlin: Springer.

Kumar, V. (2008). Managing Customers for Profit. Strategies to Increase Profits and Build Loyalty. Upper Saddle River: Wharton School Publishing.

Kumar, V. \& Reinartz, W.J. (2006). Customer Relationship Management. A Databased Approach. Hoboken: John Wiley \& Sons.

Kumar, V. \& Shah, D. (2004). Building and Sustaining Profitable Customer Loyalty for the $21^{\text {st }}$ Century. Journal of Retailing, 80(4), 317-330.

Kuß, A. \& Diller, H. (2001). Kaufrisiko. In: Diller, H. (ed.). Vahlens großes Marketinglexikon. München: Beck, 757-758.

Kuß, A. \& Tomczak, T. (2007). Käuferverhalten: Eine marketingorientierte Einführung. Stuttgart: Lucius \& Lucius.

Künzel, S. (2002). Das Bonusprogramm als Instrument zur Kundenbindung. Berlin: Logos.

\section{$\mathbf{L}$}

Laaksonen, M. (1993). Retail Patronage Dynamics: Learning About Daily Shopping Behavior in Contexts of Changing Retail Structures. Journal of Business Research, 28(1/2), 3-174.

Lacey, R. (2009). Limited Influence of Loyalty Program Membership on Relational Outcomes. Journal of Consumer Marketing, 26(6), 392-402.

Lacey, R. \& Morgan, R.M. (2009). Customer Advocacy and the Impact of B2B Loyalty Programs. Journal of Business \& Industrial Marketing, 24(1), 3-13. 
Lal, R. \& Bell, D.E. (2003). The Impact of Frequent Shopper Programs in Grocery Retailing. Quantitative Marketing and Economics, 1(2), 179-202.

Lara, P.R. \& De Madariaga, J.G. (2007). The Importance of Rewards in the Management of Multisponsor Loyalty Programmes. Journal of Database Marketing and Customer Strategy Management, 15(1), 37-48.

Leenheer, J. \& Bijmolt, T.H.A. (2008). Which Retailers Adopt a Loyalty Program? An Empirical Study. Journal of Retailing and Consumer Services, 15(6), 429-442.

Leenheer, J., van Heerde, V.J., Bijmolt, T.H.A. \& Smidts, A. (2007). Do Loyalty Programs Really Enhance Behavioral Loyalty? An Empirical Analysis Accounting for Self-Selecting Members. International Journal of Research in Marketing, 24(1), 31-47.

Lewis, M. (2004). The Influence of Loyalty Programs and Short-Term Promotions on Customer Retention. Journal of Marketing Research, 41(3), 281292.

Liebermann, Y. (1999). Membership Clubs as a Tool for Enhancing Buyers' Patronage. Journal of Business Research, 45(3), 291-297.

Liebmann, H-P., Zentes, J. \& Swoboda, B. (2008). Handelsmanagement. München: Franz Vahlen.

Liu, Y. (2007). The Long-Term Impact of Loyalty Programs on Consumer Purchase Behavior and Loyalty. Journal of Marketing, 71(4), 19-35.

Liu, Y. \& Yang, R. (2009). Competing Loyalty Programs: Impact of Market Saturation, Market Share, and Category Expandability. Journal of Marketing, 73(1), 93-108.

Lobb, J. (1997). Stuffing it to Coke: How Pepsi Used a Promotion to Counter its Rival's Olympics Megablitz. Marketing Magazine, 102(3), 18.

Louviere, J.J. \& Gaeth, G.J. (1987). Decomposing the Determinants of Retail Facility Choice Using the Method of Hierarchical Information Integration: A Supermarket Illustration. Journal of Retailing, 63(1), 25-48.

\section{M}

Manchanda, P., Ansari, A. \& Gupta, S. (1999). The "Shopping Basket": A Model for Multicategory Purchase Incidence Decisions. Marketing Science, 18(2), 95-114.

March, J.G. \& Simon, H.A. (1976). Organisation und Individuum. Menschliches Verhalten in Organisationen. Wiesbaden: Gabler.

Maslow, A.H. (1943). A Theory of Human Motivation. Psychological Review, 50(4), 370-396. 
Mauri, C. (2003). Card Loyalty. A New Emerging Issue in Grocery Retailing. Journal of Retailing and Consumer Services, 10(1), 13-25.

Mägi, A.W. (1995). Customer Satisfaction in a Store Performance Framework. EFI Research Report, Stockholm Economic Research Institute, Stockholm, Sweden.

Mägi, A.W. (2003). Share of Wallet in Retailing: The Effects of Customer Satisfaction, Loyalty Cards and Shopper Characteristics. Journal of Retailing, 79(2), 97-106.

McGoldrick, P.J. \& Andre, E. (1997). Consumer Misbehavior. Promiscuity or Loyalty in Grocery Shopping. Journal of Retailing and Consumer Services, 4(2), 73-81.

Merkle, E. (1981). Die Erfassung und Nutzung von Informationen über den Sortimentsverbund in Handelsbetrieben. Berlin: Duncker \& Humblot.

Meyer, A. \& Oevermann, D. (1995). Kundenbindung. In: Tietz, B., Köhler, R. \& Zentes, J. (eds.). Handwörterbuch des Marketing. Stuttgart: Schäffer-Poeschel, 1339-1351.

Meyer-Waarden, L. (2007). The Effects of Loyalty Programs on Customer Lifetime Duration and Share of Wallet. Journal of Retailing, 83(2), 223-236.

Meyer-Waarden, L. (2008). The Influence of Loyalty Programme Membership on Customer Purchase Behaviour. European Journal of Marketing, 42(1/2), 87-114.

Meyer-Waarden, L. \& Benavent, C. (2006). The Impact of Loyalty Programs on Repeat Purchase Behaviour. Journal of Marketing Management, 22(1/2), 61-88.

Meyer-Waarden, L. \& Benavent, C. (2008). Rewards That Reward. Most Customer-Loyalty Programs Don't Boost Market Share. Here's how to Improve the Odds. The Wall Street Journal, September 17, R5.

Meyer-Waarden, L. \& Benavent, C. (2009). Grocery Retail Loyalty Program Effects: Self-Selection or Purchase Behavior Change? Journal of the Academy of Marketing Science, 37(3), 345-358.

Mild, A. \& Reutterer, T. (2003). An Improved Collaborative Filtering Approach for Predicting Cross-Category Purchases Based on Binary Market Basket Data. Journal of Retailing and Consumer Services, 10(3), 123-133.

Miller, N.E. \& Dollard, J. (1947). Social Learning and Imitation. New Haven: Yale University Press.

Mimouni-Chaabane, A. \& Volle, P. (2010). Perceived Benefits of Loyalty Programs: Scale Development and Implications for Relational Strategies. Journal of Business Research, 63(1), 32-37.

Mittal, V. \& Kamakura, W.A. (2001). Satisfaction, Repurchase Intent, and Repurchase Behavior: Investigating the Moderating Effect of Customer Characteristics. Journal of Marketing Research, 38(1), 131-142. 
Moon, S. \& Russell, G.J. (2004). A Spatial-Choice Model for Product Recommendations. Institute Report No. 04-120, Marketing Science Institute, Cambridge, USA.

Moore, G. \& Sekhon, H. (2005). Multi-Brand Loyalty Cards: A Good Idea. Journal of Marketing Management, 21(5/6), 625-640.

Moosbrugger, H. \& Kelava, A. (2007). In: Moosbrugger, H. \& Kelava, A. (eds.). Testtheorie und Fragebogenkonstruktion. Heidelberg: Springer, 7-26.

Morgan, R.M \& Hunt, S.D. (1994). The Commitment-Trust Theory of Relationship Marketing. Journal of Marketing, 58(3), 20-38.

Morrisson, O. \& Huppertz, J.W. (2010). External Equity, Loyalty Program Membership, and Service Recovery. Journal of Services Marketing, 24(3), 244-254.

$\mathbf{N}$

Nako, S.M. (1992). Frequent Flyer Programs and Business Travellers: An Empirical Investigation. Logistics and Transportation Review, 28(4), 395-414.

Neff, J. (2005). Is Your CVS Loyalty Card a Privacy Threat? Advertising Age, 75(25), 3 and 36.

Noble, S.M. \& Phillips, J. (2004). Relationship Hindrance: Why Would Consumers not Want a Relationship With a Retailer? Journal of Retailing, 80(4), 289-303.

Noordhoff, C., Pauwels, P. \& Odekerken-Schröder, G. (2004). The Effect of Customer Card Programs. A Comparative Study in Singapore and The Netherlands. International Journal of Service Industry Management, 15(4), 351-364.

Nunes, J.C. \& Drèze, X. (2006). Your Loyalty Program is Betraying You. Harvard Business Review, 84(4), 124-131.

$\mathbf{O}$

O’Brien, L. \& Jones, C. (1995). Do Rewards Really Create Loyalty? Harvard Business Review, 73(3), 75-82.

Oggenfuss, C.W. (1992). Retention Marketing. Thexis, 9(6), 24-28.

Oliva, T.E., Oliver, R.L. \& MacMillan, I.C. (1992). A Catastrophe Model for Developing Service Satisfaction Strategies. Journal of Marketing, 56(3), 8395.

Oliver, R.L. (1977). Effect of Expectation and Discontinuation Postexposure Product Evaluations: An Alternative Interpretation. Journal of Applied Psychology, 62(4), 480-486. 
Oliver, R.L. (1980). A Cognitive Model of the Antecedents and Consequences of Satisfaction Decisions. Journal of Marketing Research, 17(4), 460-469.

Oliver, R.L. (1981). Measurement and Evaluation of Satisfaction Processes in Retail Settings. Journal of Retailing, 57(3), 25-48.

Oliver, R.L. (1997). Satisfaction. A Behavioral Perspective on the Consumer. New York: McGraw-Hill.

Oliver, R.L. (1999). Whence Customer Loyalty? Journal of Marketing, 63(Special Issue), 33-44.

Oliver, R.L. \& DeSarbo, W.S. (1988). Response Determinants in Satisfaction Judgments. Journal of Consumer Research, 14(4), 495-507.

Olshavsky, R.W. \& Miller, J.A. (1972). Consumer Expectations, Product Performance, and Perceived Product Quality. Journal of Marketing Research, 9(1), 19-21.

Olson, D.L. \& Delen, D. (2008). Advanced Data Mining Techniques. Berlin: Springer.

O’Malley, L. (1998). Can Loyalty Schemes Really Build Loyalty? Market Intelligence and Planning, 16(1), 47-55.

O'Malley, L. \& Tynan, C. (2000). Relationship Marketing in Consumer Markets - Rhetoric or Reality? European Journal of Marketing, 34(7), 797-815.

$\mathbf{P}$

Pan, Y. \& Zinkhan, G.M. (2006). Determinants of Retail Patronage: A MetaAnalytical Perspective. Journal of Retailing, 82(3), 229-243.

Parker, C. \& Worthington, S. (2000). When Lemonade is Better Than Whisky: Investigating the Equitableness of a Supermarket's Reward Scheme. International Journal of Retail and Distribution Management, 28(11), 490-497.

Passingham, J. (1998). Grocery Retailing and the Loyalty Card. Journal of the Market Research Society, 40(1), 55-63.

Payback (2001). Payback punktet nun mit 10 Millionen Karten. Retrieved on April 3, 2009, from http://www.loyaltypartner.com/presse/pressemeldun gen/meldung/select_category/7/article/payback-punktet-nun-mit-10-millionenkarten/?tx_ttnews[backPid] $=33 \& \mathrm{cHash}=6 \mathrm{cbb} 8 \mathrm{e} 40 \mathrm{cf}$.

Peck, H., Payne, A., Christopher, M. \& Clark, M. (1999). Relationship Marketing Strategy and Implementation. Oxford: Butterworth-Heinemann.

Peter, J.P. (1979). Reliability: A Review of Psychometric Basics and Recent Marketing Practices. Journal of Marketing Research, 16(1), 6-17.

Pierenkemper, T. (2000). Unternehmensgeschichte. Eine Einführung in ihre Methoden und Ergebnisse. Stuttgart: Franz Steiner. 
Plinke, W. (1989). Die Geschäftsbeziehung als Investition. In: Specht, G., Silberer, G. \& Engelhardt, W.H. (eds.). Marketing-Schnittstellen. Herausforderungen für das Management. Stuttgart: Schäffer-Poeschel, 305-325.

Plinke, W. \& Söllner, A. (2008). Kundenbindung und Abhängigkeitsbeziehungen. In: Bruhn, B. \& Homburg, C. (eds.). Handbuch Kundenbindungsmanagement. Wiesbaden: Gabler, 77-101.

Popper, K.R. (1972). Objective Knowledge. An Evolutionary Approach. Oxford: Clarendon Press.

Poth, L.G. \& Poth, G.S. (1999). Gabler Marketing Begriffe von A-Z. 4000 Begriffe nachschlagen, verstehen, anwenden. Wiesbaden: Gabler.

Pressetext Austria. (2006). Kundenbindung 2006. Ergebnisse einer repräsentativen Konsumentenbefragung. Retrieved on December 18, 2007, from http://www.pressetext.at/pte.mc?pte=060216032.

\section{$\mathbf{R}$}

Rae, J. (1905). The Sociological Theory of Capital. New York: Macmillan.

Raffée, H., Sauter, B. \& Silberer, G. (1973). Theorie der kognitiven Dissonanz und Konsumgüter-Marketing. Der Beitrag der Theorie der kognitiven Dissonanz zur Erklärung und Gestaltung von Kaufentscheidungen bei Konsumgütern. Wiesbaden: Gabler.

Ravi, V., Raman, K. \& Mantrala, M.K. (2006). Applications of Intelligent Technologies in Retail Marketing. In: Krafft, M. \& Mantrala, M.K. (eds.). Retailing in the 21st Century. Current and Future Trends. Berlin: Springer, 127-141.

Reeves, J. (1944). A Century of Rochdale Co-operation. London: Lawrence \& Wishart.

Reichheld, F.F. (1993). Loyalty-Based Management. Harvard Business Review, 71(2), 64-73.

Reichheld, F.F. (1996). The Loyalty Effect. The Hidden Force Behind Growth, Profits, and Lasting Value. New York: Harvard Business School Press.

Reichheld, F.F., Markey, R.G. \& Hopton, C. (2000). The Loyalty Effect - The Relationship Between Loyalty and Profits. European Business Journal, 12(3), 134-139.

Reichheld, F.F. \& Sasser, E.W. (1990). Zero Defections: Quality Comes to Services. Harvard Business Review, 68(5), 105-111.

Reichheld, F.F. \& Seidensticker, F.-J. (2006). Die ultimative Frage. Mit dem NetPromotor-Score zu loyalen Kunden und profitablem Wachstum. München: Hanser.

Reinartz, W.J. (2006). Understanding Customer Loyalty Programs. In: Krafft, M. \& Mantrala, M.K. (eds.). Retailing in the 21st Century. Current and Future Trends. Berlin: Springer, 361-379. 
Reinartz, W.J. \& Kumar, V. (2002). The Mismanagement of Customer Loyalty. Harvard Business Review, 80(7), 86-94.

Reinartz, W.J. \& Kumar, V. (2003). The Impact of Customer Relationship Characteristics on Profitable Lifetime Duration. Journal of Marketing, 67(1), 77-99.

Reutterer, T., Hahlser, M. \& Hornik, K. (2007). Data Mining und Marketing am Beispiel der explorativen Warenkorbanalyse. Marketing - Zeitschrift für Forschung und Praxis, 29(3), 163-179.

Reutterer, T., Mild, A., Natter, M. \& Taudes, A. (2006). A Dynamic Segmentation Approach for Targeting and Customizing Direct Marketing Campaigns. Journal of Interactive Marketing, 20(3/4), 43-57.

Reynolds, K.E. \& Arnold, M.J. (2000). Customer Loyalty to the Salesperson and the Store: Examining Relationship Customers in an Upscale Retail Context. The Journal of Personal Selling \& Sales Management, 20(2), 89-98.

Ring, A., Shriber, M. \& Horton, R.L. (1980). Some Effects of Perceived Risk on Consumer Information Processing. Journal of the Academy of Marketing Science, 8(3), 255-263.

Roehm, M.L., Pullins, E.B. \& Roehm H.A. (2002). Designing Loyalty-Building Programs for Packaged Goods Brands. Journal of Marketing Research, 39(2), 202-213.

Roland Berger (2003). Kundenbindungsprogramme in großen deutschen Unternehmen. Studienergebnisse. Retrieved on February 13, 2009, from http://www.rolandberger.com/media/pdf/rb_press/RB_Studie_Kundenbindung _final_20030509.pdf.

Rothschild, M.L. \& Gaidis, W.C. (1981). Behavioral Learning Theory: Its Relevance to Marketing and Promotions. Journal of Marketing, 45(2), 70-78.

Rowley, J. (2004). Loyalty and Reward Schemes: How Much is Your Loyalty Worth? The Marketing Review, 4(2), 121-138.

Rowley, J. (2005). Building Brand Webs. Customer Relationship Management Through the Tesco Clubcard Loyalty Scheme. International Journal of Retail and Distribution Management, 33(3), 194-206.

Russell, G.J. \& Petersen, A. (2000). Analysis of Cross Category Dependence in Market Basket Selection. Journal of Retailing, 76(3), 367-392.

Russell, G.J., Ratneshwar, S., Shocker, A.D., Bell, D., Bodapati, A., Degeratu, A., Hildebrandt, L., Kim, N., Ramaswami, S. \& Shankar, V.H. (1999). MultipleCategory Decision-Making: Review and Synthesis. Marketing Letters, 13(3), 319-332.

Rust, R.T., Zahorik, A.J. \& Keiningham, T.L. (1995). Return on Quality (ROQ): Making Service Quality Financially Accountable. Journal of Marketing, 59(2), 58-70. 
Ryals, L. (2005). Making Customer Relationship Management Work: The Measurement and Profitable Management of Customer Relationships. Journal of Marketing, 69(4), 252-261.

$\mathbf{S}$

S\&H (2009). About S\&H. Retrieved on March 16, 2009, from http://www.green points.com/info/inf_aboutsh.asp.

Sarstedt, M. \& Wilczynski, P. (2009). More for Less? A Comparison of SingleItem and Multi-Item Measures. Die Betriebswirtschaft, 69(2), 211-227.

Sayre, S. \& Horne, D. (2000). Trading Secrets for Savings: How Concerned are Consumers About Clubcards as a Privacy Threat? Advances in Consumer Research, 27(1), 151-155.

Schermelleh-Engel, K. \& Werner, C. (2007). Methoden der Reliabilitätsbestimmung. In: Moosbrugger, H. \& Kelava, A. (eds.). Testtheorie und Fragebogenkonstruktion. Heidelberg: Springer, 113-133.

Schnedlitz, P. (2006). Der Supermarkt der Zukunft. In: Schnedlitz, P., Buber, R., Reutterer, T., Schuh, A. \& Teller, C. (eds.). Innovationen in Marketing und Handel. Wien: Linde, 47-91.

Schnedlitz, P., Reutterer, T. \& Joos, W. (2001). Data-Mining und Sortimentsverbundanalyse im Einzelhandel. In: Hippner, H., Küsters, U., Meyer, M. \& Wilde, K. (eds.). Handbuch Data Mining im Marketing. Knowledge Discovery in Marketing Databases. Wiesbaden: Vieweg, 951-970.

Schoenbachler, D.D., Gordon, G.L., Foley, D. \& Spellman, L. (1997). Understanding Consumer Database Marketing. Journal of Consumer Marketing, 14(1), 5-19.

Seetharaman, P.B., Chib, S., Ainslie, A., Boatwright, P., Chan, T., Gupta, S., Mehta, N., Rao, V. \& Strijnev, A. (2005). Models of Multi-Category Choice Behavior. Marketing Letters, 16(3/4), 239-254.

Sharma, D., Alford, B.L., Bhuian, S.N. \& Pelton, L.E. (2009). A Higher-Order Model of Risk Propensity. Journal of Business Research, 62(7), 741-744.

Sharp, B. \& Sharp, A. (1997). Loyalty Programs and their Impact on RepeatPurchase Loyalty Patterns. International Journal of Research in Marketing, 14(5), 473-486.

Sherman, L. (2007). Lavish Luxury Retailer Perks. Retrieved on February 12, 2009, from http://www.forbes.com/2007/06/14/retailer-perks-lavish-forbes life-cx_1s_0614perks.html.

Sheth, J.N., Mittal, B. \& Newman, B.I. (1999). Customer Behavior. Customer Behavior and Beyond. Fort Worth: Dryden Press. 
Sheth, J.N. \& Parvatiyar, A. (1995). Relationship Marketing in Consumer Markets: Antecedents and Consequences. Journal of the Academy of Marketing Science, 23(4), 255-271.

Shimp, T.A., Stuart, E.W. \& Engle, R.W. (1991). A Program of Classical Conditioning Experiments Testing Variations in the Conditioned Stimulus and Context. Journal of Consumer Research, 18(1), 1-12.

Simon, H.A. (1948). Administrative Behavior. A Study of Decision-Making Processes in Administrative Organizations. New York: Macmillan.

Sirgy, M.J. (1984). A Social Cognition Model of Consumer Satisfaction/Dissatisfaction. An Experiment. Psychology \& Marketing, 1(2), 27-44.

Sitkin, S.B. \& Weingart, L.R. (1995). Determinants of Risky Decision-Making Behavior: A Test of the Mediating Role of Risk Perceptions and Propensity. Academy of Management Journal, 38(6), 1573-1592.

Skinner, B.F. (1938). The Behavior of Organisms. An Experimental Analysis. New York: Appleton-Century-Crofts.

Skinner, B.F. (1965). Science and Human Behavior. New York: Free Press.

Slama, M.E. \& Tashchian, A. (1987). Validating the S-O-R Paradigm for Consumer Involvement With a Convenience Good. Journal of the Academy of Marketing Science, 15(1), 36-45.

Smith, A., Sparks, L., Hart, S. \& Tzokas, N. (2003). Retail Loyalty Schemes: Results from a Consumer Diary Study. Journal of Retailing and Consumer Services, 10(2), 109-119.

Smith, A. \& Sparks, L. (2009). "It's Nice to Get a Wee Treat if You've Had a Bad Week": Consumer Motivations in Retail Loyalty Scheme Points Redemption. Journal of Business Research, 62(5), 542-547.

Sneed, G. (2005). Do Your Customers Really Feel Rewarded? Target Marketing, 28(9), 41-43.

Soman, D. (1998). The Illusion of Delayed Incentives: Evaluating Future EffortMoney Transactions. Journal of Marketing Research, 35(4), 427-437.

Stauss, B., Schmidt, M. \& Schoeler, A. (2005). Customer Frustration in Loyalty Programs. International Journal of Service Industry Management, 16(3), 229-252.

Steyn, P., Pitt, L., Strasheim, A., Boshoff, C. \& Abratt, R. (2010). A CrossCultural Study of the Perceived Benefits of a Retailer Loyalty Scheme in Asia. Journal of Retailing and Consumer Services, 17(5), 355-373.

Stone, G.P. (1954). City Shoppers and Urban Identification: Observations on the Social Psychology of City Life. American Journal of Sociology, 60(1), 36-45. Stone, M., Bearman, D., Butscher, S.A., Gilbert, D., Crick, P. \& Moffett, T. (2004). The Effect of Retail Customer Loyalty Schemes - Detailed Measurement or Transforming Marketing? Journal for Targeting, Measurement and Analysis for Marketing, 12(3), 305-318. 
Straßburger, H. (1991). Wiederkaufentscheidungsprozeß bei Verbrauchsgütern. Ein verhaltenswissenschaftliches Erklärungsmodel. Frankfurt: Lang.

Swan, J.E., Trawick, I.F. \& Carroll, M.G. (1981). Effect of Participation in Marketing Research on Consumer Attitudes Toward Research and Satisfaction with a Service. Journal of Marketing Research, 18(3), 356-362.

\section{$\mathbf{T}$}

Tan, P.-N., Steinbach, M. \& Kumar, V. (2006). Introduction to Data Mining. Boston: Addison Wesley.

Tapp, A. \& Stone, M. (2004). Dancing in Step - The Choreography of Loyalty Partnerships. Can Nectar Succeed Where Shell Smart Failed? Interactive Marketing, 6(1), 44-53.

Taylor, G.A. \& Neslin, S.A. (2005). The Current and Future Sales Impact of a Retail Frequency Reward Program. Journal of Retailing, 81(4), 293-305.

Tellis, G.J. (1988). Advertising Exposure, Loyalty, and Brand Purchase: A TwoStage Model of Choice. Journal of Marketing Research, 25(2), 134-144.

Temme, D., Paulssen, M. \& Hildebrandt, L. (2009). Common Method Variance. Ursachen, Auswirkungen und Kontrollmöglichkeiten. Die Betriebswirtschaft, 69(2), 123-146.

Thibaut, J.W. \& Kelley, H.H. (1967). The Social Psychology of Groups. New York: John Wiley \& Sons.

Thompson, B. (2004). Tesco Shines at Loyalty: An Interview With Clive Humby. Retrieved on December 18, 2007, from http://www.customerthink.com/inter view/clive_humby_tesco_shines_at_loyalty.

Thompson, B. (2008). Exploratory and Confirmatory Factor Analysis. Understanding Concepts and Applications. Washington: American Psychological Association.

TNS Emnid (2006). Bonusprogramme in Deutschland. Eine Studie der TNS Emnid Medien- und Sozialforschung GmbH. Retrieved on November 3, 2008, from http://payback.net/fileadmin/bilder/pdf/Kundenkarten_Deutschland_ Emnid_LP.pdf.

Tomczak, T., Reinecke, S. \& Dittrich, S. (2008). Kundenbindung durch Kundenkarten und -clubs. In: Bruhn, B. \& Homburg, C. (eds.). Handbuch Kundenbindungsmanagement. Wiesbaden: Gabler, 323-345.

Trommsdorff, V. (2004). Konsumentenverhalten. Stuttgart: W. Kohlhammer.

Tsao, H.-Y., Pitt, L. \& Campbell, C. (2010). Analysing Consumer Segments to Budget for Loyalty and Promotion Programmes and Maximize Market Share. The Journal of the Operational Research Society, 61(10), 1523-1529.

Tse, T.K. \& Wilton, P.C. (1988). Models of Consumer Satisfaction Formation: An Extension. Journal of Marketing Research, 25(2), 204-212. 
Uncles, M.D. (1994). Do You or Your Customers Need a Loyalty Scheme? Journal of Targeting, Measurement and Analysis for Marketing, 2(4), 335-349.

Uncles, M.D., Dowling, G.R. \& Hammond, K. (2003). Customer Loyalty and Customer Loyalty Programs. Journal of Consumer Marketing, 20(4), 294-316.

V

Venkatesan, R. \& Kumar, V. (2004). A Customer Lifetime Value Framework for Customer Selection and Resource Allocation Strategy. Journal of Marketing, 68(4), 106-125.

Venkatesh, V., Morris, M.G., Davis, G.B. \& Davis, F.D. (2003). User Acceptance of Information Technology: Toward a Unified View. MIS Quarterly, 27(3), 425-478.

Verhoef, P.C. (2003). Understanding the Effect of Customer Relationship Management Efforts on Customer Retention and Customer Share Development. Journal of Marketing, 67(4), 30-45.

Vesel, P. \& Zabkar, V. (2009). Managing Customer Loyalty Through the Mediating Role of Satisfaction in the DIY Retail Loyalty Program. Journal of Retailing and Consumer Services, 16(5), 396-406.

Volk, H. (2010). Illusion der Begeisterung. Der Standard, Jan 23/24, K12.

Voyle, S. (2002). Sainsbury Savours the Success of new Nectar Loyalty Card Scheme. Financial Times (London Edition), Nov 20, 4.

W

Wansink, B. (2003). Developing a Cost-Effective Brand Loyalty Program. Journal of Advertising Research, 43(3), 301-309.

Wansink, B. \& Seed, S. (2001). Making Brand Loyalty Programmes Succeed. Brand Management, 8(3), 211-222.

Watson, J.B. (1913). Psychology as the Behaviorist Views it. Psychological Review, 20(2), 158-177.

Weiner, B. (1985). An Attributional Theory of Achievement Motivation and Emotion. Psychological Review, 92(4), 548-573.

Weinstein (1999). Building Loyalty. Progressive Grocer, 78(6), 89-92.

Westbrook, R.A. (1980). A Rating Scale for Measuring Product/Service Satisfaction. Journal of Marketing, 44(4), 68-72.

Westbrook, R.A. (1987). Product/Consumption-Based Affective Responses and Postpurchase Processes. Journal of Marketing Research, 24(3), 258-270. 
Wilcox, J.B., Howell, R.D. \& Breivik, E. (2008). Questions About Formative Measurement. Journal of Business Research, 61(12), 1219-1228.

Williams, R.H., Painter, J.J. \& Nicholas, H.R. (1978). A Policy-Oriented Typology of Grocery Shoppers. Journal of Retailing, 54(1), 27-42.

Williamson, O.E. (1975). Markets and Hierarchies. Analysis and Antitrust Implications. A Study in the Economics of Internal Organization. New York: Free Press.

Williamson, O.E. (1985). The Economic Institutions of Capitalism. Firms, Markets, Relational Contracting. New York: Free Press.

Wirtz, J. \& Chew, P. (2002). The Effects of Incentives, Deal Proneness, Satisfaction and Tie Strength on Word-of-mouth Behaviour. International Journal of Service Industry Management, 13(2), 141-162.

Wirtz, J., Mattila, A.S. \& Lwin, M.O. (2007). How Effective are Loyalty Reward Programs in Driving Share of Wallet? Journal of Service Research, 9(4), 327-334.

Wood, A. (2003). The Value of Customer and Prospect Databases as a Corporate Asset. International Journal of Retail and Distribution Management, 31(12), 638-643.

Worthington, S. (2000). A Classic Example of a Misnomer: The Loyalty Card. Journal of Targeting, Analysis and Measurement for Marketing, 8(3), 222-234.

Wright, C. \& Sparks, L. (1999). Loyalty Saturation in Retailing: Exploring the End of Retail Loyalty Cards? International Journal of Retail and Distribution Management, 27(10), 429-439.

\section{$\mathbf{Y}$}

Yi, Y. \& Jeon, H. (2003). Effects of Loyalty Programs on Value Perceptions, Program Loyalty, and Brand Loyalty. Journal of the Academy of Marketing Science, 31(3), 229-240.

\section{$\mathbf{Z}$}

Zhang, Z.J., Krishna, A. \& Dhar, S.K. (2000). The Optimal Choice of Promotional Vehicles: Front-Loaded or Rear-Loaded Incentives? Management Science, 46(3), 348-362.

Ziliani, C. (2005). Target Promotions: How to Measure and Improve Promotional Effectiveness Through Individual Customer Information. Journal of Targeting, Measurement and Analysis for Marketing, 14(3), 249-259. 



\title{
Forschungsergebnisse der WU Wirtschaftsuniversität Wien
}

\author{
Herausgeber: WU Wirtschaftsuniversität Wien - \\ vertreten durch Univ. Prof. Dr. Barbara Sporn \\ INFORMATION UND KONTAKT: \\ WU Wirtschaftsuniversität Wien \\ Department of Finance, Accounting and Statistics \\ Institute for Finance, Banking and Insurance \\ Welthandelsplatz 1, D 4, 1. OG, 1020 Wien \\ Tel.: 0043-1-313 36/4556 \\ Fax: 0043-1-313 36/904556 \\ valentine.wendling@wu.ac.at \\ www.wu.ac.at/finance
}

Band 1 Stefan Felder: Frequenzallokation in der Telekommunikation. Ökonomische Analyse der Vergabe von Frequenzen unter besonderer Berücksichtigung der UMTS-Auktionen. 2004.

Band 2 Thomas Haller: Marketing im liberalisierten Strommarkt. Kommunikation und Produktplanung im Privatkundenmarkt. 2005.

Band 3 Alexander Stremitzer: Agency Theory: Methodology, Analysis. A Structured Approach to Writing Contracts. 2005.

Band 4 Günther Sedlacek: Analyse der Studiendauer und des Studienabbruch-Risikos. Unter Verwendung der statistischen Methoden der Ereignisanalyse. 2004.

Band 5 Monika Knassmüller: Unternehmensleitbilder im Vergleich. Sinn- und Bedeutungsrahmen deutschsprachiger Unternehmensleitbilder - Versuch einer empirischen (Re-)Konstruktion. 2005.

Band 6 Matthias Fink: Erfolgsfaktor Selbstverpflichtung bei vertrauensbasierten Kooperationen. Mit einem empirischen Befund. 2005.

Band 7 Michael Gerhard Kraft: Ökonomie zwischen Wissenschaft und Ethik. Eine dogmenhistorische Untersuchung von Léon M.E. Walras bis Milton Friedman. 2005.

Band 8 Ingrid Zechmeister: Mental Health Care Financing in the Process of Change. Challenges and Approaches for Austria. 2005.

Band 9 Sarah Meisenberger: Strukturierte Organisationen und Wissen. 2005.

Band 10 Anne-Katrin Neyer: Multinational teams in the European Commission and the European Parliament. 2005.

Band 11 Birgit Trukeschitz: Im Dienst Sozialer Dienste. Ökonomische Analyse der Beschäftigung in sozialen Dienstleistungseinrichtungen des Nonprofit Sektors. 2006

Band 12 Marcus Kölling: Interkulturelles Wissensmanagement. Deutschland Ost und West. 2006.

Band 13 Ulrich Berger: The Economics of Two-way Interconnection. 2006.

Band 14 Susanne Guth: Interoperability of DRM Systems. Exchanging and Processing XML-based Rights Expressions. 2006.

Band 15 Bernhard Klement: Ökonomische Kriterien und Anreizmechanismen für eine effiziente Förderung von industrieller Forschung und Innovation. Mit einer empirischen Quantifizierung der Hebeleffekte von F\&E-Förderinstrumenten in Österreich. 2006. 
Band 16 Markus Imgrund: Wege aus der Insolvenz. Eine Analyse der Fortführung und Sanierung insolventer Klein- und Mittelbetriebe unter besonderer Berücksichtigung des Konfigurationsansatzes. 2007.

Band 17 Nicolas Knotzer: Product Recommendations in E-Commerce Retailing Applications. 2008.

Band 18 Astrid Dickinger: Perceived Quality of Mobile Services. A Segment-Specific Analysis. 2007.

Band 19 Nadine Wiedermann-Ondrej: Hybride Finanzierungsinstrumente in der nationalen und internationalen Besteuerung der USA. 2008.

Band 20 Helmut Sorger: Entscheidungsorientiertes Risikomanagement in der Industrieunternehmung. 2008.

Band 21 Martin Rietsch: Messung und Analyse des ökonomischen Wechselkursrisikos aus Unternehmenssicht: Ein stochastischer Simulationsansatz. 2008.

Band 22 Hans Christian Mantler: Makroökonomische Effizienz des Finanzsektors. Herleitung eines theoretischen Modells und Schätzung der Wachstumsimplikationen für die Marktwirtschaften und Transformationsökonomien Europas. 2008.

Band 23 Youri Tacoun: La théorie de la valeur de Christian von Ehrenfels. 2008.

Band 24 Monika Koller: Longitudinale Betrachtung der Kognitiven Dissonanz. Eine Tagebuchstudie zur Reiseentscheidung. 2008.

Band 25 Marcus Scheiblecker: The Austrian Business Cycle in the European Context. 2008.

Band 26 Aida Numic: Multinational Teams in European and American Companies. 2008.

Band 27 Ulrike Bauernfeind: User Satisfaction with Personalised Internet Applications. 2008.

Band 28 Reinhold Schodl: Systematische Analyse und Bewertung komplexer Supply Chain Prozesse bei dynamischer Festlegung des Auftragsentkopplungspunkts. 2008.

Band 29 Bianca Gusenbauer: Öffentlich-private Finanzierung von Infrastruktur in Entwicklungsländern und deren Beitrag zur Armutsreduktion. Fallstudien in Vietnam und auf den Philippinen. 2009.

Band 30 Elisabeth Salomon: Hybrides Management in sino-österreichischen Joint Ventures in China aus österreichischer Perspektive. 2009.

Band 31 Katharina Mader: Gender Budgeting: Ein emanzipatorisches, finanzpolitisches und demokratiepolitisches Instrument. 2009.

Band 32 Michael Weber: Die Generierung von Empfehlungen für zwischenbetriebliche Transaktionen als gesamtwirtschaftliche Infrastrukturleistung. 2010.

Band 33 Lisa Gimpl-Heersink: Joint Pricing and Inventory Control under Reference Price Effects. 2009.

Band 34 Erscheint nicht.

Band 35 Dagmar Kiefer: Multicultural Work in Five United Nations Organisations. An Austrian Perspective. 2009.

Band 36 Gottfried Gruber: Multichannel Management. A Normative Model Towards Optimality. 2009.

Band 37 Rainer Quante: Management of Stochastic Demand in Make-to-Stock Manufacturing. 2009.

Band 38 Franz F. Eiffe: Auf den Spuren von Amartya Sen. Zur theoriegeschichtlichen Genese des Capability-Ansatzes und seinem Beitrag zur Armutsanalyse in der EU. 2010. 
Band 39 Astrid Haider: Die Lohnhöhe und Lohnstreuung im Nonprofit-Sektor. Eine quantitative Analyse anhand österreichischer Arbeitnehmer-Arbeitgeber-Daten. 2010.

Band 40 Maureen Lenhart: Pflegekräftemigration nach Österreich. Eine empirische Analyse. 2010.

Band 41 Oliver Schwank: Linkages in South African Economic Development. Industrialisation without Diversification? 2010.

Band 42 Judith Kast-Aigner: A Corpus-Based Analysis of the Terminology of the European Union's Development Cooperation Policy, with the African, Caribbean and Pacific Group of States. 2010.

Band 43 Emel Arikan: Single Period Inventory Control and Pricing. An Empirical and Analytical Study of a Generalized Model. 2011.

Band 44 Gerhard Wohlgenannt: Learning Ontology Relations by Combining Corpus-Based Techniques and Reasoning on Data from Semantic Web Sources. 2011.

Band 45 Thomas Peschta: Der Einfluss von Kundenzufriedenheit auf die Kundenloyalität und die Wirkung der Wettbewerbsintensität am Beispiel der Gemeinschaftsverpflegungsgastronomie. 2011.

Band 46 Friederike Hehle: Die Anwendung des Convenience-Konzepts auf den Betriebstyp Vending. 2011.

Band 47 Thomas Herzog: Strategisches Management von Koopetition. Eine empirisch begründete Theorie im industriellen Kontext der zivilen Luftfahrt. 2011.

Band 48 Christian Weismayer: Statische und longitudinale Zufriedenheitsmessung. 2011.

Band 49 Johannes Fichtinger: The Single-Period Inventory Model with Spectral Risk Measures. 2011.

Band 50 Isabella R. Hatak: Kompetenz, Vertrauen und Kooperation. Eine experimentelle Studie. 2011.

Band 51 Birgit Gusenbauer: Der Beitrag der Prospect Theory zur Beschreibung und Erklärung von Servicequalitätsurteilen und Kundenzufriedenheit im Kontext von Versicherungsentscheidungen. 2012.

Band 52 Markus A. Höllerer: Between Creed, Rhetoric Façade, and Disregard. Dissemination and Theorization of Corporate Social Responsibility in Austria. 2012.

Band 53 Jakob Müllner: Die Wirkung von Private Equity auf das Wachstum und die Internationalisierung. Eine empirische Impact-Studie des österreichischen Private Equity Marktes. 2012.

Band 54 Heidrun Rosič: The Economic and Environmental Sustainability of Dual Sourcing. 2012.

Band 55 Christian Geier: Wechselkurssicherungsstrategien exportorientierter Unternehmen. Effizienzmessung von regelgebundenen Selektionsentscheidungen. 2012.

Band 56 Ernst Gittenberger: Betriebsformenwahl älterer KonsumentInnen. 2012.

Band 57 Michael Pichlmair: Miete, Lage, Preisdiktat. Strukturelle Effekte der Lageregulierung im mietrechtlich geschützten Wiener Wohnmarkt. 2012.

Band 58 Anna Katherina Guserl: Internationalisierungsprozesse und Finanzstrategien. Ansätze und empirische Analysen. 2013.

Band 59 Christian Idinger: Konsumentenpreiswissen. Eine empirische Studie im österreichischen Lebensmitteleinzelhandel. 2013.

Band 60 Dennis Jancsary: Die rhetorische Konstruktion von Führung und Steuerung. Eine argumentationsanalytische Untersuchung deutschsprachiger Führungsgrundsätze. 2013. 
Band 61 Nicolas Hoffmann: Loyalty Schemes in Retailing. A Comparison of Stand-alone and Multipartner Programs. 2013.

www.peterlang.com 